\title{
PÓS-TRATAMENTO POR LODOS ATIVADOS DE EFLUENTE DE UM REATOR ANAERÓBIO COMPARTIMENTADO NO TRATAMENTO DE ESGOTO SANITÁRIO Volume I
}

\section{FÁBIO JOSÉ COLETTI}

Dissertação apresentada à Escola de Engenharia de São Carlos, da Universidade de São Paulo, como parte dos requisitos para obtenção do Título de Mestre em Hidráulica e Saneamento.

ORIENTADOR: Prof. Titular JURANDYR POVINELLI

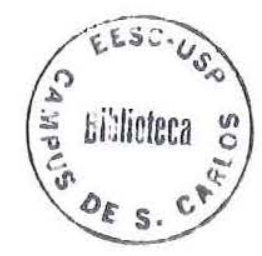

São Carlos

Dezembro, 1997 


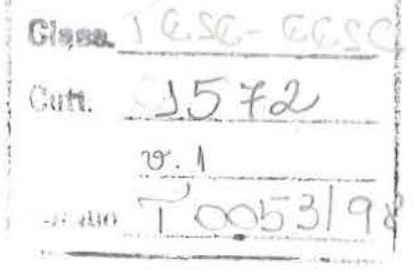

Ficha catalográfica preparada pela Seção de Tratamento da Informação do Serviço de Biblioteca - EESC-USP

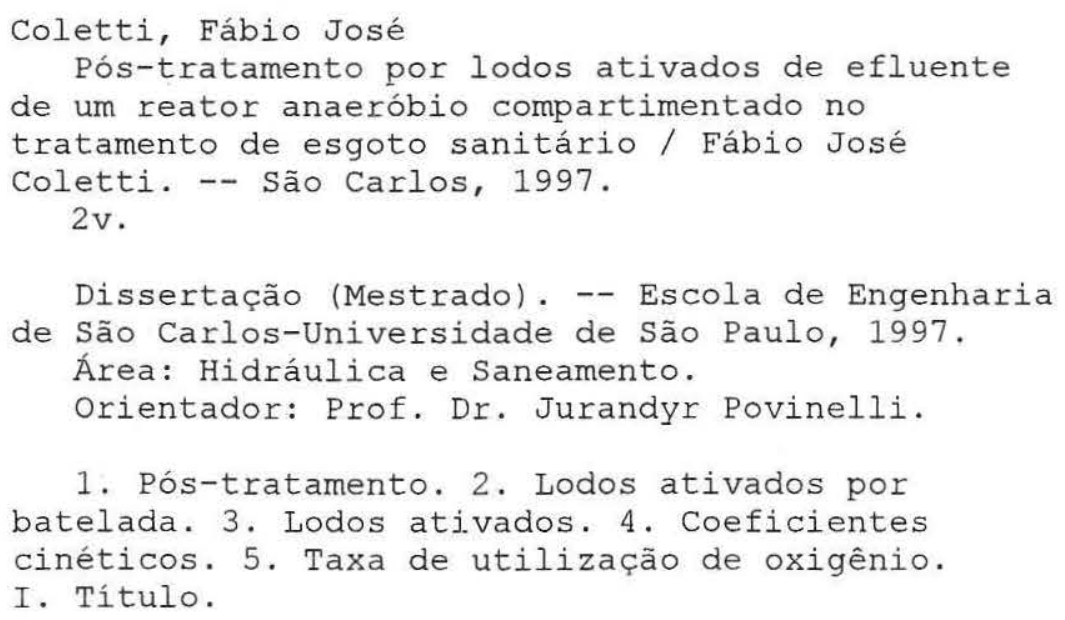


Dedico este trabalho a José e-Nair, meus pais, pelo permanente apoio; aо meu irmão, Roberto. 


\section{AGRADECIMENTOS}

Ao Prof. Dr. Jurandyr Povinelli pela constante orientação e ensinamento valioso durante a realização deste trabalho.

Agradecimento especial ao Prof. Dr. Luiz Antonio Daniel, pela permanente orientação, dedicação, ensinamento e incentivo, e também pela leitura da dissertação e sugestões apresentadas para o seu aprimoramento.

Ao Prof. Dr. José Roberto Campos, pelos conhecimentos preciosos transmitidos no decorrer desta pesquisa e empréstimo de equipamentos.

Ao Prof. Dr. Carlos Eduardo Blundi pelo auxílio prestado.

Ao CNPq pela bolsa de estudos.

A FAPESP pela verba fornecida para montagem da unidade experimental.

A Dra. Eloisa Pozzi Gianotti pela realização dos exames microscópicos e fotografação dos microrganismos.

Aos técnicos do Laboratório de Saneamento do Departamento de Hidráulica e Saneamento da EESC - USP: Eliana Aparecida Arcaida, Júlio César Trofino, Maria Aparecida Peres Viudes, Miguel Derige (in memoriam), pela ajuda durante as realizações das análises físico-químicas, especialmente ao Paulo Fragiácomo pelos ensinamentos durante a fase experimental e fornecimento de material para as análises.

Ao técnico Francisco Carlos Bergamin pela ajuda na montagem da unidade experimental. 
Aos funcionários responsáveis pela manutenção da energia elétrica, João Batista Casoti, João Ferminiano de Jesus Neto e José Carlos Gabam pela instalação dos equimanentos.

À professora Maria Inês Pereira pela revisão gramatical desta dissertação.

Aos colegas Benedito Duarte do Belém e Jefferson Luís Coutinho pela colaboração no transcorrer da pesquisa.

Aos funcionários do Departamento de Hidráulica e Saneamento pelo atendimento de qualidade.

A todos que contribuíram de forma direta ou indireta na realização deste trabalho, especialmente a minha mãe. 


\section{SUMÁRIO}

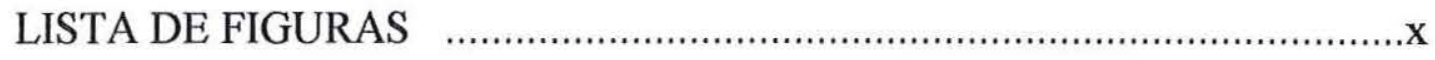

LISTA DE TABELAS ……………...............................................

LISTA DE ABREVIATURAS E SIGLAS …………………..................x

LISTA DE SÍMBOLOS ……...................................................................

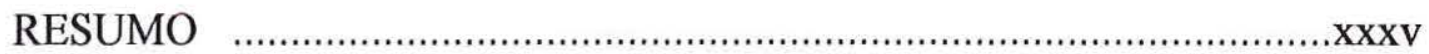

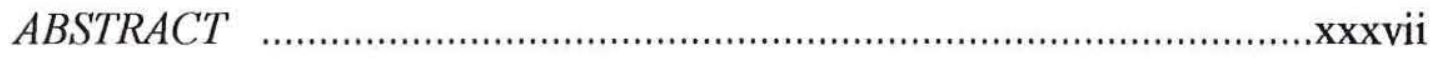

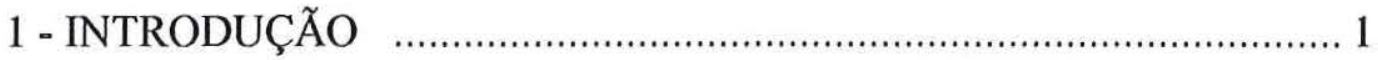

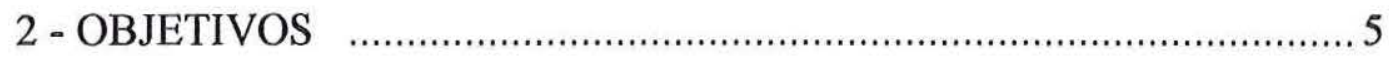

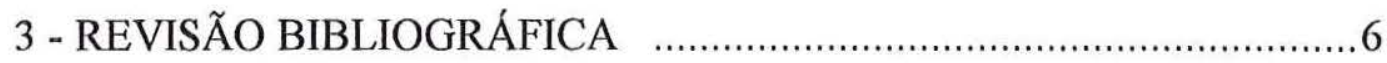

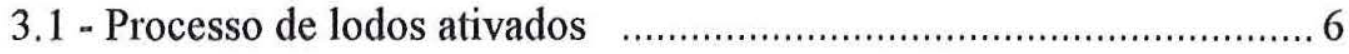

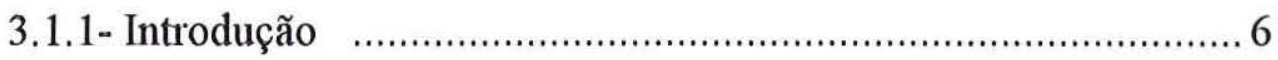

3.1.2 - Descrição do processo …………………….................... 7

3.1.3 - Microbiologia do processo ……….................................. 8

3.1.3.1 - Microrganismos presentes .....................................9

3.1.3.2 - Crescimento de microrganismos ……….................. 14

3.1.3.3 - Dinâmica da população microbiana ……………....... 17

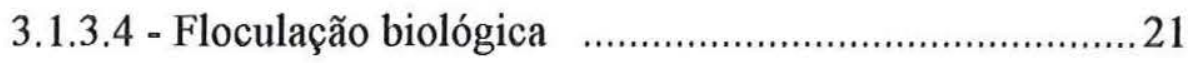

3.1.3.5 - Fatores intervenientes …….................................... 23

3.1.4 - Processo de lodo ativado por batelada ……………….......... 28

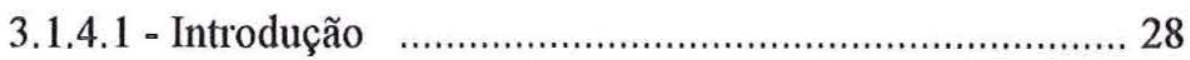

3.1.4.2 - Descrição do processo ………………………….... 29

3.1.4.3 - Modificações do processo ………………………........ 32

3.1.4.4 - Vantagens e desvantagens do SBR ………...............34 
3.2 - Pós-tratamento de efluente tratado anaerobiamente …..................... 35

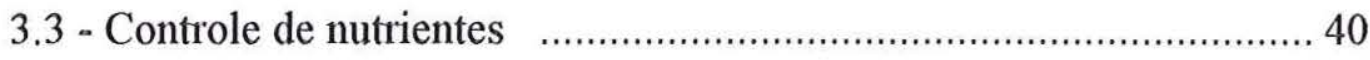

3.3.1 - Remoção do nitrogênio …………………………............... 41

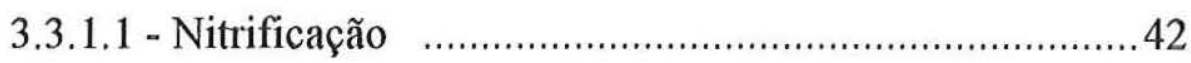

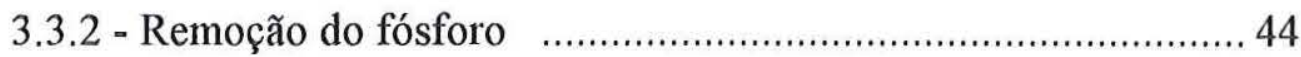

3.4 - Aplicação da cinética ao tratamento biológico …………………....46

3.4.1 - Cinética do crescimento biológico …………….................... 46

3.4.2 - Sistemas de lodos ativados sem recirculação de lodo ……..... 50

3.4.3 - Sistemas de lodos ativados com recirculação de lodo ............ 54

3.4.4 - Mecanismo da degradação aeróbia ……………………....... 62

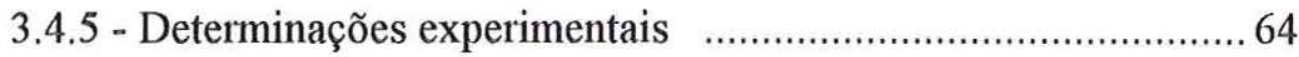

3.4.5.1 - Determinação dos coeficientes cinéticos em sistemas de lodos ativados sem recirculação

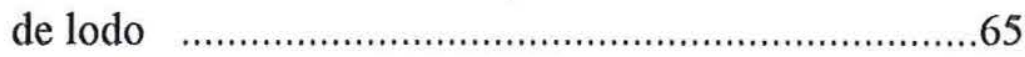

3.4.5.1.1 - Determinação de $\mathrm{k} \mathrm{e} \mathrm{K}_{\mathrm{s}}$ ………………..... 65

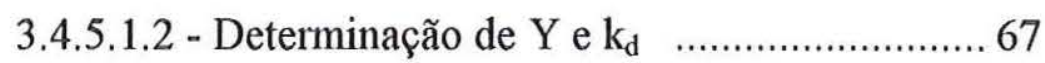

3.4.5.2 - Determinação dos coeficientes cinéticos em sistemas de lodos ativados com recirculação

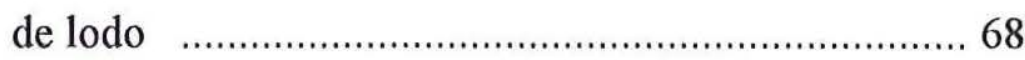

3.4.5.3 - Determinação dos parâmetros a' e b' …………….... 69

3.4.5.4 - Determinação da taxa de utilização de oxigênio ........71

3.4.5.5 - Determinação do coefíciente global de transferência de oxigênio ............................................. 74

3.4.5.5.1 - Correções de $\left(\mathrm{K}_{\mathrm{L}} \mathrm{a}\right) \quad$.................................... 76

3.4.5.5.2 - Determinação experimental de $\left(\mathrm{K}_{\mathrm{L}} \mathrm{a}\right) \quad$...... 79

3.4.5.6 - Índices do lodo ........................................................... 80

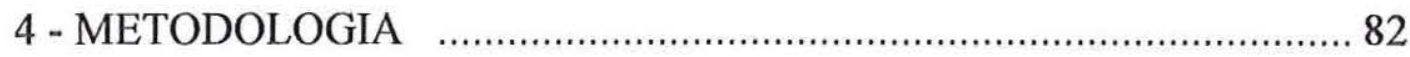

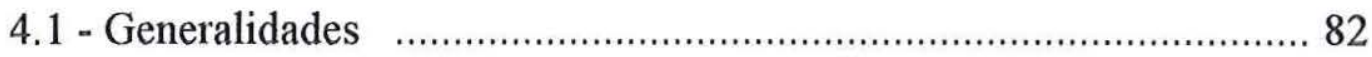

4.2 - Caracterização da água residuária …………………………….... 82

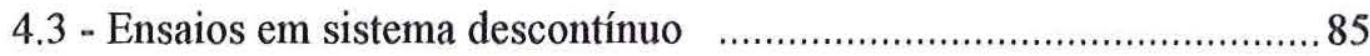


4.3.1 - Descrição da unidade experimental ……………………....... 85

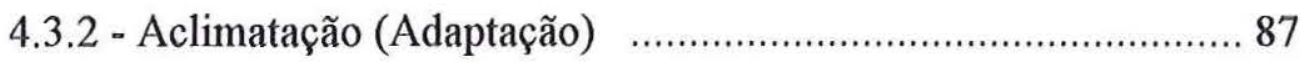

4.3.3 - Operação e controle …………………………………...... 89

4.3.4 - Análises e exames .......................................................... 92

4.4 - Ensaio em sistema contínuo ……………………....................... 95

4.4.1 - Descrição da unidade experimental ………………………... 95

4.4.2 - Aclimatą̧ão (Adaptação) ................................................... 99

4.4.3 - Operação e controle ........................................................... 99

4.4.4 - Análises e exames …………............................................ 102

4.4.4.1 - Taxa de utilização de oxigênio .................................. 105

4.4.4.2 - Coeficiente global de transferência de oxigênio ....... 107

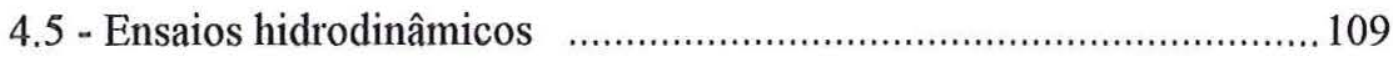

5 - APRESENTAÇÃO DOS RESULTADOS …………......................... 110

5.1 - Ensaios em sistema descontínuo .................................................... 110

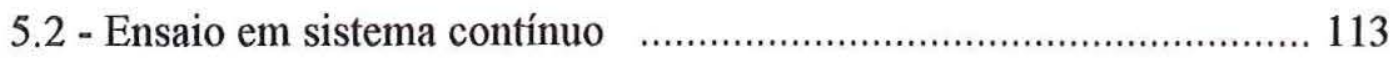

5.2 .1 - Controle do sistema …….................................................... 113

5.2.2 - Parâmetros experimentais obtidos durante o ensaio ……….... 114

5.2.3 - Determinação dos coeficientes cinéticos ...............................117

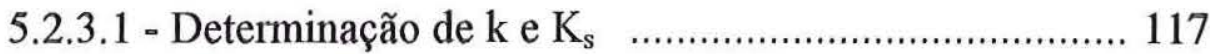

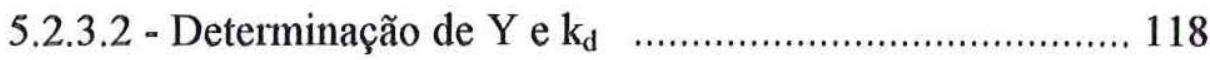

5.2.4 - Determinação da taxa de utilização de oxigênio ................... 119

5.2.5 - Determinação dos parâmetros a' e b' …………....................... 120

5.2.6 - Determinação do coeficiente $\alpha$........................................... 121

5.2.7 - Determinação da relação $\mathrm{F} / \mathrm{M}, \mathrm{U}, \mathrm{P}_{\mathrm{x}}$ e $\mathrm{P}_{\mathrm{x}}{ }^{\prime} \quad$ ………………...... 123

5.2.8 - Exames microscópicos ………………………..................... 124

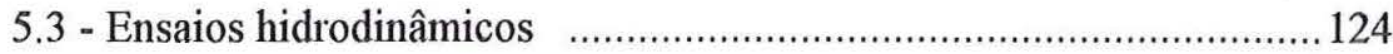

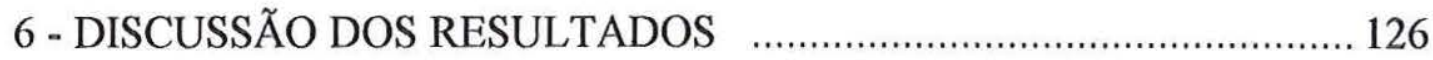

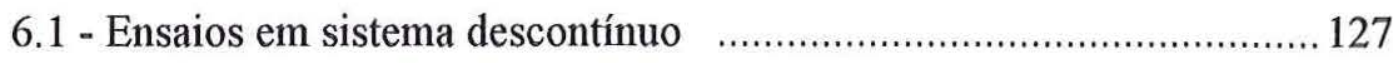

6.2 - Ensaio em sistema contínuo ......................................................... 133

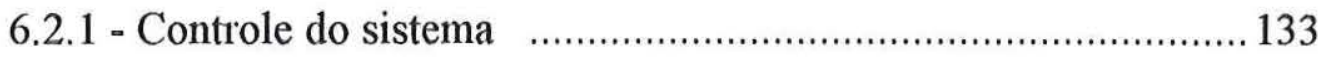


6.2.2 - Parâmetros experimentais obtidos durante o ensaio 136

6.2.3 - Coeficientes cinéticos 143

6.2.4 - Taxa de utilização de oxigênio 145

6.2.5 - Parâmetros a' e b’ 145

6.2.6 - Coeficiente $\alpha$ 147

6.2.7 - Relação F/M, U, $\mathrm{P}_{\mathrm{x}}$ e $\mathrm{P}_{\mathrm{x}}$ ' 147

6.2.8 - Exames microscópicos 149

6.3 - Ensaios hidrodinâmicos 151

7 - CONCLUSÕES 152

8 - RECOMENDAÇÕES 160

9 - REFERÊNCIAS BIBLIOGRÁFICAS 163

ANEXO A 170

ANEXO B 198

ANEXO C 295 


\section{LISTA DE FIGURAS}

Figura 3.1 - Modelo da curva de crescimento de microrganismos em cultura pura (CETESB, 1989)..................................... 16

Figura 3.2 - Curva de crescimento relativo típico de microrganismos na sucessão ecológica, durante a estabilização de resíduos orgânicos, em sistemas descontínuos (McKINNEY apud LARANJEIRA FILHO, 1989).

Figura 3.3 - Períodos de um ciclo operacional para um reator seqüencial em batelada (SBR) (USEPA apud METCALF \& EDDY, 1991)

Figura 3.4 - Configuração do reator seqüencial em batelada (SBR) para oxidação de matéria carbonácea e remoção de fósforo (WEF/ASCE apud CHERNICHARO \& SPERLING, 1993).

Figura 3.5 - Configuração do reator seqüencial em batelada (SBR) para oxidação de matéria carbonácea, remoção de nitrogênio e fósforo (WEF/ASCE apud CHERNICHARO \& SPERLING, 1993).

Figura 3.6 - Variação da taxa específica de crescimento com a concentração do substrato (METCALF \& EDDY, 1991)

Figura 3.7 - Esquema do processo de lodos ativados sem recirculação de lodo (METCALF \& EDDY, 1991)......... 
Figura 3.8 - Esquema do processo de lodos ativados com reator do tipo mistura completa e recirculação de lodo: (a) o lodo excedente é descartado no próprio reator e (b) o lodo excedente é descartado na linha de retorno do lodo (METCALF \& EDDY, 1991).

Figura 3.9 - Mecanismo da estabilização biológica aeróbia (RAMALHO apud SANT'ANNA, 1982).

Figura 3.10 - Determinação gráfica de k e $\mathrm{K}_{\mathrm{s}}$ (SANT'ANNA, 1982).. 66

Figura 3.11 - Determinação gráfica de $Y$ e $k_{d}$ (SANT'ANNA, 1982)..

Figura 3.12 - Determinação gráfica dos parâmetros a' e b' (SANT'ANNA, 1982).

Figura 3.13 - Determinação gráfica da taxa de utilização de oxigênio (SANT'ANNA, 1982)

Figura 4.1 - Corte longitudinal do Reator Anaeróbio Compartimentado (NOUR, 1996)

Figura 4.2 - Planta baixa do Reator Anaeróbio Compartimentado (NOUR, 1996)

Figura 4.3 - Unidade experimental utilizada para os ensaios em sistema descontínuo.

Figura 4.4 - Perfil da célula de aeração utilizada para os ensaios em sistema descontínuo e para o ensaio em sistema contínuo (KATO, 1982)

Figura 4.5 - Tanque de alimentação provido de agitador e bombas dosadoras utilizadas para alimentação dos reatores durante o ensaio em sistema contínuo.

Figura 4.6 - Célula de aeração utilizada durante o ensaio em sistema contínuo.

Figura 4.7 - Esquema da unidade experimental utilizada para o ensaio em sistema contínuo (KATO, 1982). 
Figura 4.8 - Sistema utilizado na determinação da taxa de utilização de oxigênio.

Figura 4.9 - S Sistema utilizado na determinação do coeficiente global de transferência de oxigênio.

Figura A.1 - Bactérias coloniais semelhantes a Zooglea ramigera em microscopia óptica comum - sistema descontínuo e aumento de 250 vezes.

Figura A.2 - Aspecto geral do floco evidenciando a presença de protozoários ciliados fixos (sésseis) pedunculados coloniais em microscopia óptica comum - sistema descontínuo e aumento de 50 vezes.

Figura A.3 - Aspecto geral do floco evidenciando a presença de protozoários ciliados fixos (sésseis) pedunculados coloniais em microscopia óptica comum - sistema descontínuo e aumento de 250 vezes.

Figura A.4 - Aspecto geral do floco evidenciando a presença de protozoário ciliado livre-natante (rastejante) em microscopia óptica comum - sistema descontínuo e aumento de 250 vezes.

Figura A.5 - Aspecto geral do floco evidenciando a presença de rotífero em microscopia óptica comum - sistema descontínuo e aumento de 250 vezes.

Figura B.1 - Variação de $\mathrm{pH}$ do afluente, do reator e do efluente durante a operação do reator R1 em sistema contínuo....

Figura B.2 - Variação de pH do afluente, do reator e do efluente durante a operação do reator $\mathrm{R} 2$ em sistema contínuo....

Figura B.3 - Variação de pH do afluente, do reator e do efluente durante a operação do reator R3 em sistema contínuo....

Figura B.4 - Variação de $\mathrm{pH}$ do afluente, do reator e do efluente durante a operação do reator R4 em sistema contínuo.... 
Figura B.5 - Variação de oxigênio dissolvido no tanque de aeração do reator R1 durante a operação em sistema contínuo....

Figura B.6 - Variação de oxigênio dissolvido no tanque de aeração do reator R2 durante a operação em sistema contínuo....

Figura B.7 - Variação de oxigênio dissolvido no tanque de aeração do reator R3 durante a operação em sistema contínuo....

Figura B.8 - Variação de oxigênio dissolvido no tanque de aeração do reator R4 durante a operação em sistema contínuo....

Figura B.9 - Variação da temperatura dos reatores e ambiente durante a operação do sistema contínuo.

Figura B.10 - Variação da DBO bruta e filtrada afluente e efluente durante a operação do reator R1 em sistema contínuo....

Figura B.11 - Variação da DBO bruta e filtrada afluente e efluente durante a operação do reator R2 em sistema contínuo....

Figura B.12 - Variação da DBO bruta e filtrada afluente e efluente durante a operação do reator $\mathrm{R} 3$ em sistema contínuo....

Figura B.13 - Variação da DBO bruta e filtrada afluente e efluente durante a operação do reator $\mathrm{R} 4 \mathrm{em}$ sistema contínuo....

Figura B.14 - Comparação da variação da DBO bruta efluente dos 4 reatores durante a operação em sistema contínuo

Figura B.15 - Comparação da variação da DBO filtrada efluente dos 4 reatores durante a operação em sistema contínuo.

Figura B.16 - Variação da DQO bruta e filtrada afluente e efluente durante a operação do reator R1 em sistema contínuo....

Figura B.17 - Variação da DQO bruta e filtrada afluente e efluente durante a operação do reator $\mathrm{R} 2 \mathrm{em}$ sistema contínuo....

Figura B.18 - Variação da DQO bruta e filtrada afluente e efluente durante a operação do reator R3 em sistema contínuo....

Figura B.19 - Variação da DQO bruta e filtrada afluente e efluente durante a operação do reator R4 em sistema contínuo.... 
Figura B.20 - Comparação da variação da DQO bruta efluente dos 4 reatores durante a operação em sistema contínuo

Figura B.21 - Comparação da variação da DQO filtrada efluente dos 4 reatores durante a operação em sistema contínuo

Figura B.22 - Comparação da variação dos sólidos suspensos voláteis nos tanques de aeração dos 4 reatores durante a operação em sistema contínuo.

Figura B.23 - Variação das formas de nitrogênio (total, amoniacal, nitrato e nitrito) afluente e efluente durante a operação do reator $\mathrm{R} 1$ em sistema contínuo.

Figura B.24 - Variação das formas de nitrogênio (total, amoniacal, nitrato e nitrito) afluente e efluente durante a operação do reator $\mathrm{R} 2$ em sistema contínuo

Figura B.25 - Variação das formas de nitrogênio (total, amoniacal, nitrato e nitrito) afluente e efluente durante a operação do reator R3 em sistema contínuo

Figura B.26 - Variação das formas de nitrogênio (total, amoniacal, nitrato e nitrito) afluente e efluente durante a operação do reator $\mathrm{R} 4 \mathrm{em}$ sistema contínuo.

Figura B.27 - Variação do fósforo (fosfato total) afluente e efluente durante a operação do reator $\mathrm{R} 1 \mathrm{em}$ sistema contínuo....

Figura B.28 - Variação do fósforo (fosfato total) afluente e efluente durante a operação do reator $\mathrm{R} 2 \mathrm{em}$ sistema contínuo....

Figura B.29 - Variação do fósforo (fosfato total) afluente e efluente durante a operação do reator R3 em sistema contínuo....

Figura B.30 - Variação do fósforo (fosfato total) afluente e efluente durante a operação do reator R4 em sistema contínuo....

Figura B.31 - Comparação da variação do índice volumétrico do lodo dos 4 reatores durante a operação em sistema contínuo.. 
Figura B.32 - Variação da alcalinidade afluente e efluente dos 4 reatores durante a operação em sistema contínuo.

Figura B.33 - Determinação dos coeficientes cinéticos $\mathrm{k}$ e $\mathrm{K}_{\mathrm{s}}$ para o sistema contínuo (base DBO filtrada)...

Figura B.34 - Determinação dos coefícientes cinéticos $\mathrm{Y}$ e $\mathrm{k}_{\mathrm{d}}$ para $\mathrm{o}$ sistema contínuo (base DBO filtrada).

Figura B.35 - Determinação dos coeficientes cinéticos $\mathrm{k}$ e $\mathrm{K}_{\mathrm{s}}$ para o sistema contínuo (base DQO filtrada).

Figura B.36 - Determinação dos coeficientes cinéticos $\mathrm{Y}$ e $\mathrm{k}_{\mathrm{d}}$ para 0 sistema contínuo (base DQO filtrada).

Figura B.37 a B.40 - Determinação da taxa de utilização de oxigênio para uma amostra do reator R1 sem adição de substrato.

Figura B.41 a B.44 - Determinação da taxa de utilização de oxigênio para uma amostra do reator R1 com adição de substrato

Figura B.45 a B.48 - Determinação da taxa de utilização de oxigênio para uma amostra do reator $\mathrm{R} 2$ sem adição de substrato

Figura B.49 a B.52 - Determinação da taxa de utilização de oxigênio para uma amostra do reator $\mathrm{R} 2$ com adição de substrato.

Figura B.53 a B.56 - Determinação da taxa de utilização de oxigênio para uma amostra do reator R3 sem adição de substrato

Figura B.57 a B.60 - Determinação da taxa de utilização de oxigênio para uma amostra do reator R3 com adição de substrato. 
Figura B.61 a B.64 - Determinação da taxa de utilização de oxigênio para uma amostra do reator R4 sem adição de substrato.

Figura B.65 a B.68 - Determinação da taxa de utilização de oxigênio para uma amostra do reator R4 com adição de substrato.

Figura B.69 - Determinação dos parâmetros a' e b' para o sistema contínuo (base DBO filtrada e determinação de R sem adição de substrato).

Figura B.70 - Determinação dos parâmetros a' e b' para o sistema contínuo (base DBO filtrada e determinação de R com adição de substrato)...

Figura B.71 - Determinação dos parâmetros a' e b' para o sistema contínuo (base DQO filtrada e determinação de R sem adição de substrato).

Figura B.72 - Determinação dos parâmetros a' e b' para o sistema contínuo (base DQO filtrada e determinação de R com adição de substrato).

Figura B.73 a B.76 - Determinação do coeficiente global de transferência de oxigênio de uma amostra do reator R1 desoxigenada com sulfito de sódio..

Figura B.77 a B.80 - Determinação do coeficiente global de transferência de oxigênio de uma amostra do reator R1 desoxigenada pelos microrganismos presentes

Figura B.81 a B.84 - Determinação do coeficiente global de transferência de oxigênio de uma amostra do reator R2 desoxigenada com sulfito de sódio.. 
Figura B.85 a B.88 - Determinação do coeficiente global de transferência de oxigênio de uma amostra do reator R2 desoxigenada pelos microrganismos presentes.

Figura B.89 a B.92 - Determinação do coeficiente global de transferência de oxigênio de uma amostra do reator R3 desoxigenada com sulfito de sódio..

Figura B.93 a B.96 - Determinação do coeficiente global de transferência de oxigênio de uma amostra do reator R3 desoxigenada pelos microrganismos presentes

Figura B.97 a B.100 - Determinação do coeficiente global de transferência de oxigênio de uma amostra do reator R4 desoxigenada com sulfito de sódio..

Figura B.101 a B.104 - Determinação do coeficiente global de transferência de oxigênio de uma amostra do reator R4 desoxigenada pelos microrganismos presentes.

Figura B.105 a B.107 - Determinação do coeficiente global de transferência de oxigênio para uma amostra de água limpa desoxigenada com sulfito de sódio

Figura B.108 - Bactérias coloniais semelhantes a Zooglea ramigera e protozoário ciliado fixo (séssil) em microscopia óptica comum - sistema contínuo e aumento de 250 vezes.....

Figura B.109 - Aspecto geral do floco evidenciando a presença de protozoários rizópodos (amebas) e ciliados fixos pedunculados em microscopia óptica comum - sistema contínuo e aumento de 250 vezes. 
Figura B.110 - Aspecto geral do floco evidenciando a presença de protozoários ciliados fixos (sésseis) pedunculados coloniais em microscopia óptica comum - sistema contínuo e aumento de 250 vezes.

Figura B.111 - Aspecto geral do floco evidenciando a presença de protozoários ciliados livre-natantes (rastejantes) em microscopia óptica comum - sistema contínuo e aumento de 250 vezes.

Figura B.112 - Aspecto geral do floco evidenciando a presença de protozoário ciliado fixo (séssil) pedunculado e rotífero em microscopia óptica comum - sistema contínuo e aumento de 250 vezes.

Figura B.113 - Aspecto geral do floco evidenciando a presença de bactérias filamentosas e rotíferos em microscopia óptica comum - sistema contínuo e aumento de 250 vezes

Figura C.1 - Estudo hidrodinâmico do reator R1 com traçador cloreto de lítio.

Figura C.2 - Estudo hidrodinâmico do reator R4 com traçador cloreto de lítio. 


\section{LISTA DE TABELAS}

Tabela 3.1 - Agrupamento de organismos de diversos gêneros presentes nos sistemas de lodos ativados (CETESB, 1989)

Tabela 3.2 - Microrganismos indicadores das condições de depuração (CETESB, 1989).

Tabela 3.3 - Relação entre o desempenho do sistema e a presença de grupos de dominantes na microfauna do processo de lodos ativado (MADONI apud PEREZ, 1995)

Tabela 3.4 - Algumas faixas de valores de temperatura para vários tipos de bactérias (METCALF \& EDDY, 1991).

Tabela 3.5 - Períodos de um ciclo operacional para um reator seqüencial em batelada (SBR) (Adaptado de USEPA apud METCALF \& EDDY, 1991)

Tabela 3.6 - Principais alternativas para o pós-tratamento de efluentes tratados anaerobicamente (Adaptado de ФDEGARD apud SOUSA, 1996)

Tabela 3.7 - Eficiência de vários processos de tratamento sobre a remoção dos compostos de nitrogênio (METCALF \& EDDY, 1991)

Tabela 3.8 - Efíciência de vários processos ou operações de tratamento sobre a remoção de fósforo (METCALF \& EDDY, 1991) 
Tabela 3.9 - Valores dos coeficientes de temperatura para a atividade microbiana de vários processos biológicos de tratamento (METCALF \& EDDY, 1991)

Tabela 3.10 - Coeficientes cinéticos típicos para o processo de lodos ativados (esgoto sanitário e temperatura de $20^{\circ} \mathrm{C}$ ) (METCALF \& EDDY, 1979; METCALF \& EDDY, 1991)

Tabela 3.11 - Valores típicos do fator de correção $\alpha$ obtidos para aeradores de superfície de baixa velocidade com vários tipos de águas residuárias (METCALF \& EDDY, 1991) 78

Tabela 4.1 - Descartes diários para manutenção da idade do lodo e tempos de ciclo com seus respectivos tempos de aeração e de sedimentação, utilizados nos ensaios em sistema descontínuo.

Tabela 4.2 - Divisão dos parâmetros analisados conforme o método das análises e exames utilizados nos ensaios em sistema descontínuo.

Tabela 4.3 - Parâmetros analisados e freqüência média das análises e exames realizados nos ensaios em sistema descontínuo.

Tabela 4.4 - Descartes diários para manutenção da idade do lodo nos reatores.

Tabela 4.5 - Divisão dos parâmetros analisados conforme o método das análises e exames utilizados no ensaio em sistema contínuo

Tabela 4.6 - Parâmetros analisados e freqüência média das análises e exames realizados no ensaio em sistema contínuo.......

Tabela 5.1 - Datas de início e de encerramento, tempos de operação e de permanência dos reatores em estabilização dinâmica para os ensaios em sistema descontínuo 
Tabela 5.2 - Valores de remoção média da DBO bruta e filtrada, DQO bruta e filtrada, SST, SSF, SSV e $\mathrm{PO}_{4}^{3-}$ obtidos no ensaio em sistema contínuo após estabilização dinâmica dos reatores

Tabela 5.3 - Valores dos coeficientes cinéticos Y e $\mathrm{k}_{\mathrm{d}}$ para o sistema contínuo e do respectivo coeficiente de correlação da reta obtida após regressão linear pelo método dos mínimos $\left(\mathrm{T}_{\text {média }}=23,9^{\circ} \mathrm{C}\right)$

Tabela 5.4 - Valores médios de $X_{V}$ e R para os 4 reatores operados em sistema contínuo, nos ensaios sem e com adição de substrato

Tabela 5.5 - Valores dos parâmetros a' e b' para o sistema contínuo e do respectivo coeficiente de correlação da reta obtida após regressão linear pelo método dos mínimos quadrados

Tabela 5.6 - Valores médios do coeficiente $\alpha$ para os 4 reatores operados em sistema contínuo, nos ensaios com e sem utilização de sulfito de sódio

Tabela A.1 - Valores de $\mathrm{pH}$, temperatura e OD obtidos para os 2 reatores no ensaio preliminar em sistema descontínuo...

Tabela A.2 - Valores de pH, temperatura e OD obtidos para os 2 reatores no ensaio em sistema descontínuo com tempo de ciclo de 24 horas.

Tabela A.3 - Valores de pH, temperatura e OD obtidos para os 2 reatores no ensaio em sistema descontínuo com tempo de ciclo de 18 horas.

Tabela A.4 - Valores de $\mathrm{pH}$, temperatura e OD obtidos para os 2 reatores no ensaio em sistema descontínuo com tempo de ciclo de 12 horas. 
Tabela A.5 - Valores médios, máximos e mínimos de pH, OD e temperatura obtidos para os 2 reatores nos ensaios em sistema descontínuo.

Tabela A.6 - Resultados obtidos na caracterização da água residuária bruta realizada nos ensaios preliminar e com tempo de ciclo de 24 horas em sistema descontínuo

Tabela A.7 - Resultados obtidos na caracterização da água residuária bruta realizada nos ensaios com tempos de ciclo de 18 e 12 horas em sistema descontínuo.

Tabela A.8 - Resultados obtidos para a água residuária tratada no ensaio preliminar em sistema descontínuo, referentes ao reator $\mathrm{R} 1$

Tabela A.9 - Resultados obtidos para a água residuária tratada no ensaio preliminar em sistema descontínuo, referentes ao reator R2

Tabela A.10 - Resultados obtidos para a água residuária tratada e tanque de aeração no ensaio em sistema descontínuo com tempo de ciclo de 24 horas, referentes ao reator R1

Tabela A.11 - Resultados obtidos para a água residuária tratada e tanque de aeração no ensaio em sistema descontínuo com tempo de ciclo de 24 horas, referentes ao reator R2

Tabela A.12 - Resultados obtidos para a água residuária tratada e tanque de aeração no ensaio em sistema descontínuo com tempo de ciclo de 18 horas, referentes ao reator R 1

Tabela A.13 - Resultados obtidos para a água residuária tratada e tanque de aeração no ensaio em sistema descontínuo com tempo de ciclo de 18 horas, referentes ao reator R2

Tabela A.14 - Resultados obtidos para a água residuária tratada e tanque de aeração no ensaio em sistema descontínuo com tempo de ciclo de 12 horas, referentes ao reator $\mathrm{R} 1$ 
Tabela A.15 - Resultados obtidos para a água residuária tratada e tanque de aeração no ensaio em sistema descontínuo com tempo de ciclo de 12 horas, referentes ao reator R2

Tabela A.16 - Valores de remoção média da DBO bruta e filtrada, DQO bruta e filtrada, SST, SSF, SSV, $\mathrm{PO}_{4}^{3-}$, NTK e Namoniacal obtidos para os 2 reatores nos ensaios em sistema descontínuo, quando estes encontravam-se estabilizados dinamicamente.

Tabela A.17 - Resultados dos exames microscópicos realizados para o reator R1 na aclimatação da água residuária e no ensaio preliminar em sistema descontínuo.

Tabela A.18 - Resultados dos exames microscópicos realizados para o reator R1 na aclimatação da água residuária e nos ensaios em sistema descontínuo com tempos de ciclo de 24,18 e 12 horas

Tabela B.1- Valores de $\mathrm{pH}, \mathrm{OD}$, temperatura e vazão obtidos durante a operação dos 4 reatores em sistema contínuo..

Tabela B.2 - Valores médios, máximos e mínimos de pH, OD, temperatura e vazão obtidos durante a operação dos 4 reatores em sistema contínuo

Tabela B.3 - Resultados obtidos na caracterização da água residuária utilizada para alimentação dos reatores durante a operação do sistema contínuo.

Tabela B.4 - Resultados obtidos durante a operação do reator R1 em sistema contínuo, relativos ao efluente e tanque de aeração

Tabela B.5 - Resultados obtidos durante a operação do reator R2 em sistema contínuo, relativos ao efluente e tanque de aeração 
Tabela B.6 - Resultados obtidos durante a operação do reator R3 em sistema contínuo, relativos ao efluente e tanque de aeração.

Tabela B.7 - Resultados obtidos durante a operação do reator R4 em sistema contínuo, relativos ao efluente e tanque de aeração.

Tabela B.8 - Resultados necessários à determinação dos coeficientes cinéticos, obtidos quando os reatores operados em sistema contínuo encontravam-se estabilizados dinamicamente.

Tabela B.9 - Resultados obtidos quando os reatores encontravam-se estabilizados dinamicamente e cálculos necessários à determinação dos coeficientes cinéticos $\mathrm{k} \mathrm{e} \mathrm{K}$

Tabela B.10 - Resultados obtidos quando os reatores encontravam-se estabilizados dinamicamente e cálculos necessários à determinação dos coeficientes cinéticos $\mathrm{Y} \mathrm{e} \mathrm{k}_{\mathrm{d}}$

Tabela B.11 - Valores do decaimento da concentração de OD em função do tempo, obtidos nos ensaios realizados com amostras do reator R1, sem e com adição de substrato... $\quad 218$

Tabela B.12 - Valores do decaimento da concentração de OD em função do tempo, obtidos nos ensaios realizados com amostras do reator R2, sem e com adição de substrato...

Tabela B.13 - Valores do decaimento da concentração de OD em função do tempo, obtidos nos ensaios realizados com amostras do reator R3, sem e com adição de substrato...

Tabela B.14 - Valores do decaimento da concentração de OD em função do tempo, obtidos nos ensaios realizados com amostras do reator R4, sem e com adição de substrato...

Tabela B.15 - Valores de $\mathrm{X}_{\mathrm{v}}$ e $\mathrm{R}$ obtidos nos ensaios realizados com amostras dos 4 reatores sem adição de substrato 
Tabela B.16 - Valores de $\mathrm{X}_{\mathrm{v}}$ e R obtidos nos ensaios realizados com amostras dos 4 reatores com adição de substrato

Tabela B.17 - Resultados obtidos quando os reatores operados em sistema contínuo encontravam-se estabilizados dinamicamente e cálculos necessários à determinação dos parâmetros a' e b' (base DBO filtrada efluente e determinação de R sem adição de substrato)

Tabela B.18 - Resultados obtidos quando os reatores operados em sistema contínuo encontravam-se estabilizados dinamicamente e cálculos necessários à determinação dos parâmetros a' e b' (base DBO filtrada efluente e determinação de $\mathrm{R}$ com adição de substrato)

Tabela B.19 - Resultados obtidos quando os reatores operados em sistema contínuo encontravam-se estabilizados dinamicamente e cálculos necessários à determinação dos parâmetros a' e b' (base DQO filtrada efluente e determinação de $\mathrm{R}$ sem adição de substrato)

Tabela B.20 - Resultados obtidos quando os reatores operados em sistema contínuo encontravam-se estabilizados dinamicamente e cálculos necessários à determinação dos parâmetros a' e b' (base DQO filtrada efluente e determinação de $\mathrm{R}$ com adição de substrato)

Tabela B.21 - Valores do aumento da concentração de OD em função do tempo, obtidos durante a reaeração de amostras do reator R1, nos ensaios com e sem utilização de sulfito de sódio 
Tabela B.22 - Valores do aumento da concentração de OD em função do tempo, obtidos durante a reaeração de amostras do reator R2, nos ensaios com e sem utilização de sulfito de sódio.

Tabela B.23 - Valores do aumento da concentração de OD em função do tempo, obtidos durante a reaeração de amostras do reator R3, nos ensaios com e sem utilização de sulfito de sódio.

Tabela B.24 - Valores do aumento da concentração de OD em função do tempo, obtidos durante a reaeração de amostras do reator $\mathrm{R} 4$, nos ensaios com e sem utilização de sulfito de sódio.

Tabela B.25 - Valores do aumento da concentração de OD em função do tempo, obtidos durante a reaeração de amostras de água limpa desoxigenadas com utilização de sulfito de sódio

Tabela B.26 - Valores da temperatura do líquido, do coeficiente global de transferência de oxigênio à temperatura do líquido e sua conversão à $20^{\circ} \mathrm{C}$ para a água limpa.........

Tabela B.27 - Valores da temperatura do líquido, do coeficiente global de transferência de oxigênio à temperatura do líquido e sua conversão à $20^{\circ} \mathrm{C}$ e do coeficiente $\alpha$ para os 4 reatores operados em sistema contínuo, nos ensaios com e sem utilização de sulfito de sódio

Tabela B.28 - Valores da relação F/M (bases DBO e DQO filtrada efluente) e de IVL para o sistema contínuo.

Tabela B.29 - Valores de U para o sistema contínuo (bases DBO e DQO filtrada efluente).

Tabela B.30 - Valores de $\mathrm{P}_{\mathrm{x}}$ para o sistema contínuo (bases DBO e DQO filtrada efluente). 
xxvii

Tabela B.31 - Valores de $\mathrm{P}_{\mathrm{x}}$ ' para o sistema contínuo....................... 234

Tabela B.32 - Valores de $\mathrm{P}_{\mathrm{x}}{ }^{\prime}, \mathrm{P}_{\mathrm{x}}$ e desvio obtidos para os reatores no sistema contínuo (bases DBO e DQO filtrada efluente). 234

Tabela B.33 - Resultados dos exames microscópicos realizados durante a aclimatação da água residuária utilizada no ensaio em sistema contínuo........................................ 235

Tabela B.34 - Resultados dos exames microscópicos realizados durante a operação dos 4 reatores em sistema contínuo.. 236

Tabela C.1 - Ensaio hidrodinâmico do reator R1 com traçador

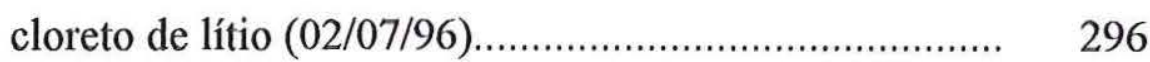

Tabela C.2 - Ensaio hidrodinâmico do reator R4 com traçador cloreto de lítio $(02 / 07 / 96)$. 


\section{LISTA DE ABREVIATURAS E SIGLAS}

$\begin{array}{lll}\text { ABES } & \text { - } & \text { Associação Brasileira de Engenharia Sanitária e Ambiental } \\ \text { ASCE } & \text { - } & \text { American Society of Civil Engineers } \\ \text { CETESB } & \text { - } & \text { Companhia de Tecnologia de Saneamento Ambiental } \\ \text { CONAMA } & \text { - } & \text { Conselho Nacional do Meio Ambiente } \\ \text { DAE } & \text { - } & \text { Departamento de Águas e Esgotos } \\ \text { DAFA } & \text { - } & \text { digestor anaeróbio de fluxo ascendente } \\ \text { EESC } & \text { - } & \text { Escola de Engenharia de São Carlos } \\ \text { LAB } & - & \text { lodos ativados por batelada } \\ \text { SBR } & - & \text { reator seqüencial em batelada ("Sequencing Batch Reactor") } \\ \text { UASB } & - & \text { reator anaeróbio de fluxo ascendente com manta de lodo } \\ & & \text { ("Up flow Anaerobic Sludge Blanket”) } \\ \text { USEPA } & - & \text { United States Environment Protection Agency } \\ \text { USP } & - & \text { Universidade de São Paulo } \\ \text { WEF } & - & \text { Water Environment Federation }\end{array}$




\section{LISTA DE SÍMBOLOS}

A

$\bar{a}$

a'

b'

C

$\mathrm{C}_{\mathrm{s}}$

$\mathrm{C}_{\mathrm{se}}$

$\mathrm{C}_{\mathrm{sPo}}$

$\mathrm{C}_{\mathrm{sPt}}$

DBO bruta

DBO filtrada
- superfície interfacial, $\mathrm{L}^{2}$

- fração de substrato removido utilizado para síntese, adimensional

- coeficiente de oxigênio necessário à remoção da parcela de substrato que é oxidado para a produção de energia ou fração de substrato removido utilizado para produção de energia, adimensional

- coeficiente de oxigênio necessário à respiração endógena, $\mathrm{T}^{-1}$

- concentração de oxigênio dissolvido no meio líquido, M.L ${ }^{-3}$

- concentração de saturação de oxigênio dissolvido, M.L $L^{-3}$

- concentração de saturação de oxigênio dissolvido para o esgoto, M.L ${ }^{-3}$

- concentração de saturação de oxigênio dissolvido à pressão padrão de $1 \mathrm{~atm}, 760 \mathrm{~mm} \mathrm{Hg}$ ou 101,33 kPa, M.L ${ }^{-3}$

- concentração de saturação de oxigênio dissolvido à pressão de teste (barométrica local em atm, $\mathrm{mm} \mathrm{Hg}$ ou $\mathrm{kPa}$ ), M.L ${ }^{-3}$

- demanda bioquímica de oxigênio da amostra bruta $\left(20^{\circ} \mathrm{C}\right.$, 5 dias), M.L ${ }^{-3}$

- demanda bioquímica de oxigênio da amostra filtrada $\left(20^{\circ} \mathrm{C}, 5\right.$ dias $), \mathrm{M}^{-L^{-3}}$ 
$\mathrm{DBO}_{\mathrm{L}} \quad$ - demanda bioquímica de oxigênio $\left(20^{\circ} \mathrm{C}, 20\right.$ dias $), \mathrm{M} \cdot \mathrm{L}^{-3}$

DQO bruta - demanda química de oxigênio da amostra bruta, M.L $\mathrm{L}^{-3}$

DQO filtrada - demanda química de oxigênio da amostra filtrada, $M \cdot L^{-3}$

$\mathrm{dX} / \mathrm{dt}$ - taxa de variação da concentração de microrganismos no reator, medida em termos de massa (sólidos suspensos voláteis), $M \cdot L^{-3} \cdot T^{-1}$

E - - eficiência do processo, \%

f - fator de conversão da $\mathrm{DBO}_{5}$ para $\mathrm{DBO}_{\mathrm{L}}\left(\mathrm{DBO}_{20}\right)$, adimensional

F/M - relação alimento/microrganismo, $\mathrm{T}^{-1}$

IVL - índice volumétrico do lodo, $\mathrm{M}^{-1} \cdot \mathrm{L}^{3}$

$\mathrm{k}$

- taxa máxima de utilização de substrato por unidade de massa de microrganismos, $\mathrm{T}^{-1}$

$k_{d}$

- coeficiente de decaimento da biomassa devido à respiração endógena, $\mathrm{T}^{-1}$

$\mathrm{K}_{\mathrm{L}} \quad$ - coeficiente típico para a massa líquida, $\mathrm{L} \cdot \mathrm{T}^{-1}$

$\left(\mathrm{K}_{\mathrm{L}} \mathrm{a}\right) \quad$ - coeficiente global de transferência de oxigênio, $\mathrm{T}^{-1}$

$\left(\mathrm{K}_{\mathrm{L}} \mathrm{a}\right)_{\text {água }} \quad$ - coeficiente global de transferência de oxigênio para a água limpa, $\mathrm{T}^{-1}$

$\left(K_{L} a\right)_{\text {esgoto }} \quad$ - coeficiente global de transferência de oxigênio para o esgoto, $\mathrm{T}^{-1}$

$\left(\mathrm{K}_{\mathrm{L}} \mathrm{a}\right)_{\mathrm{T}} \quad$ - coeficiente global de transferência de oxigênio para a temperatura $\mathrm{T} \mathrm{em}{ }^{\circ} \mathrm{C}, \mathrm{T}^{-1}$

$\left(\mathrm{K}_{\mathrm{L}} \mathrm{a}\right)_{20} \quad$ - coeficiente global de transferência de oxigênio para $20^{\circ} \mathrm{C}$, $\mathrm{T}^{-1}$

$\mathrm{K}_{\mathrm{s}} \quad$ - constante de meia velocidade, concentração de substrato para metade da taxa máxima de crescimento $\left(\mu=\mu_{\mathrm{m}} / 2\right)$, M.L - $^{-3}$

- massa de oxigênio transferido na unidade de tempo, M.T ${ }^{-1}$ 
$\mathrm{N}$-amoniacal - concentração de nitrogênio amoniacal (compreende $\mathrm{N}-\mathrm{NH}_{3}$ e N-NH$\left.{ }_{4}^{+}\right), M . L^{-3}$

$\mathrm{N}-\mathrm{NH}_{3}$ - concentração de nitrogênio como gás amoníaco (amônia), M. $\mathrm{L}^{-3}$

$\mathrm{N}-\mathrm{NH}_{4}^{+}$- concentração de nitrogênio como íon amônio, M.L $L^{-3}$

$\mathrm{N}-\mathrm{NO}_{2}^{-}$- concentração de nitrogênio como nitrito, M.L. $\mathrm{L}^{-3}$

$\mathrm{N}-\mathrm{NO}_{3}^{-}$concentração de nitrogênio como nitrato, M.L ${ }^{-3}$

$\mathrm{N}$-orgânico - concentração de nitrogênio orgânico, $M \cdot \mathrm{L}^{-3}$

NTK

- concentração de nitrogênio total Kjeldahl (compreende Norgânico e N-amoniacal), M.L.-3

OD - oxigênio dissolvido, M.L $L^{-3}$

$\mathrm{pH} \quad$ - potencial hidrogeniônico, adimensional

$\mathrm{PO}_{4}^{3-}$ - concentração de fosfato total, M.L $\mathrm{L}^{-3}$

PSF - fator de segurança do processo, adimensional

$\mathrm{P}_{\mathrm{o}} \quad$ - pressão atmosférica padrão de $1 \mathrm{~atm}, 760 \mathrm{~mm} \mathrm{Hg}$ ou $101,33 \mathrm{kPa}$

$\mathrm{P}_{\mathrm{t}} \quad$ - pressão barométrica local (atm, $\mathrm{mm} \mathrm{Hg}$ ou $\left.\mathrm{kPa}\right)$

$\mathrm{P}_{\mathrm{x}} \quad$ - produção líquida de lodo ativado por dia (quantidade a ser descartada), medido em termos SSVTA, M. $\mathrm{T}^{-1}$

$\mathrm{P}_{\mathrm{x}}{ }^{\prime} \quad$ - lodo ativado descartado diariamente do tanque de aeração, medido em termos de SSVTA, M.T ${ }^{-1}$

Q

- vazão afluente e efluente do reator (sem recirculação de lodo) e vazão afluente do reator (com recirculação de lodo), $\mathrm{L}^{3} \cdot \mathrm{T}^{-1}$

$\mathrm{Q}_{\mathrm{e}} \quad$ - vazão efluente do decantador, $\mathrm{L}^{3} \cdot \mathrm{T}^{-1}$

$\mathrm{Q}_{\mathrm{r}} \quad$ - vazão de recirculação do lodo, $\mathrm{L}^{3} \cdot \mathrm{T}^{-1}$

QTA - vazão descarta diariamente do tanque de aeração dos reatores, $\mathrm{L}^{3}$. $\mathrm{T}^{-1}$ 
$\mathrm{Q}_{\text {w }}$

$\mathrm{Q}_{\mathrm{w}}$

R

$\mathrm{R} / \mathrm{X}_{\mathrm{v}}$

$r_{d}$

$r_{g}$

$\mathrm{r}_{\mathrm{g}}$

$r_{\text {su }}$

$\mathrm{r}_{\mathrm{T}}$

$\mathrm{r}_{20}$

$\mathrm{r}^{2}$

S

$\mathrm{S}_{\mathrm{o}}$

$\mathrm{S}_{\mathrm{o}}-\mathrm{S}$

SF

SSed - 0,5 h

SSed - $1 \mathrm{~h}$

SSF

SSFTA

SST

SSTTA

SSV
- vazão de células biológicas descartadas do reator (excesso), $\mathrm{L}^{3} \cdot \mathrm{T}^{-1}$

- vazão de células biológicas descartadas na linha de retorno do lodo (excesso), $\mathrm{L}^{3} \cdot \mathrm{T}^{-1}$

- taxa de utilização de oxigênio, M.L $L^{-3} \cdot T^{-1}$

- taxa específica de utilização de oxigênio, $\mathrm{T}^{-1}$

- taxa de decaimento da biomassa devido à respiração endógena, $M \cdot L^{-3} \cdot T^{-1}$

- taxa de crescimento de microrganismos, $M \cdot L^{-3} \cdot T^{-1}$

- taxa líquida de crescimento de microrganismos, $M \cdot L^{-3} \cdot T^{-1}$

- taxa de utilização de substrato, M.L. $L^{-3} \cdot T^{-1}$

- taxa de reação à temperatura $\mathrm{T}^{\circ} \mathrm{C}$

- taxa de reação a $20^{\circ} \mathrm{C}$

- coeficiente de correlação, adimensional

- concentração de substrato no efluente, $M \cdot \mathrm{L}^{-3}$

- concentração de substrato no afluente, $M \cdot L^{-3}$

- concentração do substrato utilizado, M.L. ${ }^{-3}$

- concentração de sólidos fixos, $M \cdot L^{-3}$

- sólidos sedimentáveis em 0,5 hora, volume de sólidos que sedimenta num cone de Imhoff após 0,5 hora, $\mathrm{L}^{3} \cdot \mathrm{L}^{-3}$

- sólidos sedimentáveis em 1 hora, volume de sólidos que sedimenta num cone de Imhoff após 1 hora, $\mathrm{L}^{3} \cdot \mathrm{L}^{-3}$

- concentração de sólidos suspensos fíxos, $M \cdot L^{-3}$

- concentração de sólidos suspensos fixos no tanque de aeração, $M \cdot L^{-3}$

- concentração de sólidos suspensos totais, $M \cdot L^{-3}$

- concentração de sólidos suspensos totais no tanque de aeração, $M \cdot L^{-3}$

- concentração de sólidos suspensos voláteis, $M \cdot L^{-3}$ 
SSVTA

ST

SV

$\mathrm{T}$

$\mathrm{T}_{\text {ambiente }}$

$\mathrm{T}_{\text {reator }}$

U

V

VLS - 0,5 h

$\mathrm{V}_{\mathrm{r}}$

$\mathrm{V}_{\mathrm{s}}$

$\mathrm{V}_{\text {sistema }}$

$\mathrm{V}_{\mathrm{T}}$

$\mathrm{X}$

$\mathrm{X}_{\mathrm{e}}$

$\mathrm{X}_{\mathrm{o}}$

$X_{t}$

$X_{\text {r }}$

$\mathrm{X}_{\mathrm{v}}$

Y

$Y_{o b s}$
- concentração de sólidos suspensos voláteis no tanque de aeração, $M \cdot L^{-3}$

- concentração de sólidos totais, $M \cdot L^{-3}$

- concentração de sólidos voláteis, M.L. $L^{-3}$

- temperatura, ${ }^{\circ} \mathrm{C}$

- temperatura ambiente, ${ }^{\circ} \mathrm{C}$

- temperatura do reator (tanque de aeração), ${ }^{\circ} \mathrm{C}$

- taxa específica de utilização de substrato, $\mathrm{T}^{-1}$

- volume do tanque de aeração, $\mathrm{L}^{3}$

- volume de lodo (coletado no tanque de aeração) sedimentado em 0,5 hora num cone Imhoff, $\mathrm{L}^{3} \cdot \mathrm{L}^{-3}$

- volume do reator, $\mathrm{L}^{3}$

- volume do decantador, $\mathrm{L}^{3}$

- volume do sistema em que ocorre a transferência, $\mathrm{L}^{3}$

- volume total, incluindo reator e decantador, $\mathrm{L}^{3}$

- concentração de microrganismos no reator, $M \cdot L^{-3}$

- concentração de microrganismos no efluente do decantador, M.L ${ }^{-3}$

- concentração de microrganismos no afluente do reator, M.L. ${ }^{-3}$

- massa total de SSV no sistema, incluindo tanque de aeração, decantador e retorno do lodo, $\mathrm{M}$

- concentração de microrganismos na linha de retorno do lodo do decantador ao reator, M.L. $\mathrm{L}^{-3}$

- concentração de microrganismos no tanque de aeração, em termos de SSVTA, M.L ${ }^{-3}$

- coeficiente de produção celular ou de síntese celular, adimensional

- coeficiente de produção celular observada ou de síntese celular observada, adimensional 
$\alpha$

$\lambda$

$\mu$

$\mu_{\mathrm{m}}$

$\mu$

$\theta$

$\theta_{\mathrm{c}}$

$\theta_{\mathrm{c}}^{\mathrm{M}}$

$\theta_{\mathrm{ct}}$

$\theta_{\mathrm{s}}$
- fator de correção, adimensional

- coeficiente de temperatura para a atividade microbiana, adimensional

- taxa específica de crescimento de microrganismos, $\mathrm{T}^{-1}$

- taxa específica máxima de crescimento de microrganismos, $\mathrm{T}^{-1}$

- taxa líquida específica de crescimento, $\mathrm{T}^{-1}$

- tempo de detenção hidráulico, T

- tempo de retenção celular (idade do lodo), T

- tempo de retenção celular mínimo ou idade do lodo mínima, $\mathrm{T}$

- tempo de retenção celular total do sistema, T

- tempo de detenção hidráulico do sistema, T 


\section{RESUMO}

COLETTI, F. J. (1997). Pós-tratamento por lodos ativados de efluente de um reator anaeróbio compartimentado no tratamento de esgoto sanitário. São Carlos, 1997. 300p. 2v. Dissertação (Mestrado) - Escola de Engenharia de São Carlos, Universidade de São Paulo.

Estudou-se nesta pesquisa o processo de lodos ativados para póstratamento do efluente proveniente de um reator anaeróbio compartimentado, que recebe esgoto sanitário. Isso se deu em vários ensaios em sistema descontínuo ("batch") para avaliar a biodegradabilidade dessa água residuária e em um ensaio em sistema contínuo com finalidade de melhorar a qualidade do efluente final e determinar os coeficientes cinéticos, os parâmetros a' e b', a taxa de utilização de oxigênio e o coefíciente $\alpha$. Também realizaram-se ensaios hidrodinâmicos para verificação do tipo de reator utilizado. A pesquisa desenvolveu-se com base em uma célula de aeração, em escala de laboratório, composta por quatro câmaras (reatores) que possuiam tanque de aeração e decantador secundário justapostos, separados por uma cortina fixa. Não houve controle de temperatura nos dois sistemas utilizados. No ensaio em sistema contínuo quatro reatores foram operados simultaneamente com as respectivas idades do lodo de 5, 10, 15 e 20 dias durante 35 dias. O tempo de detenção hidráulico foi mantido próximo de 8 horas. Nesse ensaio os reatores quando se 
encontravam estabilizados dinamicamente, apresentaram remoção superior a $95 \%$ para DBO bruta, $90 \%$ para DBO filtrada, $87 \%$ para DQO bruta, $80 \%$ para DQO filtrada e $95 \%$ para SST. Mesmo não sendo realizado processo adicional para remoção de nutrientes, os reatores, após a estabilização dinâmica, apresentaram remoção de fosfato de até $28 \%$ e de nitrogênio amoniacal até níveis de não serem detectados pelos métodos de análises utilizados. Os ensaios hidrodinâmicos mostraram que os reatores são do tipo mistura completa.

Palavras-chaves: Pós-tratamento; Lodos Ativados por Batelada; Lodos Ativados; Coeficientes Cinéticos; Taxa de Utilização de Oxigênio. 
ABSTRACT

COLETTI, F. J. (1997). Post-treatment by activated sludge of anaerobic baffled reactor effluent in the treatment of sanitary sewage. São Carlos, 1997. 300p. 2v. Dissertação (Mestrado) - Escola de Engenharia de São Carlos, Universidade de São Paulo.

In this work the activated sludge process for post-treatment of effluent anaerobic baffled reactor which receives sanitary sewage was studied. This was established during various experiments in batch system to evaluate the biodegradable of this wastewater and also in an experiment of continuous system aiming to improve the quality of the final effluent and to determine the kinetic coefficients, the a' and b' parameters, the oxygen uptake rate and the $\alpha$ coefficient. Hydrodynamic tests to verify the type of reactor used in this research were also performed. The work was developed and based on an aeration cell bench-scale, composed of four chambers (reactors) which had an aeration tank and a secondary settling tank in the same chamber, separated by a fixed baffle. Temperature control was not used in both systems. In the experiment of continuous system, four reactors were simultaneously operated with sludge age of $5,10,15$ and 20 days during 35 days. The hidraulic retention time was maintained at around 8 hours. When the reactors were dynamically stabilized, they showed an average removal superior to $95 \%$ for 
BOD (biochemical oxygen demand), $90 \%$ for filtrated BOD, $87 \%$ for COD (chemical oxygen demand), $80 \%$ for filtrated COD and $95 \%$ for TSS (total suspended solids). Without additional process of nutrient removal, after the dynamic stabilization the reactors presented up to $28 \%$ of total phosphate removal and ammonia nitrogen up to levels of not being detected by the analyses methods used. The hydrodynamic tests showed that the reactors are of the complete-mix type.

Keywords: Post-treatment; Sequencing Batch Reactor; Activated Sludge; Kinetic Coefficients; Oxygen Uptake Rate. 


\section{1 - INTRODUÇÃO}

Com o aumento crescente da população, principalmente nas grandes metrópoles, o tratamento do esgoto sanitário vem se tornando uma preocupação, pois o seu lançamento sem tratamento provoca degradação ambiental, cuja poluição dos mananciais é um exemplo marcante dessa ação. A escassez dos mananciais cria problemas, como se verifica na região da Grande São Paulo, onde há necessidade da importação de água de outras bacias hidrográficas para suprir sua demanda em água potável. Poder-se-ia amenizar a situação se todo o esgoto fosse tratado e o efluente reusado para fins não potáveis.

A utilização de sistemas de tratamento de esgoto por via anaeróbia tem apresentado eficiências elevadas no que se refere à remoção de matéria carbonácea. Entretanto, devido à maior restrição imposta pelos padrões de emissão de efluentes e da qualidade das águas dos corpos receptores, torna-se necessário remover parte da carga remanescente de forma a atender à legislação brasileira vigente (Resolução CONAMA No 20 de 18/06/86).

Como pós-tratamento de efluentes de processos anaeróbios foram feitas pesquisas na Escola de Engenharia de São Carlos, Universidade de São Paulo EESC - USP empregando processos aeróbios. Esta alternativa resulta em menor consumo de energia e menor produção de lodo, pois ocorre substancial remoção de matéria orgânica no processo anaeróbio com baixo consumo de energia. O lodo aeróbio gerado pela remoção do remanescente de matéria orgânica proveniente dos processos anaeróbios, em virtude do menor volume, pode ser digerido no reator anaeróbio. 
Tendo em vista a realidade econômica brasileira e a necessidade de implantação de estações de tratamento de esgoto sanitário, é de fundamental importância que existam opções para o tratamento que apresentem tecnologia adequada à área de implantação e que não só possam substituir aos sistemas convencionais com custos de implantação e operação inferiores, mas também gerem efluente final com qualidade próxima ou até mesmo superior.

GRADY e METCALF \& EDDY citados por LARANJEIRA FILHO (1989), relatam que o sistema de lodos ativados convencionais, desde seu aparecimento na Inglaterra, vem sendo muito utilizado e difundido para o tratamento de águas residuárias de origem doméstica e industrial, não só pelo fato de se adaptarem bem a despejos de características variadas, mas também de produzir efluente de excelente qualidade, entre outras vantagens. No entanto, o consumo de energia, como em todos os processos aeróbios, é um fator limitante do processo.

SOUSA (1996) concluiu que o sistema composto de um reator de fluxo ascendente com manta de lodo - UASB seguido de dois reatores seqüenciais em batelada aeróbios - SBRs alimentados continuamente por substrato sintético simulando esgoto sanitário e com temperatura controlada de $30^{\circ} \mathrm{C}$ é uma alternativa para o tratamento de esgoto sanitário em regiões tropicais, pois apresentam baixo consumo de oxigênio (portanto baixo consumo de energia), baixa taxa de produção de lodo e alta eficiência de remoção de nutrientes e matéria carbonácea.

SILVA (1993), estudando uma associação de um digestor anaeróbio de fluxo ascendente - DAFA com um reator de lodos ativados tratando uma mistura de esgoto sanitário e efluentes industriais, observou que a associação necessitou potência de aeração aproximadamente $40 \%$ da consumida pela opção de lodos ativados convencionais.

BELÉM (1996), trabalhando com filtro biológico aeróbio de aeração forçada para tratamento do mesmo efluente utilizado neste trabalho, obteve percentagens médias de remoção da $\mathrm{DQO}$ e $\mathrm{DBO}_{5}$ de 70 e 73 \% para a taxa de 
aplicação hidráulica de $1,5 \mathrm{~m}^{3} / \mathrm{m}^{2}$.dia; 55 e $59 \%$ para $7,5 \mathrm{~m}^{3} / \mathrm{m}^{2}$.dia, e 40 e $48 \%$ para $13 \mathrm{~m}^{3} / \mathrm{m}^{2}$.dia.

Dando continuidade a essa linha de pesquisa, o presente trabalho referese a uma em particular, que empregou o sistema de lodos ativados com operação contínua e descontínua para pós-tratamento de efluente oriundo de reator anaeróbio compartimentado que recebe esgoto sanitário. A finalidade principal é melhorar a qualidade do efluente final, aumentando a remoção da $\mathrm{DBO}$, da DQO e de sólidos, com vistas a atender à legislação brasileira em vigor e também verificar se o sistema de tratamento de esgoto sanitário empregando processos anaeróbios seguidos de processo aeróbio de lodos ativados é alternativa técnica e economicamente viável. Com os reatores alimentados continuamente visa-se também a calcular os coeficientes cinéticos, os parâmetros a' e b', a taxa de utilização de oxigênio e o coeficiente $\alpha$.

A remoção de patogênicos poderia ser realizada com instalação de um sistema de desinfeç̧ão, como por exemplo, radiação ultravioleta na saída do efluente final dos reatores de lodos ativados.

A unidade experimental estudada nos ensaios em sistema descontínuo e a estudada no ensaio em sistema contínuo foram montadas no laboratório de Saneamento do Departamento de Hidráulica e Saneamento da EESC - USP. Essas unidades experimentais consistiram principalmente de uma célula de aeração, em escala de laboratório, construída em acrílico transparente e composta de quatro câmaras, com volume individual de aproximadamente 10,2 litros e que simulam o processo de lodos ativados. Cada câmara apresenta tanque de aeração e decantador secundário justapostos, separados por uma cortina fixa, que somados ao seu formato, possibilitam o retorno contínuo de lodo ao tanque de aeração, sendo que com uma aeração adequada obtém-se mistura completa no interior do mesmo. Nos ensaios em sistema descontínuo a totalidade da câmara funcionou como tanque de aeração, sendo necessários frascos de 5 litros em unidades independentes para desenvolverem o papel de 
decantador secundário. Não houve controle de temperatura nos dois sistemas utilizados.

Esta dissertação apresenta resultados obtidos nos ensaios em sistema descontínuo e no ensaio em sistema contínuo, em que, os reatores foram alimentados com efluente final de um reator anaeróbio compartimentado para tratamento de esgoto sanitário. Para o sistema contínuo, apresentam-se os valores dos coeficientes cinéticos $\mathrm{Y}$ e $\mathrm{k}_{\mathrm{d}} \mathrm{e}$ dos parâmetros a' e b' em termos da DBO e DQO filtrada efluente, e para as idades do lodo estudadas, a taxa de utilização de oxigênio e o coeficiente $\alpha$. Apresentam-se também os ensaios hidrodinâmicos com traçador cloreto de lítio que foram realizados para os reatores operados com a menor e a maior idade do lodo. 


\section{2 - OBJETIVOS}

Tratar o efluente final de um reator anaeróbio compartimentado que recebe esgoto sanitário através de câmaras de aeração, em escala de laboratório, que simulam o processo de lodos ativados, com os seguintes objetivos:

Nos ensaios em sistema descontínuo avaliar principalmente a biodegradabilidade dessa água residuária e no ensaio em sistema contínuo melhorar a qualidade final do efluente; determinar os coeficientes cinéticos e os parâmetros a' e b', e para vários tempos de retenção celular, a taxa de utilização de oxigênio e o coeficiente $\alpha$. Desenvolver ensaios hidrodinâmicos para verificação do tipo de reator utilizado nesta pesquisa. 


\section{3 - REVISÃO BIBLIOGRÁFICA}

\section{1 - Processo de lodos ativados}

\subsection{1- Introdução}

O processo de lodos ativados foi desenvolvido em 1914 na Inglaterra por Ardern e Lockett, sendo assim denominado por consistir, basicamente, na produção de uma massa ativada de microrganismos capaz de estabilizar o resíduo aerobiamente. Atualmente, muitas variações do processo original têm sido empregadas, mas fundamentalmente elas são semelhantes (METCALF \& EDDY, 1991).

Nos processos de lodos ativados o elemento ativo é o floco, composto por bactérias e outros organismos. Não existe propriamente um substrato sólido para fixação desses organismos, ou, se há, este é constituído pelas próprias partículas em suspensão no resíduo, levando a uma economia de espaço nos reatores. Outra característica do processo é a de que, sendo os flocos móveis e não permanecendo fixos em uma determinada posição no sistema, podem ser removidos do resíduo, que já se encontra numa fase de adiantada oxidação, e transferido ao resíduo bruto ou em início de depuração, sob a forma de lodo de retorno, numa verdadeira operação de inoculação. A necessária introdução constante de ar pode ser feita por intermédio de compressores, ou pela movimentação da massa líquida através da rotação de escovas, torres ou outros meios, que mantenham sua superfície em constante 
contato com o ar atmosférico, promovendo a aeração superficial. O oxigênio puro é outra forma de fornecimento do oxigênio necessário ao processo. (BRANCO, 1986).

Na atualidade, o processo de lodos ativados apresenta grande aplicação no tratamento de esgoto, pois o seu efluente apresenta baixas concentrações de matéria orgânica biodegradável, sólidos em suspensão e nutrientes. O tempo de detenção hidráulico varia de 8 a 24 horas, dependendo das características do afluente e das condições operacionais do sistema. As principais desvantagens são os custos elevados de construção e de operação e a produção de grande quantidade de lodo putrescível, que necessita ser estabilizado antes da separação sólido-líquido (van HAANDEL \& LETTINGA, 1994).

\subsection{2 - Descrição do processo}

Um sistema de lodos ativados típico consta basicamente de três unidades: reator (tanque de aeração), decantador secundário (ou tanque de sedimentação) e sistema de recirculação de lodo.

No sistema de lodos ativados, o resíduo orgânico é introduzido num reator, onde uma cultura de bactérias aeróbias é mantida em suspensão. Essas bactérias, geralmente, realizam a conversão da matéria orgânica do despejo conforme a estequiometria das eqs. (3.1) e (3.2). As reações de respiração endógena resultam produtos finais simples, energia e produtos orgânicos finais estáveis.

- Oxidação e síntese:

COHNS $+\mathrm{O}_{2}+$ nutrientes $\stackrel{\text { bacté ria }}{\longrightarrow} \mathrm{CO}_{2}+\mathrm{NH}_{3}+\mathrm{C}_{5} \mathrm{H}_{7} \mathrm{NO}_{2}+$ produtos finais

COHNS $=$ representa a matéria orgânica do despejo 
$\mathrm{C}_{5} \mathrm{H}_{7} \mathrm{NO}_{2}=$ representa novas células de bactérias

\section{- Respiração endógena:}

$\mathrm{C}_{5} \mathrm{H}_{7} \mathrm{NO}_{2}+5 \mathrm{O}_{2} \stackrel{\text { bacté rias }}{\longrightarrow} 5 \mathrm{CO}_{2}+2 \mathrm{H}_{2} \mathrm{O}+\mathrm{NH}_{3}+$ energia

A condição aeróbia no reator é obtida pela utilização de um sistema de aeração composto por difusores ou aeradores mecânicos, que servem para manter o conteúdo do tanque de aeração - "liquor" - em regime de mistura completa. Após um período específico de tempo, o liquor é levado ao decantador, onde ocorre separação das células do resíduo tratado. Uma parcela das células sedimentadas é reciclada para manter uma concentração desejada de organismos no reator, e uma outra parcela é descartada. A parcela descartada corresponde ao novo crescimento de tecido celular, associado a cada despejo. O nível de massa biológica mantido no reator depende da eficiência de tratamento desejado e de considerações relacionadas com a cinética do crescimento bacteriano (METCALF \& EDDY, 1991).

$\mathrm{O}$ decantador secundário exerce as funções de clarificação e adensamento. A importância da clarificação e do adensamento dos sólidos sedimentados no fundo reside no fato de que o arraste de sólidos suspensos caracterizam uma determinada carga de $\mathrm{DBO}$, representando assim, uma deterioração na qualidade do efluente (DICK e DINIZ apud POVINELLI \& AISSE, 1987).

\subsection{3 - Microbiologia do processo}

Neste item, referente ao processo de lodos ativados, serão abordados os principais microrganismos presentes, o crescimento destes microrganismos, a 
dinâmica da população microbiana, a floculação biológica e os fatores intervenientes no desenvolvimento dos microrganismos.

\subsubsection{1 - Microrganismos presentes}

Em sistemas de lodos ativados apenas a microfauna é encontrada, pois a turbulência, em razão da aeração, não permite o desenvolvimento de organismos maiores. A turbidez decorrente do material em suspensão provoca a ausência de luz, evitando o desenvolvimento de algas. Com relação à microbiota, encontram-se normalmente vários tipos de bactérias e, às vezes, fungos e leveduras. Representando a microfauna, encontram-se protozoários e micrometazoários (rotíferos e pequenos vermes) (CETESB, 1989).

A microfauna de um sistema de lodos ativados em operação normal é quase sempre bastante diversificada, sendo composta por diferentes grupos de organismos, onde cada grupo possui várias espécies. Quando uma microfauna é dominada por uma espécie ou grupo é quase sempre indicação de desequilíbrio trófico, proporcionado pela existência de fatores limitantes que impedem o desenvolvimento da maioria das outras espécies favorecendo o crescimento de formas mais tolerantes a tais fatores. Os fatores limitantes mais comuns são geralmente a presença de carga de choque devido à descarga tóxica, subcarga ou sobrecarga, forte descarte de lodo e insuficiência na aeração (MADONI, 1994).

A seguir, serão apresentadas algumas informações básicas dos principais microrganismos presentes nos processos de lodos ativados:

\section{a) Bactérias}

As bactérias são protistas unicelulares, que geralmente se reproduzem por fissão binária, embora em algumas espécies a reprodução ocorra 
sexuadamente ou por brotamento. A maioria das bactérias não toleraram $\mathrm{pH}$ acima de 9,5 ou abaixo de 4,0, sendo a faixa de $\mathrm{pH}$ ótimo para o crescimento entre 6,5 e 7,5 (METCALF \& EDDY, 1991). Quanto à nutrição elas podem ser autotróficas (fotossintetizantes ou quimiossintetizantes) ou heterotróficas.

Nos processos de lodos ativados as bactérias são os microrganismos mais importantes, pois são responsáveis pela decomposição da matéria orgânica presente na água residuária e formação de flocos. No tanque de aeração, as bactérias aeróbias e facultativas realizam a oxidação da matéria orgânica à compostos de baixa energia, como nitratos, sulfatos e gás carbônico e sintetizam o material orgânico remanescente em novas células (BRAILE \& CAVALCANTI, 1993).

As bactérias unicelulares mais freqüentes encontradas nos sistemas de lodos ativados, além da Zoogloea ramigera, pertencem os gêneros Achromobacterium, Chromobacterium (Flavobacterium) e Pseudomonas. Com relação às bactérias filamentosas presentes nos lodos ativados, a mais comum é a Sphaerotilus natans, estando também presentes outras bactérias como, por exemplo, Thiotrix, Beggiatoa e Nocardia. O intumescimento filamentoso do lodo (bulking) é causado pelo crescimento excessivo de bactérias filamentosas que difícultam a sedimentação do lodo (CETESB, 1989).

A observação das bactérias Nitrosomonas e Nitrobacter fornecem indicação de um bom nível de tratamento e da ocorrência da nitrificação (ALÉM SOBRINHO, 1983).

\section{b) Fungos}

Os fungos são considerados protistas heterotróficos não fotossintéticos, multicelulares e a maioria estritamente aeróbios. São geralmente classificados pelo modo de reprodução - sexuada ou assexuada, fissão, brotamento ou formação de esporos. $\mathrm{O} \mathrm{pH}$ ótimo para a maioria das espécies é de 5,6 e o 
intervalo é de 2 a 9. Sua capacidade de sobreviver em baixos valores de $\mathrm{pH}$ e em baixas concentrações de nitrogênio é muito importante no tratamento de algumas águas residuárias industriais e na compostagem de resíduos sólidos orgânicos (METCALF \& EDDY, 1991).

HU \& STROM (1991), trabalhando com sistema de lodos ativados de fluxo intermitente em unidades com diferentes valores de $\mathrm{pH}(4,5,6$ e 7), obtiveram para as unidades com $\mathrm{pH}$ de 4 e 5 altos valores do índice volumétrico do lodo mesmo com baixa concentração de bactérias filamentosas. Com isso, concluíram que os fungos podem ser responsáveis pelo intumescimento do lodo ativado para um baixo $\mathrm{pH}$.

Em processos de lodos ativados operados adequadamente, os fungos não são muito freqüentes, mas podem predominar quando ocorrer acentuada queda de $\mathrm{pH}$ e deficiência em nitrogênio. Para estabilização da matéria orgânica, não são tão eficientes como as bactérias, mas no caso de se apresentarem como organismos predominantes, podem provocar o intumescimento do lodo (ALÉM SOBRINHO, 1983 e CETESB, 1989).

HATTINGH apud ALÉM SOBRINHO (1983) cita que os gêneros Fusarium, Geotrichoides, Oospora, Phoma, Pullularia, Sporotrichum, Zoophagus e Arthrobotrys são mais observados nos processos de lodos ativados.

\section{c) Protozoários}

Os protozoários são protistas móveis microscópicos, geralmente heterótrofos aeróbios e unicelurares. Eles atuam como polidores dos efluentes dos processos de tratamento de águas residuárias, pois consomem as bactérias e a matéria orgânica particulada (METCALF \& EDDY, 1991).

Depois das bactérias, os protozoários são organismos presentes em maior número no processo de lodos ativados, sendo o principal grupo 
composto pelos ciliados, que se subdividem em livre-natantes, rastejantes e fixos.

A presença de protozoários ciliados melhora a qualidade do efluente. Muitos estudos recentes têm demonstrado que o número de ciliados encontrados em um sistema de lodos ativados funcionando normalmente é de aproximadamente $10^{6}$ indivíduos por litro de lodo. Quando este número é reduzido abaixo de $10^{4}$ por litro, indica uma depuração insuficiente, pois ocorre proliferação de bactérias dispersas que proporcionam acréscimo na turbidez e DBO do efluente (CURDS; DRAKIDES e MADONI apud MADONI, 1994). Um número elevado de ciliados (maior que $10^{7}$ indivíduos por litro de lodo) quase sempre indica boa depuração e ótimo desempenho do sistema de lodos ativados (MADONI, 1994).

A ocorrência de um número elevado de protozoários no floco, especialmente os ciliados, como Vorticella, Paramecium e Blepharisma, caracteriza indício de boas condições do lodo ativado, pois são reguladores do número de bactérias, contribuem para formação do floco e removem DBO (BRANCO, 1986).

BUX \& KASAN apud PEREZ (1995), pesquisando dez sistemas de lodos ativados, observaram que os ciliados predominavam sobre os flagelados e rizópodes. Ainda observaram a predominância dos ciliados livres sobre os pedunculados, tendo como justificativa o alto grau de agitação do conteúdo dos tanques de aeração, dificultando assim a fixação das formas pedunculadas nos flocos.

Os rizópodes (amebas) nos lodos ativados são representados por três gêneros principais: Arcella, Diffugia e Euglypha. Estes protozoários surgem no lodo de sistemas de lodos ativados com baixa carga, sendo particularmente encontrados em tanques de aeração de sistemas utilizados para remoção de nitrogênio. Eles são mais abundantes ou dominantes em lodos caracterizados por baixa carga, longo tempo de retenção, e alta concentração de oxigênio 
dissolvido em tanques de aeração que permitem completa nitrificação (CHIERICI \& MADONI; DRAKIDES e POOLE apud MADONI, 1994).

Conclusões sobre o funcionamento do processo de lodos ativados baseadas na população de protozoários, só poderão ser consideradas pelo acompanhamento das variações das populações dominantes ao longo do tempo (ALÉM SOBRINHO, 1983).

\section{d) Metazoários}

No processo de lodos ativados, em conseqüência da turbulência, somente os micrometazoários se desenvolvem, indicando um sistema eficiente e com boa operação. Algumas informações sobre os principais micrometazoários estão descritas a seguir.

\section{d.1) Rotíferos}

Os micrometazoários mais freqüentes no processo de lodos ativados são os rotíferos, que são associados a lodos com boa efíciência de depuração.

Os rotíferos são animais aeróbios, heterotróficos e multicelulares. São muitos eficazes no consumo de bactérias dispersas e floculadas, e de pequenas partículas de matéria orgânica. A presença deles no efluente final fornece indicação de um processo aeróbio de purificação biológica muito eficiente (METCALF \& EDDY, 1991).

\section{d.2) Nematóides}

Os nematóides são vermes alongados, aeróbios, heterotróficos multicelulares e de reprodução geralmente sexuada. Nas águas residuárias podem ser encontrados ovos de nematóides parasitas do homem, que resistem 
aos processos de tratamento, inclusive à digestão e secagem do lodo. São encontrados raramente no processo de lodos ativados (BRANCO, 1986).

\section{d.3) Anelídeos}

Os anelídeos são os micrometazoários menos freqüentes no processo de lodos ativados. São vermes alongados, aeróbios, multicelulares e de reprodução normalmente sexuada (BRANCO, 1986).

$\mathrm{Na}$ Tabela 3.1, estão agrupados os organismos dos diversos gêneros representantes da microfauna, freqüentemente encontrados no processo de lodos ativados.

\subsubsection{2 - Crescimento de microrganismos}

O crescimento dos microrganismos em culturas puras pode ser observado segundo o modelo da curva de crescimento, conforme MONOD apud CETESB (1989), reproduzida na Figura 3.1, e que apresenta as seguintes etapas ou fases:

a) Fase lag, ou de aclimatação (adaptação): não ocorre aumento do número de microrganismos, mas estes elaboram o arsenal enzimático necessário ao consumo dos substratos. A velocidade de crescimento é nula;

b) Fase de aceleração: início de crescimento dos microrganismos face ao consumo de substrato. A velocidade de crescimento aumenta com o tempo;

c) Fase log ou exponencial: a velocidade de crescimento é máxima, sendo representada por uma função exponencial;

d) Fase de desaceleração: a velocidade de crescimento passa a diminuir, pois ocorre diminuição do substrato disponível e acúmulo ponderável de excretas tóxicas; 
e) Fase estacionária: a velocidade de crescimento volta a ser nula, em decorrência do esgotamento dos substratos ou do acúmulo de substâncias tóxicas em níveis incompatíveis;

f) Fase de declínio: a velocidade de crescimento passa ser negativa, pois o número de microrganismos é reduzido pela morte e lise.

TABELA 3.1 - Agrupamento de organismos de diversos gêneros presentes nos sistemas de lodos ativados.

\section{GRANDES GRUPOS}

Classe Ciliata

a) ciliados livre-natantes

b) ciliados pedunculados

c) ciliados livres, predadores do floco

Classe Mastigophora - flagelados

Classe Sarcodina - amebas

\section{GÊNEROS FREQÜENTES}

Paramecium, Colpidium,

Litonotus, Trachelophyllum, Amphileptus, Chilodonella

Vorticella, Operculária, Epistylis, Charchesium e as suctórias Acineta e Podophrya Aspidisca, Euplotes, Stylonychia, Oxytricha Bodo, Cercobodo, Mona sp, Oicomona sp, Euglena sp,

Cercomona sp, Peranema Amoeba, Arcella, Actinophrys, Vahlkampfi, Astramoeba, Difflugia, Cochliopodium Classe Rotífera - rotíferos Philodina, Rotaria, Epiphanes Classe Nematoda - nematóides

Filo Änelida - anelídeos A elosoma

Fonte: CETESB (1989). 


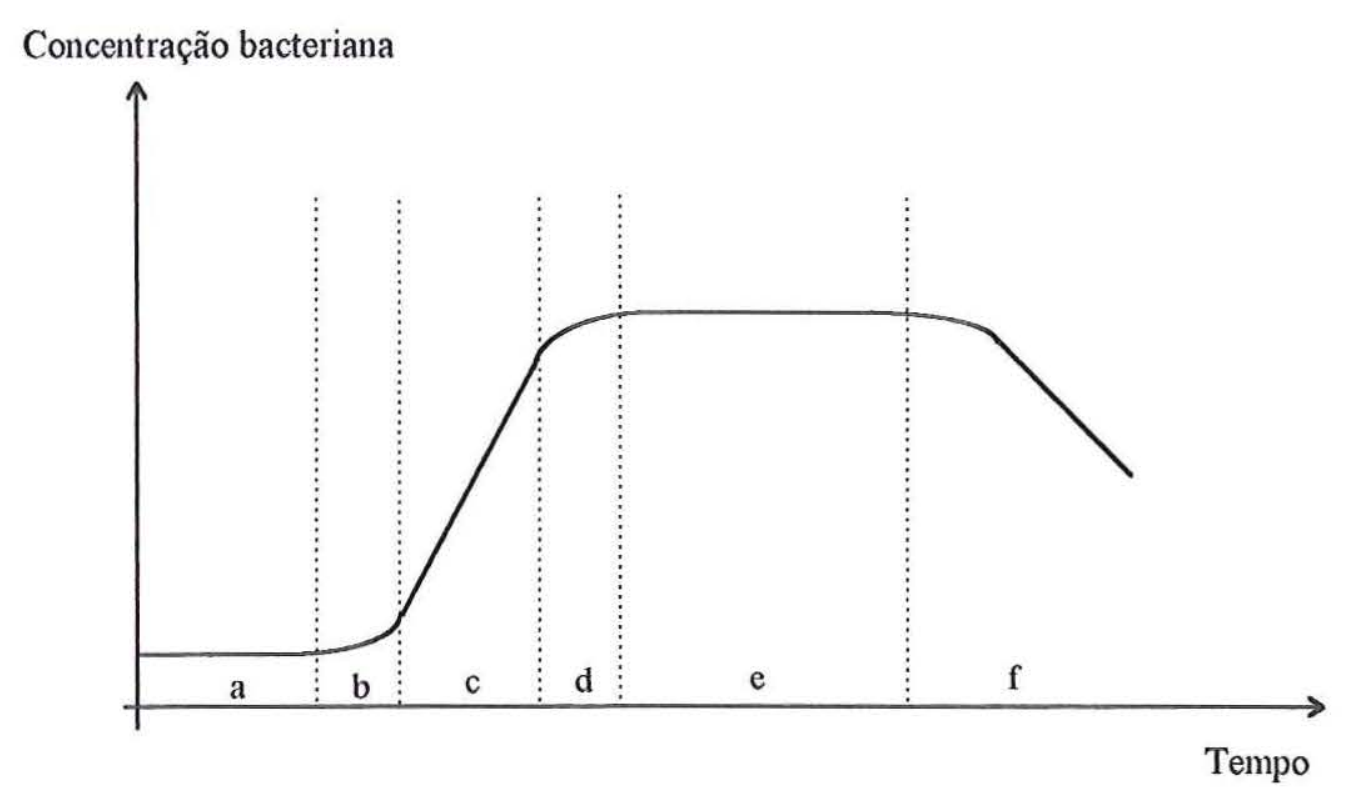

FIGURA 3.1 - Modelo da curva de crescimento de microrganismos em cultura pura (CETESB, 1989).

Esta curva de crescimento foi descrita para culturas puras, mas é frequente sua utilização em culturas mistas, como ocorre no processo de lodos ativados. Nas fases estacionárias e de declínio, chamadas de fase endógena, os microrganismos consomem suas reservas protoplasmáticas, num processo denominado de metabolismo endógeno. Essa população mista de bactérias não está em crescimento sincronizado e dependendo das condições de operação do sistema é possível manter uma parcela maior de bactérias na fase endógena. A importância da manutenção da fase endógena está na diminuição da biomassa e também porque nestas condições ocorre a floculação bacteriana. A floculação biológica do lodo é uma característica importante do processo, pois a massa bacteriana formada pode ser separada do efluente tratado e recirculada ao sistema (CETESB, 1989). 


\subsubsection{3 - Dinâmica da população microbiana}

Em sistemas de tratamento aeróbio, onde se realiza a decomposição da matéria orgânica, como por exemplo nos lodos ativados, uma diversidade de espécies se inter-relacionam de diversas formas, incluindo as interações comensalistas, mutualistas e antagonistas (relações de competição e predadorpresa). Como cada microrganismo tem sua própria curva de crescimento com forma e posição em relação ao tempo, ocorre uma sucessão ecológica, como a mostrada esquematicamente na Figura 3.2, que depende da disponibilidade e do tipo de substrato, de fatores ambientais como $\mathrm{pH}$, temperatura e disponibilidade ou não de oxigênio. Pelo fato dos processos de lodos ativados serem operados continuamente, a população microbiana desenvolvida permanece em equilíbrio dinâmico, portanto, não se observa nitidamente a sucessão ecológica mostrada na Figura 3.2 (LARANJEIRA FILHO, 1989).

A proliferação de diferentes tipos de microrganismos, sucedendo-se uns aos outros no processo de lodos ativados, é resultado da seqüência de alterações químicas e físicas ocorridas durante a estabilização. $\mathrm{O}$ reconhecimento dos grupos predominantes, em dado instante, permite avaliar a eficiência do tratamento ou o grau de estabilidade atingido. Bactérias, fungos e alguns protozoários, que são organismos holofíticos, isto é, nutrem-se de alimento em solução ou solubilizado externamente por ação enzimática, enquanto houver predominância de compostos orgânicos solúveis, serão majoritariamente observados. Em seguida, surgem os primeiros protozoários holozóicos, isto é, que se nutrem de partículas, alimentando-se das próprias bactérias dispersas e, depois, dos flocos formados (BRANCO, 1986).

Conforme observações de BARKER e referências de HAWKES e McKINNEY apud BRANCO (1986), os primeiros protozoários obedecem à seguinte sucessão: rizópodos (amebas), flagelados incolores e ciliados livrenatantes. Estes últimos são holozóicos e, enquanto a população bacteriana for elevada, alcançam alta concentração, pois possuem grande atividade 
locomotora, demandando elevadas quantidades de energia. Na fase de flocos bem formados, os ciliados sésseis, pendiculados ou não, aparecem em elevada concentração e pelo fato de serem fixos necessitam de menores quantidades de energia, sendo conhecidos universalmente como indicadores de boas condições de funcionamento do sistema, pois sua maior concentração coincide com a presença de boa floculação. $\mathrm{O}$ sistema pode atingir graus de estabilidade ainda mais elevados, com desaparecimento dos ciliados sésseis, que serão substituídos por rotíferos, nematóides e até mesmo larvas de insetos, que se alimentam de restos de bactérias mortas, flocos, etc.

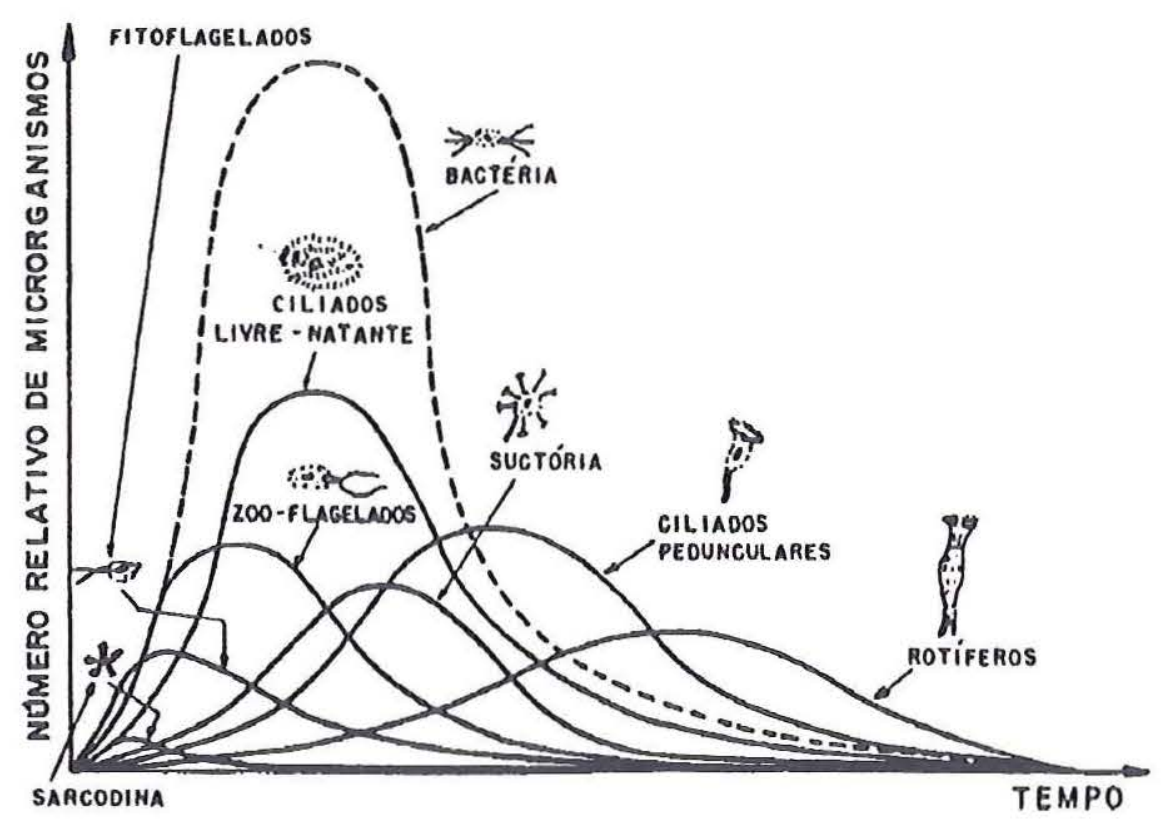

FIGURA 3.2 - Curva de crescimento relativo típico de microrganismos na sucessão ecológica, durante a estabilização de resíduos orgânicos, em sistemas descontínuos (McKINNEY apud LARANJEIRA FILHO, 1989). 
De acordo com observações de HAWKES apud BRANCO (1986), os rizópodos não foram observados nas etapas iniciais do processo, mas algumas vezes, em etapas mais avançadas, com o lodo já formado.

Nos sistemas de lodos ativados utilizando esgoto sanitário como substrato, entre os microrganismos presentes, algumas espécies são consideradas indicadoras das condições de depuração do sistema de tratamento. Nas Tabelas 3.2 e 3.3 estão indicados os microrganismos e as características do processo a eles associados.

TABELA 3.2 - Microrganismos indicadores das condições de depuração.

\begin{tabular}{|c|c|}
\hline MICRORGANISMO & CARACTERÍSTICAS DO PROCESSO \\
\hline Predominância de flagelados e rizópodes & $\begin{array}{l}\text { Lodo jovem, característico de início de } \\
\text { operação ou idade do lodo baixa }\end{array}$ \\
\hline Predominância de flagelados & $\begin{array}{l}\text { Deficiência de aeração, má depuração e } \\
\text { sobrecarga orgânica }\end{array}$ \\
\hline $\begin{array}{l}\text { Predominância de ciliados pedunculados } \\
\text { e livres }\end{array}$ & Boas condições de depuração \\
\hline Presença de Arcella (rizópode com teca) & Boa depuração \\
\hline $\begin{array}{l}\text { Presença de Aspidisca costata } \\
\text { (ciliado livre) }\end{array}$ & Nitrificação \\
\hline $\begin{array}{l}\text { Presença de Trachelophyllum } \\
\text { (ciliado livre) }\end{array}$ & Idade do lodo alta \\
\hline $\begin{array}{llr}\text { Presença } & \text { de Vorticella microstoma } \\
\text { (ciliado } & \text { pedunculado) } & \text { e } \\
\text { baixa }\end{array}$ & Efluente de má qualidade \\
\hline concentração de ciliados livres & \\
\hline $\begin{array}{l}\text { Predominância de anelídeos do gênero } \\
\text { Aelosoma }\end{array}$ & Excesso de oxigênio dissolvido \\
\hline Predominância de filamentos & $\begin{array}{l}\text { Intumescimento do lodo ou bulking } \\
\text { filamentoso* }\end{array}$ \\
\hline
\end{tabular}

(*) Para caracterizar o intumescimento do lodo é necessário avaliar os flocos.

Fonte: CETESB (1989) 
TABELA 3.3 - Relação entre o desempenho do sistema e a presença de grupos de dominantes na microfauna do processo de lodos ativados.

\begin{tabular}{|c|c|c|}
\hline GRUPO DOMINANTE & DESEMPENHO & POSSÍVEIS CAUSAS \\
\hline Pequenos flagelados & Fraco & $\begin{array}{l}\text { Deficiência de aeração, choques } \\
\text { devido à sobrecarga e presença de } \\
\text { subprodutos de fermentação. }\end{array}$ \\
\hline $\begin{array}{l}\text { Pequenos ciliados livres } \\
\text { natantes }\end{array}$ & Médio & $\begin{array}{l}\text { Deficiência de aeração, baixo tempo } \\
\text { de detenção hidráulico. }\end{array}$ \\
\hline $\begin{array}{lll}\text { Grandes } & \text { ciliados livres } \\
\text { natantes } & & \end{array}$ & Médio & $\begin{array}{l}\text { Choques devido à sobrecarga e } \\
\text { defíciência de aeração. }\end{array}$ \\
\hline $\begin{array}{l}\text { Ciliados livres predadores de } \\
\text { floco }\end{array}$ & Bom & $\cdots$ \\
\hline $\begin{array}{l}\text { Ciliados pedunculados e livres } \\
\text { predadores de floco }\end{array}$ & Bom & $\cdots$ \\
\hline Ciliados pedunculados & Decaindo & $\begin{array}{l}\text { Alimentação irregular e perda de } \\
\text { lodo recente. }\end{array}$ \\
\hline Pequenas amebas & Muito fraco & $\begin{array}{l}\text { Alta carga de composto de difícil } \\
\text { degradação. }\end{array}$ \\
\hline Arcella & Bom & $\cdots$ \\
\hline
\end{tabular}

Fonte: MADONI apud PEREZ (1995).

Como a microfauna pode ser identificada com maior facilidade do que as bactérias, as quais necessitam de um processo mais lento e oneroso, é utilizada como indicador biológico. Embora a observação qualitativa e quantitativa da microfauna venha sendo muito utilizada, ainda necessita ser desenvolvida como instrumento de diagnóstico, devido à complexidade das interações de microrganismos da microfauna (CETESB, 1989). 
A análise rotineira da microfauna como um indicador do desempenho de sistemas de lodos ativados tornou-se comum, pois fornece rápidas informações sobre a atividade biológica do lodo baseadas na estrutura da comunidade dos microrganismos presentes (MADONI, 1994).

\subsubsection{4 - Floculação biológica}

Mesmo existindo várias hipóteses sobre os mecanismos da floculação biológica, o seu processo não está ainda totalmente esclarecido.

O desempenho dos processos de lodos ativados depende da floculação biológica e separação desses flocos do efluente tratado. Num floco biológico típico observa-se uma grande variedade de microrganismos presentes no processo (LARANJEIRA FILHO, 1989).

Até recentemente, a idéia que prevalecia sobre o formação de flocos, era a de que a propriedade de floculação estava diretamente relacionada com a capacidade especial das bactérias em produzir zoogléia, isto é, massa gelatinosa capaz de absorver grande número de partículas em suspensão, dando origem a grandes flocos. Portanto, acreditava-se que a bactéria Zooglea ramigera, cuja principal característica é a formação de grande quantidade de massa gelatinosa, era responsável pela floculação. Pesquisas posteriores alteraram essa idéia, pois obteve-se floculação por inúmeras espécies de bactérias, além da Zooglea ramigera e mostraram que a característica de produzir floculação está relacionada com as condições de vida em que as bactérias se encontram (BRANCO, 1986).

Para McKNNEY apud LARANJEIRA FILHO (1989), a habilidade dos microrganismos de flocularem é função do nível de energia do sistema. As células são consideradas como sendo colóides hidrofílicos, carregadas negativamente e a dispersão é ocasionada pelas forças eletrostáticas repulsivas existentes entre elas. No caso da relação alimento/microrganismo (F/M) ser 
alta, o nível de energia é suficiente para manter dispersos os microrganismos, sendo máxima a remoção do substrato orgânico e o crescimento dos microrganismos (fase do crescimento logarítmico). No caso da relação ser baixa, as bactérias começam a metabolizar, principalmente as reservas de alimento contidas no interior das suas próprias células (fase endógena); com isso o nível de energia sofre uma queda, não sendo suficiente para superar as forças de atração (forças de Van der Waals) existentes entre as células. Assim, a taxa de formação dos flocos cresce rapidamente.

TENNEY \& STUM apud LARANJEIRA FILHO (1989) concordam que os microrganismos são colóides hidrofílicos e que a biofloculação depende da fase de crescimento, mas questionam a hipótese de que a floculação é dada pela redução de carga e pelo decréscimo da repulsão eletrostática. Defendem a hipótese de que polímeros naturais (polissacarídeos e poliaminoácidos) são excretados ou expostos nas superfícies das células, predominantemente durante a fase de respiração endógena, ocasionando a floculação similarmente à dos polieletrólitos sintéticos.

Estudos realizados por CRABTREE et al. apud ALÉM SOBRINHO (1983) indicavam que a presença do ácido poli- $\beta$-hidroxibutírico (PHB) era responsável pela floculação biológica. Estudos posteriores de ANGELBERCK \& KIRSH; FORSTER e PAINTER et al. apud ALÉM SOBRINHO (1983) observaram que a presença de PHB não apresenta influência sobre a biofloculação.

PETER \& WUHRMANN apud ALÉM SOBRINHO (1983) sugerem que a ação de polieletrólitos naturais, assim como ácidos húmicos no gel de excreção das células, são causadores da biofloculação.

FORSTER apud ALÉM SOBRINHO (1983) concluiu que a floculação biológica no processo de lodos ativados depende parcialmente, se não totalmente, dos componentes da superfície das partículas do lodo, que são controlados pela concentração de nutrientes, modificando o potencial zeta das partículas e portanto o grau de dispersão das partículas do lodo. 
De acordo com HEUKELEKIAN \& CURBAXANI; McKINNEY e ROHLICH apud BRANCO (1986), a floculação realizada pelos protozoários ocorre quando os protozoários, especialmente os ciliados, encontrando-se na fase de declínio de crescimento, começam a formar corpos esféricos, relativamente grandes, no interior de suas células, que são liberados após a morte, unindo-se em massas de capacidade adsorvente, dando assim origem aos flocos.

Conforme BRANCO e McKINNEY apud BRANCO (1986), a presença de fungos como formadores de flocos está relacionada ao $\mathrm{pH}$ baixo e à deficiência em nitrogênio e fósforo.

\subsubsection{5 - Fatores intervenientes}

\section{a) Nutrientes}

Nos sistemas de tratamento biológico é necessário que todos os elementos utilizados para a síntese celular dos microrganismos estejam presentes no meio. $\mathrm{O}$ nitrogênio e o fósforo, que são macronutrientes, são requeridos em grandes quantidades e, quando insuficientes nos despejos, podem atuar como fatores limitantes. Já os micronutrientes, tais como potássio, magnésio, cálcio, ferro, sódio, cobalto, zinco, molibidênio, cobre e iodo, são encontrados em quantidades suficientes na maior parte dos despejos orgânicos (LARANJEIRA FILHO, 1989 e SANT'ANNA, 1982).

Conforme BRANCO (1986), nos sistemas de lodos ativados uma boa floculação bacteriana é obtida para relações $\mathrm{DBO} / \mathrm{N}=17 / 1$ e DBO/P $=90 / 1$. Os fungos (ou leveduras) passam a predominar, quando o nitrogênio ou o fósforo se tornam insuficientes. Segundo McKINNEY apud BRANCO (1986), a composição média das bactérias pode ser representada por $\mathrm{C}_{5} \mathrm{H}_{7} \mathrm{NO}_{2}$ e os 
fungos por $\mathrm{C}_{10} \mathrm{H}_{17} \mathrm{NO}_{6}$, portanto, estes últimos necessitam de menores proporções de nitrogênio em sua nutrição.

A insuficiência dos nutrientes nitrogênio e fósforo tem sido apresentada como uma das causas do intumescimento filamentoso, sendo a relação DBO:N:P::100:5:1 a mínima desejada para o desenvolvimento de um lodo ativado adequado. Os esgotos domésticos sempre possuem nitrogênio e fósforo em excesso, mas muitos despejos industriais necessitam da adição desses nutrientes (ALÉM SOBRINHO, 1983).

A quantidade total necessária de nutrientes dependerá da massa líquida de microrganismos produzidos. Com isso, processos operados com elevadas idades do lodo necessitarão de menores quantidades de nutrientes. Isto é freqüentemente usado para explicar como duas estações de lodos ativados similares operadas com idades do lodo diferentes podem apresentar eficiências diferentes tratando o mesmo resíduo (METCALF \& EDDY, 1991).

\section{b) Temperatura}

A temperatura é um fator muito importante, pois influi sobre o crescimento, metabolismo e predominância de microrganismos, sendo que existe uma temperatura ótima para o melhor desempenho de cada espécie (LARANJEIRA FILHO, 1989).

A temperatura não exerce somente influência sobre a atividade metabólica dos microrganismos, mas também sobre a taxa de transferência de oxigênio e sobre as características de sedimentação dos sólidos biológicos (METCALF \& EDDY, 1991).

Segundo COLLINS et al. e SAYIGH \& MALINA apud ALÉM SOBRINHO (1983) a taxa de utilização de oxigênio dissolvido aumenta com a elevação da temperatura, principalmente para valores acima de $20^{\circ} \mathrm{C}$. 
PIPES apud ALÉM SOBRINHO (1983) menciona que o intumescimento filamentoso é mais comum em temperaturas elevadas e que mudanças repentinas na temperatura ocasionam a desfloculação.

COLLINS apud ALÉM SOBRINHO (1983) relata que para temperaturas inferiores a $10^{\circ} \mathrm{C}$, têm-se geralmente maiores concentrações de sólidos suspensos no efluente final, e em temperaturas mais altas, com a diminuição da viscosidade da água, a floculação e a sedimentação tendem a uma maior eficiência.

A maioria dos processos de lodos ativados são operados entre $20 \mathrm{e}$ $40^{\circ} \mathrm{C}$, sendo que as bactérias mesófilas melhor se desenvolvem nessa faixa de temperatura. A taxa de crescimento é duplicada cada aumento de $10^{\circ} \mathrm{C}$ até atingir valor ótimo e posteriores aumentos provocarão a reação de desnaturação de proteínas (SANT’ANNA, 1982).

Algumas faixas de valores de temperatura e as faixas ótimas de desenvolvimento para vários tipos de bactérias, estão na Tabela 3.4.

TABELA 3.4 - Algumas faixas de valores de temperatura para crescimento de vários tipos de bactérias.

\begin{tabular}{ccc}
\hline & \multicolumn{2}{c}{ Temperatura, $^{\circ} \mathrm{C}$} \\
\cline { 2 - 3 } Tipo & Faixa & Ótimo \\
\hline Psicrófila & -10 a 30 & 12 a 18 \\
Mesófila & 20 a 50 & 25 a 40 \\
Termófila & 35 a 75 & 55 a 65 \\
\hline
\end{tabular}

Fonte: METCALF \& EDDY (1991). 


\section{c) Oxigênio Dissolvido}

Os lodos ativados, por se tratar de um processo aeróbio, para o sistema funcionar com eficiência, é necessário em todo tanque de aeração manter a concentração ótima de oxigênio dissolvido (SANT'ANNA, 1982).

A concentração mínima necessária no tanque de aeração deve ser de 1 a $2 \mathrm{mgO}_{2} / \mathrm{L}$ (METCALF \& EDDY, 1991). Quando o oxigênio é um fator limitante no crescimento dos microrganismos, organismos filamentosos podem predominar, e a sedimentabilidade e qualidade do lodo ativado pode ser deteriorada. Na prática, a concentração de oxigênio dissolvido na totalidade do tanque de aeração deve ser mantida em torno de 1,5 a $4 \mathrm{mgO}_{2} / \mathrm{L}$, sendo $2 \mathrm{mgO}_{2} / \mathrm{L}$ usualmente utilizado. Valores superiores a $4 \mathrm{mgO}_{2} / \mathrm{L}$ não fornecem resultados significantes, mas elevam consideravelmente os custos de aeração (WPCF apud METCALF \& EDDY, 1991).

ALÉM SOBRINHO (1983) menciona que para obter-se a nitrificação, o oxigênio dissolvido deve ser mantido próximo de $2 \mathrm{mgO}_{2} / \mathrm{L}$. Baixas concentrações de oxigênio dissolvido, inferiores a $0,5 \mathrm{mgO}_{2} / \mathrm{L}$, convertem-se em uma das causas do intumescimento filamentoso do lodo.

ECHEVERRÍA et al. (1992), variando a concentração de oxigênio dissolvido de 0 a $4 \mathrm{mgO}_{2} / \mathrm{L}$, em um sistema de lodos ativados, em escala piloto, alimentado com esgoto sanitário da cidade de Valência - Espanha, obteve para níveis inferiores a $0,8 \mathrm{mgO}_{2} / \mathrm{L}$ decréscimo gradual de organismos, como ciliados e rotíferos, e acréscimo da população de bactérias, principalmente filamentosas, tendo como resultado o aparecimento do intumescimento do lodo.

\section{d) $\mathrm{pH}$}

Nos sistemas de tratamento biológico, o $\mathrm{pH}$ apresenta grande influência, pois atua no desenvolvimento e seleção dos microrganismos. 
O pH ótimo para crescimento das bactérias está entre 6,5 e 7,5 (METCALF \& EDDY, 1991). BRANCO (1986) afirma que para $\mathrm{pH}$ abaixo de 6,5 os fungos competem mais eficientemente com as bactérias e entre 4,5 e 5,0 passam a predominar como formadores de flocos.

$\mathrm{O}$ pH no tanque de aeração é altamente dependente da composição do afluente e exerce grande influência na presença dos microrganismos. Os flocos desejáveis ao processo de lodos ativados são formados em $\mathrm{pH}$ na faixa de 6 a 9. O lodo ativado tende a desflocular-se e perder-se no efluente final em valores baixos de $\mathrm{pH}$ (ALÉM SOBRINHO, 1983).

De acordo com PIPES apud ALÉM SOBRINHO (1983), baixos valores de $\mathrm{pH}$ ocasionados por carga de choque momentâneas do afluente causam a defloculação. Se o valor do $\mathrm{pH}$ é mantido baixo por longos períodos, ocorre a formação de um lodo composto quase totalmente por organismos filamentosos e de difícil sedimentabilidade.

Em valor baixo de $\mathrm{pH}$ a concentração do íon hidrogênio provoca desnaturação de enzimas importantes, mas quando o $\mathrm{pH}$ assume valor muito alto o íon hidroxila torna-se tóxico. Poucos microrganismos podem suportar valores de pH superiores a 9,5 e inferiores a 4 (SANT'ANNA, 1982).

\section{e) Toxicidade}

SANT’ANNA (1982) cita que vários elementos podem ser tóxicos aos sistemas de tratamento biológico, tais como:

. metais pesados como cromo e cobre;

. substâncias orgânicas como fenol e formaldeído;

. amônia, e sais orgânicos. 
Grandes concentrações de metais pesados são tóxicos aos microrganismos e interferem no processo de lodos ativados (ALÉM SOBRINHO, 1983).

INGOLS \& FETNER apud ALÉM SOBRINHO (1983) relatam que baixas concentrações de cromo podem favorecer o intumescimento filamentoso do lodo. BARTH et al. apud ALÉM SOBRINHO (1983) relatam que pequenas concentrações de cobre, níquel, zinco e cromo causam a formação de um lodo praticamente sem organismos filamentosos. $\mathrm{O}$ ferro também pode ter grande influência no controle de filamentos.

Os processos de nitrificação são sensíveis à inibição tóxica (WEF/ASCE, 1992).

\subsection{4 - Processo de lodo ativado por batelada}

\subsubsection{1 - Introdução}

Nos anos 60, deu-se o início da utilização do processo de lodos ativados com operação intermitente (batelada), mas foi a partir da década de 80 que esse sistema de tratamento tornou-se mais difundido e aplicado ao tratamento de diversas águas residuárias. No Brasil existe um aumento no número de estações operando segundo esse processo. Segundo dados da Agência de Proteção Ambiental dos Estados Unidos (USEPA, 1992), em 1992 existiam mais de 170 reatores de batelada em operação nos Estados Unidos. Recentemente, com a crescente preocupação quanto ao lançamento de nutrientes nos cursos d'água, os reatores de batelada têm sido modificados para se obter a nitrificação, desnitrificação e remoção biológica de fósforo (CHERNICHARO \& von SPERLING, 1993). 
No início dos anos 60 , progressos nos equipamentos de aeração e de controle permitiram o desenvolvimento de sistemas de tratamento intermitentes que alcançassem níveis de eficiência capazes de competir com o sistema convencional, e com capacidade de tratar as mesmas águas residuárias (METCALF \& EDDY, 1991).

O processo de lodo ativado por batelada para o tratamento de esgoto vem sendo cada vez mais utilizado nos países desenvolvidos, como os Estados Unidos, o Japão e a Austrália. Como nesses países a maioria das cidades grandes já possui algum tipo de sistema convencional de tratamento, o lodo ativado por batelada é utilizado para tratamento de esgoto nas cidades de pequeno e médio porte. A maior vantagem do processo de lodos ativados por batelada em relação ao lodo ativado convencional (fluxo contínuo) está na flexibilidade operacional, que possibilita economia nos custos de energia elétrica (KAMIYAMA \& TSUTIYA, 1992).

\subsubsection{2 - Descrição do processo}

O processo de lodo ativado por batelada (LAB) é também conhecido como reator seqüencial em batelada ("Sequencing Batch Reactor" - SBR).

Nos sistemas de lodos ativados convencionais, os processos de aeração e sedimentação/clarificação são realizados simultaneamente em unidades separadas, mas num SBR os processos são realizados seqüencialmente num mesmo tanque. Os cinco períodos de um ciclo operacional para um SBR estão descritos na Tabela 3.5 e ilustrados na Figura 3.3. O descarte do lodo usualmente é feito durante as fases de sedimentação ou repouso, sendo a quantidade e a freqüência determinada pela eficiência desejada. O SBR não necessita do sistema de bombeamento para o retorno de lodo. Como a aeração e a sedimentação são realizadas no mesmo tanque, nenhum lodo é perdido no período de reação (USEPA apud METCALF \& EDDY, 1991). 
TABELA 3.5 - Períodos de um ciclo operacional para um reator seqüencial em batelada (SBR).

\begin{tabular}{|c|c|}
\hline Período & Finalidade \\
\hline Enchimento & $\begin{array}{l}\text { Adição do substrato (água residuária bruta ou efluente } \\
\text { primário) no reator. }\end{array}$ \\
\hline Reação & $\begin{array}{l}\text { Completar as reações que foram iniciadas durante o período } \\
\text { de enchimento. }\end{array}$ \\
\hline Sedimentação & $\begin{array}{l}\text { Separação do material sólido do líquido, fornecendo um } \\
\text { sobrenadante clarificado para ser descartado como efluente. } \\
\text { Num SBR, este processo é normalmente muito mais eficiente } \\
\text { que num sistema de fluxo contínuo, porque o conteúdo do } \\
\text { reator está completamente imóvel. }\end{array}$ \\
\hline Descarte & $\begin{array}{l}\text { Remoção do despejo tratado (efluente) do reator. O tempo } \\
\text { dedicado para esta fase pode variar de } 5 \text { a } 30 \% \text { do tempo } \\
\text { total do ciclo ( } 15 \text { minutos a } 2 \text { horas), sendo } 45 \text { minutos um } \\
\text { valor típico. }\end{array}$ \\
\hline Repouso * & $\begin{array}{l}\text { Tempo em que o lodo permanece em repouso. Pelo fato de } \\
\text { não ser uma fase necessária, muitas vezes é omitido. }\end{array}$ \\
\hline
\end{tabular}

* O descarte do lodo usualmente é realizado na fase de sedimentação ou repouso, mas o descarte pode ocorrer em outras fases dependendo do modo de operação.

Fonte: Adaptado de USEPA apud METCALF \& EDDY (1991).

A duração usual de cada período que compõe o ciclo operacional pode ser alterada em função das variações da vazão afluente, das necessidades de tratamento, das características da água residuária a ser tratada e da biomassa presente no sistema (CHERNICHARO \& von SPERLING, 1993). 


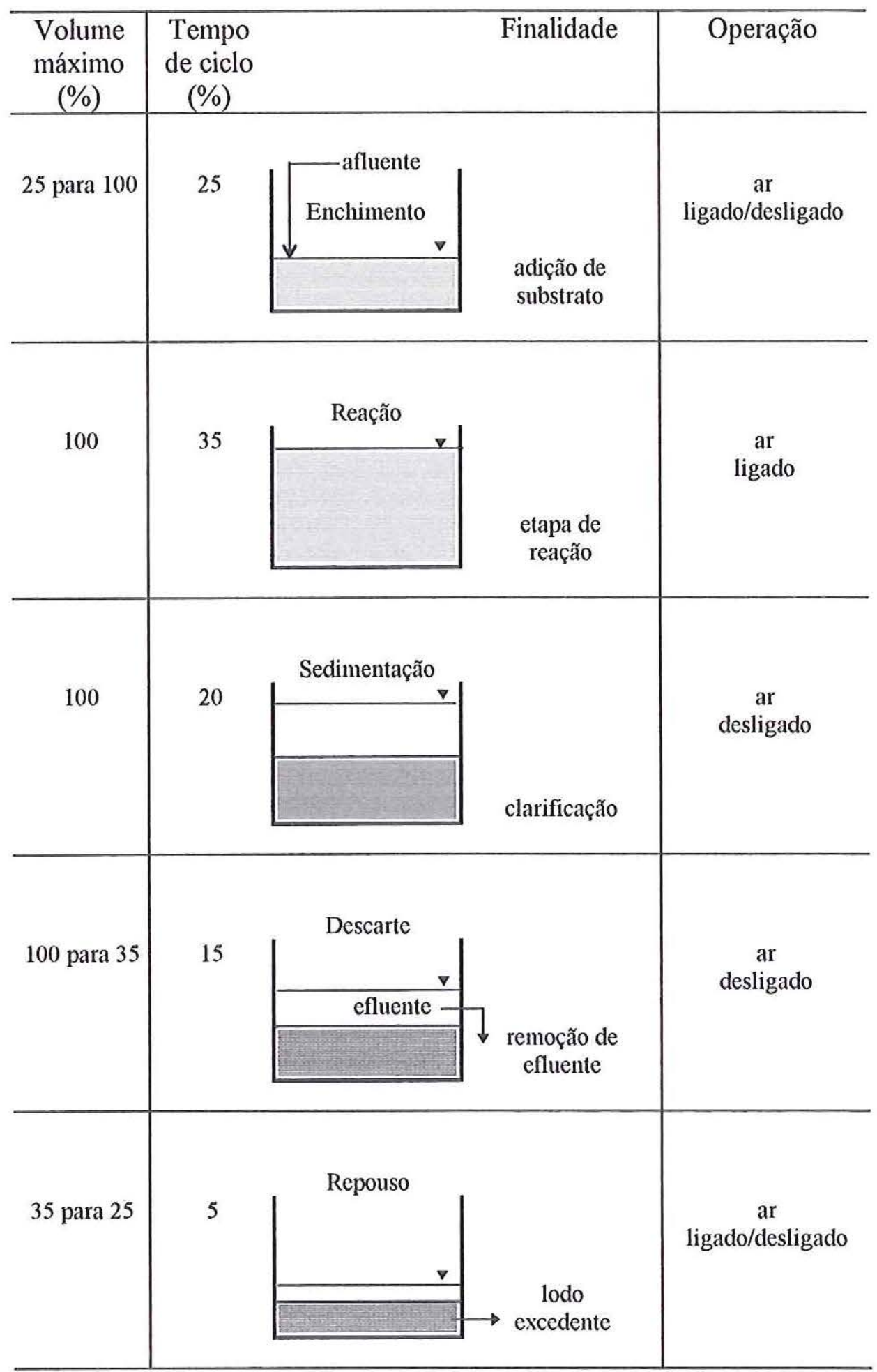

FIGURA 3.3 - Períodos de um ciclo operacional para um reator seqüencial em batelada (SBR) (USEPA apud METCALF \& EDDY, 1991). 


\subsubsection{3 - Modificações do processo}

Várias modificações têm sido adicionadas ao processo de lodos ativados por batelada para se atingir certos objetivos no tratamento de esgoto sanitário. Essas modificações referem-se tanto à forma de operação do sistema, como, por exemplo, alimentação contínua e esvaziamento descontínuo, quanto à seqüência e duração dos períodos do ciclo operacional (CHERNICHARO \& von SPERLING, 1993).

O sistema de tanque único é aplicado para fluxo não contínuo, sendo utilizado em pequenas comunidades e em algumas indústrias. $\mathrm{O}$ sistema de tanques múltiplos é utilizado para fluxo contínuo, podendo ser operado de forma simples ou complexa, sendo função das variações de vazão, da carga orgânica e da eficiência desejada no tratamento (DORNELLAS \& FIGUEIREDO, 1993).

Quando o objetivo inclui a remoção biológica de nutrientes (nitrogênio e fósforo) são incorporadas modificações na configurą̧ão básica do ciclo operacional para remoção de matéria carbonácea e sólidos suspensos (Figura 3.3) como, por exemplo, as apresentadas nas Figuras 3.4 e 3.5.

Para se obter a remoção biológica de fósforo, faz-se necessária a criação de uma seqüência de etapas anaeróbia - aeróbia, desde que haja presença de suficiente matéria orgânica biodegradável durante a etapa anaeróbia (CHERNICHARO \& SPERLING, 1993; SOUSA, 1996).

A configuração do SBR da Figura 3.4 apresenta uma opção para oxidação de matéria carbonácea e remoção de fósforo. No período de reação anaeróbia ocorrem incorporações de matéria orgânica e liberação de fósforo, conseqüentemente, no período de reação aeróbio ocorrem incorporação de fósforo em excesso e oxidação da matéria orgânica (SOUSA, 1996). 


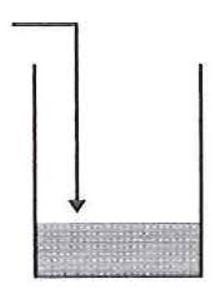

Enchimento estático

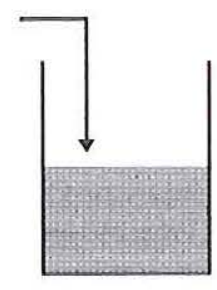

Enchimento com mistura

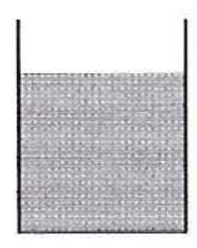

Reação anaeróbia

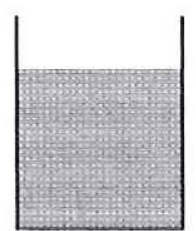

Reação aeróbia

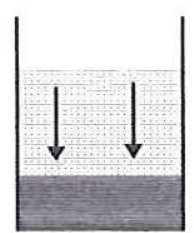

Sedimentação

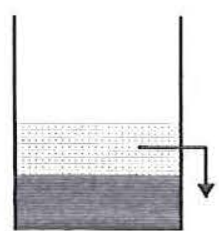

Descarte

FIGURA 3.4 - Configuração do reator seqüencial em batelada (SBR) para oxidação de matéria carbonácea e remoção de fósforo (WEF/ASCE apud CHERNICHARO \& SPERLING, 1993).

A Figura 3.5 mostra uma opção de configuração do SBR para oxidação de compostos nitrogenados reduzidos a nitrato $\left(\mathrm{NO}_{3}^{-}\right)$e de matéria carbonácea e a remoção biológica de nitrato e fósforo. A oxidação de compostos nitrogenados reduzidos a nitrato se dá no período de reação aeróbio num processo denominado de nitrificação. A remoção do nitrato é feita através do processo de desnitrificação no período de reação anóxico, em que ocorre sua redução a gás nitrogênio $\left(\mathrm{N}_{2}\right)$.

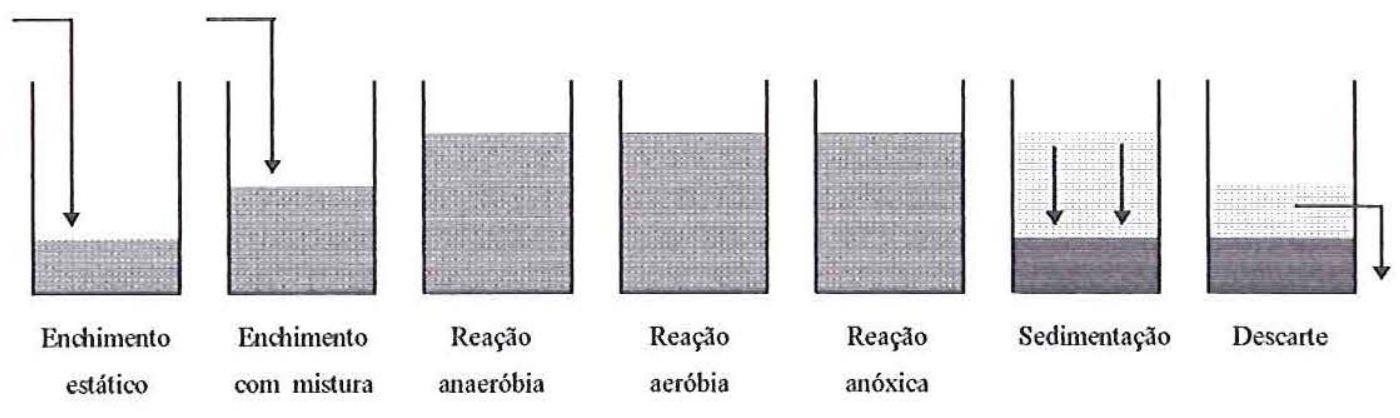

FIGURA 3.5 - Configuração do reator seqüencial em batelada (SBR) para oxidação de matéria carbonácea, remoção de nitrogênio e fósforo (WEF/ASCE apud CHERNICHARO \& SPERLING, 1993). 


\subsubsection{4 - Vantagens e desvantagens do SBR}

A utilização do SBR apresenta muitas vantagens em relação ao processo de lodo ativado convencional.

Conforme WEF/ASCE (1992), as vantagens operacionais do SBR são:

- eliminação do decantador secundário e sistema de bombeamento para recirculação de lodo;

- alta tolerância para vazões de pico e cargas de choque;

- evita o arraste de lodo durante as vazões de pico;

- clarificação sobre condições imóveis ideais;

- flexibilidade do processo no controle do intumescimento filamentoso do lodo.

ARORA et al. apud SOUSA (1996) citam as seguintes vantagens na utilização do SBR:

- o reator pode funcionar como tanque de equalização durante o período de enchimento;

- flexibilidade na ativação do sistema de aeração, permitindo programar um sistema que proporcione um menor consumo de energia;

- o crescimento de bactérias filamentosas é atenuado, pois o SBR permite um melhor controle de operação;

- o sistema de bombeamento para recirculação de lodo pode ser abolido;

- esse sistema não perde biomassa na ocorrência de um choque hidráulico;

- os períodos de enchimento e de reação, quando controlados, possibilitam a nitrificação, desnitrificação e remoção de fósforo. 
WEF/ASCE (1992) mencionam que a maior desvantagem desse sistema está na falta relativa de dados sobre experiências operacionais.

ARORA et al. apud SOUSA (1996) relatam duas desvantagens básicas para esse sistema:

- falta de um equacionamento bem definido para projetar e para estabelecer. os procedimentos operacionais;

- utilização de equipamentos, como por exemplo, misturadores, válvulas de controle e controladores de tempo e de nível.

\section{2 - Pós-tratamento de efluente tratado anaerobiamente}

Existem poucos trabalhos descritos na literatura sobre o pós-tratamento de efluentes tratados anaerobiamente.

TDEGARD apud SOUSA (1996) relata as principais alternativas para o tratamento de efluentes tratados anaerobiamente, de acordo com a Tabela 3.6, e cita dois fatores que podem influenciar na biodegradação aeróbia de resíduos pré-tratados por processos anaeróbios. Como primeiro fator, tem-se no processo anaeróbio uma remoção bem superior de DBO e DQO à de outros componentes como, por exemplo, os nutrientes nitrogênio e fósforo, ocasionando assim um desbalanceamento dos componentes constituintes do efluente, sobretudo da relação DQO:N:P. Como segundo fator, tem-se que o processo anaeróbio ocorre em etapas, onde são formados produtos intermediários que sofrerão tratamento aeróbios. É pouco provável que os produtos intermediários da hidrólise, formadores de ácidos e formadores de metano, apresentem inibição sobre o tratamento aeróbio, mas não se pode excluir totalmente que as condições redutivas do processo anaeróbio possam apresentar efeitos inibitórios.] 
TABELA 3.6 - Principais alternativas para o pós-tratamento de efluentes tratados anaerobiamente.

\begin{tabular}{|c|c|c|}
\hline Métodos de Tratamento & Remoção & Unidades de Processo \\
\hline Separação sólido/líquido & SST & $\begin{array}{l}\text { Sedimentação, flotação, membrana de } \\
\text { filtração e lagoa de estabilização. }\end{array}$ \\
\hline Tratamento biológico aeróbio & $\mathrm{DBO} / \mathrm{DQO}$ & $\begin{array}{l}\text { Lodos ativados, filtro biológico, reator } \\
\text { biológico de contato, leito fluidizado e lagoa } \\
\text { de estabilização. }\end{array}$ \\
\hline Tratamento biológico aeróbio & $\mathrm{N}-\mathrm{NH}_{4}^{+}$ & $\begin{array}{l}\text { Nitrificação em lodos ativados, filtro } \\
\text { biológico, leito fluidizado, reator biológico } \\
\text { de contato e lagoa de estabilização. }\end{array}$ \\
\hline $\begin{array}{l}\text { Físico / químico } \\
\text { Tratamento aeróbio/anóxico }\end{array}$ & N-NTK & $\begin{array}{l}\text { Stripping de } \mathrm{NH}_{3} \text {, desnitrificação em } \\
\text { biofiltro, lodos ativados, leito fluidizado e } \\
\text { LAB. }\end{array}$ \\
\hline $\begin{array}{l}\text { Físico / químico } \\
\text { Tratamento anaeróbio/aeróbio }\end{array}$ & Fósforo & Precipitação e lodos ativados. \\
\hline $\begin{array}{l}\text { Oxidação biológica } \\
\text { Oxidação química }\end{array}$ & Odor & Oxidação sulfidrica e ozonização / cloração. \\
\hline $\begin{array}{l}\text { Tratamento físico / químico } \\
\text { Oxidação química }\end{array}$ & Cor & Coagulação e membrana de filtração. \\
\hline $\begin{array}{l}\text { Irradiação } \\
\text { Química }\end{array}$ & Patógenos & $\begin{array}{l}\text { Lagoa de estabilização, luz UV e } \\
\text { desnitrificação com } \mathrm{Cl}_{2} \text { ou } \mathrm{O}_{3} \text {. }\end{array}$ \\
\hline
\end{tabular}

Fonte: Adaptado de ФDEGARD apud SOUSA (1996).

SOUSA (1996), estudando um sistema composto de um reator anaeróbio de fluxo ascendente com manta de lodo - UASB, seguido de dois reatores seqüenciais em batelada aeróbios - SBRs alimentados continuamente por substrato sintético simulando esgoto sanitário e com temperatura controlada de $30^{\circ} \mathrm{C}$, obteve remoção média de DQO, SSV, NTK e fósforo de $95,96,85$ e $57 \%$, respectivamente. Com os resultados obtidos durante a 
pesquisa concluiu que esse sistema é uma alternativa para o tratamento de esgoto sanitário em regiões tropicais, pois apresenta baixo consumo de oxigênio (portanto baixo consumo de energia), baixa taxa de produção de lodo e alta eficiência de remoção de nutrientes e matéria carbonácea.

O tratamento de esgotos sanitários, anaerobiamente através de digestores anaeróbios de fluxo ascendente - DAFA, tem demonstrado bons resultados quando aplicado em regiões tropicais e de condições climáticas moderadas. Entretanto, os efluentes desses reatores apresentam ainda matéria orgânica, sólidos em suspensão, nutrientes, surfactantes, gases dissolvidos, microrganismos patogênicos e ausência de oxigênio. Com o objetivo de atender aos padrões da legislação ambiental e para proteção da saúde pública, os efluentes desse tratamento devem ser submetidos a pós-tratamento (SILVA, 1993).

SOUZA et al. apud SILVA (1993) testaram cinco alternativas de póstratamento para vinhaça tratada anaerobiamente incluindo lagoas de estabilização, filtro biológico, filtro anaeróbio, lodos ativados e lagoa aerada. Todos os processos utilizados na pesquisa apresentaram elevadas eficiências de remoção de matéria orgânica. As maiores eficiências e os menores problemas operacionais foram obtidos pelos processos de lagoa anaeróbia seguida de lagoa facultativa e lagoa aerada. Esses autores comentaram que o processo de lodos ativados apresentou as maiores eficiências de remoção de DQO (88 \%) e DBO (99 \%), possibilitando em diversas situações, o lançamento do seu efluente direto em rios. Porém, a obtenção de um tempo de detenção mínimo de 23 horas inviabilizou economicamente sua utilização.

OLSSON apud SILVA (1993) pesquisou o tratamento de efluente de indústria de ácido cítrico, em escala piloto, utilizando um reator anaeróbio (de contato) seguido de pós-tratamento aeróbio pelo processo de lodos ativados, onde se obtiveram resultados satisfatórios. O reator anaeróbio removeu de 70 a $80 \%$ de $\mathrm{DQO}$ e de $\mathrm{DBO}$. O reator aeróbio demonstrou alto grau de 
estabilidade. O efluente final apresentou remoção total superior a $80 \%$ de DQO e a $93 \%$ de DBO.

Vários pesquisadores vêm estudando a remoção de nitrogênio de efluentes de reatores anaeróbios por processos aeróbios. A importância desses estudos está no fato de que na degradação anaeróbia dos compostos contendo nitrogênio, como por exemplo, uréia, aminoácidos, proteínas e outros, o nitrogênio é convertido em amônia, que não é degradada anaerobiamente. A amônia deve ser convertida para nitrato pelo processo de nitrificação biológica, com a finalidade de diminuir a demanda de oxigênio nas águas receptoras (SILVA, 1993).

SILVA (1993), trabalhando com um reator DAFA e um reator de lodos ativados para tratamento de uma mistura de esgoto sanitário e efluentes industriais, obteve as seguintes faixas de remoção: 78 a 89 \% para DQO total; 82 a $90 \%$ para DQO filtrada; 74 a $96 \%$ para DBO total; 93 a $98 \%$ para DBO filtrada; 77 a $86 \%$ para SST e 79 a $96 \%$ para SSV. A potência de aeração da associação foi de aproximadamente $40 \%$ da consumida pela opção de lodos ativados convencionais.

${ }^{\star}$ CYNAMON \& ROQUE (1993) estudaram, em escala piloto, o tratamento de esgoto sanitário em um sistema constando de um reator anaeróbio seguido de um reator aeróbio. A remoção média do sistema no período de estudo foi de $72 \%$ para DQO, $85 \%$ para DBO e $32 \%$ para fósforo e nitrogênio.

* BELÉM (1996), pesquisando um filtro biológico aeróbio de aeração forçada para tratamento do mesmo efluente utilizado neste trabalho, obteve eficiências médias de remoção da DQO, $\mathrm{DBO}_{5}$ e SSV de 70, 73 e $64 \%$ para a taxa de aplicação hidráulica de $1,5 \mathrm{~m}^{3} / \mathrm{m}^{2}$.dia; 55,59 e $47 \%$ para $7,5 \mathrm{~m}^{3} / \mathrm{m}^{2}$.dia, e 40,48 e $28 \%$ para $13 \mathrm{~m}^{3} / \mathrm{m}^{2}$.dia. O filtro também apresentou resultados razoáveis na conversão de nitrogênio amoniacal para as taxas adotadas. 
Estabelecendo-se que a qualidade do efluente final para o sistema anaeróbio - aeróbio no mínimo é equivalente ao sistema aeróbio convencional, van HAANDEL \& LETTINGA (1994) identificaram importantes vantagens do sistema de lodo ativado (reator e decantador) precedido por um reator DAFA, com estabilização do lodo ativado de excesso no reator DAFA, em relação ao sistema de lodo ativado convencional, composto de um reator e um decantador, com estabilização anaeróbia do lodo de excesso no digestor após adensamento. As razões são as seguintes:

1. o reator DAFA reduz signitivamente a concentração de material orgânico e dos sólidos em suspensão; com isso, a massa de lodo ativo e o volume total do sistema de lodo ativado também será reduzido;

2. a unidade de estabilização de lodo do tratamento aeróbio (incluindo adensador e digestor anaeróbio de lodo) pode ser dispensada, pois o lodo de excesso do sistema de lodo ativado pode ser recirculado para o reator DAFA, onde será digerido e adensado;

3. a quantidade de lodo estabilizado em um sistema combinado anaeróbio aeróbio será bem menor que num sistema aeróbio, já que a produção de lodo por unidade de massa de material orgânico é bem menor num sistema anaeróbio. Como o lodo estabilizado no reator DAFA apresenta uma concentração superior à daquela obtida pelo adensamento de lodo ativado, ocorre uma redução no volume de lodo estabilizado, facilitando a sua manipulação até o destino final;

4. como o reator anaeróbio remove grande parte da carga orgânica, ocorre uma redução na demanda de oxigênio e conseqüentemente no consumo de energia para aeração, sendo que parte dessa demanda de energia pode ser gerada pela combustão do biogás. Para o caso do tratamento de esgoto sanitário, estequiometricamente, o potencial de produção de biogás é mais que suficiente para tornar o sistema de tratamento anaeróbio - aeróbio independente de energia extra; mas na prática, isto depende da eficiência na 
coleta e na combustão do metano. Pelo fato do reator DAFA funcionar como um tanque de equalização, a variação da concentração da matéria orgânica que passa para sistema de lodo ativado é menor do que no afluente; com isso, a demanda máxima (base de dimensionamento dos aeradores) aproxima-se da média, reduzindo assim a demanda de energia.

* DALTRO et al. (1993) utilizaram para tratamento de esgoto sanitário um sistema, em escala piloto, composto por um reator UASB, um bioaerador de cascata e um decantador. Os autores concluíram que o sistema proposto com remoção média de $83,9 \%$ para DQO e 76,2 \% para SST, dentro da limitação da própria realização da pesquisa, apresentou desempenho razoável, quando comparado com uma unidade convencional de tratamento de esgoto sanitário.

\section{3 - Controle de nutrientes}

Os principais nutrientes, nitrogênio e fósforo, costumam ser controlados no lançamento das águas residuárias tratadas, principalmente o esgoto sanitário. Estes nutrientes podem acelerar a eutrofização dos corpos d'água fechados, e podem estimular o crescimento de algas e plantas aquáticas com raiz em córregos pouco profundos (JORDÃO \& PESSOA, 1995).

A presença de algas e plantas aquáticas podem interferir nos usos benéficos dos recursos hídricos, principalmente quando estes são utilizados para abastecimento, criação de peixes e recreação. A presença de altas concentrações de nitrogênio no efluente tratado pode também ocasionar outros efeitos adversos, como diminuição do oxigênio dissolvido nas águas receptoras, toxicidade para a vida aquática, podendo também interferir na eficiência da desinfeç̧ão com cloro e na conveniência da utilização da água residuária para reuso (METCALF \& EDDY, 1991). 
Antigamente, os sistemas de lodos ativados eram utilizados exclusivamente para remoção de material orgânico e sólidos em suspensão das águas residuárias, isto é, em tratamento secundário. Nas últimas décadas, tornou-se claro que o tratamento secundário nem sempre evitava a eutrofização do corpo de água receptor do efluente, sendo necessário um tratamento a nível terciário, com o objetivo de reduzir as concentrações dos nutrientes, nitrogênio e fósforo (van HAANDEL, 1993).

\subsection{1 - Remoção do nitrogênio}

A forma de nitrogênio encontrado nas águas residuárias brutas e no esgoto sanitário é de amônia ou nitrogênio orgânico, solúvel e particulado. A parcela sob a forma de nitrito ou nitrato é muito pequena ou inexistente. $\mathrm{O}$ nitrogênio orgânico solúvel está principalmente na forma de uréia e aminoácidos. No tratamento primário, uma parte do nitrogênio orgânico sob a forma de material particulado é removida, e no tratamento secundário, biológico, a maior parte do nitrogênio orgânico particulado é transformado em amônio e outras formas inorgânicas. Uma parcela do amônio é assimilada nas células dos organismos, e a maioria do nitrogênio encontrado no efluente secundário tratado está sob a forma de amônio. Pelo tratamento secundário convencional, a remoção de nitrogênio é ainda muito limitada, não chegando a $30 \%$. No tratamento secundário, através da nitrificação biológica, o amônio é transformado em nitrato, sendo a remoção final realizada pela desnitrificação biológica posterior (JORDÃO \& PESSOA, 1995 e METCALF \& EDDY, 1991).

Vários processos de tratamento das águas residuárias utilizados para conversão e remoção de nitrogênio, os efeitos sobre os compostos de nitrogênio e as eficiências destes processos de tratamento encontram-se na Tabela 3.7. 
TABELA 3.7 - Eficiência de vários processos de tratamento sobre a remoção dos compostos de nitrogênio.

\begin{tabular}{|c|c|c|c|c|}
\hline \multirow[b]{2}{*}{ Processos de Tratamento } & \multicolumn{3}{|c|}{ Compostos de Nitrogênio } & \multirow[b]{2}{*}{$\begin{array}{c}\text { Remoção total } \\
\text { de nitrogênio, } \\
\%\end{array}$} \\
\hline & $\mathrm{N}$-orgânico & $\mathrm{NH}_{3}-\mathrm{NH}_{4}^{+}$ & $\mathrm{NO}_{3}^{-}$ & \\
\hline \multicolumn{5}{|l|}{ Tratamento convencional } \\
\hline - Primário & $10-20 \%$ & sem efeito & sem efeito & $5-10$ \\
\hline - Secundário & $\begin{array}{c}15-50 \% \\
\text { uréia } \rightarrow \mathrm{NH}_{3}-\mathrm{NH}_{4}^{+}\end{array}$ & $<10 \%$ & pouco efeito & $10-30$ \\
\hline $\begin{array}{l}\text { Processos biológicos } \\
\text { - Assimilação por } \\
\text { bactérias }\end{array}$ & sem efeito & $40-70 \%$ & pouco efeito & $30-70$ \\
\hline - Desnitrificação & sem efeito & sem efeito & $80-90 \%$ & $70-95$ \\
\hline - Nitrificação & efeito limitado & $\rightarrow \mathrm{NO}_{3}^{-}$ & sem efeito & $5-20$ \\
\hline - Valos de oxidação & $\begin{array}{l}\text { conversão parcial } \\
\text { a } \mathrm{NH}_{3}-\mathrm{NH}_{4}^{+}\end{array}$ & $\begin{array}{l}\text { remoção } \\
\text { parcial por } \\
\text { "stripping" }\end{array}$ & $\begin{array}{c}\text { remoção } \\
\text { parcial por } \\
\text { nitrificação / } \\
\text { desnitrificação }\end{array}$ & $20-90$ \\
\hline
\end{tabular}

Fonte: METCALF \& EDDY (1991).

\subsubsection{1 - Nitrificação}

Em regiões de clima quente a ocorrência da nitrificação nos processos de lodos ativados é praticamente inevitável, tornando-se também necessário realizar a desnitrificação para impedir a entrada de nitrato no decantador. As bolhas de nitrogênio molecular, formadas pela presença de nitrato no decantador, agregam-se ao lodo, formando-se assim uma camada de lodo 
flutuante, proporcionando uma perda de lodo no efluente (van HAANDEL \& LETTINGA, 1994).

A nitrificação biológica de amônio a nitrato é um processo realizado em duas etapas por dois gêneros de microrganismos, Nitrosomonas e Nitrobacter.

Na primeira etapa, o amônio é convertido para nitrito, como mostra a eq. (3.3).

$$
\mathrm{NH}_{4}^{+}+\frac{3}{2} \mathrm{O}_{2} \stackrel{\text { Nitrosomonas }}{\longrightarrow} \mathrm{NO}_{2}^{-}+2 \mathrm{H}^{+}+\mathrm{H}_{2} \mathrm{O}
$$

Na segunda etapa, o nitrito é convertido para nitrato, conforme a eq. (3.4).

$$
\mathrm{NO}_{2}^{-}+\frac{1}{2} \mathrm{O}_{2} \stackrel{\text { Nitrobacter }}{\longrightarrow} \mathrm{NO}_{3}^{-}
$$

A reação global da nitrificação é representada pela eq. (3.5).

$$
\mathrm{NH}_{4}^{+}+2 \mathrm{O}_{2} \rightarrow \mathrm{NO}_{3}^{-}+2 \mathrm{H}^{+}+\mathrm{H}_{2} \mathrm{O}
$$

As bactérias nitrificantes possuem longos tempos de geração. A baixa produção de energia das reações de oxidação proporcionam baixa produção celular. Estes organismos são sensíveis a certas condições ambientais, como $\mathrm{pH}$, concentração de oxigênio dissolvido, temperatura, e inibidores químicos (LAUDELOT \& van TICHELEN; PAINTER e STRATTON apud GEE et al., 1990).

GEE et al. (1990) realizando experiências em tanques de aeração com volume de 10 litros para tratamento de três tipos de afluentes, um contendo somente amônia, outro nitrito, e um terceiro composto por várias misturas de 
amônia e nitrito, nas mesmas condições ambientais, mostraram que a atividade das bactérias Nitrobacter depende profundamente das Nitrosomonas, mas o inverso não foi notado. Observaram que a completa oxidação da amônia a nitrato, durante alimentação com afluente contendo somente amônia, ocorria para tempo de detenção hidráulico de apenas 2,7 dias à temperatura de $23 \pm$ $2^{\circ} \mathrm{C}$ e pH de $8 \pm 0,2$. Porém, a oxidação do nitrito a nitrato na ausência da amônia, resultou em um sistema instável e necessitou tempo de detenção hidráulico de 10 dias para oxidação de 99,8 \% de nitrito.

\subsection{2 - Remoção do fósforo}

No tratamento primário é removido aproximadamente $10 \%$ do fósforo correspondente à parcela insolúvel. Exceto a parcela incorporada ao tecido celular, a remoção no tratamento biológico convencional é mínima, pois quase todo fósforo presente após o tratamento primário é solúvel. A remoção do fósforo pode ser realizada através de processos químicos, físicos e biológicos. Na remoção por precipitação química têm-se utilizado sais de metais (ferro e alumínio) ou cal. Recentemente, processos biológicos de remoção de fósforo tem sido desenvolvidos como alternativa para precipitação química. Nos casos de tratamento avançado, em que se deseja concentrações de fósforo inferiores a $1 \mathrm{mg} / \mathrm{L}$, a filtração é usada para complementar o tratamento por processos químicos ou biológicos. Outros processos físicos, como a ultrafiltração e osmose reversa, são eficientes na remoção do fósforo, mas são usados principalmente na redução total dos sólidos inorgânicos dissolvidos (METCALF \& EDDY, 1991).

A remoção biológica de fósforo através da incorporação na massa de lodo é uma opção vantajosa quando se aplica o sistema de lodos ativados, pois não há necessidade de adição do agente para precipitação nem de um decantador do precipitado. Através da imposição de condições operacionais 
adequadas no sistema de lodos ativados, isto é, colocando o lodo alternadamente em um ambiente anaeróbio e depois num ambiente aeróbio, os microrganismos primeiramente liberarão fosfato para a fase líquida e, em seguida, absorvem no ambiente aeróbio fosfato em excesso. Através desta absorção (em inglês "luxury uptake") a fração de massa de fósforo em lodo ativo pode ser aumentada de $6 \%$, como em sistemas sem a parte anaeróbia, para um máximo de $35 \%$ (van HAANDEL \& LETTINGA, 1994).

As eficiências de vários processos ou operações de tratamento sobre a remoção de fósforo estão mostradas na Tabela 3.8.

TABELA 3.8 - Eficiência de vários processos ou operações de tratamento sobre a remoção de fósforo.

\begin{tabular}{lc}
\hline Processos ou operações de tratamento & Remoção total de fósforo, \% \\
\hline Tratamento convencional & $10-20$ \\
Primário & $10-25$ \\
Lodos ativados & $8-12$ \\
Filtros biológicos & $70-90$ \\
Remoção biológica de fósforo & $70-90$ \\
Remoção biológica combinada & \\
fósforo e nitrogênio & \\
Remoção química & $70-90$ \\
Precipitação com sais de metais & $70-90$ \\
Precipitação com cal & \\
Remoção física & $20-50$ \\
Filtração & $90-100$ \\
Osmose reversa & $10-30$ \\
Adsorção por carbono & \\
\hline
\end{tabular}

Fonte: METCALF \& EDDY (1991). 


\section{4 - Aplicação da cinética ao tratamento biológico}

Neste item serão abordados a cinética do crescimento biológico, os sistemas de lodos ativados sem e com recirculação de lodo, o mecanismo da degradação aeróbia e determinações experimentais.

\subsection{1 - Cinética do crescimento biológico}

A cinética do crescimento biológico será descrita conforme METCALF \& EDDY (1991).

A taxa de crescimento de microrganismos em sistemas de alimentação contínuo e descontínuo é dada por:

$$
r_{g}=\mu X
$$

$r_{\mathrm{g}}=$ taxa de crescimento de microrganismos, $M \cdot L^{-3} \cdot \mathrm{T}^{-1}$

$\mu=$ taxa específica de crescimento de microrganismos, $\mathrm{T}^{-1}$

$\mathrm{X}=$ concentração de microrganismos, $M \cdot \mathrm{L}^{-3}$

Experimentalmente, tem-se chegado à conclusão de que o efeito de um substrato ou um nutriente limitante pode definir-se segundo a expressão proposta por Monod:

$$
\mu=\mu_{\mathrm{m}} \frac{\mathrm{S}}{\mathrm{K}_{\mathrm{s}}+\mathrm{S}}
$$

$\mu_{\mathrm{m}}=$ taxa específica máxima de crescimento de microrganismos, $\mathrm{T}^{-1}$

$\mathrm{S}=$ concentração do substrato limitante ao crescimento, $M \cdot \mathrm{L}^{-3}$

$\mathrm{K}_{\mathrm{s}}=$ constante de meia velocidade, concentração de substrato para metade da taxa de crescimento máxima $\left(\mu=\mu_{\mathrm{m}} / 2\right), M . L^{-3}$ 
O efeito da concentração do substrato sobre a taxa específica de crescimento é mostrado na Figura 3.6.

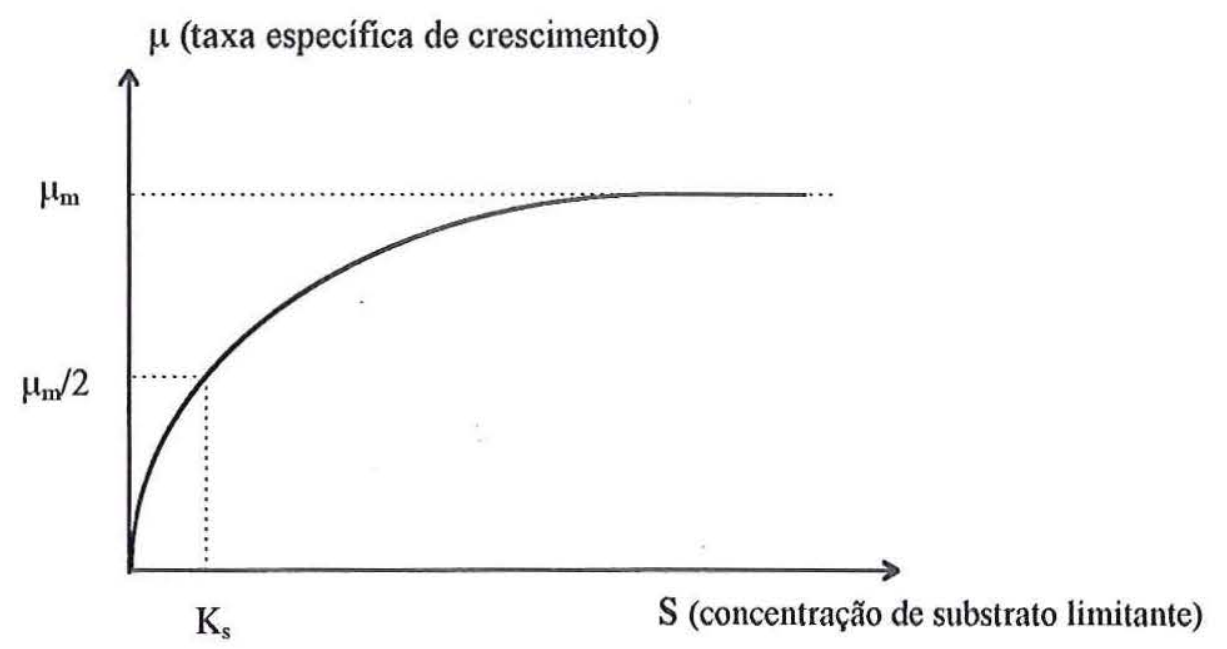

FIGURA 3.6 - Variação da taxa específica de crescimento com a concentração do substrato (METCALF \& EDDY, 1991).

Substituindo o valor de $\mu$ dado pela eq. (3.7) na eq. (3.6) obtém-se:

$$
\mathrm{r}_{\mathrm{g}}=\frac{\mu_{\mathrm{m}} \mathrm{XS}}{\mathrm{K}_{\mathrm{s}}+\mathrm{S}}
$$

Entre a taxa de crescimento e a taxa de utilização de substrato, tem-se a seguinte relação:

$$
\mathrm{r}_{\mathrm{g}}=-\mathrm{Yr}_{\mathrm{su}}
$$

$\mathrm{Y}=$ coeficiente de máxima produção celular ou de síntese celular, adimensional

$r_{\mathrm{su}}=$ taxa de utilização de substrato, $M \cdot L^{-3} \cdot \mathrm{T}^{-1}$ 
Substituindo o valor de $r_{g}$ dado pela eq. (3.8) na eq. (3.9), a taxa de utilização de substrato é definida por:

$$
r_{\mathrm{su}}=-\frac{\mu_{\mathrm{m}} \mathrm{XS}}{\mathrm{Y}\left(\mathrm{K}_{\mathrm{s}}+\mathrm{S}\right)}
$$

A taxa máxima de utilização de substrato por unidade de massa de microrganismos é dada por:

$$
\mathrm{k}=\frac{\mu_{\mathrm{m}}}{\mathrm{Y}}
$$

$\mathrm{k}$ = taxa máxima de utilização de substrato por unidade de massa de microrganismo, $\mathrm{T}^{-1}$

Substituindo o termo k da eq. (3.11) na eq. (3.10), obtém-se:

$$
r_{\mathrm{su}}=-\frac{\mathrm{kXS}}{\mathrm{K}_{\mathrm{s}}+\mathrm{S}}
$$

O decaimento endógeno da biomassa é dado por:

$$
r_{d}=-k_{d} X
$$

$\mathrm{r}_{\mathrm{d}}=$ taxa de decaimento da biomassa devido à respiração endógena, $\mathrm{M} \cdot \mathrm{L}^{-3} \cdot \mathrm{T}^{-1}$

$\mathrm{k}_{\mathrm{d}}=$ coeficiente de decaimento da biomassa devido à respiração endógena, $\mathrm{T}^{-1}$ 
Combinado a eq. (3.13) com as eq. (3.8) e (3.9), obtém-se para taxa líquida de crescimento de microrganismos, a seguinte expressão:

$$
\begin{gathered}
r_{\mathrm{g}}^{\prime}=\frac{\mu_{\mathrm{m}} \mathrm{XS}}{\mathrm{K}_{\mathrm{s}}+\mathrm{S}}-\mathrm{k}_{\mathrm{d}} \mathrm{X} \\
\mathrm{r}_{\mathrm{g}}^{\prime}=-\mathrm{Yr}_{\mathrm{su}}-\mathrm{k}_{\mathrm{d}} \mathrm{X} \\
\mathrm{r}_{\mathrm{g}}^{\prime}=\text { taxa líquida de crescimento de microrganismos, } \mathrm{M} \cdot \mathrm{L}^{-3} \cdot \mathrm{T}^{-1}
\end{gathered}
$$

A taxa líquida específica de crescimento é dada por:

$$
\mu^{\prime}=\mu_{\mathrm{m}} \frac{\mathrm{S}}{\mathrm{K}_{\mathrm{s}}+\mathrm{S}}-\mathrm{k}_{\mathrm{d}}
$$

$\mu^{\prime}=$ taxa líquida específica de crescimento, $\mathrm{T}^{-1}$

Os efeitos da respiração endógena sobre a produção líquida dos microrganismos são representados pela produção observada:

$$
\begin{gathered}
\mathrm{Y}_{\mathrm{obs}}=-\frac{\mathrm{r}_{\mathrm{g}}^{\prime}}{\mathrm{r}_{\mathrm{su}}} \\
\mathrm{Y}_{\mathrm{obs}}=\begin{array}{c}
\text { coeficiente de produção celular observada ou de síntese celular } \\
\text { observada, adimensional }
\end{array}
\end{gathered}
$$

O efeito da temperatura sobre a taxa de reação dos processos biológicos é expresso pela seguinte expressão:

$$
\mathbf{r}_{\mathrm{T}}=\mathrm{r}_{20} \lambda^{(\mathrm{T}-20)}
$$


$\mathrm{r}_{\mathrm{T}}=$ taxa de reação à temperatura $\mathrm{T}^{\circ} \mathrm{C}$

$r_{20}=$ taxa de reação a $20^{\circ} \mathrm{C}$

$\lambda=$ coeficiente de temperatura para a atividade microbiana

$\mathrm{T}=$ temperatura, ${ }^{\circ} \mathrm{C}$

Na Tabela 3.9 estão apresentados valores típicos de $\lambda$ para vários processos biológicos de tratamento.

TABELA 3.9- Valores dos coeficientes de temperatura para a atividade microbiana de vários processos biológicos de tratamento.

\begin{tabular}{lcc}
\hline \multirow{2}{*}{ PROCESSO } & \multicolumn{2}{c}{ VALOR DE $\lambda$} \\
\cline { 2 - 3 } & INTERVALO & TÍPICO \\
\hline Lodos ativados & 1,00 a 1,08 & 1,04 \\
Lagoas aeradas & 1,04 a 1,10 & 1,08 \\
Filtros biológicos & 1,02 a 1,08 & 1,035 \\
\hline
\end{tabular}

Fonte: METCALF \& EDDY (1991).

\subsection{2 - Sistemas de lodos ativados sem recirculação de lodo}

A apresentação da cinética do sistema de lodos ativados sem recirculação de lodo, esquematizado na Figura 3.7, será descrita conforme METCALF \& EDDY (1991). 


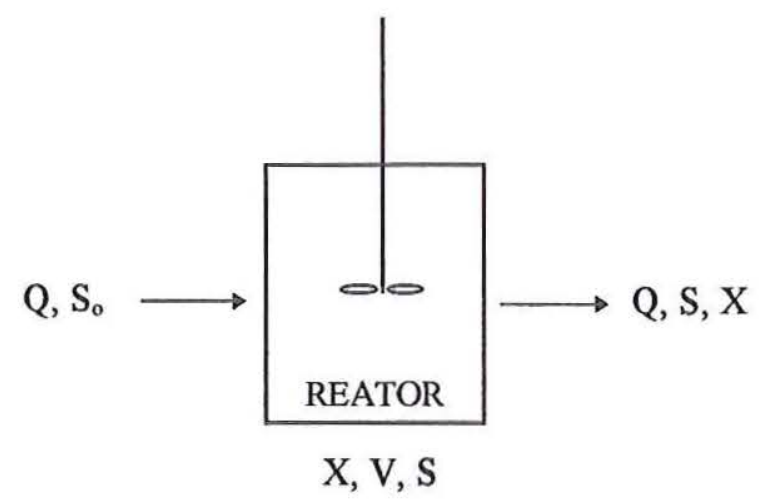

FIGURA 3.7 - Esquema do processo de lodos ativados sem recirculação de lodo (METCALF \& EDDY, 1991).

Um balanço de massa considerando a massa de microrganismos no reator de mistura completa mostrado na Figura 3.7, pode ser estabelecido da seguinte forma:

$\left(\begin{array}{l}\text { taxa de acumulação } \\ \text { da massa de } \\ \text { microrganismos } \\ \text { dentro do sistema }\end{array}\right)=\left(\begin{array}{l}\text { taxa de entrada } \\ \text { da massa de } \\ \text { microrganismos } \\ \text { no sistema }\end{array}\right)-\left(\begin{array}{l}\text { taxa de saída da } \\ \text { massa de } \\ \text { microrganismos } \\ \text { no sistema }\end{array}\right)+\left(\begin{array}{l}\text { taxa de crescimento } \\ \text { líquido da massa de } \\ \text { microrganismos } \\ \text { dentro do sistema }\end{array}\right)$

Simplificando: $\quad$ acumulação = entrada - saída + crescimento líquido

Representação simbólica:

$$
\frac{d X}{d t} \cdot V_{r}=Q X_{o}-Q X+V_{r} r_{g}^{\prime}
$$

$\mathrm{dX} / \mathrm{dt}=$ taxa de variação da concentração de microrganismos no reator, medida em termos de massa (sólidos suspensos voláteis), $M \cdot \mathrm{L}^{-3} \cdot \mathrm{T}^{-1}$

$\mathrm{V}_{\mathrm{r}} \quad=$ volume do reator, $\mathrm{L}^{3}$ 
$\mathrm{Q}=$ vazão, $\mathrm{L}^{3} \cdot \mathrm{T}^{-1}$

$\mathrm{X}_{\mathrm{o}}=$ concentração de microrganismos no afluente, $\mathrm{M} \cdot \mathrm{L}^{-3}$

$\mathrm{X}=$ concentração de microrganismos no reator (tanque de aeração), M.L. ${ }^{-3}$

$\mathrm{r}_{\mathrm{g}}^{\prime}=$ taxa líquida de crescimento de microrganismos, $\mathrm{M} \cdot \mathrm{L}^{-3} \cdot \mathrm{T}^{-1}$

Substituindo o valor de $r_{g}^{\prime}$ dado pela eq. (3.14) na (3.19), tem-se:

$$
\frac{d X}{d t} V_{r}=Q X_{o}-Q X+V_{r}\left(\frac{\mu_{m} X S}{K_{s}+S}-k_{d} X\right)
$$

$S=$ concentração de substrato no efluente, $M \cdot L^{-3}$

Assumindo que a concentração de microrganismos no afluente pode ser desprezada, $\mathrm{X}_{\mathrm{o}}=0$, e que para a condição de equilíbrio $\mathrm{dX} / \mathrm{dt}=0$, a eq. (3.20), pode ser simplificada para:

$$
\frac{\mathrm{Q}}{\mathrm{V}_{\mathrm{r}}}=\frac{1}{\theta}=\frac{\mu_{\mathrm{m}} \mathrm{S}}{\mathrm{K}_{\mathrm{s}}+\mathrm{S}}-\mathrm{k}_{\mathrm{d}}
$$

$\theta=$ tempo de detenção hidráulico $=\mathrm{V} / \mathrm{Q}, \mathrm{T}$

O tempo de retenção celular é definido como sendo a massa de organismos no reator dividido pela massa de microrganismos removida do sistema por dia, sendo dado para o reator da Figura 3.7 por:

$$
\theta_{c}=\frac{V_{r} X}{Q X}=\frac{V_{r}}{Q}
$$

$\theta_{c}=$ tempo de retenção celular, $\mathrm{T}$ 
Realizando um balanço de substrato correspondente ao balanço de massa de microrganismos dado pela eq. (3.20), resulta na seguinte expressão:

$$
\frac{d S}{d t} V_{r}=Q S-Q S+V_{r}\left(\frac{k X S}{K_{s}+S}\right)
$$

$\mathrm{S}_{\mathrm{o}}=$ concentração de substrato no afluente, $\mathrm{M} \cdot \mathrm{L}^{-3}$

Para a condição de equilíbrio, $\mathrm{dS} / \mathrm{dt}=0$, obtém-se:

$$
\left(s_{o}-s\right)-\theta\left(\frac{k X S}{K_{s}+S}\right)=0
$$

$\theta=V_{r} / Q$

As concentrações de microrganismos e substrato no efluente são obtidas explicitando o termo $\mathrm{S} /\left(\mathrm{K}_{\mathrm{s}}+\mathrm{S}\right)$ da eq. (3.21) e substituindo-o na eq. (3.24), considerando também a eq. (3.11).

A concentração de microrganismos no efluente é dada por:

$$
X_{e}=\frac{\mu_{m}\left(S_{o}-S\right)}{k\left(1+k_{d} \theta\right)}=\frac{Y\left(S_{o}-S\right)}{\left(1+k_{d} \theta\right)}
$$

Similarmente, a concentração de substrato no efluente é dada por:

$$
\mathrm{S}=\frac{\mathrm{K}_{\mathrm{S}}\left(1+\theta \mathrm{k}_{\mathrm{d}}\right)}{\theta\left(\mathrm{Yk}-\mathrm{k}_{\mathrm{d}}\right)-1}
$$

A produção celular observada é dada por: 


$$
\mathrm{Y}_{\mathrm{obs}}=\frac{\mathrm{Y}}{1+\mathrm{k}_{\mathrm{d}} \theta}
$$

$\mathrm{Y}_{\mathrm{obs}}=$ coeficiente de produção ou síntese celular observada, adimensional

\subsection{3 - Sistemas de lodos ativados com recirculação de lodo}

A apresentação da cinética do sistemas de lodos ativados com recirculação de lodo, esquematizado na Figura 3.8, será descrita conforme METCALF \& EDDY (1991).

O tempo de detenção hidráulico do sistema é dado por:

$$
\theta_{\mathrm{s}}=\frac{\mathrm{V}_{\mathrm{T}}}{\mathrm{Q}}=\frac{\mathrm{V}_{\mathrm{r}}+\mathrm{V}_{\mathrm{s}}}{\mathrm{Q}}
$$

$\theta_{\mathrm{s}}=$ tempo de detenção hidráulico do sistema, $\mathrm{T}$

$\mathrm{V}_{\mathrm{T}}=$ volume total, incluindo reator e decantador, $\mathrm{L}^{3}$

$\mathrm{Q}=$ vazão afluente do reator, $\mathrm{L}^{3} \cdot \mathrm{T}^{-1}$

$\mathrm{V}_{\mathrm{r}}=$ volume do reator, $\mathrm{L}^{3}$

$\mathrm{V}_{\mathrm{s}}=$ volume do decantador, $\mathrm{L}^{3}$

O tempo de detenção hidráulico do reator é dado por:

$$
\theta=\frac{V_{r}}{Q}
$$

$\theta=$ tempo de detenção hidráulico do reator, $\mathrm{T}$ 


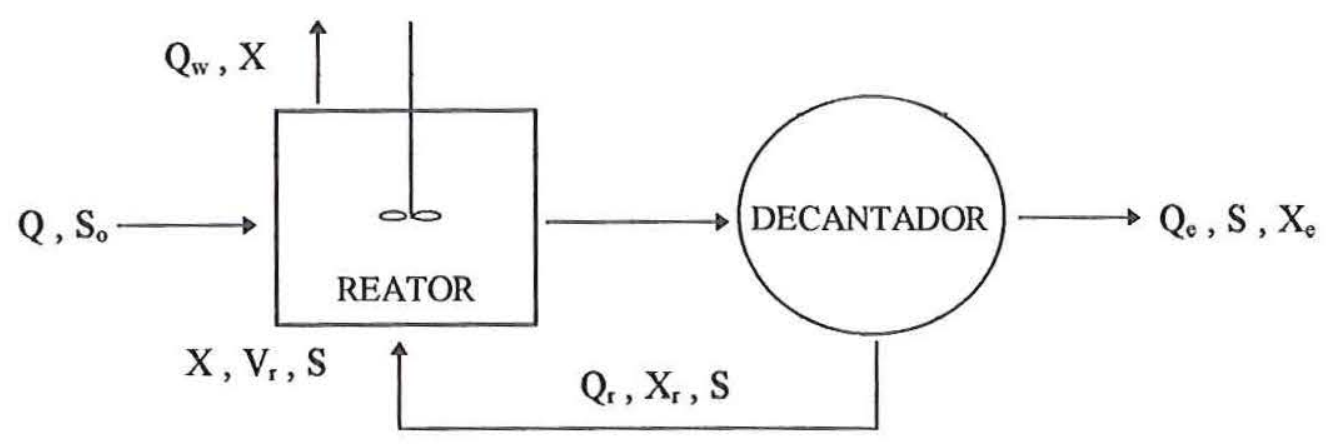

(a)

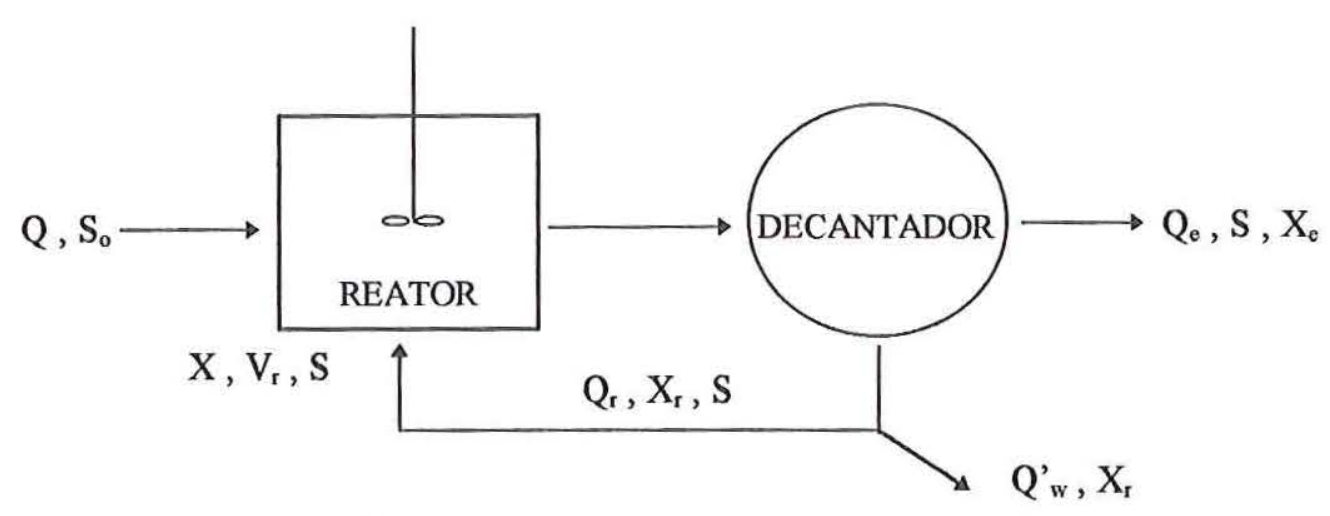

(b)

FIGURA 3.8 - Esquema do processo de lodos ativados com reator do tipo mistura completa e recirculação de lodo: (a) o lodo excedente é descartado no próprio reator e (b) o lodo excedente é descartado na linha de retorno do lodo (METCALF \& EDDY, 1991).

Para o sistema mostrado na Figura 3.8a, o tempo de retenção celular é definido como a massa de organismos contida no reator dividido pela massa de organismos removida do sistema por dia, dado pela seguinte expressão:

$$
\theta_{c}=\frac{V_{r} X}{Q_{w} X+Q_{e} X_{e}}
$$


$\theta_{\mathrm{c}}=$ tempo de retenção celular, $\mathrm{T}$

$\mathrm{Q}_{\mathrm{w}}=$ vazão de células biológicas descartadas do reator (excesso), $\mathrm{L}^{3} \cdot \mathrm{T}^{-1}$

$\mathrm{Q}_{\mathrm{e}}=$ vazão efluente do decantador, $\mathrm{L}^{3} \cdot \mathrm{T}^{-1}$

$\mathrm{X}_{\mathrm{e}}=$ concentração de microrganismos no efluente do decantador, $M \cdot \mathrm{L}^{-3}$

Para o sistema mostrado na Figura 3.8b, o tempo de retenção celular é dado por:

$$
\theta_{c}=\frac{V_{r} X}{Q_{w}^{\prime} X_{r}+Q_{e} X_{e}}
$$

$\mathrm{X}_{\mathrm{r}}=$ concentração de microrganismos na linha de retorno do lodo do decantador ao reator, $M . L^{-3}$

$\mathrm{Q}_{\mathrm{w}}{ }_{\mathrm{w}}=$ vazão de células biológicas descartadas na linha de retorno do lodo (excesso), $\mathrm{L}^{3} \cdot \mathrm{T}^{-1}$

O balanço de massa de microrganismos para a Figura 3.8a, fornece:

$$
\left(\begin{array}{l}
\text { taxa de acumulação } \\
\text { da massa de } \\
\text { microrganismos } \\
\text { dentro do sistema }
\end{array}\right)=\left(\begin{array}{l}
\text { taxa de entrada } \\
\text { da massa de } \\
\text { microrganismos } \\
\text { no sistema }
\end{array}\right)-\left(\begin{array}{l}
\text { taxa de saída da } \\
\text { massa de } \\
\text { microrganismos } \\
\text { no sistema }
\end{array}\right)+\left(\begin{array}{l}
\text { taxa de crescimento } \\
\text { líquido da massa de } \\
\text { microrganismos } \\
\text { dentro do sistema }
\end{array}\right)
$$

Simplificando:

$$
\text { acumulação = entrada }- \text { saída }+ \text { crescimento líquido }
$$

Representação simbólica:

$$
\frac{d X}{d t} \cdot V_{r}=Q X_{o}-\left[Q_{w} X+Q_{e} X_{e}\right]+V_{r} r_{g}^{\prime}
$$


$\mathrm{r}_{\mathrm{g}}^{\prime}$ é dado pela eq. (3.15).

Substituindo a eq. (3.15) na (3.32), assumindo nula a concentração de microrganismo no afluente e sabendo-se que para a condição de equilíbrio $\mathrm{dX} / \mathrm{dt}=0$, tem-se:

$$
\frac{Q_{w} X+Q_{e} X_{e}}{V_{r} X}=-Y \frac{r_{s u}}{X}-k_{d}
$$

ou

$$
\frac{1}{\theta_{\mathrm{c}}}=-\mathrm{Y} \frac{\mathrm{r}_{\mathrm{su}}}{\mathrm{X}}-\mathrm{k}_{\mathrm{d}}
$$

O termo $\mathrm{r}_{\text {su }}$ é determinado por:

$$
\mathrm{r}_{\mathrm{su}}=-\frac{\mathrm{Q}}{\mathrm{V}_{\mathrm{r}}}\left(\mathrm{S}_{\mathrm{o}}-\mathrm{S}\right)=-\frac{\mathrm{S}_{\mathrm{o}}-\mathrm{S}}{\theta}
$$

$\mathrm{S}_{\mathrm{o}}-\mathrm{S}=$ concentração do substrato utilizado, $\mathrm{M} \mathrm{L}^{-3}$

$\mathrm{S}_{\mathrm{o}} \quad=$ concentração de substrato no afluente, $\mathrm{M} \mathrm{L}^{-3}$

$\mathrm{S}=$ concentração de substrato no efluente, $\mathrm{M} \mathrm{L}^{-3}$

A concentração de microrganismos no reator é obtida substituindo a eq. (3.35) em (3.34) e resolvendo para X.

$$
X=\frac{\theta_{c}}{\theta} \frac{Y\left(S_{o}-S\right)}{\left(1+k_{d} \theta_{c}\right)}
$$

Realizando um balanço do substrato, a concentração do substrato efluente é dada por: 


$$
S=\frac{K_{s}\left(1+\theta_{c} k_{d}\right)}{\theta_{c}\left(Y k-k_{d}\right)-1}
$$

A produção celular observada é dada por:

$$
\mathrm{Y}_{\mathrm{obs}}=\frac{\mathrm{Y}}{1+\mathrm{k}_{\mathrm{d}}\left(\theta_{\mathrm{c}} \text { ou } \theta_{\mathrm{ct}}\right)}
$$

$\theta_{\mathrm{ct}}=$ tempo de retenção celular total do sistema, $\mathrm{T}$

Para Figura 3.8a, o tempo de retenção celular total do sistema é dado por:

$$
\theta_{c t}=\frac{X_{t}}{Q_{w} X+Q_{e} X_{e}}
$$

$\mathrm{X}_{\mathrm{t}}=$ massa total de SSV no sistema, incluindo tanque de aeração, decantador e retorno do lodo, $\mathrm{M}$

O termo (- $\left.\mathbf{r}_{\mathrm{su}} \mathrm{X}\right)$ da eq.(3.34) é definido como taxa específica de utilização do substrato e substituindo-se $r_{\text {su }}$ dado pela eq. (3.35), tem-se:

$$
U=-\frac{r_{\text {su }}}{X}=\frac{S_{0}-S}{\theta X}=\frac{Q}{V_{r}} \frac{S_{0}-S}{X}
$$

$U=$ taxa específica de utilização de substrato, $T^{-1}$

Se o termo $-\mathrm{r}_{\mathrm{su}} / \mathrm{X}$ for substituído por $U$ na eq. (3.34), resulta: 


$$
\frac{1}{\theta_{\mathrm{c}}}=\mathrm{YU}-\mathrm{k}_{\mathrm{d}}
$$

Assumindo $\mathrm{X}_{\mathrm{e}}$ muito pequeno, a eq. (3.31) torna-se:

$$
\theta_{\mathrm{C}} \approx \frac{\mathrm{V}_{\mathrm{r}} \mathrm{X}}{\mathrm{Q}_{\mathrm{w}}^{\prime} \mathrm{X}_{\mathrm{r}}}
$$

A relação alimento/microrganismo é definida como:

$$
\mathrm{F} / \mathrm{M}=\frac{\mathrm{S}_{\mathrm{o}}}{\theta \mathrm{X}}
$$

$\mathrm{F} / \mathrm{M}=$ relação alimento/microrganismo, $\mathrm{T}^{-1}$

Os termos U e F/M estão relacionados com a eficiência do processo, pela seguinte relação:

$$
\mathrm{U}=\frac{(\mathrm{F} / \mathrm{M}) \mathrm{E}}{100}
$$

Sendo a eficiência do processo, E, dada por:

$$
E=\frac{S_{0}-S}{S_{0}} \times 100
$$

$\mathrm{E}=$ eficiência do processo, $\%$

Combinando-se a eq. (3.40) com a (3.24), obtém-se: 


$$
\mathrm{U}=\frac{\mathrm{kS}}{\mathrm{K}_{\mathrm{s}}+\mathrm{S}}
$$

ou

$$
\mathrm{S}=\frac{\mathrm{UK}_{\mathrm{s}}}{\mathrm{k}-\mathrm{U}}
$$

Existe um valor crítico de $\theta_{\mathrm{c}}$, abaixo do qual não ocorre estabilização do resíduo, denominado tempo de retenção celular mínimo e definido fisicamente como sendo o tempo de retenção para o qual as células são descartadas do sistema mais rapidamente do que podem reproduzir. A eq. (3.48) para cálculo do tempo de retenção celular mínimo é derivada das eqs. (3.33) (3.10) e (3.11). Quando isto ocorre, a concentração do afluente $S_{o}$ é igual a do efluente $S$.

$$
\frac{1}{\theta_{\mathrm{c}}^{\mathrm{M}}}=\mathrm{Y} \frac{\mathrm{kS}}{\mathrm{K}_{\mathrm{s}}+\mathrm{S}_{\mathrm{o}}}-\mathrm{k}_{\mathrm{d}}
$$

$\theta_{\mathrm{c}}^{\mathrm{M}}=$ tempo de retenção celular mínimo ou idade do lodo mínima, $\mathrm{T}$

No caso de $\mathrm{S}_{\mathrm{o}}$ ser muito maior que $\mathrm{K}_{\mathrm{s}}$, tem-se:

$$
\frac{1}{\theta_{\mathrm{c}}^{\mathrm{M}}} \approx \mathrm{Yk}-\mathrm{k}_{\mathrm{d}}
$$

Segundo METCALF \& EDDY (1991), os sistemas de tratamento biológico não podem ser projetados com valores de $\theta_{\mathrm{c}}$ iguais a $\theta_{\mathrm{c}}^{\mathrm{M}}$, portanto, para assegurar um tratamento adequado, devem ser projetados e operados com 
$\theta_{c}$ de 2 a 20 vezes $\theta_{c}^{\mathrm{M}}$. A relação entre $\theta_{c}$ e $\theta_{c}^{\mathrm{M}}$ pode ser considerada como um fator de segurança do processo:

$$
\mathrm{PSF}=\frac{\theta_{\mathrm{c}}}{\theta_{\mathrm{c}}^{\mathrm{M}}}
$$

PSF = fator de segurança do processo, adimensional

A quantidade de lodo produzida diariamente (e que deve ser descartada) é estimada por:

$$
P_{x}=Y_{o b s} Q\left(S_{o}-S\right) \times\left(10^{3} \mathrm{~g} / \mathrm{kg}\right)^{-1}
$$

$\mathrm{P}_{\mathrm{x}} \quad=$ produção líquida de lodo ativado por dia (quantidade a ser descartada), medido em termos de sólidos suspensos voláteis $(\mathrm{kg} / \mathrm{d}), M . \mathrm{T}^{-1}$

$\mathrm{Q}, \mathrm{S}_{\mathrm{o}}, \mathrm{S}=$ como definido anteriormente, sendo expressos $\mathrm{em} \mathrm{m}^{3} / \mathrm{dia}, \mathrm{mg} / \mathrm{L}$ $\left(\mathrm{g} / \mathrm{m}^{3}\right), \mathrm{mg} / \mathrm{L}\left(\mathrm{g} / \mathrm{m}^{3}\right)$, respectivamente

A produção celular observada, $\mathrm{Y}_{\mathrm{obs}}$, é dada pela eq. (3.38).

O oxigênio teórico necessário para remoção da matéria orgânica carbonácea na água residuária no processo de lodos ativados é calculada por:

$$
\mathrm{kg}, \mathrm{O}_{2} / \mathrm{d}=\frac{\mathrm{Q}\left(\mathrm{S}_{\mathrm{o}}-\mathrm{S}\right) \times\left(10^{3} \mathrm{~g} / \mathrm{kg}\right)^{-1}}{\mathrm{f}}-1,42\left(\mathrm{P}_{\mathrm{x}}\right)
$$

$\mathrm{f}=$ fator de conversão de $\mathrm{DBO}_{5}$ a $\mathrm{DBO}_{\mathrm{L}}\left(\mathrm{DBO}_{20}\right)$, adimensional

O valor de $\mathrm{f}$ para o esgoto sanitário é de aproximadamente 0,68 . 


\subsection{4 - Mecanismo da degradação aeróbia}

A degradação biológica aeróbia da matéria orgânica é função de sua composição e natureza dos substratos, dos microrganismos presentes e das condições ambientais do meio. Nesse processo a matéria orgânica solúvel e biodegradável é utilizada pelos microrganismos para a síntese ou produção de novas células e para produção de energia (oxidação), em que os substratos orgânicos são oxidados em produtos finais mais estáveis (KATO, 1982).

As funções básicas das bactérias como movimento e ativação enzimática requerem energia, que é obtida a partir da respiração endógena, com metabolismo de suas próprias reservas nutritivas, isto é, componentes do protoplasma (SANT'ANNA, 1982). Segundo McKINNEY apud SANT'ANNA (1982), o metabolismo endógeno ocorre mesmo quando existe disponibilidade de matéria orgânica em excesso.

As bactérias aeróbias consomem oxigênio durante a oxidação da matéria orgânica e do seu próprio material protoplasmático.

A Figura 3.9 representa um esquema do mecanismo da estabilização biológica aeróbia da matéria orgânica.

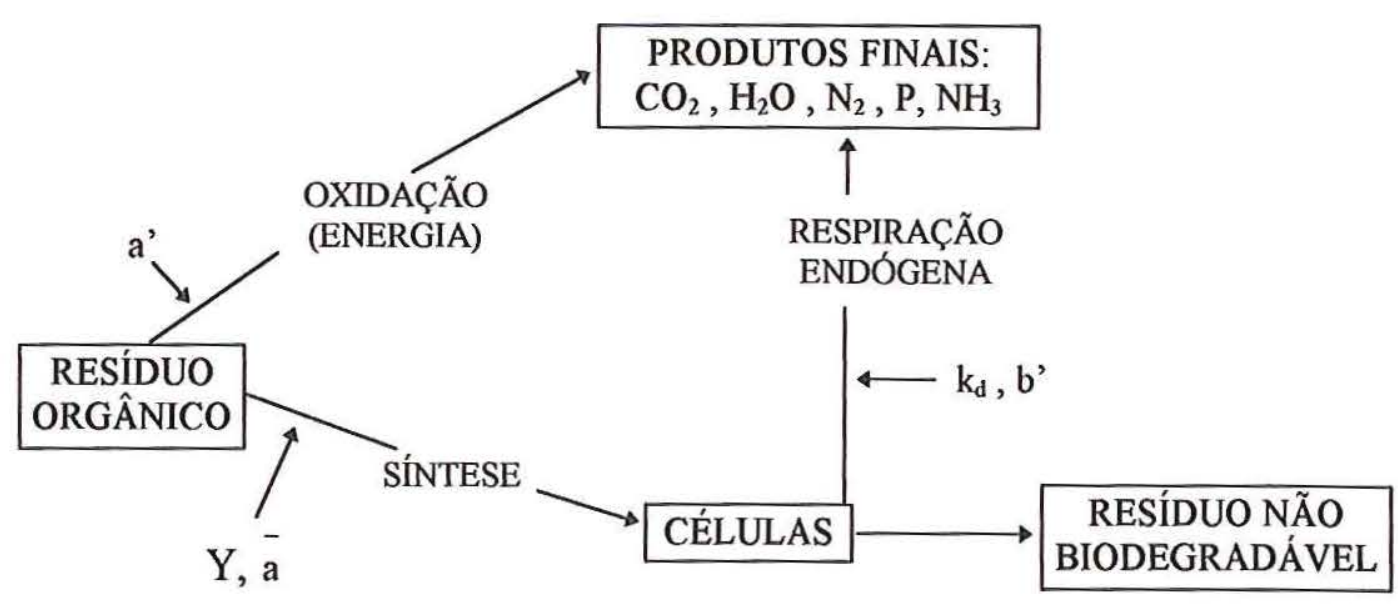

FIGURA 3.9 - Mecanismo da estabilização biológica aeróbia (RAMALHO apud SANT'ANNA, 1982). 
A seguir, serão definidos os parâmetros presentes no mecanismo da estabilização aeróbia da Figura 3.9, sendo que o substrato é quantificado em termos de DBO ou DQO.

a) Parâmetro a': coeficiente de oxigênio necessário à remoção da parcela de substrato que é oxidado para produção de energia ou fração de substrato removido utilizado para produção de energia. Representa a fração de substrato utilizado na produção de energia. É dado pelas seguintes relações:

$a^{\prime}=$ massa de substrato removido utilizado para obtenção de energia / massa total de substrato removido

ou

$\mathrm{a}^{\prime}=$ massa de oxigênio utilizado na oxidação de substrato por dia / massa total de substrato removido por dia

b) Parâmetro $\overline{\mathbf{a}}$ : fração de substrato removido utilizado para síntese. Representa a fração de substrato utilizado para síntese. É expresso pela seguinte relação:

$\overline{\mathrm{a}}=$ massa de substrato removido utilizado para síntese / massa total de substrato removido

c) Parâmetro Y: coeficiente de produção celular ou de síntese celular. Representa a fração de substrato utilizado para síntese, em termos de lodo biológico produzido. É dado pela seguinte relação: 
$\mathrm{Y}=$ massa de SSVTA produzido por dia / massa total de substrato removido por dia

d) Parâmetro $\mathbf{k}_{\mathrm{d}}$ : coeficiente de decaimento da biomassa devido à respiração endógena. Representa a fração de SSVTA oxidado no processo de respiração endógena. É expresso pela seguinte relação:

$\mathrm{k}_{\mathrm{d}}=$ massa de SSVTA oxidado por dia / massa de SSVTA

e) Parâmetro b': coeficiente de oxigênio necessário à respiração endógena. Representa a quantidade de oxigênio consumido no processo de respiração endógena. É dado pela seguinte relação:

b' = massa de oxigênio utilizada para respiração endógena por dia / massa de SSVTA

Os parâmetros a' e à representam a fração de substrato utilizado para energia e síntese, respectivamente, e estão relacionados pela seguinte equação:

$$
a^{\prime}+\bar{a}=1
$$

\subsection{5 - Determinações experimentais}

Neste item serão abordados a determinação experimental dos coeficientes cinéticos $\mathrm{k}, \mathrm{K}_{\mathrm{s}}$, $\mathrm{Y}$ e $\mathrm{k}_{\mathrm{d}}$ para sistemas de lodos ativados sem e com recirculação de lodo, dos parâmetros a' e b', da taxa de utilização de oxigênio, do coeficiente global de transferência de oxigênio e dos índices do lodo. 


\subsubsection{1 - Determinação dos coeficientes cinéticos em sistemas de} lodos ativados sem recirculação de lodo

A determinação experimental dos coeficientes cinéticos $\mathrm{k}, \mathrm{K}_{\mathrm{s}}, \mathrm{Y}$ e $\mathrm{k}_{\mathrm{d}}$, utilizados para projeto e operação de um sistema de lodos ativados será apresentada partindo da equação de Monod conforme descrito em METCALF \& EDDY (1991). BLUNDI (1982), cita que para sua determinação utilizam-se em geral 4 reatores, em escala de laboratório, de mistura completa, sendo cada um operado com um tempo de retenção celular, mas com tempo de detenção hidráulico mantido constante. Nas condições de equilíbrio, para cada $\theta_{\mathrm{c}}$, obtém-se um valor de $\mathrm{X}$ e $\mathrm{S}$. Os valores dos coeficientes cinéticos são calculados de acordo com os gráficos e equações que estão descritos a seguir.

Para determinação dos coeficientes cinéticos, tem-se que:

$\mathrm{S}_{\mathrm{o}}=$ concentração de substrato no afluente, em termos de DBO ou DQO bruta, M.L $\mathrm{L}^{-3}$

$\mathrm{S}$ = concentração de substrato no efluente, em termos de DBO ou DQO filtrada, M.L - $^{-3}$

$\mathrm{X}_{\mathrm{v}}=$ concentração de microrganismos no tanque de aeração, em termos de SSVTA, M.L ${ }^{-3}$

\subsubsection{1 - Determinação de $k$ e $K_{s}$}

Igualando o valor de $r_{\mathrm{su}}$ dado pela eq. (3.12) com o valor de $\mathrm{r}_{\mathrm{su}}$ dado pela eq. (3.35), obtém-se:

$$
r_{s u}=-\frac{k X_{v} S}{K_{s}+S}=-\frac{S_{o}-S}{\theta}
$$


Dividindo por $\mathrm{X}_{\mathrm{v}}$ obtêm-se:

$$
\frac{\mathrm{kS}}{\mathrm{K}_{\mathrm{s}}+\mathrm{S}}=\frac{\mathrm{S}_{\mathrm{o}}-\mathrm{S}}{\theta \mathrm{X}_{\mathrm{v}}}
$$

A forma linearizada da eq. (3.61), obtida tomando sua inversa é:

$$
\frac{\mathrm{X}_{\mathrm{v}} \theta}{\mathrm{S}_{\mathrm{o}}-\mathrm{S}}=\frac{\mathrm{K}_{\mathrm{s}}}{\mathrm{k}} \frac{1}{\mathrm{~S}}+\frac{1}{\mathrm{k}}
$$

Os coeficientes cinéticos $\mathrm{k}$ e $\mathrm{K}_{\mathrm{s}}$ serão determinados graficamente, após ajuste pelo método dos mínimos quadrados, plotando-se em ordenadas os valores de $\frac{X_{v} \theta}{S_{o}-S}$ e em abcissas os de $\frac{1}{S}$, conforme a Figura 3.10. Os valores de $k$ e $K_{s}$ serão dados pela combinação do coeficiente angular $\left(K_{s} / k\right)$ com o linear $(1 / k)$ da reta obtida.

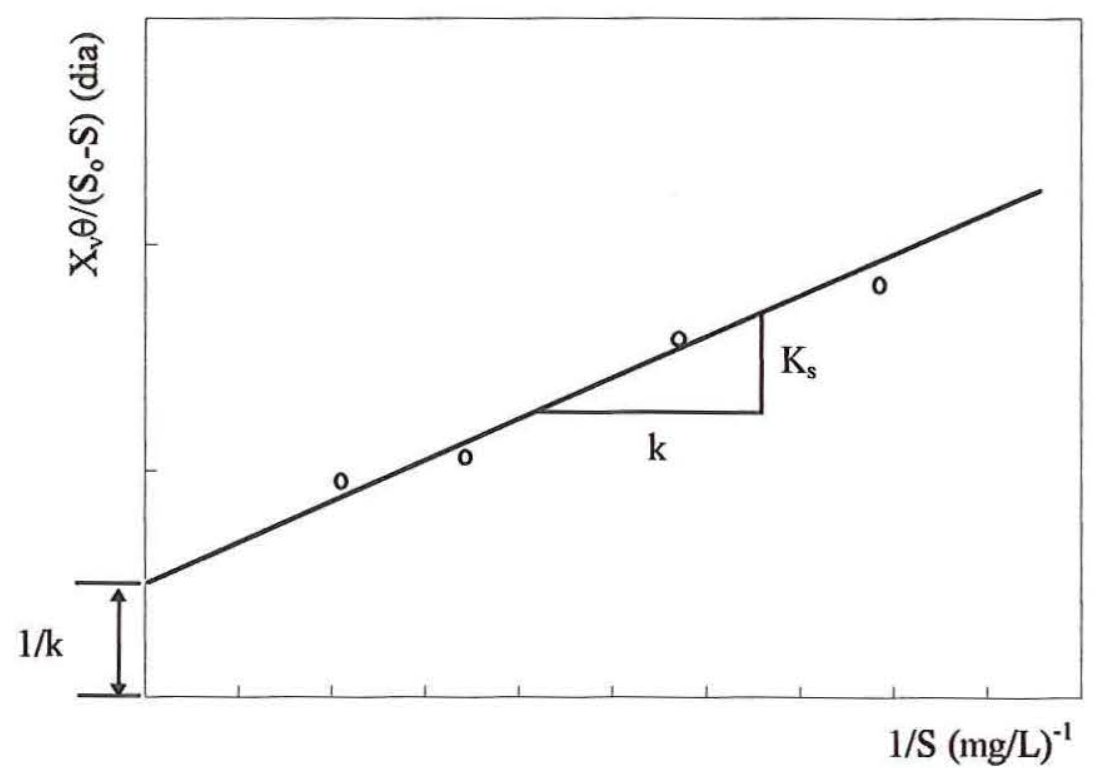

FIGURA 3.10 - Determinação gráfica de k e $\mathrm{K}_{\mathrm{s}}$ (SANT'ANNA, 1982). 


\subsubsection{2 - Determinação de $Y \mathbf{e} \mathbf{k}_{\mathrm{d}}$}

Substituindo a eq. (3.35) em (3.34) obtém-se:

$\frac{1}{\theta_{c}}=Y \frac{S_{o}-S}{X_{v} \theta}-k_{d}$

Os coeficientes cinéticos $\mathrm{Y}$ e $\mathrm{k}_{\mathrm{d}}$ serão determinados graficamente, após ajuste pelo método dos mínimos quadrados, lançando-se os valores de $\frac{1}{\theta_{\mathrm{c}}}$ em ordenadas e os de $\frac{S_{o}-S}{\theta X_{v}}$ em abcissas, conforme a Figura 3.11. Os valores de $\mathrm{Y}$ e $\mathrm{k}_{\mathrm{d}}$ serão dados, respectivamente, pelo coeficiente angular e linear da reta obtida.

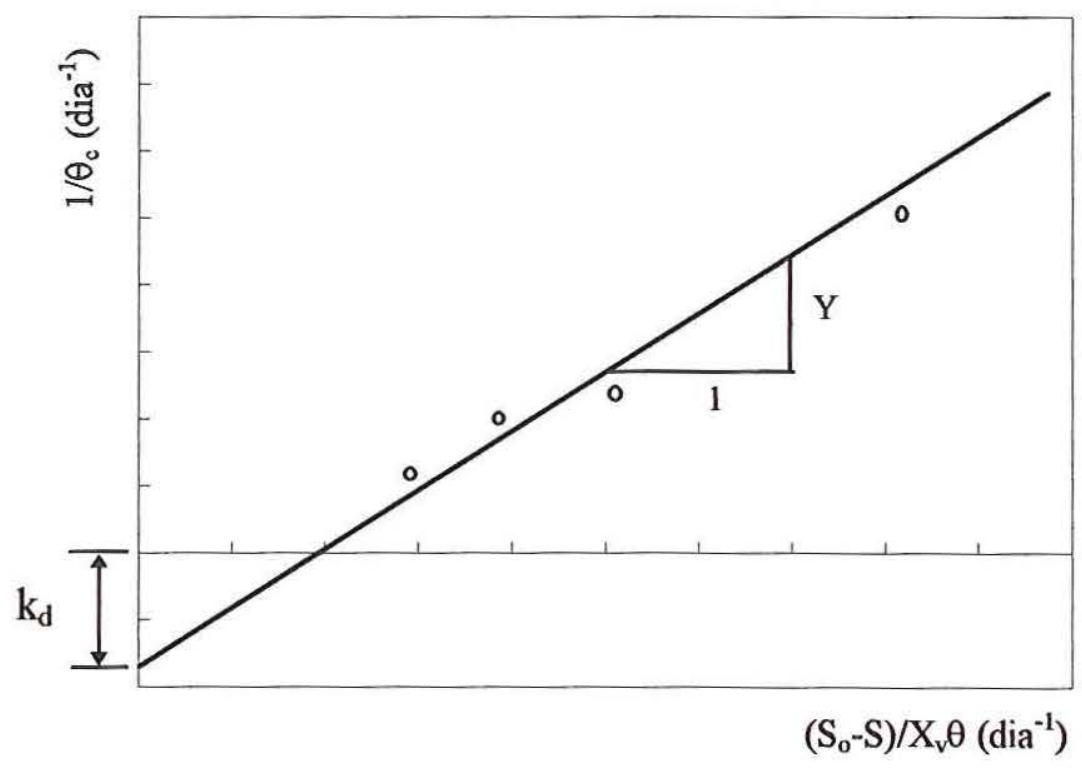

FIGURA 3.11 - Determinação gráfica de Y e k k (SANT’ANNA, 1982). 


\subsubsection{2 - Determinação dos coeficientes cinéticos em sistemas de} lodos ativados com recirculação de lodo

Para o sistema de lodos ativados, reatores em escala de laboratório de mistura completa, que apresentam recirculação de lodo, os coeficientes cinéticos $\mathrm{Y}, \mathrm{k}, \mathrm{K}_{\mathrm{s}}$ e $\mathrm{k}_{\mathrm{d}}$ podem ser determinados através de dados experimentais da mesma forma que para o sistema sem recirculação de lodo (METCALF \& EDDY, 1991).

Um vantagem apresentada pelos reatores com reciclo é que o tempo de retenção celular pode ser variado independente do tempo de detenção hidráulico. Uma desvantagem dos pequenos reatores de bancada com reciclo é a dificuldade de controle.

Os coeficientes cinéticos típicos para o processo de lodos ativados no tratamento de esgoto sanitário à temperatura de $20^{\circ} \mathrm{C}$ estão indicados na Tabela 3.10.

TABELA 3.10 - Coeficientes cinéticos típicos para o processo de lodos ativados (esgoto sanitário e temperatura de $20^{\circ} \mathrm{C}$ ).

\begin{tabular}{clcc}
\hline \multirow{2}{*}{ COEFICIENTE } & \multicolumn{1}{c}{ UNIDADE } & \multicolumn{2}{c}{ FALOR } \\
\cline { 3 - 4 } $\mathrm{k}$ & $\mathrm{dia}^{-1}$ & $2-10$ & TÍPICO \\
\hline $\mathrm{K}_{\mathrm{s}}$ & $\mathrm{mg} / \mathrm{L} \mathrm{DBO}_{5}$ & $25-100$ & 60 \\
& $\mathrm{mg} / \mathrm{L} \mathrm{DQO}$ & $15-70$ & 40 \\
$\mathrm{Y}$ & $\mathrm{mg} \mathrm{SSV} / \mathrm{mg} \mathrm{DBO}_{5}$ & $0,4-0,8$ & 0,6 \\
& $\mathrm{mg} \mathrm{SSV} / \mathrm{mg} \mathrm{DQO}^{*}$ & $0,25-0,4$ & 0,4 \\
& $\mathrm{dia}^{-1}$ & $0,025-0,075$ & 0,06 \\
\hline
\end{tabular}

Fonte: $\quad$ METCALF \& EDDY (1991)

* METCALF \& EDDY (1979) 


\subsubsection{3 - Determinação dos parâmetros a' e b'}

Com a determinação da quantidade de oxigênio necessária para os processos de lodos ativados e conhecendo-se as características dos equipamentos de aeração, dimensiona-se corretamente os sistemas de aeração.

KATO (1982) relata que o oxigênio consumido pelos microrganismos no processo de lodos ativados é composto pelo oxigênio utilizado na oxidação do substrato para obtenção de energia e na respiração endógena, representado respectivamente pelos parâmetros a' e b'.

A determinação experimental dos parâmetros a' e b' será apresentada conforme descrito em SANT'ANNA (1982).

A partir das eqs. (3.54) e (3.58) e definindo R como a taxa de utilização de oxigênio por unidade de volume, obtém-se a quantidade total de oxigênio requerido pela eq. (3.64).

$$
R \cdot V=a^{\prime}\left(S_{o}-S\right) Q+b^{\prime} X_{v} V
$$

$\mathrm{R}=$ taxa de utilização de oxigênio, isto é, a quantidade de oxigênio utilizado por dia e por unidade de volume do reator, $M \cdot L^{-3} \cdot \mathrm{T}^{-1}$

$\mathrm{V}=$ volume do tanque de aeração, $\mathrm{L}^{3}$

$\mathrm{a}^{\prime}=$ coeficiente de oxigênio necessário à remoção da parcela de substrato que é oxidado para a produção de energia ou fração de substrato removido utilizado para a produção de energia, adimensional

$\mathrm{S}_{\mathrm{o}}=$ concentração de substrato no afluente, em termos de DBO ou DQO bruta, M.L $\mathrm{L}^{-3}$

$\mathrm{S}=$ concentração de substrato no efluente, em termos de DBO ou DQO filtrada, $M \cdot L^{-3}$

$\mathrm{Q}=$ vazão afluente ao sistema, $\mathrm{L}^{3} \cdot \mathrm{T}^{-1}$

b' = coeficiente de oxigênio necessário à respiração endógena, $\mathrm{T}^{-1}$ 
$\mathrm{X}_{\mathrm{V}}=$ concentração de microrganismos no tanque de aeração, em termos SSVTA, M.L ${ }^{-3}$

Dividindo a eq. (3.64) por $\mathrm{X}_{\mathrm{v}} \mathrm{V}$, resulta:

$$
\frac{\mathrm{R}}{\mathrm{X}_{\mathrm{v}}}=\mathrm{a}^{\prime} \frac{\left(\mathrm{S}_{\mathrm{o}}-\mathrm{S}\right) \mathrm{Q}}{\mathrm{X}_{\mathrm{v}} \mathrm{V}}+\mathrm{b}^{\prime}
$$

ou

$$
\frac{\mathrm{R}}{\mathrm{X}_{\mathrm{v}}}=\mathrm{a}^{\prime} \frac{\left(\mathrm{S}_{\mathrm{o}}-\mathrm{S}\right)}{\mathrm{X}_{\mathrm{v}} \theta}+\mathrm{b}^{\prime}
$$

$\mathrm{R} / \mathrm{X}_{\mathrm{v}}=$ taxa específica de utilização de oxigênio, $\mathrm{T}^{-1}$

$\theta=$ tempo de detenção hidráulico, $\mathrm{T}$

Plotando-se em um par de eixos cartesianos os valores de $\frac{\mathrm{R}}{\mathrm{X}_{\mathrm{v}}}$ nas ordenadas e os de $\frac{S_{0}-S}{X_{v} \theta}$ nas abcissas, o valor de a' é dado pelo coeficiente angular da reta ajustada pelo método dos mínimos quadrados e o de b' pelo coeficiente linear, conforme mostra a Figura 3.12.

De acordo com as normas da NB-570 de 1990 da ABNT apud JORDÃO \& PESSOA (1995), independentemente do cálculo estimativo, a massa de oxigênio a ser fornecida deve ser igual ou superior a:

- 1,5 vezes a carga de DBO aplicada quando a idade do lodo for inferior a 18 dias ou a taxa de utilização de substrato for igual ou superior a $0,15 / \mathrm{d}$;

- 2,5 vezes a carga de DBO aplicada quando a idade do lodo for igual ou superior a 18 dias ou a taxa de utilização de substrato for igual ou inferior a $0,15 / \mathrm{d}$; 
- 3 vezes a carga de DBO aplicada quando for necessária a nitrificação do efluente e não se processa a denitrificação biológica.

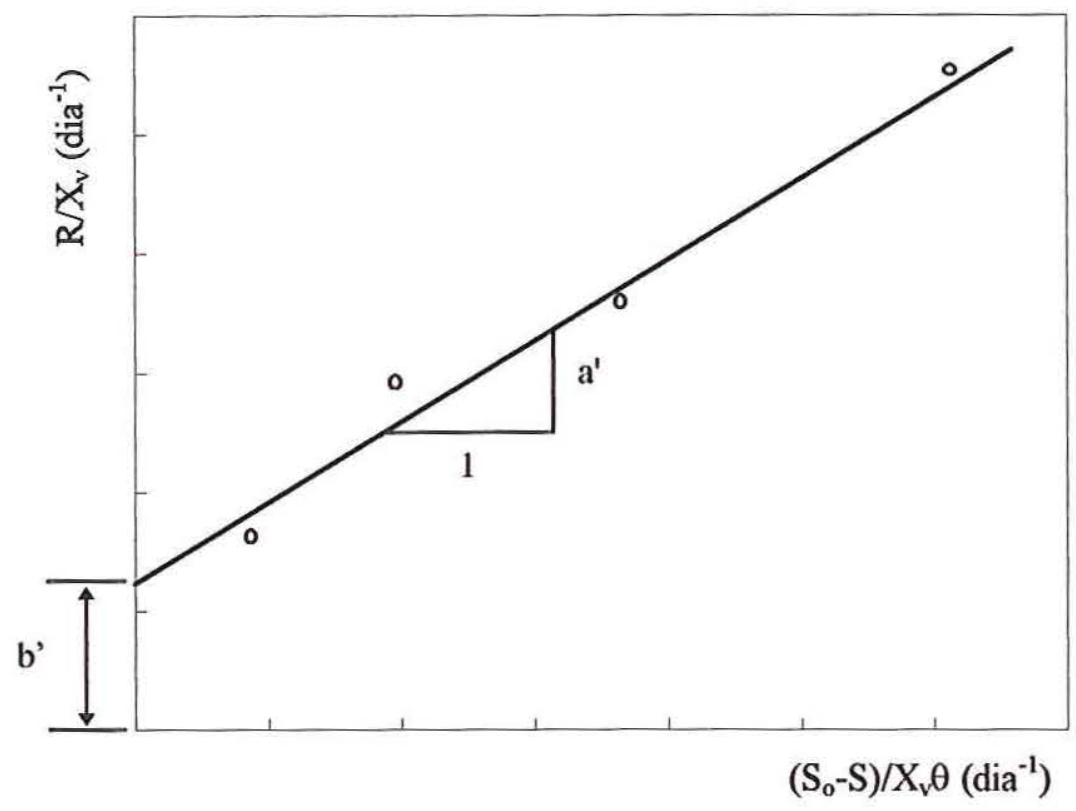

FIGURA 3.12 - Determinação gráfica dos parâmetros a' e b' (SANT'ANNA, 1982).

\subsubsection{4 - Determinação da taxa de utilização de oxigênio}

No processo de lodos ativados os microrganismos utilizam oxigênio como consomem alimento. A taxa com que eles utilizam oxigênio, denominada de taxa de utilização de oxigênio, pode ser utilizada como uma medida da atividade biológica. Alta taxa de utilização de oxigênio indica alta atividade biológica e baixa taxa indica baixa atividade biológica (METCALF \& EDDY, 1991).

A taxa de utilização de oxigênio tem sido usada nos sistemas de lodos ativados para ajudar no dimensionamento dos sistemas de aeração assim como 
avaliar "in situ" fatores que influenciam na eficiência de transferência de oxigênio (ALBERTSON \& DIGREGORIO apud CHIESA et al., 1990). A taxa de utilização tem sido similarmente usada para controle de taxas de retorno do lodo (HAAS apud CHIESA et al., 1990), para controle de descarte do lodo (BENEFIELD et al. apud CHIESA et al., 1990), para avaliar a resistência a toxicidade da água residuária (KING \& DUTKA e SUMMER et al. apud CHIESA et al., 1990), e estimar a viabilidade da biomassa (BLOK; HUANG; HUANG \& CHENG e WEDDLE \& JENKINS apud CHIESA et al., 1990). Posteriormente, a taxa de utilização de oxigênio tem sido usada como um parâmetro chave amplo na determinação de balanço de massa de oxigênio nos sistemas de lodos ativados (MINES \& SHERRAD e RANDALL et al. apud CHIESA et al., 1990).

$O$ valor da taxa de utilização de oxigênio - $R$, isto é, a quantidade de oxigênio utilizado por unidade de tempo e por unidade de volume do reator, pode ser determinado de uma amostra coletada no tanque de aeração, saturada com oxigênio dissolvido, medindo-se o decréscimo da concentração de oxigênio dissolvido com o tempo. Os valores desta taxa são tipicamente expressos em $\mathrm{mgO}_{2} / \mathrm{L}$.min, $\mathrm{mgO}_{2} /$ L.hora ou $\mathrm{mgO}_{2} / \mathrm{L}$.dia. As medidas de oxigênio dissolvido são realizadas com auxílio de um medidor de oxigênio dissolvido.

A determinação da taxa de utilização (ou consumo) de oxigênio dos microrganismos presentes nos processos de tratamentos aeróbios é de fundamental importância, embora persistam consideráveis limitações nos aspectos metodológicos empregados (SOUSA, 1996).

O procedimento experimental é o seguinte:

- encher o frasco com amostra coletada no tanque de aeração;

- adicionar oxigênio até atingir a saturação; 
- vedar bem o frasco com uma rolha que contenha o eletrodo do medidor de OD. Evitar a entrada de oxigênio e as bolhas de ar no interior do frasco;

- manter o conteúdo do frasco em constante agitação, com auxílio de um agitador magnético;

- fazer a leitura da redução da concentração de OD em intervalos de tempos regulares;

- com os valores obtidos, construir um gráfico das concentrações de OD contra o tempo, conforme a Figura 3.13;

- o valor da taxa de utilização de oxigênio é dado pelo coeficiente angular da reta obtida após regressão linear, pelo método dos mínimos quadrados.

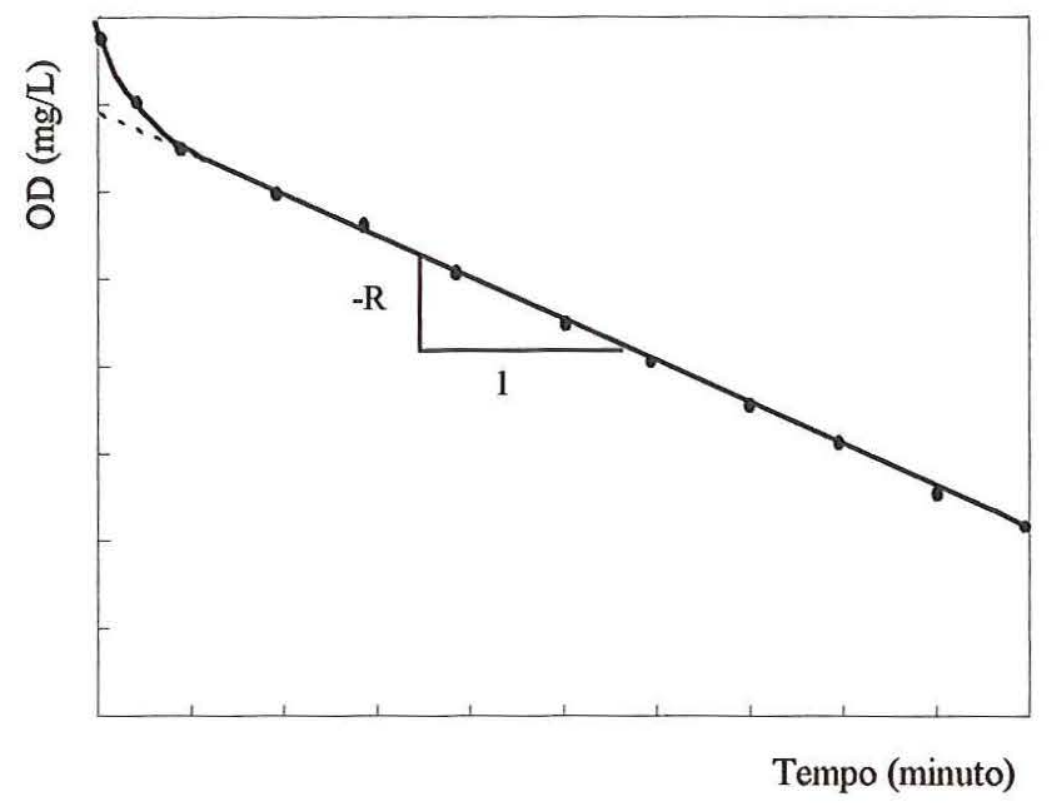

FIGURA 3.13 - Determinação gráfica da taxa de utilização de oxigênio (SANT'ANNA, 1982). 
3.4.5.5 - Determinação do coeficiente global de transferência de oxigênio

Conforme JORDÃO \& PESSOA (1995), a transferência de oxigênio do ar para o meio líquido processa-se em três fases:

- as moléculas de oxigênio do ar transferem-se para a superfície do líquido que se satura; forma-se uma interface composta de moléculas de água, sendo a extremidade negativa voltada para a fase gasosa e a positiva para a fase líquida;

- as moléculas de oxigênio atravessam esse interface, por difusão, no sentido do meio líquido;

- as moléculas de oxigênio são misturadas no meio líquido por difusão e convecção, sob agitação elevada.

A velocidade de transferência de oxigênio do ar para o meio líquido pode ser expressa pela seguinte expressão:

$$
\mathrm{N}=\mathrm{K}_{\mathrm{L}} \mathrm{A}\left(\mathrm{C}_{\mathrm{s}}-\mathrm{C}\right)
$$

$\mathrm{N}=$ massa de oxigênio transferido na unidade de tempo, $\mathrm{M} \cdot \mathrm{T}^{-1}$

$\mathrm{A}=$ superfície interfacial, $\mathrm{L}^{2}$

$\mathrm{C}_{\mathrm{s}}=$ concentração de saturação de oxigênio dissolvido, $\mathrm{M} \cdot \mathrm{L}^{-3}$

$\mathrm{C}=$ concentração do oxigênio dissolvido no meio líquido, $M \cdot \mathrm{L}^{-3}$

$\mathrm{K}_{\mathrm{L}}=$ coeficiente típico para a massa líquida (varia e cresce com a rapidez da mudança líquida e com o nível de agitação), $L . T^{-1}$

Exprimindo a eq. (3.67) em relação ao volume do sistema em que se processa a transferência tem-se: 


$$
\frac{\mathrm{N}}{\mathrm{V}_{\text {sistema }}}=\frac{\mathrm{dC}}{\mathrm{dt}}=\mathrm{K}_{\mathrm{L}} \frac{\mathrm{A}}{\mathrm{V}_{\text {sistema }}}\left(\mathrm{C}_{\mathrm{s}}-\mathrm{C}\right)
$$

$\mathrm{V}_{\text {sistema }}=$ volume do sistema em que ocorre a transferência, $\mathrm{L}^{3}$

Como na maioria dos sistemas o valor de A não pode ser determinado exatamente, adota-se a $=\mathrm{A} / \mathrm{V}_{\text {sistema }}$, e determina-se $\left(\mathrm{K}_{\mathrm{L}} \mathrm{a}\right)$ como um coeficiente global, resultando na seguinte equação:

$$
\frac{d C}{d t}=\left(K_{L} a\right) \cdot\left(C_{s}-C\right)
$$

ou

$$
\frac{d C}{\left(C_{s}-C\right)}=\left(K_{L} a\right) \cdot d t
$$

$\left(\mathrm{K}_{\mathrm{L}} \mathrm{a}\right)=$ coeficiente global de transferência de oxigênio, $\mathrm{T}^{-1}$

Integrando-se a eq. (3.70) obtém-se:

$$
\log \left(\mathrm{C}_{\mathrm{s}}-\mathrm{C}\right)=-\left(\mathrm{K}_{\mathrm{L}} \mathrm{a}\right) \cdot \mathrm{t}+\text { constante }
$$

Plotando-se em gráfico semilogarítmico, nas ordenadas $\log \left(\mathrm{C}_{\mathrm{s}}-\mathrm{C}\right)$ e nas abcissas o tempo t, o valor de $\left(\mathrm{K}_{\mathrm{L}} \mathrm{a}\right)$ é dado pelo coeficiente angular da reta obtida, após regressão linear pelo método dos mínimos quadrados.

$\mathrm{Na}$ determinação de $\left(\mathrm{K}_{\mathrm{L}} \mathrm{a}\right)$ para o conteúdo do tanque de aeração do processo de lodos ativados (meio com microrganismos ativos), deve-se considerar o consumo de oxigênio pelos microrganismos, conforme mostra a eq. (3.72).

$$
\frac{d C}{d t}=\left(K_{L} a\right) \cdot\left(C_{s e}-C\right)-R
$$


$\mathrm{R}=$ taxa de utilização de oxigênio, $M \cdot \mathrm{L}^{-3} \cdot \mathrm{T}^{-1}$

$\mathrm{C}_{\mathrm{se}}=$ concentração de saturação de oxigênio dissolvido para o esgoto, $M \cdot \mathrm{L}^{-3}$

Os valores de $\mathrm{dC} / \mathrm{dt}$ são obtidos a partir da curva construída com os dados experimentais, tomando-se as declividades das tangentes em diferentes pontos.

Nos processos de lodos ativados a determinação adequada da taxa de transferência de oxigênio é muito importante para projeto e economia operacional dos equipamentos de aeração (KIM et al., 1993).

von SPERLING (1993) conclui que nas estações de lodos ativados existentes, é fundamental o conhecimento da real capacidade de transferência de oxigênio, nas condições de operação. Os dados fornecidos pelos fabricantes podem diferir em muitos casos da taxa de transferência real, a qual é função da geometria do reator, do número e assentamento dos aeradores, de características específicas das águas residuárias e outros aspectos. Os testes realizados nas condições de operação necessitam do conhecimento da taxa de utilização de oxigênio. $O$ autor propõe a correção desta taxa quando as concentrações de oxigênio dissolvido no reator forem baixas a ponto de inibir o consumo de oxigênio pelos microrganismos.

\subsubsection{1 - Correções de $\left(K_{L} a\right)$}

\section{a) Características do esgoto}

O fator de correção $\alpha$ relaciona o oxigênio transferido nas condições reais, ou seja, esgoto a ser tratado, com o oxigênio transferido para a água limpa, tal que: 


$$
\left(\mathrm{K}_{\mathrm{L}} \mathrm{a}\right)_{\text {esgoto }}=\alpha \cdot\left(\mathrm{K}_{\mathrm{L}} \mathrm{a}\right)_{\mathrm{á} \text { gua }}
$$

$\begin{aligned} &\left(\mathrm{K}_{\mathrm{L}} \mathrm{a}\right)_{\text {esgoto }}= \text { coeficiente global de transferência de oxigênio para o esgoto, } \\ & \mathrm{T}^{-1}\end{aligned}$ $\left(\mathrm{K}_{\mathrm{L}} \mathrm{a}\right)_{\dot{a} \text { gů }}=$ coeficiente global de transferência de oxigênio para a água limpa, $\mathrm{T}^{-1}$

$\alpha=$ fator de correção, adimensional

O coeficiente $\alpha$ é influenciado por:

- temperatura;

- natureza da matéria orgânica e minerais contidos na massa líquida;

- intensidade de mistura do líquido (agitação);

- características do equipamento de agitação;

- profundidade da lâmina líquida e geometria do tanque de aeração.

O fator de correção sofre variação com a presença de efluentes industriais, diminui com a presença de detergentes e aumenta com a elevação da oxidação do esgoto e da turbulência. Para o esgoto sanitário situa-se entre 0,8 a 0,9 (JORDÃO \& PESSOA, 1995).

$\mathrm{O}$ valor de $\alpha$ varia de aproximadamente 0,3 a 1,2 . Valores típicos para equipamentos de aeração por difusão e mecânica situam-se na faixa de 0,4 a 0,8 e 0,6 a 1,2, respectivamente (METCALF \& EDDY, 1991).

A Tabela 3.11 apresenta valores típicos do fator de correção $\alpha$ obtidos para aeradores de superfície de baixa velocidade com vários tipos de águas residuárias. 
TABELA 3.11 - Valores típicos do fator de correção $\alpha$ obtidos para aeradores de superfície de baixa velocidade com vários tipos de águas residuárias.

\begin{tabular}{lcccccc}
\hline & \multicolumn{2}{c}{$\mathrm{DBO}_{5}(\mathrm{mg} / \mathrm{L})$} & & \multicolumn{2}{c}{$\alpha$} \\
\cline { 2 - 3 } \cline { 6 - 7 } Tipo de Água Residuária & Afluente & Efluente & & Afluente & Efluente \\
\hline Esgoto sanitário & 180 & 3 & & 0,82 & 0,98 \\
Indústria de papel e celulose & 187 & 50 & & 0,68 & 0,77 \\
Indústria de papel pardo & 150 a 300 & 37 a 48 & & 0,48 a 0,68 & 0,7 a 1,1 \\
Indústria farmacêutica & 4500 & 380 & & 1,65 a 2,15 & 0,75 a 0,83 \\
Indústria de fibra sintética & 5400 & 585 & & 1,88 a 3,25 & 1,04 a 2,65 \\
\hline
\end{tabular}

Fonte: METCALF \& EDDY (1991).

\section{b) Temperatura}

$\mathrm{O}$ coeficiente global $\left(\mathrm{K}_{\mathrm{L}} \mathrm{a}\right)$ aumenta com a elevação da temperatura, sendo a correção conforme a eq. (3.74).

$$
\left(\mathrm{K}_{\mathrm{L}} \mathrm{a}\right)_{\mathrm{T}}=\left(\mathrm{K}_{\mathrm{L}} \mathrm{a}\right)_{20} \times 1,024^{(\mathrm{T}-20)}
$$

$\left(\mathrm{K}_{\mathrm{L}} \mathrm{a}\right)_{\mathrm{T}}=$ coeficiente global de transferência de oxigênio para a temperatura $\mathrm{T} \mathrm{em}{ }^{\circ} \mathrm{C}, \mathrm{T}^{-1}$

$\left(\mathrm{K}_{\mathrm{L}} \mathrm{a}\right)_{20}=$ coeficiente global de transferência de oxigênio para $20^{\circ} \mathrm{C}, \mathrm{T}^{-1}$

$\mathrm{T}=$ temperatura, ${ }^{\circ} \mathrm{C}$

$1,024=$ valor tipicamente usado para aeração mecânica e por difusão 


\section{c) Pressão}

A eq. (3.75) fornece a correção da concentração de saturação de oxigênio dissolvido devido à variação de pressão barométrica.

$$
\mathrm{C}_{\mathrm{sPo}}=\mathrm{C}_{\mathrm{sPt}} \frac{\mathrm{P}_{\mathrm{o}}}{\mathrm{P}_{\mathrm{t}}}
$$

$\mathrm{C}_{\mathrm{sPo}}=$ concentração de saturação de oxigênio dissolvido à pressão padrão de $1 \mathrm{~atm}, 760 \mathrm{~mm} \mathrm{Hg}$ ou 101,33 kPa, M.L.-3

$\mathrm{C}_{\mathrm{sPt}}=$ concentração de saturação de oxigênio dissolvido à pressão de teste (barométrica local em atm, mm Hg ou kPa), M.L $L^{-3}$

$\mathrm{P}_{\mathrm{o}}=$ pressão atmosférica padrão de $1 \mathrm{~atm}, 760 \mathrm{~mm} \mathrm{Hg}$ ou $101,33 \mathrm{kPa}$

$\mathrm{P}_{\mathrm{t}}=$ pressão barométrica local, atm, $\mathrm{mm} \mathrm{Hg}$ ou $\mathrm{kPa}$

\subsubsection{2 - Determinação experimental de $\left(K_{L} a\right)$}

O procedimento experimental é o seguinte:

- colocar amostra num frasco;

- manter o conteúdo do frasco em constante agitação, com auxílio de um agitador magnético;

- adicionar sulfito de sódio até obtenção de uma concentração de oxigênio dissolvido igual a zero. Esta reação é catalisada com cloreto de cobalto (eq. (3.76)) ou fluxionando-se a amostra com gás nitrogênio. Estequiometricamente cada grama de oxigênio dissolvido consome 7,9 gramas de sulfito de sódio. Na prática é usado em excesso de 10 a $20 \%$ de sulfito de sódio. $\mathrm{O}$ cloreto de cobalto é adicionado à razão de 0,5 a $1,5 \mathrm{mg} / \mathrm{L}$; 


$$
\mathrm{Na}_{2} \mathrm{SO}_{3}+0,5 \mathrm{O}_{2} \stackrel{\mathrm{CoCl}_{2}}{\longrightarrow} \mathrm{Na}_{2} \mathrm{SO}_{4}
$$

- iniciar a reaeração;

- fazer as leituras do aumento da concentração de oxigênio dissolvido, com auxílio de um medidor de oxigênio dissolvido em intervalos de tempos regulares, até atingir a saturação;

- com os valores obtidos, construir um gráfico semilogarítmico de $\log \left(\mathrm{C}_{\mathrm{s}}-\mathrm{C}\right)$ contra o tempo;

- o valor do coefíciente global de transferência de oxigênio é dado pelo coeficiente angular da reta obtida após regressão linear, pelo método dos mínimos quadrados.

\subsubsection{6 - Índices do lodo}

O índice do lodo mais usualmente utilizado é o índice volumétrico do lodo, IVL, ou índice de Molham. É definido como o volume, em mililitros, ocupado por 1 grama de lodo seco após 30 minutos de sedimentação de uma amostra coletada na saída do tanque de aeração num cone ou cilindro graduados de 1 litro e é dado por:

$$
\mathrm{IVL}=\frac{\mathrm{VLS}-0,5 \mathrm{~h}(\mathrm{~mL} / \mathrm{L})}{\operatorname{SSTTA}(\mathrm{mg} / \mathrm{L})} \times 1000(\mathrm{~mL} / \mathrm{g})
$$

IVL = índice volumétrico do lodo, $\mathrm{M}^{-1} \cdot \mathrm{L}^{3}$

VLS $-0,5 \mathrm{~h}=$ volume de lodo (coletado no tanque de aeração) sedimentado em 0,5 hora num cone Imhoff, $L^{3} \cdot L^{-3}$

SSTTA = concentração de sólidos suspensos totais no tanque de aeração, M.L ${ }^{-3}$ 
O IVL, embora amplamente utilizado para avaliar a sedimentabilidade dos lodos ativados, apresenta diversas restrições, pois não representa um bom indicador da adensabilidade do lodo e também não representa uma medida real das características de sedimentação do lodo nos decantadores secundários nas estações de tratamento. Ainda, esse índice, que depende da concentração dos sólidos em suspensão, sofre influência da temperatura e das dimensões do recipiente utilizado no ensaio (ALÉM SOBRINHO, 1983).

Para DICK apud SANT'ANNA (1982), o IVL é um teste bastante conveniente para acompanhar o desempenho de uma estação de tratamento em particular. Porém ao se comparar valores de IVL de estações diferentes, provavelmente mediria propriedades diferentes de cada lodo.

Valores do IVL situados entre 40 e $150 \mathrm{~mL} / \mathrm{g}$ indicam lodo de boa qualidade e superiores a $200 \mathrm{~mL} / \mathrm{g}$, lodo de qualidade inferior (JORDÃO \& PESSOA, 1995).

Quando o IVL é superior a $150 \mathrm{~mL} / \mathrm{g}$ é indicativo de intumescimento. O lodo intumescido é ainda reconhecido pela presença de bactérias filamentosas no líquido límpido sobrejacente (IMHOFF \& IMHOFF, 1986).

Lodo com boas características de sedimentação pode apresentar IVL entre 50 e $100 \mathrm{~mL} / \mathrm{g}$; e lodo intumescido, com características inferiores de sedimentação, pode apresentar IVL superior a $400 \mathrm{~mL} / \mathrm{g}$ (NOVOTNY et al., 1989).

Um lodo bom apresenta IVL variando de 40 a $100 \mathrm{~mL} / \mathrm{g}$, mas quando excede $200 \mathrm{~mL} / \mathrm{g}$, o lodo possui características inferiores com tendência ao intumescimento (TEBBUT, 1992).

ECHEVERRÍA et al. (1992) concluiu que altas concentrações de gordura no afluente não exerceram influência sobre os valores do IVL, mas afetaram a depuração. 


\section{4 - METODOLOGIA}

\section{1 - Generalidades}

Para atender à legislação brasileira em vigor (Resolução CONAMA $\mathrm{N}_{-}^{\circ} 20$ de 18/06/86), com relação aos padrões de emissão de efluentes e de qualidade das águas dos corpos receptores, torna-se necessário em algumas situações, através de processos aeróbios, realizar o pós-tratamento de efluentes de reatores anaeróbios que recebem esgoto sanitário.

Com este objetivo, na presente pesquisa operou-se uma célula de aeração, que simula o processo de lodos ativados, em escala de laboratório, para dois tipos de ensaios: descontínuo e contínuo. Os ensaios em sistema descontínuo tiveram como finalidade verificar a viabilidade do tratamento, em que se analisou a biodegradabilidade da água residuária, e as condições para operar-se em sistema contínuo. O ensaio em sistema contínuo teve como principal enfoque a determinação dos coeficientes cinéticos.

\section{2 - Caracterização da água residuária}

A água residuária que foi tratada na célula de aeração era proveniente do efluente de um reator anaeróbio compartimentado (Figuras 4.1 e 4.2), composto por três câmaras e um filtro de pedregulho, com volume total (câmaras + filtro) de $11 \mathrm{~m}^{3}$ localizado junto ao Departamento de Hidráulica e Saneamento da EESC - USP. 


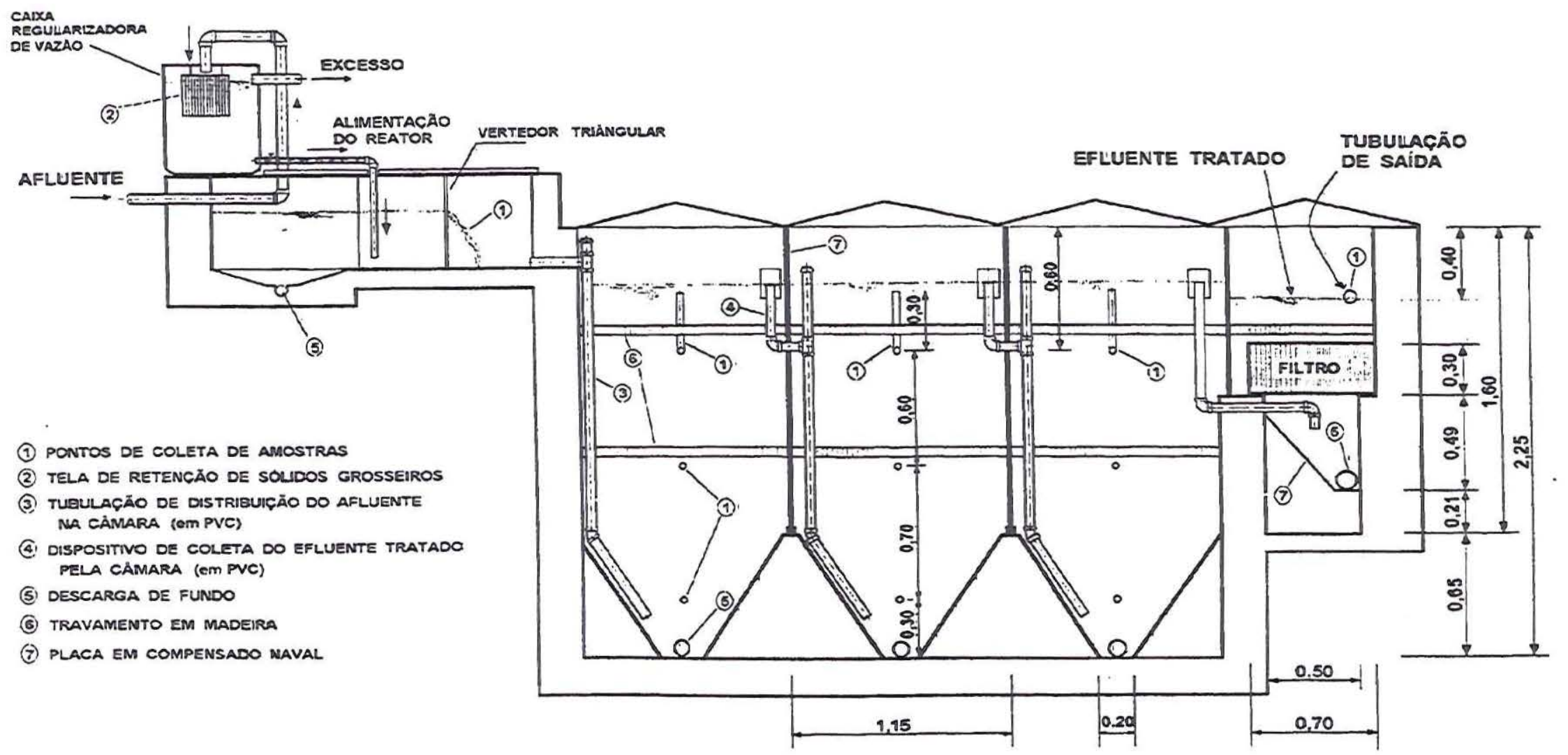

Obs: Este sistema é o mesmo utilizado durante a operação dos reatores de lodos ativados de forma descontínua e contínua, excluindo a caixa regularizadora de vazão e as tubulações dela provenientes.

FIGURA 4.1 - Corte longitudinal do Reator Anaeróbio Compartimentado (NOUR, 1996). 


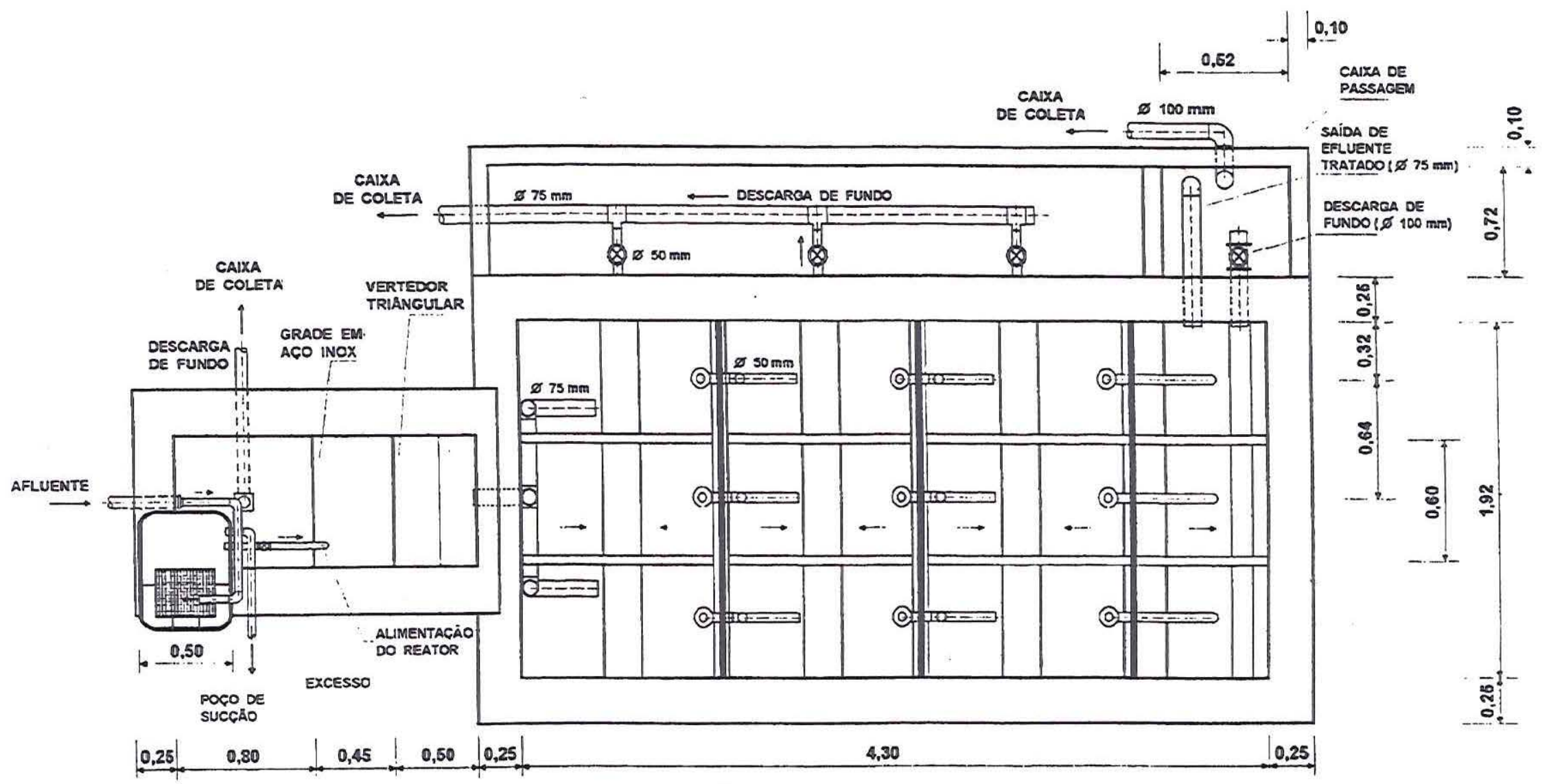

Obs: Este sistema é o mesmo utilizado durante a operação dos reatores de lodos ativados de forma descontínua e contínua, excluindo a caixa regularizadora de vazão e as tubulações dela provenientes.

FIGURA 4.2 - Planta baixa do Reator Anaeróbio Compartimentado (NOUR, 1996). 
Esse reator anaeróbio vem sendo utilizado para tratar esgoto sanitário, submetido a gradeamento preliminar, proveniente da rede coletora pública que passa pelo Campus da Escola de Engenharia de São Carlos. Como não foi operado regularmente durante os ensaios em sistema descontínuo e o ensaio em sistema contínuo, isto é, a vazão de entrada do esgoto sanitário bruto e os descartes do lodo das câmaras e do filtro de pedregulho não foram controlados, seu efluente apresentou grandes oscilações na qualidade. A vazão não foi controlada pela inexistência de um medidor de vazão, pois esse reator sofreu modificações após o encerramento de dois trabalhos, o mestrado da Silvia Cláudia Semensato Povinelli e o doutorado de Edson Aparecido Abdul Nour.

Todos os exames e análises para caracterização da água residuária, durante os ensaios em sistema descontínuo e o ensaio em sistema contínuo, foram realizados segundo os métodos descritos em Standard Methods for the Examination of Water and Wastewater (1992).

\section{3 - Ensaios em sistema descontínuo}

A finalidade dos ensaios em sistema descontínuo foi avaliar a biodegradabilidade do efluente do reator anaeróbio compartimentado que recebe esgoto sanitário.

\subsection{1 - Descrição da unidade experimental}

Os ensaios em sistema descontínuo foram realizados em uma unidade experimental, em escala de laboratório, constituída basicamente de uma célula de aeração e três aeradores de aquário, conforme Figura 4.3, que foi instalada 
no Laboratório de Saneamento do Departamento de Hidráulica e Saneamento da EESC - USP.

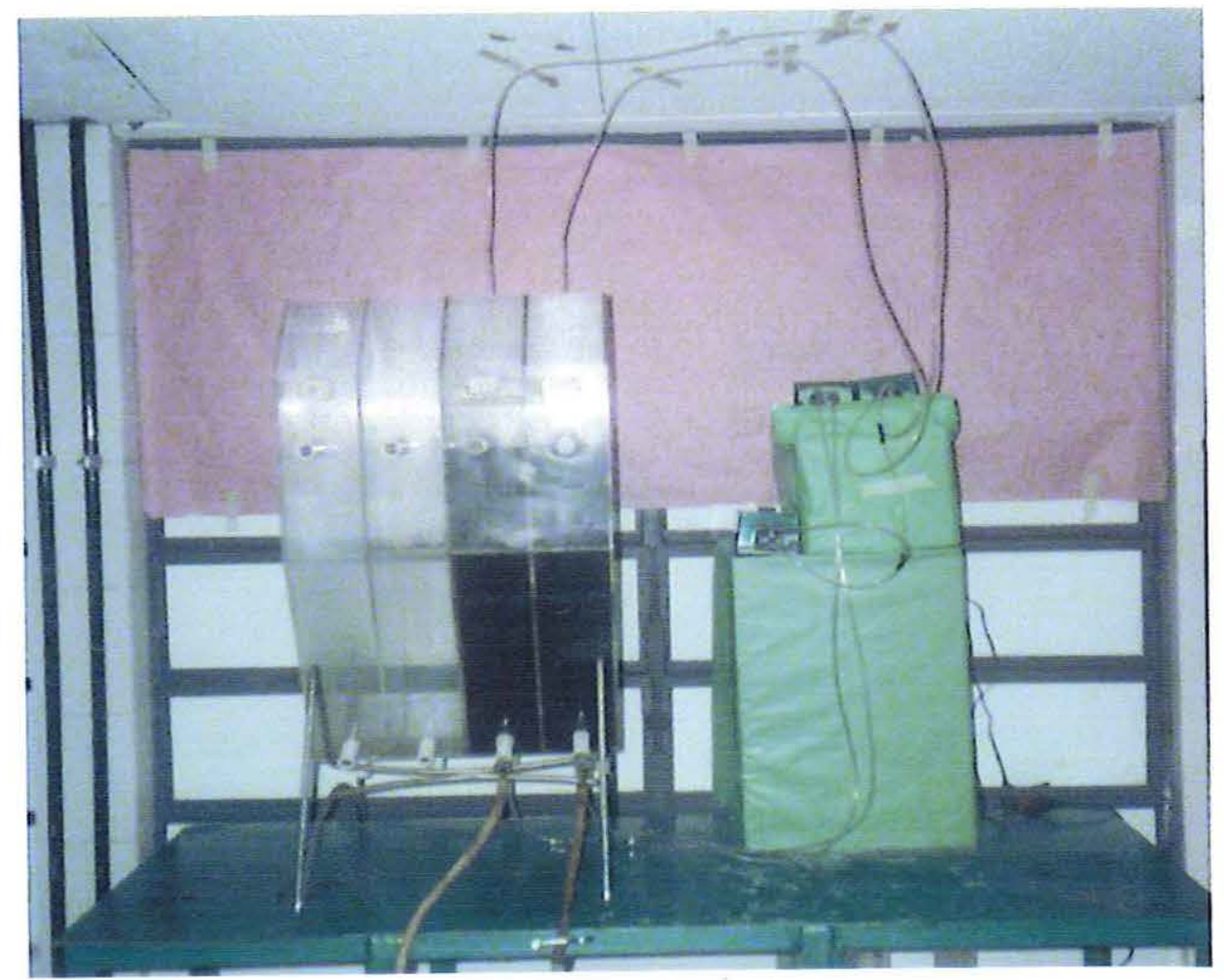

FIGURA 4.3 - Unidade experimental utilizada para os ensaios em sistema descontínuo.

A célula de aeração era construída em acrílico transparente e composta por quatro câmaras (reatores), com capacidade individual de aproximadamente 10,2 litros, conforme o esquema da Figura 4.4. Cada câmara possuía um tanque de aeração e um decantador justapostos, separados por uma cortina fixa, e com características conseqüentes do formato como retorno contínuo de lodo e regime de mistura completa. Na parte superior da câmara estava o ponto de coleta dos efluentes, que permaneceu vedado durante os ensaios em sistema 
descontínuo, e na parte inferior a entrada de ar e o dreno, que foi utilizado para coleta de amostras do tanque de aeração.

Nos ensaios em sistema descontínuo a totalidade da câmara funcionou como tanque de aeração, sendo necessários frascos de 5 litros em unidades independentes para desenvolverem o papel de decantador secundário.

A introdução de ar em cada câmara realizou-se por intermédio de aeradores de aquário com duas saídas, sendo a vazão de ar regulada para manter o teor de oxigênio dissolvido numa concentração superior a $2 \mathrm{mg} / \mathrm{L} \mathrm{e}$ uma boa agitação. A difusão de ar foi obtida com a utilização de pedras porosas. Quando houve interrupção no fornecimento de energia elétrica no laboratório, utilizaram-se aeradores de aquário com uma saída a pilha.

A célula de aeração utilizada neste trabalho é a mesma empregada em vários trabalhos desenvolvidos no Departamento de Hidráulica e Saneamento da EESC - USP, como BLUNDI (1982), KATO (1982), SANT'ANNA (1982), LARANJEIRA FILHO (1989), entre outros.

\subsection{2 - Aclimatação (Adaptação)}

Antes da realização dos ensaios, foi necessário aclimatar a água residuária às condições aeróbias de operação, pois o sistema anterior de tratamento era anaeróbio, sendo ainda pequena ou nula a presença de microrganismos aeróbios.

O lodo utilizado como inóculo na aclimatação da água residuária foi proveniente do sistema de tratamento por lodos ativados da indústria SOLVAY SAÚDE ANIMAL LTDA, localizada na cidade de Campinas, Estado de São Paulo, por apresentar boa sedimentabilidade e baixa concentração de microrganismos filamentosos. 


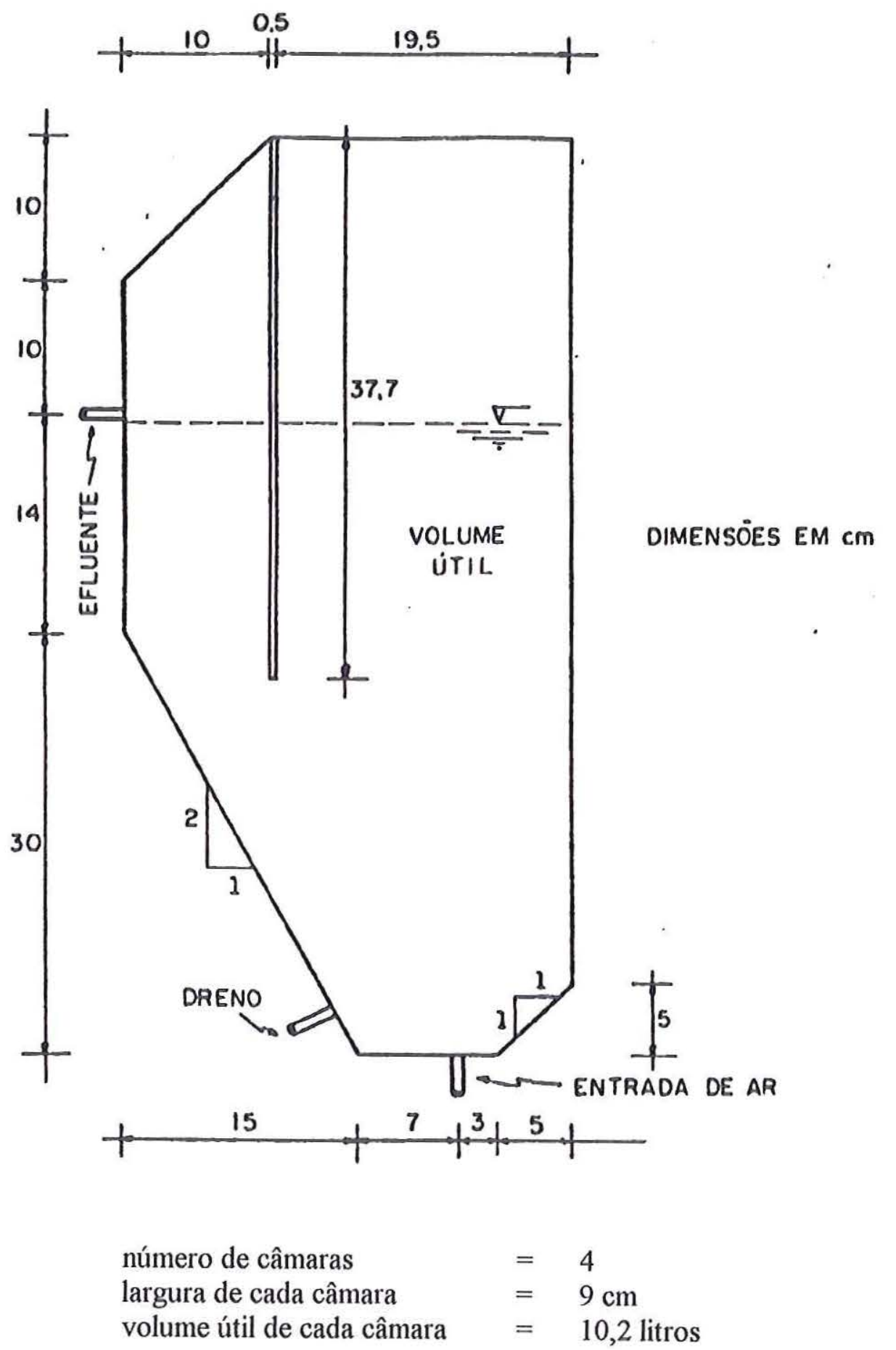

FIGURA 4.4 - Perfil da célula de aeração utilizada para os ensaios em sistema descontínuo e para o ensaio em sistema contínuo (KATO, 1982). 
A aclimatação foi iniciada em dois reatores, colocando-se em cada reator 1 litro de lodo e 9 litros de água residuária. Após 24 horas de aeração contínua, retiraram-se 5 litros do conteúdo de cada reator, descartando-se o sobrenadante após 2 horas de sedimentação. O lodo sedimentado foi retornado ao respectivo reator e completou-se o volume de 10 litros com água residuária. Este procedimento foi realizado por 7 dias, em que, por observações microscópicas, estimaram-se os microrganismos predominantes no meio baseando-se em anotações da estimativa visual relativa; verificou-se então que a água residuária estava aclimatada, ou seja, em condições de ser utilizada como semente, quando apresentou uma comunidade biológica diversificada, desde os primeiros microrganismos holofíticos (bactérias e protozoários flagelados), até organismos que caracterizam etapas mais avançadas de estabilização da matéria orgânica, como ciliados fixos, rotíferos e nematóides (POVINELLI et al., 1989).

Durante a fase de aclimatação, o $\mathrm{pH}$ foi mantido em valores próximos de 7 e o oxigênio dissolvido em concentração superior a $2 \mathrm{mg} / \mathrm{L}$. Estes dois parâmetros e a temperatura dos reatores foram determinados duas vezes ao dia, e coletou-se amostra dos tanques de aeração a cada 2 ou 3 dias para exames microscópicos.

\subsection{3 - Operação e controle}

Nos ensaios em sistema descontínuo, dois reatores denominados de R1 e R2 foram operados simultaneamente nas mesmas condições para comparação dos resultados obtidos.

Primeiramente, realizou-se um ensaio preliminar que permitiu verificar a viabilidade do tratamento. Em seguida, os dois reatores foram operados para os tempos de ciclo de 24,18 e 12 horas, com duração média de aproximadamente 20 dias por ensaio. $\mathrm{O}$ tempo de retenção celular de 10 dias 
foi mantido constante para todos os ensaios, excluindo o preliminar, que não apresentou controle. Para se iniciar os descartes diários do conteúdo dos reatores, analisou-se a concentração de sólidos suspensos voláteis no tanque de aeração e o tempo de ciclo utilizado. O tempo de ciclo foi composto pelo tempo de aeração e pelo de sedimentação. Não houve controle de temperatura.

Após a aclimatação, colocou-se em dois frascos de 5 litros o conteúdo de cada reator, sedimentou-se por duas horas, descartou-se o sobrenadante, retornou-se o lodo para o reator correspondente e completaram-se os 10 litros com o efluente do reator anaeróbio compartimentado.

No ensaio preliminar, após 22 horas de aeração contínua, retiraram-se 5 litros do conteúdo de cada reator, descartando-se o sobrenadante após 2 horas de sedimentação. O lodo sedimentado foi retornado ao respectivo reator e completou-se o volume de 10 litros com água residuária. A aeração dos 5 litros remanescentes nos reatores não foi interrompida. Este procedimento foi realizado até o término do ensaio. Não houve controle da idade do lodo.

Pela existência de um grande intervalo entre o ensaio preliminar e os ensaios em sistema descontínuo com tempos de ciclo de 24,18 e 12 horas, foi necessário repetir a aclimatação, pois não foi possível utilizar o lodo já aclimatado.

O procedimento utilizado para os ensaios em sistema descontínuo com tempos de ciclo de 24, 18 e 12 horas, após a aclimatação, foi o mesmo que o utilizado no ensaio preliminar.

Para o tempo de ciclo de 24 horas, aerou-se o resíduo por 22 horas, colocou-se o volume contido no interior dos dois reatores em frascos de 5 litros, sedimentou-se por 2 horas, descartou-se o sobrenadante e retornou-se o lodo ao respectivo reator. Este ciclo repetiu-se até terminar o ensaio, o mesmo acontecendo para o outros dois ensaios, mantendo-se constante o tempo de sedimentação, variando-se o tempo de aeração conforme o ciclo. Os descartes diários dos reatores para manutenção da idade do lodo foram realizados, em média, após uma semana do início do ensaio. 
Na Tabela 4.1 estão indicados os volumes descartados diariamente de cada reator para manutenção da idade do lodo e os tempos de aeração e de sedimentação para controle dos tempos de ciclo utilizados nos ensaios em sistema descontínuo com tempos de ciclo de 24, 18 e 12 horas.

TABELA 4.1 - Descartes diários para manutenção da idade do lodo e tempos de ciclo com seus respectivos tempos de aeração e de sedimentação, utilizados nos ensaios em sistema descontínuo.

\begin{tabular}{ccccccc}
\hline Reator & $\begin{array}{c}\text { Volume do } \\
\text { reator } \\
\text { (litro) }\end{array}$ & $\begin{array}{c}\theta_{c} \\
\text { (dia) }\end{array}$ & $\begin{array}{c}\text { Volume diário } \\
\text { descartado } \\
\text { (litro) }\end{array}$ & $\begin{array}{c}\text { Tempo de } \\
\text { ciclo } \\
\text { (hora) }\end{array}$ & $\begin{array}{c}\text { Tempo de } \\
\text { aeração } \\
\text { (hora) }\end{array}$ & $\begin{array}{c}\text { Tempo de } \\
\text { sedimentação } \\
\text { (hora) }\end{array}$ \\
\hline R1 & 10 & 10 & 1 & 24 & 22 & 2 \\
R2 & 10 & 10 & 1 & 24 & 22 & 2 \\
R1 & 10 & 10 & 1 & 18 & 16 & 2 \\
R2 & 10 & 10 & 1 & 18 & 16 & 2 \\
R1 & 10 & 10 & 1 & 12 & 10 & 2 \\
R2 & 10 & 10 & 1 & 12 & 10 & 2 \\
\hline
\end{tabular}

$\mathrm{O} \mathrm{pH}$ do reator foi determinado potenciometricamente por meio de $\mathrm{pH}-$ metro B272 da MICRONAL e ajustado, quando necessário, para valores próximos de 7 com adição de hidróxido de sódio $1 \mathrm{~N}$ ou ácido sulfúrico $1 \mathrm{~N}$.

As temperaturas dos reatores foram medidas com termômetro de mercúrio.

O oxigênio dissolvido foi obtido pelo método de Winkler modificado por Alsterberg, em que se procurou manter uma concentração superior a $2 \mathrm{mg} / \mathrm{L}$. As amostras foram coletadas pelo dreno após homogeneização do conteúdo dos reatores por meio de bastão, tomando-se cuidado para não aerar a amostra durante a coleta. 
Pelo fato da água residuária utilizada tratar-se de esgoto sanitário, não foi necessário corrigir as concentrações dos nutrientes nitrogênio e fósforo, pois os resultados de várias análises comprovaram as relações mínimas de $\mathrm{C}: \mathrm{N}: \mathrm{P}$, necessárias para crescimento dos microrganismos aeróbios.

A espuma formada nos tanques de aeração pela presença de detergentes na água residuária foi controlada com adição do Antiespumante P-116 da ADESOL PRODUTOS QUÍMICOS LTDA.

As paredes dos reatores foram escovadas três vezes por semana, para minimizar o acúmulo de lodo.

\subsection{4 - Análises e exames}

Durante a realização dos ensaios analisou-se: DBO bruta e filtrada, DQO bruta e filtrada, sólidos totais, sólidos fixos, sólidos voláteis, sólidos suspensos totais, sólidos suspensos fixos, sólidos suspensos voláteis, fosfato total, nitrogênio total Kjeldahl, nitrogênio amoniacal, sólidos sedimentáveis e índice volumétrico do lodo e realizou-se exame microscópico para avaliação do grau de estabilização do resíduo. Para monitoramento do sistema procurouse manter nos reatores o valor do $\mathrm{pH}$ próximo de 7 e a concentração de OD superior a $2 \mathrm{mg} / \mathrm{L}$ e mediu-se a temperatura no seu interior.

Todas as análises e exames utilizados para os ensaios em sistema descontínuo foram realizadas segundo os métodos descritos em Standard Methods for the Examination of Water and Wastewater (1992). Essas análises e exames foram realizadas no Laboratório de Saneamento do Departamento de Hidráulica e Saneamento da EESC-USP.

Com o auxílio de um fotomicroscópico óptico OLYMPUS, modelo BH2, acompanhou-se a dinâmica das populações presentes nos reatores através de exames microscópicos, quando foram estimados os microrganismos baseandose em estimativa visual relativa, com anotações dos predominantes no meio. 
Para acompanhamento da evolução dos microrganismos também foram tiradas fotos de algumas amostras de lodo biológico.

Os volumes de amostras necessários para as diluições, utilizados na determinação da DBO filtrada e DQO filtrada, foram submetidos a filtração a vácuo em membrana GF-92 de $47 \mathrm{~mm}$ de diâmetro e poros com abertura de $1,2 \mu \mathrm{m}$.

$\mathrm{Na}$ determinação do IVL, utilizaram-se os volumes descartados diariamente dos tanques de aeração para manutenção da idade do lodo.

Na Tabela 4.2 os parâmetros analisados estão divididos conforme o método das análises e exames utilizados nos ensaios em sistema descontínuo.

TABELA 4.2 - Divisão dos parâmetros analisados conforme o método das análises e exames utilizados nos ensaios em sistema descontínuo.

Método utilizado

\begin{tabular}{lc}
\hline Temperatura & Termométrico \\
$\mathrm{pH}$ & Potenciométrico \\
$\mathrm{OD}, \mathrm{DBO}$ bruta, DBO filtrada, NTK e N-amoniacal & Titulométrico \\
$\mathrm{DQO}$ bruta, DQO filtrada e $\mathrm{PO}_{4}^{3-}$ & Espectrofotométrico \\
$\mathrm{ST}, \mathrm{SF}, \mathrm{SV}, \mathrm{SST}, \mathrm{SSF}, \mathrm{SSV}, \mathrm{SSed} \mathrm{e} \mathrm{IVL}$ & Gravimétrico \\
Exame microscópico & Microscópico \\
\hline
\end{tabular}

Os parâmetros analisados e a frequiência média das análises e exames que foram realizados nos ensaios em sistema descontínuo estão mostrados na Tabela 4.3. 
TABELA 4.3 - Parâmetros analisados e freqüência média das análises e exames realizados nos ensaios em sistema descontínuo.

\begin{tabular}{|c|c|c|c|c|}
\hline \multirow[b]{2}{*}{$\begin{array}{l}\text { Parâmetro } \\
\text { analisado }\end{array}$} & \multirow[b]{2}{*}{$\begin{array}{l}\text { Freqüência da análise } \\
\qquad \text { ( } 2 \text { reatores) }\end{array}$} & \multicolumn{3}{|c|}{ Pontos de coleta } \\
\hline & & $\begin{array}{c}\text { Resíduo } \\
\text { Bruto }\end{array}$ & $\begin{array}{l}\text { Tanque de } \\
\text { Aeração }\end{array}$ & $\begin{array}{l}\text { Resíduo } \\
\text { Tratado }\end{array}$ \\
\hline $\mathrm{T}\left({ }^{\circ} \mathrm{C}\right)$ & $2 \times$ por dia & & $\mathrm{X}$ & \\
\hline pH (adimensional) & $2 \times$ por dia & $\mathrm{X}$ & $\mathrm{X}$ & $\mathrm{X}$ \\
\hline $\mathrm{OD}(\mathrm{mg} / \mathrm{L})$ & $1 \times$ por dia & & $\mathrm{X}$ & \\
\hline DBO bruta $(\mathrm{mg} / \mathrm{L})$ & $2 \times$ por semana & $\mathrm{X}$ & & $\mathrm{X}$ \\
\hline DBO filtrada $(\mathrm{mg} / \mathrm{L})$ & $2 \mathrm{x}$ por semana & $\mathrm{X}$ & & $\mathrm{X}$ \\
\hline DQO bruta $(\mathrm{mg} / \mathrm{L})$ & $2 \times$ por semana & $\mathrm{X}$ & & $\mathrm{X}$ \\
\hline DQO filtrada $(\mathrm{mg} / \mathrm{L})$ & $2 \times$ por semana & $\mathrm{X}$ & & $\mathrm{X}$ \\
\hline $\mathrm{ST}(\mathrm{mg} / \mathrm{L})$ & $2 \times$ por semana & $\mathrm{X}$ & & $\mathrm{X}$ \\
\hline $\mathrm{SF}(\mathrm{mg} / \mathrm{L})$ & $2 \times$ por semana & $\mathrm{X}$ & & $\mathrm{X}$ \\
\hline $\mathrm{SV}(\mathrm{mg} / \mathrm{L})$ & $2 \times$ por semana & $\mathrm{X}$ & & $\mathrm{X}$ \\
\hline $\mathrm{SST}(\mathrm{mg} / \mathrm{L})$ & $2 \times$ por semana & $\mathrm{X}$ & $\mathrm{X}$ & $\mathrm{X}$ \\
\hline $\mathrm{SSF}(\mathrm{mg} / \mathrm{L})$ & $2 \times$ por semana & $\mathrm{X}$ & $\mathrm{X}$ & $\mathrm{X}$ \\
\hline $\operatorname{SSV}(\mathrm{mg} / \mathrm{L})$ & $2 \times$ por semana & $\mathrm{X}$ & $\mathrm{X}$ & $\mathrm{x}$ \\
\hline $\mathrm{PO}_{4}^{3-}(\mathrm{mg} / \mathrm{L})$ & $1 \times$ por semana & $\mathrm{X}$ & & $\mathrm{x}$ \\
\hline NTK (mg/L) & $1 \times$ por semana & $\mathrm{X}$ & & $\mathrm{X}$ \\
\hline $\mathrm{N}$-amoniacal (mg/L) & $1 \times$ por semana & $\mathrm{X}$ & & $\mathrm{X}$ \\
\hline $\operatorname{SSed}(\mathrm{mL} / \mathrm{L}) *$ & $2 \times$ por semana & $X$ & $\mathrm{X}$ & $\mathrm{X}$ \\
\hline $\operatorname{IVL}(\mathrm{mL} / \mathrm{g})$ & $2 \times$ por semana & & $\mathrm{X}$ & \\
\hline Exame microscópico & $1 \times$ por semana & & $\mathrm{X}$ & \\
\hline
\end{tabular}

* Para amostra coletada no tanque de aeração denominou-se de volume de lodo sedimentado - VLS. 


\section{4 - Ensaio em sistema contínuo}

O ensaio em sistema contínuo teve as seguintes finalidades: determinar os coeficientes cinéticos, os parâmetros a' e b', e para cada idade do lodo utilizada, a taxa de utilização de oxigênio e o coefíciente $\alpha$.

\subsection{1 - Descrição da unidade experimental}

Para realização do ensaio em sistema contínuo utilizou-se uma unidade experimental, em escala de laboratório, conforme Figuras 4.5 e 4.6, que também foi instalada no Laboratório de Saneamento do Departamento de Hidráulica e Saneamento da EESC-USP.

O esquema da unidade experimental está mostrado na Figura 4.7. Essa unidade experimental consistiu basicamente de uma célula de aeração construída em acrílico transparente e composta por quatro câmaras (reatores), a mesma utilizada para os ensaios em sistema descontínuo, duas bombas dosadoras, um tanque de alimentação e um compressor de ar.

Um sistema de lodos ativados em escala de laboratório é representado por esta unidade experimental, mas como cada câmara possui um tanque de aeração e um decantador secundário justapostos, constitui uma forma simplificada de disposição em relação à forma freqüentemente encontrada nos processos de lodos ativados convencionais.

$\mathrm{O}$ tanque de alimentação consistiu de uma caixa de cimento amianto de 150 litros, provido de agitador para homogeneizar a água residuária e evitar uma sedimentação excessiva. $\mathrm{O}$ agitador era formando por: eixo em aço inóx com 4 hastes também em aço inóx distribuídas em forma de cruz na extremidade inferior e rolamento na superior, redutor da marca CESTARI (redução de aproximadamente 80 vezes), motor monofásico da marca WEG $(1730 \mathrm{rpm})$ e sistema de polia e correia. Esse agitador trabalhou com rotação 
de aproximadamente $40 \mathrm{rpm}$ durante todo o ensaio. Também foram instalados no tanque um registro de fundo para descarga e um suporte em aço inóx em forma de grade para prender as 4 mangueiras de silicone provenientes das bombas dosadoras.

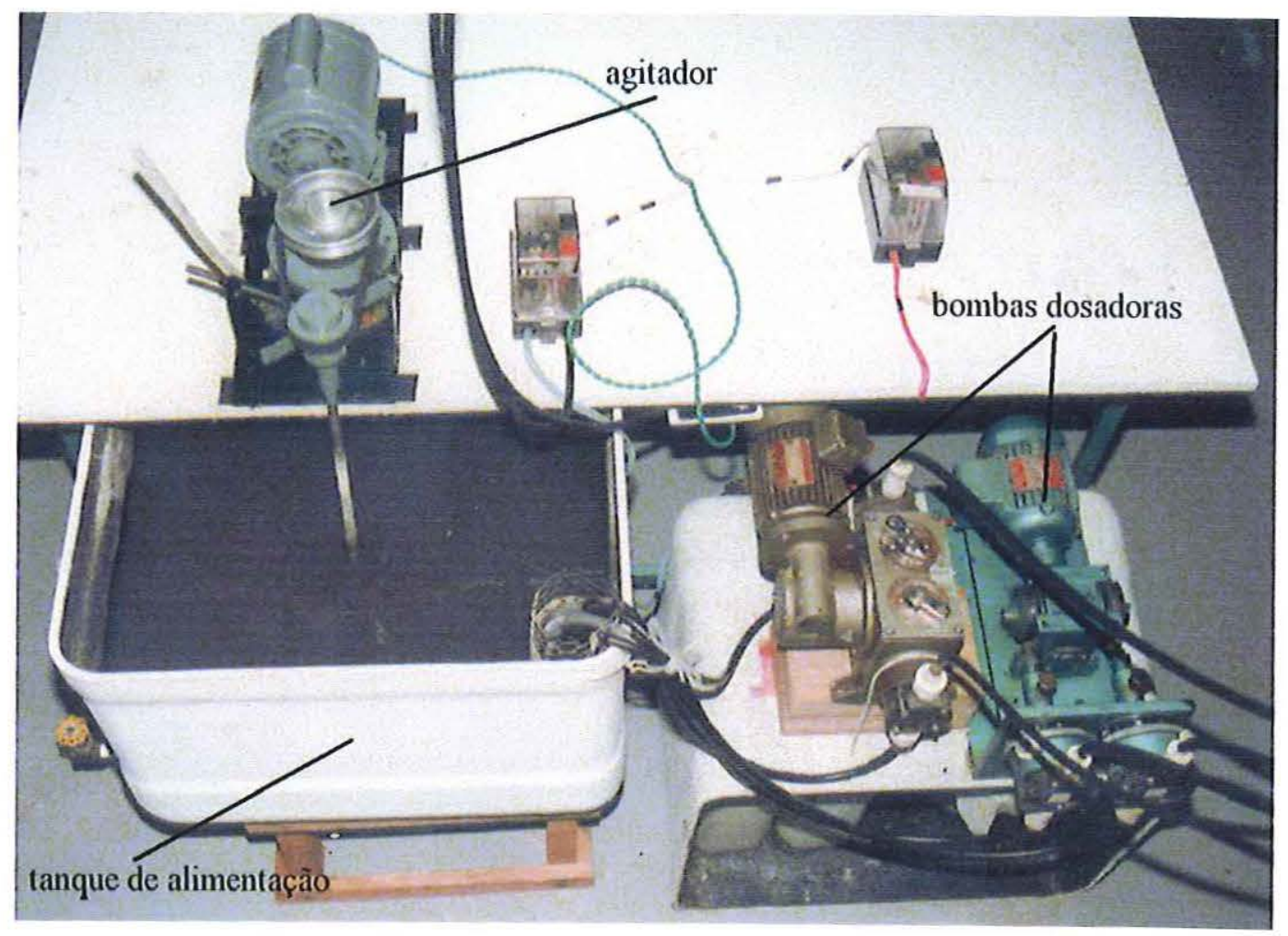

FIGURA 4.5 - Tanque de alimentação provido de agitador e bombas dosadoras utilizadas para alimentação dos reatores durante o ensaio em sistema contínuo.

A alimentação dos reatores foi feita por duas bombas dosadoras, cada uma com duas cabeças, uma FMC FILSAN e outra ECOSAN, que bombeavam e conduziam continuamente a água residuária do tanque de alimentação à parte superior dos tanques de aeração, por meio de mangueiras de silicone. 


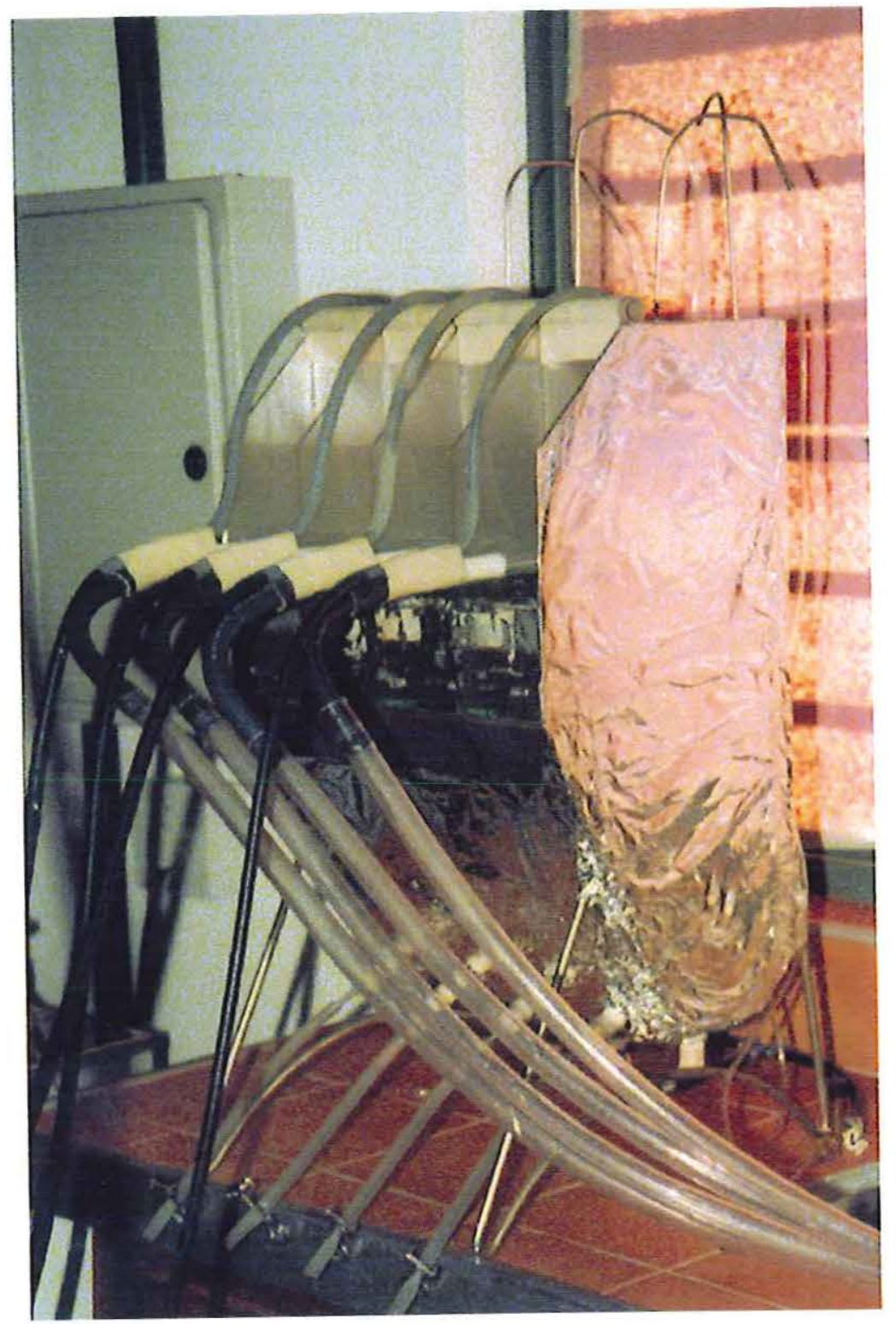

FIGURA 4.6 - Célula de aeração utilizada durante o ensaio em sistema contínuo.

O efluente tratado foi conduzido por mangueiras plásticas (cristal), dos extravasores posicionados na parte superior dos decantadores, para a rede de esgoto. 


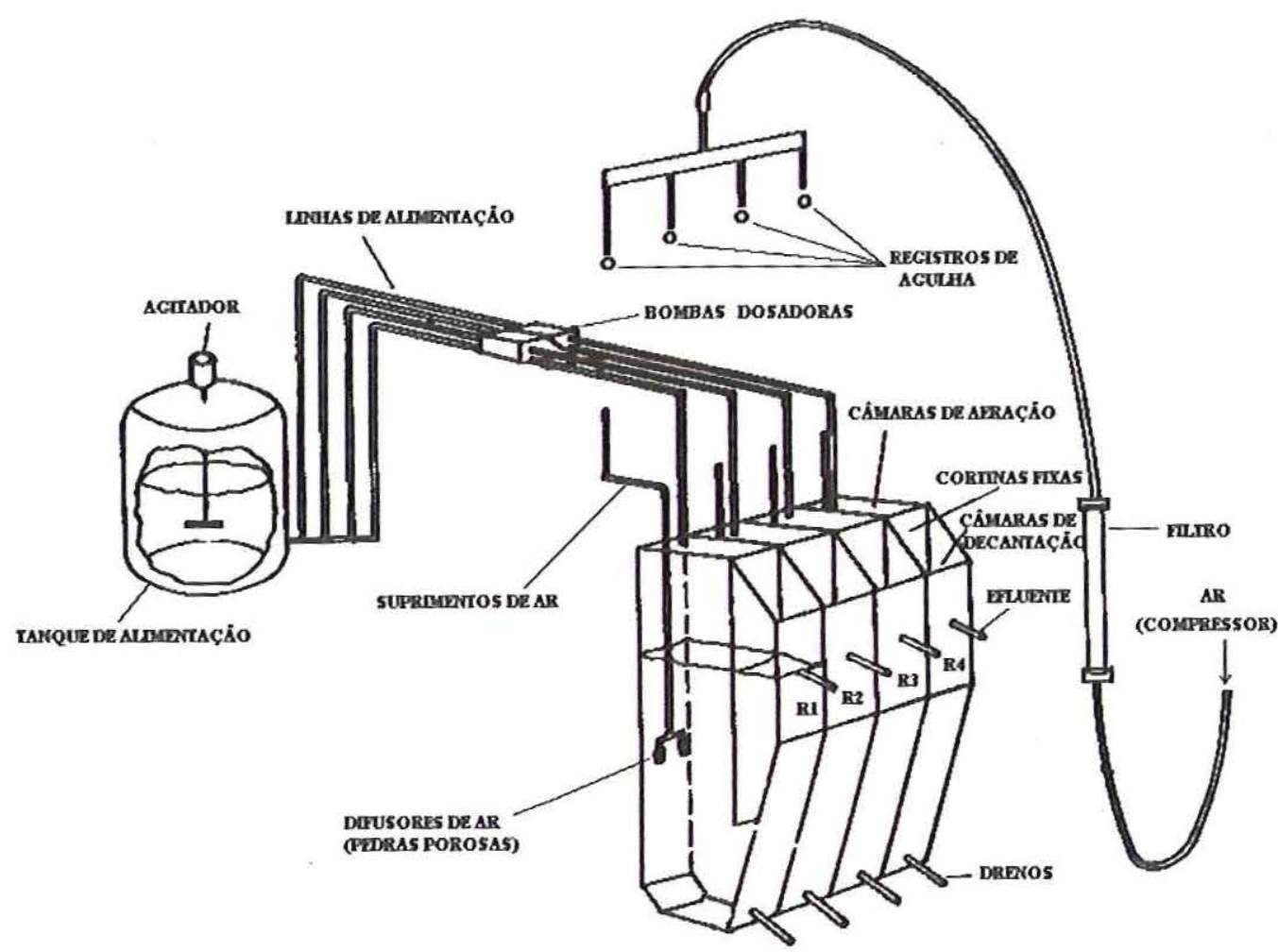

FIGURA 4.7 - Esquema da unidade experimental utilizada para o ensaio em sistema contínuo (KATO, 1982).

$\mathrm{O}$ ar fornecido pelo compressor PRIMAX foi introduzido constantemente nos tanques de aeração após passar por um filtro, que também serviu como controlador da vazão total de ar. Para melhor controle da vazão, utilizou-se registro de agulha na tubulação de alimentação de cada câmara. Procurou-se manter o teor de oxigênio dissolvido em concentração superior a $2 \mathrm{mg} / \mathrm{L}$ e agitação com intensidade suficiente para manter os sólidos em suspensão no tanque de aeração, sem ocasionar perturbações no decantador secundário. A aeração no interior do reator foi obtida com uma entrada de ar posicionada na parte inferior do tanque de aeração, que possuía uma conexão de vidro com duas derivações. A difusão de ar foi feita com a utilização de pedras porosas. Quando houve interrupção no fornecimento energia elétrica no 
laboratório, utilizaram-se para cada reator dois aeradores de aquário a pilha, cada um com uma saída.

Para evitar o crescimento das algas, envolveu-se a célula de aeração com papel alumínio e as mangueiras de silicone de alimentação com fita adesiva opaca de cor preta (fita-isolante).

\subsection{2 - Aclimatação (Adaptação)}

Como houve um grande intervalo de tempo entre os ensaios em sistema descontínuo e o ensaio em sistema contínuo, não foi possível aproveitar o lodo, já aclimatado, sendo necessário repetir a aclimatação.

O lodo do sistema de tratamento por lagoa aerada do curtume PODBOI, localizado na cidade de Leme, Estado de São Paulo, foi utilizado como inóculo por apresentar boas condições de sedimentabilidade e baixa concentração de microrganismos filamentosos.

A aclimatação da água residuária foi realizada simultaneamente nos quatro reatores por um período de 5 dias, utilizando-se a mesma metodologia do sistema descontínuo. Nesse período, manteve-se o $\mathrm{pH}$ em valores próximos de 7 e o oxigênio dissolvido em concentrações acima de $2 \mathrm{mg} / \mathrm{L}$. Esses dois parâmetros e a temperatura dos reatores foram determinados duas vezes ao dia, e a cada dois dias foram feitos exames microscópicos.

\subsection{3 - Operação e controle}

No ensaio em sistema contínuo, quatro reatores denominados de R1, R2, R3 e R4 foram operados simultaneamente com os tempos de retenção celular de 5, 10, 15 e 20 dias, respectivamente, por 35 dias. 
A vazão de alimentação de cada reator foi de aproximadamente 30,6L/dia $(1275 \mathrm{~mL} / \mathrm{h})$, com a finalidade de manter o tempo de detenção hidráulico próximo de 8 horas.

O controle do processo de lodos ativados foi feito através da idade do lodo conforme mostrado na Tabela 4.4, em que se descartava diariamente determinado volume de cada reator, dependendo da idade estabelecida. Com a finalidade de evitar o desequilíbrio nos reatores, os descartes diários do reator $\mathrm{R} 1$ foram divididos em 3 parcelas iguais, em intervalos de aproximadamente 8 horas e do reator R2 em 2 duas parcelas iguais, sendo uma pela manhã e outra pela tarde. Para os reatores R3 e R4 os descartes diários foram únicos e realizados pela manhã. Antes dos descartes, limpavam-se as paredes dos reatores e agitava-se o seu interior para melhor homogeneização e tomava-se cuidado para não perder lodo na saída do efluente.

TABELA 4.4 - Descartes diários para manutenção da idade do lodo nos reatores.

\begin{tabular}{ccccccc}
\hline Reator & Volume do & Idade do & Descarte & \multicolumn{3}{c}{ Descartes Parciais $(\mathrm{mL})$} \\
\cline { 5 - 7 } & reator (litro) & lodo (dia) & diário $(\mathrm{mL})$ & Manhã & Tarde & Noite \\
\hline R1 & 10,2 & 5 & 2040 & 680 & 680 & 680 \\
R2 & 10,2 & 10 & 1020 & 510 & 510 & --- \\
R3 & 10,2 & 15 & 680 & 680 & --- & --- \\
R4 & 10,2 & 20 & 510 & 510 & --- & --- \\
\hline
\end{tabular}

O tanque de alimentação era reabastecido duas vezes ao dia, em intervalos de aproximadamente 12 horas, com a água residuária coletada em frascos de 5 litros na saída do reator anaeróbio compartimentado e passado por peneira de nylon com malha de abertura de aproximadamente $1 \mathrm{~mm}$, para remoção de sólidos grosseiros. Com a finalidade de evitar o acúmulo de

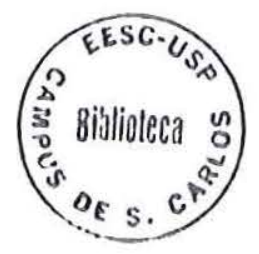


material aderido nas paredes e no fundo, o tanque era lavado uma vez por semana.

As paredes dos reatores eram escovadas 2 vezes por dia para minimizar o acúmulo de lodo, tomando-se cuidado para não perder lodo na saída do efluente.

As bombas dosadoras utilizadas para bombear a água residuária, assim como as mangueiras de silicone, eram limpas uma vez por semana, para evitar o acúmulo de material e grandes variações nas vazões.

A espuma formada nos tanques de aeração pela presença de detergentes na água residuária foi controlada com adição de antiespumante, quando o tanque de alimentação era reabastecido. $\mathrm{O}$ antiespumante utilizado foi $\mathrm{o}$ mesmo do sistema descontínuo.

As vazões das duas bombas dosadoras foram aferidas duas vezes ao dia, em intervalos de aproximadamente 12 horas. Para a aferição coletava-se na entrada do tanque de aeração, numa proveta de $100 \mathrm{~mL}$, o volume corresponde a 4 minutos, sendo esse volume retornado ao respectivo reator.

As medidas de OD foram obtidas com a introdução da sonda do medidor de oxigênio dissolvido dentro dos tanques de aeração duas vezes ao dia, em intervalos de aproximadamente 12 horas, em que se procurou manter a concentração em valores superiores de $2 \mathrm{mg} / \mathrm{L}$. A aeração foi regulada com o objetivo de obter-se uma aproximação de mistura completa no tanque de aeração sem ocasionar turbulências no decantador, minimizando assim a perda de lodo no efluente. $\mathrm{O}$ medidor de oxigênio dissolvido utilizado foi da marca HORIBA, modelo $12 \mathrm{M}$.

Para manter o pH do tanque de aeração em torno de 7, conservou-se o $\mathrm{pH}$ do tanque de alimentação próximo a 8, ajustando-se, quando necessário, com auxílio de solução de hidróxido de cálcio. Os valores do $\mathrm{pH}$ foram determinados potenciometricamente através do pH-metro B272 da MICRONAL duas vezes ao dia, em intervalos de aproximadamente 12 horas. 
Como a unidade experimental foi operada em condições ambientais, a temperatura do tanque de aeração e a temperatura ambiente foram medidas duas vezes ao dia, em intervalos de aproximadamente 12 horas. As temperaturas foram determinadas pelo mesmo oxímetro utilizado para medir o oxigênio dissolvido, que era provido de termômetro digital.

Como a água residuária utilizada para alimentação dos reatores foi a mesma dos ensaios em sistema descontínuo, não foi necessário corrigir as concentrações dos nutrientes (nitrogênio e fósforo).

\subsection{4 - Análises e exames}

Durante a realização do ensaio em sistema contínuo analisou-se: DBO bruta e filtrada, DQO bruta e filtrada, sólidos totais, sólidos fixos, sólidos voláteis, sólidos suspensos totais, sólidos suspensos fixos, sólidos suspensos voláteis, fosfato total, nitrogênio total Kjeldahl e amoniacal, nitrito, nitrato, sólidos sedimentáveis e índice volumétrico do lodo, sendo também realizado exame microscópico para avaliação do grau de estabilização do resíduo. Para monitoramento do sistema procurou-se manter nos tanques de aeração o valor do $\mathrm{pH}$ próximo de 7, a concentração de OD superior a $2 \mathrm{mg} / \mathrm{L}$ e a vazão de alimentação próxima de $30,6 \mathrm{~L} /$ dia em cada reator, medindo-se a temperatura ambiente e dos reatores.

Como no sistema descontínuo, todas as análises e exames utilizados seguiram os métodos descritos em Standard Methods for the Examination of Water and Wastewater (1992), exceto a determinação de nitrito, que seguiu o método recomendado por MACKERETH et. al (1978). As análises e exames foram feitas no Laboratório de Saneamento do Departamento de Hidráulica e Saneamento da EESC-USP.

O oxigênio dissolvido para determinação da $\mathrm{DBO}$ foi obtido com medidor de OD (oxímetro) da marca ANALION, modelo OX-901. 
Acompanhou-se a dinâmica das populações presentes nos reatores através de exames microscópicos, quando se estimou os microrganismos predominantes no meio, baseando-se em estimativa visual relativa e fotografaram-se algumas amostras de lodo biológico dos reatores com o fotomicroscópico óptico OLYMPUS, modelo BH-2.

Os volumes de amostras necessários para as diluições utilizadas na determinação da DBO e DQO filtrada foram obtidos pelo mesmo procedimento usado no sistema descontínuo.

As amostras de água residuária utilizadas nas análises foram coletadas no tanque de alimentação, após o ajuste do $\mathrm{pH}$ para valores próximos de 8 .

Na determinação do IVL, os volumes necessários foram obtidos pelo armazenamento, em geladeira, dos descartes diários dos reatores para manutenção da idade do lodo.

Na Tabela 4.5 os parâmetros analisados estão divididos conforme o método das análises e exames utilizados no ensaio em sistema contínuo.

TABELA 4.5 - Divisão dos parâmetros analisados conforme o método das análises e exames utilizados no ensaio em sistema contínuo.

\begin{tabular}{lc}
\hline \multicolumn{1}{c}{ Parâmetros analisados } & Método utilizado \\
\hline Temperatura & Termométrico \\
$\mathrm{pH}, \mathrm{OD}, \mathrm{DBO}$ bruta e DBO filtrada & Potenciométrico \\
Alcalinidade, NTK e N-amoniacal & Titulométrico \\
$\mathrm{DQO}$ bruta, DQO filtrada, $\mathrm{PO}_{4}^{3-}, \mathrm{N}^{-\mathrm{NO}_{3}^{-}}$e N-NO \\
$\mathrm{ST}, \mathrm{SF}, \mathrm{SV}, \mathrm{SST}, \mathrm{SSF}, \mathrm{SSV}, \mathrm{SSed}$ e IVL & Espectrofotométrico \\
Exame microscópico & Gravimétrico \\
\hline
\end{tabular}

Os parâmetros analisados e a freqüência média das análises e exames que foram realizados no ensaio em sistema contínuo estão mostrados na Tabela 4.6. 
TABELA 4.6 - Parâmetros analisados e frequêencia média das análises e exames realizados no ensaio em sistema contínuo.

\begin{tabular}{|c|c|c|c|c|}
\hline \multirow[b]{2}{*}{$\begin{array}{c}\text { Parâmetro } \\
\text { analisado }\end{array}$} & \multirow[b]{2}{*}{$\begin{array}{c}\text { Freqüência da análise } \\
\qquad \text { (4 reatores) }\end{array}$} & \multicolumn{3}{|c|}{ Pontos de coleta } \\
\hline & & Afluente & $\begin{array}{c}\text { Tanque de } \\
\text { aeração }\end{array}$ & Efluente \\
\hline $\mathrm{T}\left({ }^{\circ} \mathrm{C}\right)$ & $2 \times$ por dia & & $\mathrm{X}$ & \\
\hline $\mathrm{pH}$ (adimensional) & $2 \times$ por dia & $\mathrm{X}$ & $\mathrm{X}$ & $\mathrm{X}$ \\
\hline Alcalinidade $\left(\mathrm{mgCaCO}_{3} / \mathrm{L}\right)$ & $2 \times$ por semana & $\mathrm{X}$ & & $\mathrm{X}$ \\
\hline $\mathrm{OD}(\mathrm{mg} / \mathrm{L})$ & $2 \times$ por dia & & $\mathrm{X}$ & \\
\hline DBO bruta $(\mathrm{mg} / \mathrm{L})$ & $2 \times$ por semana & $\mathrm{X}$ & & $\mathrm{X}$ \\
\hline DBO filtrada $(\mathrm{mg} / \mathrm{L})$ & $2 \times$ por semana & $\mathrm{X}$ & & $\mathrm{X}$ \\
\hline DQO bruta $(\mathrm{mg} / \mathrm{L})$ & $2 \times$ por semana & $\mathrm{X}$ & & $\mathrm{x}$ \\
\hline DQO filtrada (mg/L) & $2 \times$ por semana & $\mathrm{X}$ & & $\mathrm{X}$ \\
\hline ST $(\mathrm{mg} / \mathrm{L})$ & $2 \times$ por semana & $\mathrm{X}$ & & $\mathrm{X}$ \\
\hline $\mathrm{SF}(\mathrm{mg} / \mathrm{L})$ & $2 \times$ por semana & $\mathrm{X}$ & & $X$ \\
\hline $\mathrm{SV}(\mathrm{mg} / \mathrm{L})$ & $2 \times$ por semana & $\mathrm{X}$ & & $\mathrm{X}$ \\
\hline SST (mg/L) & $2 \times$ por semana & $\mathrm{X}$ & $\mathrm{X}$ & $\mathrm{X}$ \\
\hline $\mathrm{SSF}(\mathrm{mg} / \mathrm{L})$ & $2 \times$ por semana & $\mathrm{X}$ & $\mathrm{X}$ & $X$ \\
\hline $\mathrm{SSV}(\mathrm{mg} / \mathrm{L})$ & $2 \times$ por semana & $\mathrm{X}$ & $\mathrm{X}$ & $\mathrm{X}$ \\
\hline $\mathrm{PO}_{4}^{3-}(\mathrm{mg} / \mathrm{L})$ & $2 \times$ por semana & $X$ & & $\mathrm{X}$ \\
\hline NTK $(\mathrm{mg} / \mathrm{L})$ & $2 \times$ por semana & $\mathrm{X}$ & & $X$ \\
\hline $\mathrm{N}$-amoniacal (mg/L) & $2 \times$ por semana & $\mathrm{X}$ & & $\mathrm{X}$ \\
\hline $\mathrm{N}-\mathrm{NO}_{3}^{-}(\mathrm{mg} / \mathrm{L})$ & $2 \times$ por semana & $\mathrm{X}$ & & $\mathrm{X}$ \\
\hline $\mathrm{N}-\mathrm{NO}_{2}^{-}(\mathrm{mg} / \mathrm{L})$ & $2 \times$ por semana & $\mathrm{X}$ & & $X$ \\
\hline SSed $(\mathrm{mL} / \mathrm{L}) *$ & $2 \times$ por semana & $\mathrm{X}$ & $\mathrm{X}$ & $\mathrm{X}$ \\
\hline IVL (mL/g) & $2 \times$ por semana & & $\mathrm{X}$ & \\
\hline Exame Microscópico & $1 \times$ por semana & & $\mathrm{X}$ & \\
\hline
\end{tabular}

* Para amostra coletada no tanque de aeração denominou-se de volume de lodo sedimentado - VLS. 


\subsubsection{1 - Taxa de utilização de oxigênio}

Para determinação da taxa de utilização de oxigênio - $\mathrm{R}$ - foram feitos vários ensaios de amostras de cada reator, sem e com adição de substrato, após o encerramento das análises para determinação dos coefícientes cinéticos, quando os reatores se encontravam estabilizados dinamicamente. Os ensaios sem adição de substrato foram feitos com $750 \mathrm{~mL}$ de amostra coletada do tanque de aeração e os ensaios com adição de substrato utilizaram volume de $350 \mathrm{~mL}$ do tanque de aeração e $400 \mathrm{~mL}$ de substrato (água residuária bruta) autoclavado por 20 minutos. Os ensaios com adição de substrato foram realizados para verificar se havia deficiência de carbono e nutrientes necessários para o metabolismo dos microrganismos.

Os ensaios foram realizados com utilização de um frasco de aproximadamente 1 litro, um agitador magnético e um medidor de oxigênio dissolvido da marca HORIBA, modelo $12 \mathrm{M}$, de acordo com a Figura 4.8.

Para os ensaios sem e com adição de substrato, partiu-se do seguinte procedimento:

- colocou-se a amostra num frasco e manteve-se o conteúdo em constante agitação com auxílio de agitador magnético;

- adicionou-se oxigênio com um aerador de aquário até ser obtida a saturação;

- interrompeu-se a aeração, mas continuou-se a agitação por intermédio de agitador magnético para homogeneização da mistura;

- vedou-se o frasco com rolha de borracha transpassada pela sonda do medidor de OD;

- anotou-se a redução da concentração de OD até valores próximos de zero, em intervalos de 30 segundos; 
- obteve-se graficamente a taxa de utilização de oxigênio, após regressão linear pelo método dos mínimos quadrados.

Plotando os valores das reduções das concentrações de OD em função do tempo, a taxa de utilizacão de oxigênio é dada pelo coeficiente angular da reta ajustada pelo método dos mínimos quadrados.

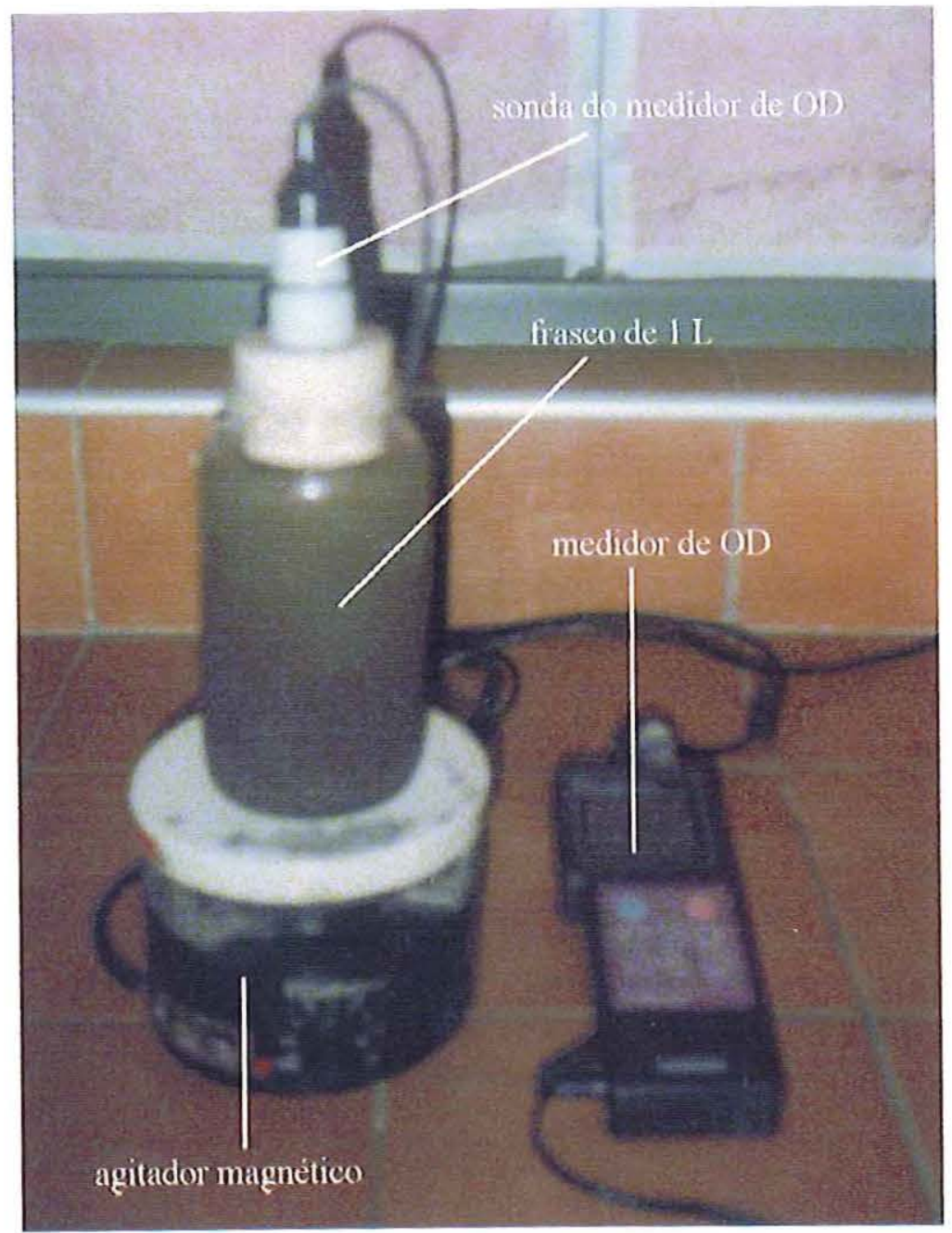

FIGURA 4.8 - Sistema utilizado na determinação da taxa de utilização de oxigênio. 


\subsubsection{2 - Coeficiente global de transferência de oxigênio}

$\mathrm{O}$ coeficiente global de transferência de oxigênio - $\mathrm{K}_{\mathrm{L}} \mathrm{a}$ - foi obtido através de vários ensaios para cada reator, sem e com utilização de sulfito de sódio para desoxigenar as amostras. Esses ensaios também foram realizados após a conclusão das análises para determinação dos coeficientes cinéticos, quando os reatores se encontravam estabilizados dinamicamente. Nos ensaios sem utilização de sulfito de sódio as amostras foram desoxigenadas pela atividade metabólica dos microrganismos presentes e nos ensaios com utilização de sulfito as amostras foram desoxigenadas com adição de sulfito de sódio, sendo a reação catalisada com cloreto de cobalto. Os ensaios sem utilização de sulfito foram feitos para analisar a influência do sulfito de sódio na utilização de oxigênio pelos microrganismos.

Para realização desses ensaios utilizou-se um béquer de 1 litro, um aerador de aquário e um medidor de oxigênio dissolvido da marca HORIBA, modelo $12 \mathrm{M}$, conforme Figura 4.9.

Seguiu-se o seguinte procedimento:

- coletaram-se $750 \mathrm{~mL}$ de amostra do tanque de aeração que foram colocados em um béquer, juntamente com a sonda do medidor de OD;

- nos ensaios sem utilização de sulfito, esperou-se a concentração de OD baixar para valores próximo a zero com o consumo dos próprios microrganismos, sendo que não se promoveu agitação;

- nos ensaios com utilização de sulfito, adicionou-se sulfito de sódio em quantidade superior a relação estiquiométrica (estequiometricamente cada grama de oxigênio dissolvido consome 7,9 gramas de sulfito de sódio) e cloreto de cobalto até atingir-se concentração de $1,0 \mathrm{mg} / \mathrm{L}$. Manteve-se em constante agitação com auxílio de agitador magnético até obter-se 
concentração de oxigênio dissolvido igual a zero. $\mathrm{O}$ mesmo procedimento foi utilizado para as amostras de água limpa.

Os seguintes itens foram seguidos para os ensaios sem e com utilização de sulfito de sódio:

- iniciou-se a reaeração com um aerador de aquário;

- mediu-se o aumento da concentração de OD até a saturação, em intervalos de 15 segundos até 6 minutos de aeração e a cada 30 segundos de 6 minutos até o final do ensaio;

- estimou-se graficamente o coeficiente global de transferência de oxigênio, após regressão linear pelo método dos mínimos quadrados.

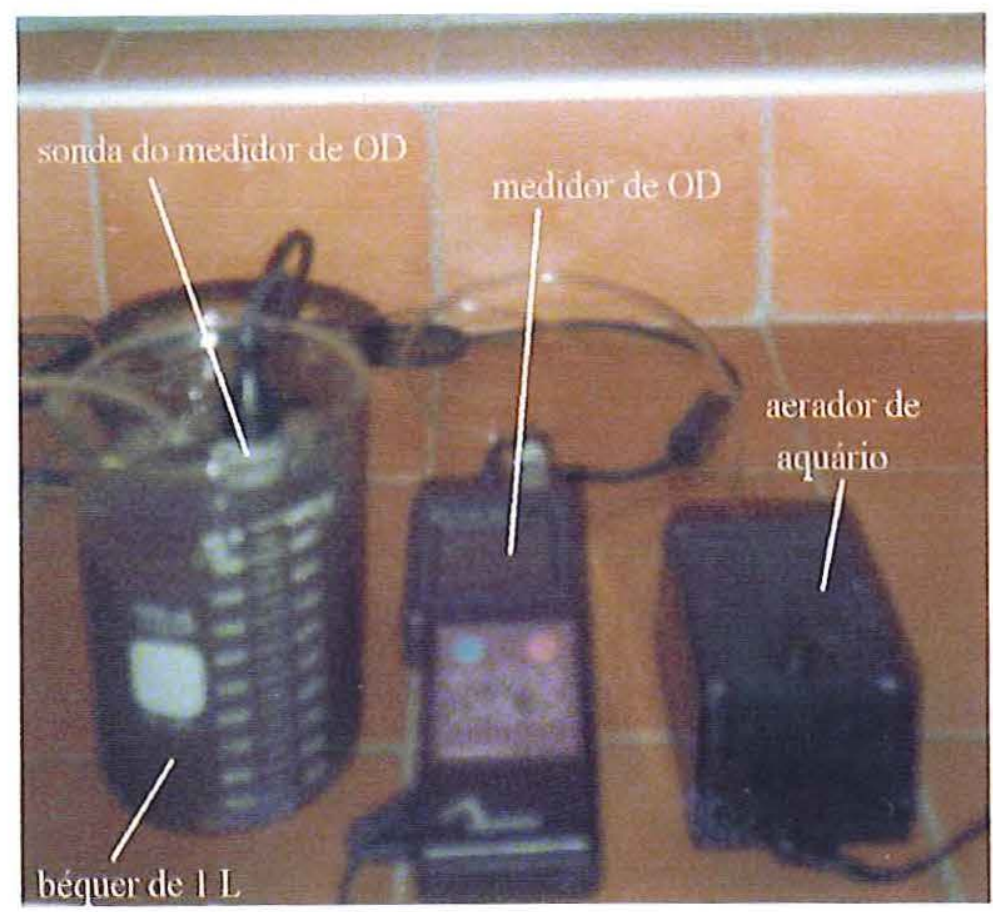

FIGURA 4.9 - Sistema utilizado na determinação do coeficiente global de transferência de oxigênio. 
Plotando nas ordenadas, em escala logarítmica, os valores da concentração de saturação menos o aumento da concentração de oxigênio dissolvido e nas abcissas, em escala aritmética os valores do tempo correspondente, o coeficiente global de transferência de oxigênio é dado pelo coeficiente angular da reta ajustada pelo método dos mínimos quadrados.

\section{5 - Ensaios hidrodinâmicos}

A finalidade principal deste estudo foi verificar se o comportamento dos reatores aproximava-se ao de mistura completa, no qual são baseadas as equações dos modelos para determinação dos coeficientes cinéticos.

Após o término de todas as análises, realizou-se ensaio hidrodinâmico nos reatores R1 e R4, simultaneamente operados com a menor e a maior idade do lodo respectivamente, utilizando-se como traçador o cloreto de lítio.

Em cada reator foi adicionado $50 \mathrm{~mL}$ de cloreto de lítio com concentração de $2420 \mathrm{mg} / \mathrm{L}$, resultando uma concentração de aproximadamente $2,0 \mathrm{mgLi}^{+} / \mathrm{L}$. O traçador foi introduzido nas mangueiras de alimentação, na entrada do tanque de alimentação dos reatores, com auxílio de seringas de $50 \mathrm{~mL}$ e de forma rápida.

As amostras foram coletadas na saída dos dois reatores após a adição do traçador a cada 15 minutos até 12 horas de ensaio e a cada 30 minutos de 12 até as 20 horas de ensaio. As vazões de alimentação foram aferidas a cada 2 horas para os dois reatores.

As concentrações de lítio foram lidas no espectrofotômetro de absorção atômica. 


\section{5 - APRESENTAÇ̃̃o DOS RESULTADOS}

Os resultados obtidos durante a fase experimental estão apresentados em 3 itens, que são: ensaios em sistema descontínuo, ensaio em sistema contínuo e ensaios hidrodinâmicos.

\section{1 - Ensaios em sistema descontínuo}

Durante todos os ensaios em sistema descontínuo, dois reatores, denominados de R1 e R2 foram operados simultaneamente em condições idênticas e com finalidade de comparar os resultados obtidos. Primeiramente, realizou-se um ensaio preliminar, em que se verificou a viabilidade do tratamento e em seguida operou-se com os seguintes tempos de ciclo: 24,18 e 12 horas. $\mathrm{O}$ tempo de retenção celular de 10 dias foi mantido constante para os ensaios com tempos de ciclo de 24,18 e 12 horas.

A Tabela 5.1 mostra as datas de início e de encerramento, os tempos de operação e os de permanência dos reatores em estabilização dinâmica obtidos no ensaio preliminar e nos ensaios com tempos de ciclo de 24,18 e 12 horas realizados em sistema descontínuo.

Os valores de $\mathrm{pH}$ da água residuária bruta, do reator, do reator após correção do $\mathrm{pH}$ e da água residuária tratada, de temperatura e oxigênio dissolvido do reator obtidos no ensaio preliminar e nos ensaios com tempos de ciclo de 24,18 e 12 horas para os dois reatores operados em sistema descontínuo estão apresentados, respectivamente, nas Tabelas A.1, A.2, A.3 e A.4 do Anexo A. 
TABELA 5.1 - Datas de início e de encerramento, tempos de operação e de permanência dos reatores em estabilização dinâmica para os ensaios em sistema descontínuo.

\begin{tabular}{cccccc}
\hline \multirow{2}{*}{$\begin{array}{c}\text { Tempo de ciclo } \\
\text { (hora) }\end{array}$} & Início & Encerramento & $\begin{array}{c}\text { Tempo de } \\
\text { operação } \\
\text { (dia) }\end{array}$ & \multicolumn{2}{c}{$\begin{array}{c}\text { Tempo em estabilização } \\
\text { dinâmica (dia) }\end{array}$} \\
\hline Ensaio preliminar & $04 / 08 / 95$ & $24 / 08 / 95$ & 20 & 12 & 14 \\
24 & $21 / 09 / 95$ & $26 / 10 / 95$ & 35 & 17 & 14 \\
18 & $30 / 10 / 95$ & $16 / 11 / 95$ & 17,25 & 11,5 & 7,5 \\
12 & $17 / 11 / 95$ & $07 / 12 / 95$ & 20,5 & 7 & 7 \\
\hline
\end{tabular}

Os valores médios, máximos e mínimos de $\mathrm{pH}$, temperatura e oxigênio dissolvido obtidos no ensaio preliminar e nos ensaios com tempos de ciclo de 24,18 e 12 horas para os dois reatores operados em sistema descontínuo estão mostrados na Tabela A.5 do Anexo A.

$\mathrm{Na}$ Tabela A.6 estão apresentados os resultados obtidos na caracterização da água residuária bruta realizada nos ensaios preliminar e com tempo de ciclo de 24 horas em sistema descontínuo e na Tabela A.7 os resultados da caracterização da água residuária bruta realizada nos ensaios com tempos de ciclo de 18 e 12 horas, também em sistema descontínuo. Essas tabelas localizadas no Anexo A referem-se aos seguintes parâmetros: DBO bruta e filtrada, DQO bruta e filtrada, sólidos totais, sólidos fixos, sólidos voláteis, sólidos suspensos totais, sólidos suspensos fixos, sólidos suspensos voláteis, sólidos sedimentáveis em 1 hora, fosfato total, nitrogênio total Kjeldahl (NTK), nitrogênio amoniacal e pH.

A relação de DBO bruta:NTK:Fosfato obtida na caracterização da água residuária bruta realizada no ensaio preliminar e nos ensaios com tempos de ciclo de 24, 18 e 12 horas foram, respectivamente, 100:87,5:30,0, 100:76,7:32,2, 100:46,9:21,9 e 100:28,7:16,8. Estas relações revelam o excesso dos nutrientes nitrogênio e fósforo, uma vez que é bem superior à relação DBO:N:P = 100:5:1 recomendada para sistema de lodos ativados convencionais, dispensando correção das concentrações desses nutrientes. 
Os resultados obtidos para os dois reatores operados em sistema descontínuo, tanto no ensaio preliminar como nos ensaios com tempos de ciclo de 24,18 e 12 horas estão apresentados nas Tabelas A.8 a A.15 do Anexo A, e referem-se aos mesmos parâmetros analisados na caracterização da água residuária bruta, excluindo-se os sólidos sedimentáveis em 1 hora para água residuária tratada e incluindo-se os sólidos suspensos totais no tanque de aeração, sólidos suspensos fixos no tanque de aeração, sólidos suspensos voláteis no tanque de aeração, volume de lodo sedimentado em 0,5 hora e índice volumétrico do lodo para amostra do tanque de aeração dos reatores. Os sólidos sedimentáveis em 1 hora para água residuária tratada, por não serem detectados nos dois reatores em todos os ensaios, não foram tabelados.

Na Tabela A.16 do Anexo A estão mostradas as percentagens médias de remoção da DBO bruta e filtrada, da DQO bruta e filtrada, sólidos suspensos totais, sólidos suspensos fixos, sólidos suspensos voláteis, fosfato total, nitrogênio total Kjeldahl e nitrogênio amoniacal obtidos para os dois reatores nos ensaios em sistema descontínuo, quando esses se encontravam estabilizados dinamicamente.

A Tabela A.17 apresenta os resultados dos exames microscópicos realizados para o reator R1 na aclimatação da água residuária e do ensaio preliminar em sistema descontínuo; e a Tabela A.18, os resultados para o reator R1 na aclimatação da água residuária e dos ensaios em sistema descontínuo com tempos de ciclo de 24,18 e 12 horas, ambas localizadas no Anexo A. Nestes exames realizou-se a contagem dos microrganismos predominantes no meio baseando-se em estimativa visual relativa, sendo feitos somente para o reator R1, pois os dois reatores não apresentaram diferenças significativas em termos de tipos e freqüências de microrganismos presentes. A aclimatação da água residuária foi realizada duas vezes, devido ao grande intervalo de tempo entre o ensaio preliminar e o ensaio com tempo de ciclo de 24 horas, mas utilizou-se o mesmo lodo como inóculo. 
Nas fotografias das Figuras A.1 a A.5 do Anexo A estão apresentados os principais microrganismos presentes nas amostras de lodo do reator R1 operado em sistema descontínuo com tempo de ciclo de 12 horas.

\section{2 - Ensaio em sistema contínuo}

O ensaio em sistema contínuo iniciou-se em 30 de abril de 1996 e encerrou-se após 35 dias em 4 de junho de 1996. Durante este período, quatro reatores denominados de R1, R2, R3 e R4 foram operados com os tempos de retenção celular de 5, 10, 15 e 20 dias, respectivamente. O tempo de detenção hidráulico para o sistema foi mantido próximo de 8 horas. Conforme os resultados apresentados, os reatores permaneceram estabilizados dinamicamente por aproximadamente 8 dias, quando se observou produção de efluentes com características relativamente constantes e bem nitrificados.

Neste item serão abordados para o sistema de lodos ativados operado de forma contínua: controle do sistema, parâmetros experimentais obtidos durante o ensaio, determinação dos coeficientes cinéticos, da taxa de utilização de oxigênio, dos parâmetros a' e b', do coeficiente $\alpha$, da relação $\mathrm{F} / \mathrm{M}$, da taxa específica de utilização de substrato, da produção líquida de lodo ativado por dia (valor estimado) e do lodo ativado descartado diariamente do tanque de aeração e os exames microscópicos.

\subsection{1 - Controle do sistema}

Os valores de $\mathrm{pH}$ do tanque de alimentação (água residuária afluente), do reator e do efluente, de oxigênio dissolvido do tanque de aeração, de temperatura do reator e ambiente e da vazão de alimentação obtidos durante a 
operação dos quatro reatores em sistema contínuo, com a finalidade de monitorá-los, estão apresentados na Tabela B.1 do Anexo B.

Na Tabela B.2 do Anexo B estão apresentados os valores médios, máximos e mínimos de $\mathrm{pH}$, do oxigênio dissolvido, da temperatura e vazão obtidos durante a operação dos quatro reatores em sistema contínuo. Para efeito de cálculo dos coeficientes cinéticos, adotou-se a vazão de $1,287 \mathrm{~L} / \mathrm{h}$, que corresponde ao valor médio das vazões médias obtidas para os quatro reatores e resulta num tempo de detenção hidráulico de 7,93 horas.

A variação de $\mathrm{pH}$ do afluente, do reator e do efluente obtida para os reatores R1, R2, R3 e R4 durante a operação em sistema contínuo estão representadas, respectivamente, nos gráficos das Figuras B.1, B.2, B.3 e B.4 do Anexo $\mathrm{B}$ e os dados correspondentes a estes gráficos encontram-se na Tabela B.1 do mesmo anexo.

Os gráficos das Figuras B.5, B.6, B.7 e B.8 do Anexo B produzidos com os dados da Tabela B.1 do mesmo anexo mostram respectivamente a variação de oxigênio dissolvido obtida para os reatores R1, R2, R3 e R4 durante a operação em sistema contínuo.

$\mathrm{O}$ gráfico correspondente à variação da temperatura dos reatores e temperatura ambiente durante o ensaio em sistema contínuo está apresentado na Figura B.9 do Anexo B e os dados referentes a este gráfico estão na Tabela B. 1 do mesmo anexo.

\subsection{2 - Parâmetros experimentais obtidos durante o ensaio}

Na Tabela B.3 do Anexo B estão apresentados os resultados obtidos na caracterização da água residuária utilizada na alimentação dos reatores durante o ensaio em sistema contínuo, e referem-se aos seguintes parâmetros: DBO bruta e filtrada, DQO bruta e filtrada, sólidos totais, sólidos fixos, sólidos voláteis, sólidos suspensos totais, sólidos suspensos fixos, sólidos suspensos 
voláteis, sólidos sedimentáveis em 0,5 e 1 hora, nitrogênio total Kjeldahl (NTK), nitrogênio amoniacal, nitrato, nitrito, fosfato total, $\mathrm{pH}$ e alcalinidade.

A relação DBO bruta:NTK:Fosfato $=100: 34,3: 14,3$ obtida para a água residuária utilizada para alimentação dos reatores durante a operação do sistema contínuo revela, como foi comentado anteriormente para o sistema descontínuo, o excesso dos nutrientes nitrogênio e fósforo, uma vez que é bem superior à relação $\mathrm{DBO}: \mathrm{N}: \mathrm{P}=100: 5: 1$ recomendada para o sistema de lodos ativados convencionais, dispensando assim a correção da concentração desses nutrientes.

Os resultados obtidos durante a operação dos reatores R1, R2, R3 e R4 em sistema contínuo estão apresentados, respectivamente, nas Tabelas B.4, B.5, B.6 e B.7 do Anexo B, e referem aos mesmos parâmetros analisados na caracterização da água residuária, excluindo-se os sólidos sedimentáveis em 0,5 e 1 hora para o efluente e adicionando-se os sólidos suspensos totais no tanque de aeração, sólidos suspensos fixos no tanque de aeração, sólidos suspensos voláteis no tanque de aeração, volume de lodo sedimentado em 0,5 hora e índice volumétrico do lodo para amostra do tanque de aeração dos reatores. Os sólidos sedimentáveis em 0,5 e 1 hora para o efluente dos quatro reatores, por não serem detectados em todas as análises realizadas durante $o$ ensaio, não foram tabelados.

A variação da DBO bruta e filtrada, afluente e efluente durante a operação dos reatores R1, R2, R3 e R4 em sistema contínuo, estão mostradas, respectivamente nos gráficos das Figuras B.10, B.11, B.12 e B.13 do Anexo B e os dados referentes a este gráficos encontram-se nas Tabelas B. 3 a B.7 do mesmo anexo.

Os gráficos das Figuras B.14 e B.15 do Anexo B, construídos com os dados apresentados nas Tabelas B.4 a B.7 do mesmo anexo representam, respectivamente, a comparação da variação da DBO bruta e filtrada efluente dos quatro reatores durante a operação em sistema contínuo. 
Os gráficos referentes à variação da DQO bruta e filltrada, afluente e efluente durante a operação dos reatores R1, R2, R3 e R4 em sistema contínuo, estão apresentados, respectivamente, nas Figuras B.16, B.17, B.18 e B.19 do Anexo B, e os dados utilizados na construção destes gráficos estão nas Tabelas B.3 a B.7 do mesmo anexo.

A comparação da variação da DQO bruta e filtrada efluente dos quatro reatores durante a operação em sistema contínuo estão mostradas, respectivamente, nos gráficos das Figuras B.20 e B.21 do Anexo B e foram produzidas com os dados das Tabelas B.4 a B.7 do mesmo anexo.

O gráfico da Figura B.22 do Anexo B, gerado com os dados apresentados nas Tabelas B.4 a B.7 do mesmo anexo, representa a comparação da variação dos sólidos suspensos voláteis no tanque de aeração dos quatro reatores durante a operação em sistema contínuo.

A variação das formas de nitrogênio (total Kjeldahl, amoniacal, nitrato e nitrito) afluente e efluente durante a operação dos reatores R1, R2, R3 e R4 em sistema contínuo estão mostrados, respectivamente, nos gráficos das Figuras B.23, B.24, B.25 e B.26 do Anexo B e os dados utilizados para produzir estes gráficos encontram-se nas Tabelas B.3 a B.7 do mesmo anexo.

Os gráficos das Figuras B.27, B.28, B.29 e B.30 do Anexo B, gerados a partir dos dados apresentados nas Tabelas B.3 a B.7 do mesmo anexo representam a variação de fósforo (fosfato total) afluente e efluente durante a operação dos reatores R1, R2, R3 e R4 em sistema contínuo, respectivamente.

$\mathrm{O}$ gráfico referente à comparação da variação do índice volumétrico do lodo dos quatro reatores durante a operação em sistema contínuo encontra-se na Figura B.31 do Anexo B e os dados correspondentes ao gráfico, nas Tabelas B.4 a B.7 do mesmo anexo.

A variação da alcalinidade afluente e efluente dos quatro reatores durante a operação em sistema contínuo está mostrada no gráfico da Figura B.32 do Anexo B, que foi gerada com os dados das Tabelas B.3 a B.7 do mesmo anexo. 
Os valores de remoção média da DBO bruta e filtrada, DQO bruta e filtrada, sólidos suspensos totais, sólidos suspensos fixos, sólidos suspensos voláteis e fosfato total obtidos quando os quatro reatores operados em sistema contínuo encontravam-se estabilizados dinamicamente estão mostrados na Tabela 5.2.

TABELA 5.2 - Valores de remoção média da DBO bruta e filtrada, DQO bruta e filtrada, SST, SSF, SSV e $\mathrm{PO}_{4}^{3-}$ obtidos no ensaio em sistema contínuo após estabilização dinâmica dos reatores.

\begin{tabular}{ccccccccc}
\hline & \multicolumn{7}{c}{ \% Média de Remoção } \\
\cline { 2 - 9 } Reator & $\begin{array}{c}\text { DBO } \\
\text { bruta }\end{array}$ & $\begin{array}{c}\text { DBO } \\
\text { filtrada }\end{array}$ & $\begin{array}{c}\text { DQO } \\
\text { bruta }\end{array}$ & $\begin{array}{c}\text { DQO } \\
\text { filtrada }\end{array}$ & SST & SSF & SSV & PO $_{4}^{3-}$ \\
\hline R1 & 95 & 90 & 87 & 80 & 98,1 & 99,6 & 96,8 & 28 \\
R2 & 95 & 90 & 87 & 80 & 96,8 & 99,3 & 94,7 & 23 \\
R3 & 95 & 92 & 88 & 82 & 97,0 & 99,3 & 95,1 & 24 \\
R4 & 97 & 92 & 88 & 83 & 95,8 & 98,2 & 93,6 & 27 \\
\hline
\end{tabular}

\subsection{3 - Determinação dos coeficientes cinéticos}

Os resultados necessários à determinação dos coeficientes cinéticos $\mathrm{k}$, $\mathrm{K}_{\mathrm{s}}$, $\mathrm{Y}$ e $\mathrm{k}_{\mathrm{d}}$, obtidos quando os quatro reatores operados em sistema contínuo encontravam-se estabilizados dinamicamente, estão apresentados na Tabela B.8 do Anexo B.

Neste item, serão apresentados separadamente as determinações de $\mathrm{k}$ e $\mathrm{K}_{\mathrm{s}} \mathrm{e}$ as de $\mathrm{Y}$ e $\mathrm{k}_{\mathrm{d}}$.

\subsubsection{1 - Determinação de $k$ e $K_{s}$}

Os coeficientes cinéticos $\mathrm{k}$ e $\mathrm{K}_{\mathrm{s}}$ foram determinados com base na metodologia apresentada anteriormente no item 3.4.5.1.1, utilizando-se a eq. (3.62) e a determinação gráfica apresentada na Figura 3.10. 
Os resultados obtidos após estabilização dinâmica dos reatores e cálculos necessários à determinação dos coeficientes cinéticos $\mathrm{k}$ e $\mathrm{K}_{\mathrm{s}}$, encontram-se na Tabela B.9 do Anexo B e suas determinações gráficas estão apresentadas nas Figuras B.33 e B.35 do mesmo anexo, para as bases DBO e DQO filtrada efluente, respectivamente.

Os resultados obtidos nas determinações gráficas apresentadas nas Figuras B.33 e B. 35 do Anexo B resultaram em valores negativos para os coeficientes cinéticos $\mathrm{k}$ e $\mathrm{K}_{\mathrm{s}}$, portanto, sem significado físico.

\subsubsection{2 - Determinação de $Y \mathbf{e} \mathbf{k}_{\mathbf{d}}$}

Os coeficientes cinéticos $\mathrm{Y}$ e $\mathrm{k}_{\mathrm{d}}$ foram determinados com base na metodologia apresentada no item 3.4.5.1.2, utilizando-se a eq. (3.63) e a determinação gráfica descrita na Figura 3.11.

Os resultados obtidos após estabilização dinâmica dos reatores e cálculos necessários à determinação dos coeficientes cinéticos $\mathrm{Y} \mathrm{e} \mathrm{k}_{\mathrm{d}}$, encontram-se na Tabela B.10 do Anexo B e suas determinações gráficas nas Figuras B.34 e B.36 do mesmo anexo, para as bases DBO e DQO filtrada efluente, respectivamente.

Na Tabela 5.3 estão indicados, conforme a base utilizada, os valores dos coeficientes cinéticos $\mathrm{Y}$ e $\mathrm{k}_{\mathrm{d}}$ para o sistema contínuo e do respectivo coeficiente de correlação da reta obtida após regressão linear pelo método dos mínimos quadrados. 
TABELA 5.3 - Valores dos coeficientes cinéticos $\mathrm{Y}$ e $\mathrm{k}_{\mathrm{d}}$ para o sistema contínuo e do respectivo coefíciente de correlação da reta obtida após regressão linear pelo método dos mínimos $\left(\mathrm{T}_{\text {média }}=23,9^{\circ} \mathrm{C}\right)$.

\begin{tabular}{cccc}
\hline Base & $\begin{array}{c}\mathrm{r}^{2} \\
\text { (coeficiente de correlação) }\end{array}$ & $\mathrm{Y}$ & $\begin{array}{c}\mathrm{k}_{\mathrm{d}} \\
\left(\mathrm{dia}^{-1}\right)\end{array}$ \\
\hline DBO filtrada (efluente) & 0,6913 & 0,528 & 0,046 \\
DQO filtrada (efluente) & 0,6898 & 0,266 & 0,047 \\
\hline
\end{tabular}

\subsection{4 - Determinação da taxa de utilização de oxigênio}

A taxa de utilização de oxigênio foi determinada conforme a metodologia apresentada no item 3.4.5.4, utilizando-se a determinação gráfica descrita na Figura 3.13.

Os valores do decaimento da concentração de OD em função do tempo, obtidos nos ensaios realizados com amostras dos reatores R1, R2, R3 e R4, sem e com adição de substrato, estão indicados nas Tabelas B.11, B.12, B.13 e B.14 do Anexo B, respectivamente. A determinação destes valores foi realizada após o encerramento das análises que determinaram os parâmetros descritos nas Tabelas B.4 a B.7 do Anexo B, quando o sistema se encontrava estabilizado dinamicamente, evitando assim, a ocorrência de distúrbios no interior dos reatores pelas retiradas dos volumes necessários.

A determinação gráfica da taxa de utilização de oxigênio para os reatores R1, R2, R3 e R4 estão demonstradas, respectivamente, nas Figuras B. 37 a B. 44 , B. 45 a B.52, B.53 a B.60 e B.61 a B.68 do Anexo B, que foram geradas com os dados descritos nas Tabelas B.11 a B.14 do mesmo anexo.

Os valores dos sólidos suspensos voláteis no tanque de aeração e da taxa de utilização de oxigênio obtidos nos ensaios com amostras dos quatro reatores operados em sistema contínuo estão apresentados nas Tabelas B.15 e 
B.16 do Anexo B, para os ensaios sem e com adição de substrato, respectivamente.

Na Tabela 5.4 estão mostrados os valores médios dos sólidos suspensos voláteis no tanque de aeração e da taxa de utilização de oxigênio obtidos para os quatro reatores operados em sistema contínuo, nos ensaios sem e com adição de substrato.

TABELA 5.4 - Valores médios de $X_{v}$ e $R$ para os 4 reatores operados em sistema contínuo, nos ensaios sem e com adição de substrato.

\begin{tabular}{|c|c|c|c|c|}
\hline \multirow[b]{2}{*}{ Reator } & \multicolumn{2}{|c|}{ Sem adição de substrato } & \multicolumn{2}{|c|}{ Com adição de substrato } \\
\hline & $\begin{array}{c}\mathrm{X}_{\mathrm{v}} \\
(\mathrm{mg} / \mathrm{L})\end{array}$ & $\begin{array}{c}\mathrm{R} \\
\left(\mathrm{mgO}_{2} / \text { L.dia }\right)\end{array}$ & $\begin{array}{c}\mathrm{X}_{\mathrm{v}} \\
(\mathrm{mg} / \mathrm{L})\end{array}$ & $\begin{array}{c}\mathrm{R} \\
\left(\mathrm{mgO}_{2} / \text { L.dia }\right)\end{array}$ \\
\hline $\mathrm{R} 1$ & 931 & 424 & 621 & 528 \\
\hline R2 & 1802 & 585 & 1009 & 803 \\
\hline R3 & 2068 & 668 & 877 & 761 \\
\hline $\mathrm{R} 4$ & 3238 & 637 & 1415 & 1057 \\
\hline
\end{tabular}

\subsection{5 - Determinação dos parâmetros a' e b'}

Os parâmetros a' e b' foram determinados de acordo com a metodologia apresentada anteriormente no item 3.4.5.3, utilizando-se a eq. (3.66) e a determinação gráfica da Figura 3.12.

Tantos os resultados obtidos quando os quatro reatores operados em sistema contínuo encontravam-se estabilizados dinamicamente como os cálculos necessários à determinação dos parâmetros a' e b' estão apresentados nas Tabelas B. 17 a B.20 do Anexo B, que foram expostos conforme a base e determinação da taxa de utilização de oxigênio. A determinação gráfica destes parâmetros encontram-se nas Figuras B.69 a B.72 do Anexo B, que foram geradas com os dados apresentados nas Tabela B.17 a B.20 do mesmo anexo. 
Na Tabela 5.5 estão apresentados, conforme a base utilizada e o modo de determinação da taxa de utilização de oxigênio, os valores dos parâmetros a' e b' para o sistema contínuo e do respectivo coeficiente de correlação da reta obtida após regressão linear pelo método dos mínimos quadrados.

TABELA 5.5 - Valores dos parâmetros a' e b' para o sistema contínuo e do respectivo coeficiente de correlação da reta obtida após regressão linear pelo método dos mínimos quadrados.

\begin{tabular}{ccccc}
\hline Base & Determinação de R & $\mathrm{r}^{2}$ & $\mathrm{a}^{\prime}$ & $\begin{array}{c}\mathrm{b}^{\prime} \\
\left(\mathrm{dia}^{-1}\right)\end{array}$ \\
\hline DBO filtrada (efluente) & sem adição de substrato & 0,8964 & 0,761 & 0,121 \\
DBO filtrada (efluente) & com adição de substrato & 0,5123 & 0,548 & 0,556 \\
DQO filtrada (efluente) & sem adição de substrato & 0,8965 & 0,382 & 0,120 \\
DQO filtrada (efluente) & com adição de substrato & 0,5159 & 0,276 & 0,553 \\
\hline
\end{tabular}

\subsection{6 - Determinação do coeficiente $\alpha$}

O coeficiente global de transferência de oxigênio foi determinado conforme a metodologia apresentada no item 3.4.5.5. Utilizando-se a eq. (3.71) plotou-se nas ordenadas $\log \left(\mathrm{C}_{\mathrm{s}}-\mathrm{C}\right)$ e nas abcissas tempo t. $\mathrm{O}$ valor de $\left(\mathrm{K}_{\mathrm{L}} \mathrm{a}\right)$ foi dado pelo coeficiente angular da reta obtida após regressão linear pelo método dos mínimos quadrados.

Os valores do aumento da concentração de oxigênio dissolvido em função do tempo, obtidos durante a reaeração de amostras dos reatores R1, R2, R3 e R4, nos ensaios com e sem utilização de sulfito de sódio encontram-se, respectivamente, nas Tabelas B.21, B.22, B.23 e B.24 do Anexo B. Pelo mesmo motivo descrito anteriormente na determinação da taxa de utilização de oxigênio, estes também foram realizados após o encerramento das análises, quando o sistema encontrava-se estabilizado dinamicamente. 
Na Tabela B.25 do Anexo B estão apresentados os valores do aumento da concentração de OD em função do tempo, obtidos durante a reaeração de amostras de água limpa que foram desoxigenadas com utilização de sulfito de sódio

A determinação gráfica do coeficiente global de transferência de oxigênio para os reatores R1, R2, R3, R4 e água limpa estão demonstradas, respectivamente, nas Figuras B.73 a B.80, B.81 a B.88, B.89 a B.96, B.97 a B.104 e B.105 a B.107 do Anexo B, que foram obtidas com resultados apresentados nas Tabelas B.21 a B.25 do mesmo anexo.

Na Tabela B.26 do Anexo B estão demonstrados para amostras de água limpa, os valores da temperatura do líquido, do coeficiente global de transferência de oxigênio à temperatura do líquido e sua conversão à $20^{\circ} \mathrm{C}$.

Os valores da temperatura do líquido, do coeficiente global de transferência de oxigênio à temperatura do líquido e sua conversão à $20^{\circ} \mathrm{C}$ e do coeficiente $\alpha$ determinados para os quatro reatores operados em sistema contínuo, nos ensaios sem e com utilização de sulfito de sódio, estão apresentados na Tabela B.27 do Anexo B.

As conversões de $\left(\mathrm{K}_{\mathrm{L}} \mathrm{a}\right)$ da temperatura do líquido para $20^{\circ} \mathrm{C}$ foram feitas através da eq. (3.74) e os cálculos do coeficiente $\alpha$ pela eq. (3.73).

Na Tabela 5.6 estão apresentados os valores médios do coeficiente $\alpha$ obtidos para os quatro reatores operados em sistema contínuo, nos ensaios com e sem utilização de sulfito de sódio. 
TABELA 5.6 - Valores médios do coeficiente $\alpha$ para os 4 reatores operados em sistema contínuo, nos ensaios com e sem utilização de sulfito de sódio.

\begin{tabular}{ccc}
\hline Reator & $\begin{array}{c}\alpha \\
\text { (com utilização de sulfito) }\end{array}$ & $\begin{array}{c}\alpha \\
\text { (sem utilização de sulfito) }\end{array}$ \\
& 1,03 & 0,91 \\
R1 & 0,85 & 0,99 \\
R2 & 0,83 & 1,06 \\
R3 & 0,96 & 1,02 \\
\hline
\end{tabular}

\subsection{7 - Determinação da relação $F / M, U, P_{x}$ e $P_{x}$,}

Os valores da relação $\mathrm{F} / \mathrm{M}$, da taxa específica de utilização de substrato, da produção líquida de lodo ativado por dia e do lodo ativado descartado diariamente do tanque de aeração foram determinados para os quatro reatores após a estabilização dinâmica.

A Tabela B.28 do Anexo B mostra os valores da relação F/M para as bases DBO e DQO filtrada efluente e do índice volumétrico do lodo obtidos para os quatro reatores no ensaio em sistema contínuo.

Na Tabela B.29 do Anexo B estão indicados, conforme a base utilizada, os valores da taxa específica de utilização de substrato obtidos para os quatro reatores no sistema contínuo.

Os valores da produção líquida de lodo ativado por dia (quantidade a ser descartada - valor estimado) obtidos para os quatro reatores operados em sistema contínuo nas bases DBO e DQO filtrada efluente estão apresentados na Tabela B.30 do Anexo B.

A Tabela B.31 do Anexo B apresenta os valores do lodo ativado descartado diariamente do tanque de aeração (valor real) determinados para os quatro reatores operados em sistema contínuo. 
Os valores do lodo ativado descartado diariamente do tanque de aeração, da produção líquida de lodo ativado por dia e do respectivo desvio obtidos no ensaio em sistema contínuo estão mostrados na Tabela B.32 do Anexo B.

\subsection{8 - Exames microscópicos}

Em todos os exames microscópicos feitos durante a aclimatação da água residuária, bem como no decorrer do ensaio em sistema contínuo, realizou-se a contagem dos microrganismos predominantes no meio baseandose em estimativa visual relativa.

Os resultados dos exames microscópicos realizados durante a aclimatação da água residuária utilizada no ensaio em sistema contínuo estão apresentados na Tabela B.33 do Anexo B.

A Tabela B.34 do Anexo B mostra os resultados dos exames microscópicos realizados durante a operação dos quatro reatores em sistema contínuo, praticamente, de semana em semana, uma vez que não ocorreram alterações significativas no decorrer do ensaio.

As fotografias das Figuras B.108 a B.113 do Anexo B mostram os principais microrganismos presentes nas amostras de lodo dos reatores durante a operação em sistema contínuo.

\section{3 - Ensaios hidrodinâmicos}

Os ensaios hidrodinâmicos foram realizados após o término de todas as análises laboratoriais, pois a concentração de lítio utilizada poderia prejudicar o desenvolvimento dos microrganismos e com isso mudar as características dos reatores. 
Os dados referentes aos ensaios hidrodinâmicos dos reatores R1 e R4, utilizando-se como traçador o cloreto de lítio, estão apresentados, respectivamente, nas Tabelas C. 1 e C. 2 do Anexo C. A curva resposta do ensaio hidrodinâmico e a curva exponencial de $\left(-t / t_{0}\right)$ realizadas para os reatores R1 e R4 encontram-se nas Figuras C.1 e C.2 do Anexo C, respectivamente. 


\section{6 - DISCUSSÃO DOS RESULTADOS}

A discussão dos resultados obtidos durante a fase experimental está dividida em 3 itens, a saber: ensaios em sistema descontínuo, ensaio em sistema contínuo e ensaios hidrodinâmicos.

A água residuária utilizada para alimentação dos reatores nos ensaios em sistema descontínuo e no ensaio em sistema contínuo apresentou grandes oscilações na qualidade, principalmente por causa do reator anaeróbio compartimentado não ter sido operado regularmente durante os ensaios, isto é, a vazão de entrada do esgoto sanitário bruto e os descartes do lodo das câmaras e do filtro de pedregulho não foram controlados. Porém, aproximaram-se da situação real.

A eficiência dos reatores nos dois sistemas seria menor, caso o reator anaeróbio compartimentado tivesse sido operado regularmente durante os ensaios, em virtude da menor concentração de matéria orgânica disponível no seu efluente. Porém, os valores da concentração da maioria dos parâmetros analisados, em especial, DBO, DQO e sólidos suspensos, no efluente dos reatores apresentariam pequena variação, independente da qualidade da água residuária afluente.

A falta de controle do reator anaeróbio compartimentado durante a operação dos dois sistemas não afetou a concentração dos nutrientes nitrogênio e fósforo no seu efluente, pois POVINELLI (1994) concluiu que esse reator apresenta baixa remoção de tais nutrientes. 


\section{1 - Ensaios em sistema descontínuo}

A relação de DBO bruta:NTK:Fosfato de 100:76,7:32,2, 100:46,9:21,9 e 100:28,7:16,8, obtidas na caracterização da água residuária bruta realizada para os ensaios em sistema descontínuo com tempos de ciclo de 24,18 e 12 horas, respectivamente, por serem bem superiores a relação 100:5:1 recomendada para os processos de lodos ativados convencionais, comprovaram o excesso dos nutrientes nitrogênio e fósforo.

Os valores de $\mathrm{pH}$ da água residuária bruta variaram de 6,5 a 7,0 nos ensaios com tempos de ciclo de 24, 18 e 12 horas. A maioria dos valores de $\mathrm{pH}$ no interior dos dois reatores, mesmo antes de serem corrigidos para valores próximos de 8, se mantiveram próximos de 7,0 após alguns dias de operação, o que significou que os reatores estavam se estabilizando. Mesmo os valores máximos e mínimos ficaram próximos da faixa de 6,5 a 7,5 citada por METCALF \& EDDY (1991) como a ótima para crescimento das bactérias. O pH do conteúdo dos reatores foi corrigido com hidróxido de sódio para valores próximos de 8 , com finalidade de evitar o crescimento e aglutinação de fungos ocasionados pela queda do $\mathrm{pH}$, que pode ser causada pela geração de ácidos provenientes do processo de nitrificação e geração de $\mathrm{CO}_{2}$ durante a decomposição da matéria orgânica.

Apesar de os ensaios serem realizados em meses diferentes e sem controle térmico, os valores de temperatura média no interior dos dois reatores apresentaram pequenas variações entre os ensaios, de 24,3 a $26,3{ }^{\circ} \mathrm{C}$, portanto, situando-se na faixa mesófila $\left(20\right.$ a $\left.50{ }^{\circ} \mathrm{C}\right)$ de acordo com METCALF \& EDDY (1991).

Analisando-se os valores médios, máximos e mínimos da concentração de oxigênio dissolvido (Tabela A.5 do Anexo A), observa-se que não ocorreu insuficiência, pois até os valores mínimos, que foram superiores a $1,9 \mathrm{mg} / \mathrm{L}$, estão situados no intervalo de 1 a $2 \mathrm{mg} / \mathrm{L}$ recomendado por METCALF \& EDDY (1991). A diferença entre os valores máximos e mínimos apresentaram 
grandes variações em decorrência da redução da concentração de matéria orgânica disponível ao longo do tempo de aeração (sistema em batelada), temperatura do reator e controle manual da entrada de oxigênio, através de aeradores de aquário.

A definição do período em que o reator atingiu a estabilidade dinâmica foi difícil para a maioria dos ensaios, pois ao se analisar a DBO e DQO bruta da água residuária tratada e os sólidos suspensos voláteis no tanque de aeração, principalmente, as concentrações da DBO como as da DQO mantiveram-se com valores que apresentaram pequena variação no decorrer de cada ensaio.

Observando-se os valores da DBO bruta e filtrada e da DQO bruta e filtrada da água residuária bruta obtidos para os ensaios com tempos de ciclo de 24, 18 e 12 horas (Tabelas A.6 e A.7 do Anexo A), nota-se que foram oscilantes no decorrer de cada ensaio e que também apresentaram oscilações entre os mesmos. Essas oscilações dificultaram a comparação das eficiências entre os tempos de ciclo empregados.

De acordo com os resultados da DBO e DQO apresentados nas Tabelas A.10 a A.15 do Anexo A para a água residuária tratada, verifica-se que as oscilações presentes na água residuária bruta são amortecidas no interior dos dois reatores, pois os valores médios da DBO bruta e filtrada da água residuária tratada obtidos após a estabilização dinâmica dos reatores são praticamente constantes em todos os ensaios; em termos da DQO bruta e filtrada, os valores médios são próximos. Verifica-se ainda que a água residuária tratada dos dois reatores com operação simultânea apresentou valores bem próximos para cada tempo de ciclo estudado.

Conforme mostrado na Tabela A.16 do Anexo A, as percentagens médias de remoção da DBO bruta e filtrada obtidas nos ensaios em sistema descontínuo, quando os dois reatores se encontravam estabilizados dinamicamente, foram superiores a $91 \%$ e com relação a DQO bruta e filtrada foram superiores a 72 e a $83 \%$, respectivamente. Estas remoções podem ser 
consideradas satisfatórias para pós-tratamento de água residuária proveniente de reator anaeróbio compartimentado que recebe esgoto sanitário através de processo de lodos ativados por batelada, pois conferiram à água residuária tratada dos dois reatores em todos os ensaios concentração média inferior a 9 $\mathrm{mg} / \mathrm{L}$ para DBO bruta, $4 \mathrm{mg} / \mathrm{L}$ para DBO filtrada, $96 \mathrm{mg} / \mathrm{L}$ para DQO bruta $\mathrm{e}$ $36 \mathrm{mg} / \mathrm{L}$ para DQO filtrada.

Ainda na Tabela A.16, também pode ser observado que os diferentes tempos de ciclo mantidos nos reatores durante os ensaios tiveram pequena influência nas percentagens médias de remoção da DBO bruta e filtrada e da DQO bruta e filtrada, sendo que as percentagens médias de remoção da DQO bruta no ensaio com tempo de ciclo de 18 horas apresentaram as maiores variações, e que os dois reatores operados simultaneamente apresentaram praticamente a mesma remoção para cada tempo de ciclo empregado.

Pelos altos valores de sólidos totais da água residuária tratada obtidos nos ensaios antes e após a estabilização dinâmica dos reatores, pode-se dizer que os sólidos totais não foram removidos, pois a maioria dos valores foram superiores aos valores obtidos na caracterização da água residuária bruta. Estes resultados podem ser proporcionados por erros oriundos da metodologia utilizada, como possíveis erros na determinação do peso da cápsula (interferência da umidade e limpeza) e medição do volume de amostra. Uma melhor representação poderia ser conseguida com a realização de duplicata ou triplicata de análises da mesma amostra e aumento do volume de amostra de 50 para $100 \mathrm{~mL}$.

Ao analisar os valores médios da concentração de sólidos suspensos totais, sólidos suspensos fixos e sólidos suspensos voláteis da água residuária tratada obtidos nos ensaios após a estabilização dinâmica dos reatores (Tabelas A.10 a A.15 do Anexo A), verifica-se que as grandes oscilações ao longo de cada ensaio e entre os ensaios da água residuária bruta (Tabelas A.6 e A.7 do Anexo A), são amortecidas no interior dos dois reatores em todos os ensaios, 
pois a água residuária tratada apresentou valores inferiores a 17,3 e $15 \mathrm{mg} / \mathrm{L}$, respectivamente.

As percentagens médias de remoção de sólidos suspensos totais, sólidos suspensos fixos e sólidos suspensos voláteis, após a estabilização dinâmica dos dois reatores, foram superiores a 76,77 e $75 \%$, respectivamente, o que pode ser considerado satisfatório para o pós-tratamento da água residuária utilizada nessa pesquisa.

Os sólidos sedimentáveis presentes na água residuária bruta, que apresentaram valores maiores no ensaio com tempo de ciclo de 12 horas, foram retidos satisfatoriamente nos dois reatores no decorrer de todos os ensaios, não sendo detectados na água residuária tratada.

Após a estabilização dinâmica dos reatores, observou-se que houve aumento da concentração de sólidos suspensos totais no tanque de aeração com diminuição do tempo de ciclo, como era de se esperar, pois a concentração de microrganismos aumenta para consumir praticamente a mesma quantidade de matéria orgânica num intervalo de tempo menor.

A concentração de sólidos suspensos voláteis no tanque de aeração dos dois reatores para o ensaio com tempo de ciclo de 24 horas reduziu gradativamente durante o ensaio. Isso pode ser atribuído ao fato dos descartes diários necessários para manutenção da idade do lodo de 10 dias serem superiores à produção de lodo. A baixa produção de lodo para esse tempo de ciclo, possivelmente tenha ocorrido devido ao metabolismo endógeno da biomassa, em que, pelo elevado tempo de aeração, de aproximadamente 22 horas, os microrganismos consumiram suas próprias reservas protoplasmáticas.

Os valores do índice volumétrico do lodo, na faixa de 50 a $100 \mathrm{~mL} / \mathrm{g}$, indicaram lodo com boas condições de sedimentabilidade. Estes valores também comprovaram a inexistência do entumescimento filamentoso do lodo ("bulking"), o que facilitou a retenção do lodo nos frascos de 5 litros após o tempo de sedimentação. 
Os reatores foram operados durante os ensaios em sistema descontínuo sem processo adicional para remoção de nutrientes. $O$ fosfato total e uma fração do nitrogênio amoniacal provavelmente foram removidos no lodo, correspondente ao utilizado na síntese celular dos microrganismos e a outra fração do nitrogênio amoniacal, pode ter sido transformada pelo processo de nitrificação em nitrito e nitrato ou até mesmo volatilizada. $\mathrm{O}$ nitrogênio total Kjeldahl (NTK) é composto pelo nitrogênio amoniacal e orgânico, sendo que o orgânico é convertido pelo processo de amonificação em amoniacal. As concentrações de NTK e nitrogênio amoniacal obtidas para a água residuária bruta apresentaram maiores oscilações entre os ensaios do que no decorrer de cada um deles, mas as de fosfato total mantiveram-se estáveis.

As percentagens médias de remoção de fosfato total após a estabilização dinâmica dos reatores variaram de 31 a $9 \%$, sendo que as menores remoções ocorreram para o tempo de ciclo de 12 horas. Esta remoção inferior obtida para o tempo de ciclo de 12 horas pode ser considerada contraditória, pois os reatores operados com esse tempo de ciclo possuíam as maiores concentrações de sólidos suspensos voláteis, portanto, necessitavam de uma maior quantidade de fósforo para os microrganismos realizarem a síntese da biomassa; entretanto, pelo curto tempo de operação dos ensaios e o reduzido número de análises, não é possível concluir sobre as causas.

Os valores de NTK e nitrogênio amoniacal obtidos nos ensaios, apesar de serem provenientes de um número reduzido de análises, mostram que as oscilações presentes na água residuária bruta são amortecidas no interior dos reatores e que os diferentes tempos de ciclo empregados tiveram pequena influência nas percentagens médias de conversão, que foram superiores a 93 e $98 \%$, respectivamente, sendo que os dois reatores operados simultaneamente apresentaram praticamente a mesma conversão em cada ensaio. As percentagens médias de conversão de NTK e nitrogênio amoniacal próximas de $100 \%$, indicaram que praticamente todo nitrogênio orgânico presente também foi convertido. 
Com relação aos resultados dos exames microscópicos realizados durante a aclimatação da água residuária bruta, conforme apresentados na Tabela A.18 do Anexo A, nota-se diminuição das bactérias isoladas em suspensão e, conseqüentemente, dos protozoários ciliados livre-natantes e protozoários flagelados com aumento dos protozoários ciliados fixos.

A presença dos protozoários ciliados livre-natantes e protozoários flagelados está relacionada com a das bactérias, uma vez que, ao se alimentarem destes microrganismos, sua presença diminui à medida que a população bacteriana decresce, pois requerem grande quantidade de energia para locomoção. Já os protozoários ciliados fixos, por serem organismos fixos, necessitam de menor quantidade de energia e apresentam as maiores concentrações na fase de boa floculação (BRANCO, 1986).

Observou-se também a presença constante de bactérias filamentosas, cistos de protozoários e flocos compactos de bordos dendríticos, que foram provenientes do lodo utilizado como inóculo.

Considerou-se a água residuária como aclimatada, com seu lodo em condições de ser utilizado como inóculo nos dois reatores no ensaio com tempo de ciclo de 24 horas, quando surgiram os primeiros rotíferos, pelo fato de serem indicadores de um grau avançado de estabilidade.

Observando-se na Tabela A.18 os resultados dos exames microscópicos realizados durante os ensaios em sistema descontínuo, verifica-se que a baixa freqüência de microrganismos móveis, principalmente protozoários ciliados livres-natantes e protozoários flagelados está relacionada com a baixa freqüência das bactérias isoladas em suspensão.

A presença de ciliados fixos e rotíferos, indicaram boa estabilidade no processo, associada às remoções obtidas para os dois reatores. A predominância dos protozoários rhizópodos (amebas) no primeiro dia de aeração do ensaio com tempo de ciclo de 24 horas é característica do lodo jovem em início de operação (CETESB, 1989). 
As maiores concentrações de rotíferos, e até presença de nematóides obtidas para o ensaio com tempo de ciclo de 12 horas, que são indicadores de um estágio avançado de estabilidade, podem ter sido conseqüência do longo tempo de aeração que se prolongou desde o início do ensaio com tempo de ciclo de 24 horas, já que se manteve o mesmo lodo durante os ensaios, sendo realizadas as retiradas parciais para manutenção da idade do lodo de 10 dias e modificando o tempo de aeração conforme o tempo de ciclo empregado.

\section{2 - Ensaio em sistema contínuo}

Neste item serão discutidos para o sistema de lodos ativados operado em sistema contínuo os resultados do controle do sistema, dos parâmetros experimentais obtidos durante o ensaio, dos coeficientes cinéticos, da taxa de utilização de oxigênio, dos parâmetros a' e b', do coeficiente $\alpha$, da relação F/M, da taxa específica de utilização de substrato, da produção líquida de lodo ativado por dia (valor estimado), do lodo ativado descartado diariamente do tanque de aeração e dos exames microscópicos.

\subsection{1 - Controle do sistema}

$-\mathbf{p H}$

Nas Figuras B.1 a B.4 do Anexo B, nota-se que após o ajuste de pH do tanque de alimentação (água residuária afluente) para valores próximos de 8 , com auxílio de solução de hidróxido de cálcio, os valores de $\mathrm{pH}$ dos quatro reatores mantiveram-se próximos de 7, sem necessidade de correção, portanto, situados na faixa ótima para desenvolvimento dos microrganismos necessários 
ao processo de lodos ativados, pois não comprometeram o desempenho dos reatores.

Observa-se, principalmente, nas Figuras B.1 e B.3, referentes aos reatores R1 e R3, respectivamente, como também, na Figura B.2, referente ao reator R2, que após alguns dias de ensaio, antes do ajuste de $\mathrm{pH}$ do tanque de alimentação, que os valores de $\mathrm{pH}$ destes reatores eram inferiores a 6,5, sendo esta queda responsável pela presença de fungos nestes reatores no $9_{-}^{\circ}$ dia de aeração. Este declínio nos valores de $\mathrm{pH}$ pode ter sido provocado pela geração de ácidos no processo de nitrificação e de $\mathrm{CO}_{2}$ durante a decomposição da matéria orgânica.

\section{- Oxigênio Dissolvido}

Como para o sistema descontínuo, procurou-se manter a concentração de oxigênio dissolvido nos tanques de aeração superior a $2 \mathrm{mg} / \mathrm{L}$, para, conforme mencionado anteriormente na revisão bibliográfica obter-se a nitrificação.

Pela análise das Figuras B.5 a B.8 do Anexo B, verifica-se que não ocorreu insufíciência de oxigênio dissolvido nos reatores durante o ensaio, pois a maioria das concentrações foram próximas ou superiores a $2 \mathrm{mg} / \mathrm{L}$. Alguns valores inferiores a $2 \mathrm{mg} / \mathrm{L}$, principalmente os do reator R4 (ver Figura B.8), que apresentou a mais elevada concentração de sólidos suspensos no tanque de aeração, foram ocasionados pelo motivo do decantador secundário ser justaposto ao tanque de aeração, limitando assim a vazão de oxigênio afluente, para não provocar perturbações no decantador. Observa-se também que as concentrações foram oscilantes nos quatro reatores no decorrer do ensaio, provavelmente devidas à falta de controle de temperatura, às concentrações variáveis de matéria orgânica afluente e ao controle manual das vazões de ar, através de registros de agulha. A descontinuidade nos gráficos 
deu-se pelo descarregamento da bateria do oxímetro, impossibilitando a determinação.

Os valores médios de oxigênio dissolvido obtidos nos quatro reatores apresentaram-se próximos, como também os máximos e mínimos, sendo que as menores concentrações ocorreram no reator R4, conforme descrito na Tabela B.2 do Anexo B.

\section{- Temperatura}

$\mathrm{O}$ monitoramento da temperatura no interior dos reatores, apresentado na Figura B.9 do Anexo B mostrou que, apesar da inexistência de controle, esta não teve grandes variações ao longo do ensaio, situando-se entre 21,0 e $26,3{ }^{\circ} \mathrm{C}$, sendo que seu valor médio de $23,9^{\circ} \mathrm{C}$ enquadra-se na faixa mesófila. Nota-se também que ficaram próximas da temperatura ambiente, com média de $24,8{ }^{\circ} \mathrm{C}$ em quase todo o ensaio. Isso ocorreu devido ao pequeno volume dos reatores, facilitando a transferência de calor. Os valores mais elevados da temperatura ambiente ocorreram nos primeiros dias de ensaio, ocasionados pelo aquecimento do ambiente por interferência externa de equipamentos como autoclave e mufla.

\section{- Vazão}

A vazão de alimentação dos quatro reatores, conforme mostrado nas Tabelas B.1 e B.2 do Anexo B, não variou significativamente em relação ao valor de $1,275 \mathrm{~L} / \mathrm{h}$, que representa a média estabelecida em cada reator para atender ao tempo de detenção hidráulico de 8 horas, pois apresentaram variações inferiores a 17 e a $12 \%$, respectivamente, para as vazões máximas e mínimas. 
Pelos valores médios das vazões, pode-se dizer que o tempo de detenção hidráulico foi mantido em torno de 8 horas nos reatores, sendo adotado para cálculo dos coeficientes cinéticos a vazão de $1,287 \mathrm{~L} / \mathrm{h}$, que corresponde ao valor médio das vazões médias obtidas para os quatro reatores, resultando num tempo de detenção hidráulico de 7,93 horas.

Como a concentração de matéria orgânica da água residuária variou durante o ensaio, não se pode afirmar que a carga orgânica foi mantida constante.

\subsection{2 - Parâmetros experimentais obtidos durante o ensaio}

\section{- DBO}

De acordo com as Figuras B.10 a B.13 do Anexo B, observa-se que os valores da DBO bruta e filtrada da água residuária afluente foram oscilantes durante o ensaio, variando de 121 a $203 \mathrm{mg} / \mathrm{L}$ e de 38 a $85 \mathrm{mg} / \mathrm{L}$, respectivamente. Mas os valores da DBO bruta efluente, principalmente os obtidos após 27 dias de operação, quando os reatores se encontravam estabilizados dinamicamente, mostraram que as variações de carga foram absorvidas pelos reatores, pois estes apresentaram valores bem próximos e médias inferiores a $8 \mathrm{mg} / \mathrm{L}$. O mesmo aconteceu com a DBO filtrada efluente, só que com médias inferiores a $5 \mathrm{mg} / \mathrm{L}$.

Como se pode ver na Figura B.14 do Anexo B, as diferentes idades do lodo mantidas nos reatores praticamente não tiveram influência sobre os valores da DBO bruta efluente, que foram semelhantes nos quatro reatores, sobretudo quando estes se achavam estabilizados dinamicamente. $\mathrm{O}$ mesmo pode ser verificado na Figura B.15, também do Anexo B, para a DBO filtrada efluente. 
Conforme descrito na Tabela 5.2, as percentagens médias de remoção da DBO bruta e filtrada superiores a 95 e a $90 \%$, respectivamente, obtidas após a estabilização dinâmica dos reatores, podem ser consideradas satisfatórias para água residuária proveniente de reator anaeróbio compartimentado que recebe esgoto sanitário. Pode-se também notar que as diferentes idades do lodo mantidas nos reatores tiveram reduzida influência nas eficiências.

- DQO

Observando-se as Figuras B.16 a B.19 do Anexo B, nota-se que os valores da DQO bruta e filtrada da água residuária afluente possuem variações significantes, indo de 299 a $373 \mathrm{mg} / \mathrm{L}$ e de 119 a $210 \mathrm{mg} / \mathrm{L}$, respectivamente. Mas os valores da DQO bruta efluente obtidos após a estabilização dinâmica dos reatores, próximos e com médias inferiores a $43 \mathrm{mg} / \mathrm{L}$, mostraram que as variações foram amortecidas pelos reatores. O mesmo ocorreu com a DQO filtrada efluente, que apresentou média inferior a $33 \mathrm{mg} / \mathrm{L}$.

Na Figura B.20 do Anexo B, pode-se observar que as diferentes idades do lodo utilizadas nos reatores, proporcionaram a obtenção de valores da DQO bruta efluente semelhantes nos quatro reatores, principalmente quando estes se achavam estabilizados dinamicamente, independente das variações externas. Nota-se também que os valores da DQO bruta efluente estabilizaram-se após 27 dias de ensaio nos quatro reatores, quando foram considerados estabilizados dinamicamente. Em termos da DQO filtrada efluente, o mesmo pode ser verificado na Figura B.21, também do Anexo B.

Com relação às percentagens médias de remoção de DQO bruta $\mathrm{e}$ filtrada mostradas na Tabela 5.2, que foram obtidas quando os reatores se encontravam estabilizados dinamicamente, o desempenho destes pode ser considerado satisfatório, com remoção da DQO bruta e filtrada superior a 87 e 
a $80 \%$, respectivamente. Analisando-se as diferentes idades do lodo mantidas nos reatores, pode-se observar que estas tiveram reduzida influência nas suas eficiências.

\section{- Sólidos}

Pelos resultados dos sólidos totais determinados no decorrer do ensaio em sistema contínuo, mesmo os obtidos após a estabilização dinâmica dos reatores, conclui-se que a remoção foi baixa e irregular, sendo que até algumas análises apresentaram valores superiores aos obtidos para água residuária afluente. Estes resultados podem ser proporcionados por erros oriundos da metodologia utilizada, como possíveis erros na determinação do peso da cápsula (interferência da umidade e limpeza) e medição do volume de amostra. Uma melhor representação poderia ser conseguida com a realização de duplicata ou triplicata de análises da mesma amostra e aumento do volume de amostra de 50 para $100 \mathrm{~mL}$.

Com os valores médios de sólidos suspensos totais, sólidos suspensos fixos e sólidos suspensos voláteis dos efluentes obtidos no ensaio após a estabilização dinâmica dos reatores, pode-se verificar que as variações presentes na água residuária afluente foram amortecidas no interior dos reatores, pois seus efluentes apresentaram valores próximos e inferiores a 6,5, 1,3 e $5,3 \mathrm{mg} / \mathrm{L}$, respectivamente.

Analisando as percentagens médias de remoção de sólidos suspensos totais, sólidos suspensos fixos e sólidos suspensos voláteis (Tabela 5.2) obtidas quando os reatores estabilizaram-se dinamicamente, nota-se que foram superiores a 95,8, 98,2 e 93,6\%, respectivamente, valores esses que podem ser considerados satisfatórios para a água residuária em questão. Pode-se também ver que as diferentes idades do lodo mantidas nos reatores tiveram pequena 
influência nas eficiências, especialmente em relação aos sólidos suspensos fixos.

Os sólidos sedimentáveis presentes na água residuária afluente (obtidos após 1 hora), que apresentou valor médio de $1,1 \mathrm{~mL} / \mathrm{L}$, foram retidos satisfatoriamente nos quatro reatores durante todo o ensaio, não sendo detectados no efluente.

Na Figura B.22 do Anexo B, que compara a variação dos sólidos suspensos voláteis no tanque de aeração dos quatro reatores que representam a concentração de microrganismos, pode-se observar que até 27 dias de ensaio, os valores do reator R4 tiveram um aumento crescente até praticamente estabilizar-se em concentrações acima de $3000 \mathrm{mg} / \mathrm{L}$ e que os valores dos outros reatores tiveram uma menor oscilação. Observa-se também que após 27 dias de ensaio, quando se consideraram os reatores estabilizados dinamicamente, a concentração em cada reator praticamente manteve-se estabilizada, excluindo o reator R3 que teve uma maior variação. Esta oscilação não implicou em aumento ou queda de remoção da DBO e da DQO.

\section{- Índice volumétrico do lodo}

Pode-se observar na Figura B.31 do Anexo B, que compara a variação do índice volumétrico do lodo dos quatro reatores durante a operação em sistema contínuo, que quase todos valores se situaram na faixa compreendida entre 40 a $100 \mathrm{~mL} / \mathrm{g}$, que segundo diversos autores, indicam que o lodo presente nos reatores possui boas características de sedimentabilidade. Estes resultados também permitiram comprovar a inexistência do entumescimento filamentoso do lodo ("bulking"), o que ajudou na retenção do mesmo nos decantadores secundários durante os descartes contínuos dos efluentes.

Nesta Figura, verifica-se que, principalmente após 27 dias de operação, quando se consideraram os reatores estabilizados dinamicamente, os valores 
do índice volumétrico do lodo foram próximos, com exceção de alguns resultados do reator R3 que se apresentaram maiores, indicando uma pior qualidade do lodo.

Pode-se também notar que os menores valores e até alguns inferiores a $40 \mathrm{~mL} / \mathrm{g}$ foram obtidos no reator R1, operado com a menor idade do lodo, $\mathrm{e}$ que o reator R4, mesmo operado com a maior idade do lodo $\mathrm{e}$ conseqüentemente possuindo a maior concentração de sólidos suspensos totais no tanque de aeração, após estabilizar-se dinamicamente, apresentou valores praticamente constantes e bem próximos aos do reator $\mathrm{R} 1$, indicando que seu lodo possuía uma boa qualidade de sedimentação.

\section{- Nutrientes}

Como o objetivo principal deste ensaio foi remoção de matéria orgânica, os reatores foram operados sem processo adicional para remoção de nutrientes. Conforme descrito anteriormente para os ensaios em sistema descontínuo, o fosfato total e uma parcela do nitrogênio amoniacal podem ter sidos removidos no lodo, outra parcela do nitrogênio amoniacal foi transformada em nitrito e nitrato e ainda outra parcela pode ter sido volatilizada.

A relação DBO:NTK:Fosfato total $=100: 34,3: 14,3$ obtida para a água residuária afluente durante o ensaio contínuo é bem superior à relação $\mathrm{DBO}: \mathrm{N}: \mathrm{P}=100: 5: 1$ recomendada para o processo de lodos ativados convencionais, comprovando-se o excesso destes nutrientes.

Nas Figuras B.23 a B.26 do Anexo B observa-se que, excluindo o $8_{-}^{\circ}$ dia de ensaio, as concentrações de NTK, nitrato e nitrito presentes na água residuária afluente não tiveram grandes oscilações durante o ensaio. $\mathrm{O}$ mesmo também ocorreu com o nitrogênio amoniacal, só que em todo o ensaio. A alta concentração de NTK no $8_{-}^{\circ}$ dia de ensaio deve-se à elevada parcela de 
nitrogênio orgânico, uma vez que a concentração de nitrogênio amoniacal apresentou praticamente o mesmo valor durante todo ensaio. A elevada concentração de nitrito e nitrato nesse dia de ensaio foi dada pela maior presença destas substâncias inorgânicas.

Nota-se também nas Figuras B.23 a B.26 que os efluentes dos reatores, quando esses se achavam estabilizados dinamicamente, apresentaram concentração de NTK, com algumas exceções, e de nitrogênio amoniacal com valores bem baixos e até alguns não detectados pelos métodos de análises utilizados. Os valores mais elevados de NTK podem ser proporcionados pelo nitrogênio orgânico remanescente, uma vez que o amoniacal foi praticamente todo convertido. Pode-se também verificar que o nitrito presente nos efluentes dos quatro reatores sofreu considerável redução após estabilizarem-se dinamicamente, sem aumento do nitrato. Com isto, as concentrações de NTK e nitrogênio amoniacal afluentes foram mantidas, indicando que a parcela de nitrogênio amoniacal, que era convertida em nitrato, pode ter sido utilizada pelos microrganismos na síntese celular, pois houve aumento na remoção de DQO. Com relação aos valores do nitrato presente nos efluentes dos quatro reatores, pode-se ver nas Figuras B.25 e B.26 referentes aos reatores R3 e R4, respectivamente, que estes apresentaram as maiores variações.

Ao analisar as Figuras B.27 a B.30 do Anexo B, em que se compara em cada figura a variação da concentração do fosfato total da água residuária afluente, sendo a mesma para os quatro reatores, com a do efluente do reator correspondente, durante a operação do sistema contínuo, pode-se notar que as concentrações da água residuária afluente e, principalmente, as dos efluentes dos reatores não tiveram grandes variações no decorrer do ensaio. Como a remoção de fosfato total nos quatro reatores foi próxima em quase todo ensaio, seus efluentes apresentaram um comportamento gráfico semelhante em relação à concentração de fosfato total presente na água residuária afluente.

As percentagens médias de remoção de fosfato total obtidas para os quatro reatores, após a estabilização dinâmica, por serem efetuadas somente no 
lodo, foram baixas e inferiores a $28 \%$, evidenciando assim a necessidade de remoção do residual desse nutriente.

A conversão de NTK e nitrogênio amoniacal alcançou níveis elevados a ponto de não serem detectados pelos métodos de análises utilizados, resultados esses que podem ser considerados satisfatórios e que somados com os resultados obtidos para nitrito e nitrato demonstraram a necessidade da desnitrificação. A alta conversão de NTK e nitrogênio amoniacal, próximas de 100 \%, indicaram que praticamente todo nitrogênio orgânico presente foi também convertido.

Os resultados obtidos indicaram que uma parcela de nitrogênio amoniacal, que inclui o disponível na água residuária afluente e o nitrogênio orgânico convertido em amoniacal por amonificação foi nitrificada, conforme demonstram os resultados de nitrito e nitrato, sendo que o restante pode ter sido removido no lodo ou volatilizado, mas pela falta de determinação de NTK e nitrogênio amoniacal do lodo, fica difícil provar esta hipótese.

O possível consumo elevado de nitrogênio amoniacal no lodo pode ser dado à natureza da água residuária utilizada ou dos microrganismos presentes, que também necessitou de fosfato total acima da relação 100:5:1 recomendada para crescimento dos microrganismos nos processos de lodos ativados. As diferentes idades do lodo mantidas nos reatores tiveram reduzida influência na remoção desses nutrientes.

\section{- Alcalinidade}

$\mathrm{O}$ ajuste de $\mathrm{pH}$ do tanque de alimentação com auxílio de solução de hidróxido de cálcio para valores próximos de 8 pode ter proporcionado acréscimo na alcalinidade da água residuária afluente em conseqüência da introdução de cálcio. 
Na Figura B.32 do Anexo B nota-se que tanto os valores da alcalinidade da água residuária afluente obtidos após o ajuste de $\mathrm{pH}$ como os dos efluentes dos reatores, com exceção de alguns valores do efluente do reator R1, não tiveram grandes variações ao longo do ensaio. Observa-se que após 27 dias, quando se consideraram os reatores estabilizados dinamicamente, seus efluentes, para as idades do lodo estudadas, apresentaram valores próximos e inferiores aos valores antes da estabilização, excluindo o reator R3 que teve os menores valores em decorrência dos valores de $\mathrm{pH}$ também menores.

Os resultados dos efluentes mostraram que uma parcela da alcalinidade presente na água residuária foi consumida no interior dos reatores juntamente com diminuição do valor do $\mathrm{pH}$ de aproximadamente 8 para valores em torno de 7, provavelmente ocasionados pela geração de ácidos durante o processo de nitrificação e de $\mathrm{CO}_{2}$ durante a decomposição da matéria orgânica e pelo consumo dos ácidos voláteis e nitrogênio amoniacal.

\subsection{3 - Coeficientes cinéticos}

Os valores negativos de $\mathrm{k}$ e $\mathrm{K}_{\mathrm{s}}$ obtidos para as bases DBO e DQO filtrada efluente, portanto, sem nenhum significado físico, evidenciam que os dados experimentais determinados no ensaio em sistema contínuo não se ajustam ao modelo aplicado. Resultados de outros pesquisadores como BLUNDI (1982) e LARANJEIRA FILHO (1989), que empregaram para alimentação dos reatores, respectivamente, a lactose e resíduos de tomate maduros triturados, também obtiveram resultados com o mesmo comportamento.

A realização de apenas um ensaio dificulta a obtenção de qualquer conclusão sobre as limitações de aplicação desse modelo ou sobre a interferência dos erros realizados nas medições dos parâmetros utilizados ou nas considerações adotadas. Erros ocorreram na adoção de que a totalidade 
dos sólidos suspensos voláteis presentes no tanque de aeração pertencem à biomassa ativa, na desconsideração das perdas de lodo no efluente, na falta de manutenção da carga orgânica constante durante a alimentação dos reatores, na determinação da DBO e DQO filtrada efluente, em que se utilizou membrana com porosidade $1,2 \mu \mathrm{m}$ no lugar de $0,45 \mu \mathrm{m}$, que não reteve todos microrganismos. Estes valores negativos também podem ter ocorrido devido à característica da água residuária, que possibilitou a todos reatores, independente da idade do lodo, apresentarem praticamente a mesma remoção.

Para melhor compreensão, esse ensaio deveria ser repetido várias vezes para comparação dos resultados e realizar outros variando-se apenas a idade do lodo. Mais ainda, poderia utilizar-se um sistema com tanque de aeração e decantador secundário em unidades independentes para minimizar a perda de lodo no efluente e verificar se ocorre influência do retorno controlado do lodo.

Na Tabela 5.3 estão mostrados os valores dos coefícientes cinéticos $\mathrm{Y}$ e $\mathrm{k}_{\mathrm{d}}$ determinados com o sistema contínuo para as bases DBO e DQO filtrada efluente. Os valores destes coeficientes, apesar de serem obtidos numa temperatura média dos reatores de $23,9^{\circ} \mathrm{C}$ e da água residuária ser proveniente de efluente de reator anaeróbio compartimentado que recebe esgoto sanitário, enquadram-se nos intervalos apresentados na Tabela 3.10, que foram obtidos a $20{ }^{\circ} \mathrm{C}$ e com esgoto sanitário bruto. Mas, pela inexistência na literatura da determinação destes coeficientes utilizando esta água residuária, não foi possível realizar nenhuma comparação. Os coeficientes de correlação $-r^{2}$ inferiores a 0,7 demonstraram que não ocorreram bons ajustes dos valores experimentais em relação às retas teóricas obtidas após regressão linear pelo método dos mínimos quadrados. 


\subsection{4 - Taxa de utilização de oxigênio}

Com relação aos valores médios da taxa de utilização de oxigênio apresentados na Tabela 5.4, observa-se para os quatro reatores que os valores dos ensaios de amostras sem adição de substrato foram inferiores aos dos ensaios com adição de substrato. Isso pode ter ocorrido pela deficiência de carbono e nutrientes necessários para o metabolismo dos microrganismos. Para os ensaios de amostras sem adição de substrato, observa-se nesta tabela que o valor médio da taxa de utilização de oxigênio aumentou com o aumento da idade do lodo e o conseqüente aumento do valor médio de sólidos suspensos voláteis no tanque de aeração. O reator R4, que operado com idade do lodo de 20 dias, comportou-se de forma diferente, atingindo valor médio de sólidos suspensos voláteis no tanque de aeração de $3238 \mathrm{mg} / \mathrm{L}$ e valor médio da taxa de utilização de oxigênio próximo ao do reator R3, que pode ter sido ocasionada pela falta de alimento para os microrganismos. Nesta tabela também se pode notar para os ensaios com adição de substrato que o valor médio da taxa de utilização de oxigênio cresceu com o aumento da idade do lodo, mas o reator R3, por algum problema de retenção de lodo no decantador secundário apresentou valor médio da taxa de utilização de oxigênio e dos sólidos suspensos voláteis no tanque de aeração inferiores aos do reator R2.

\subsection{5 - Parâmetros a' e b'}

A determinação gráfica dos parâmetros a' e b', para as bases DBO e DQO filtrada efluente, em que se utilizaram os valores da taxa de utilização de oxigênio determinada sem adição de substrato, apresentou melhor ajuste dos valores experimentais em relação à reta teórica obtida após regressão linear pelo método dos mínimos quadrados, do que quando se utilizaram os valores da taxa de utilização de oxigênio determinada com adição de substrato. 
Os valores de a', obtidos com a taxa de utilização de oxigênio determinada sem adição de substrato, superiores aos obtidos com a taxa de utilização de oxigênio determinada com adição de substrato, para as bases DBO e DQO filtrada efluente, são devidos às maiores concentrações de microrganismos nas amostras sem adição de substrato, o que acarretou maior consumo de oxigênio pelos microrganismos, pois foi necessário oxidar uma fração maior de substrato para produção de energia.

Para o parâmetro b', os valores obtidos com a taxa de utilização de oxigênio determinada com adição de substrato, para as bases DBO e DQO filtrada efluente, foram superiores àqueles obtidos sem adição de substrato. Como as amostras com adição de substrato apresentaram uma maior disponibilidade de alimento, os microrganismos podem se encontrar na fase exponencial de crescimento e também apresentar um avançado metabolismo endógeno, o que pode ter ocasionado um maior consumo de oxigênio durante a respiração endógena. Os valores de b' obtidos com a taxa de utilização de oxigênio determinada sem adição de substrato foram próximos para as bases DBO e DQO filtrada efluente. O mesmo ocorreu para os valores de b' obtidos com a taxa de utilização de oxigênio determinada com adição de substrato.

RAMALHO apud KATO (1982) e JORDÃO \& PESSOA (1995) citam que os valores dos parâmetros a' e b' determinados para o esgoto sanitário bruto para a base $\mathrm{DBO}_{5}$ são $0,52 \mathrm{e} 0,12 \mathrm{dia}^{-1}$, respectivamente. Conforme pode se ver na Tabela 5.5, os valores de a' e b' determinados para o pós-tratamento da água residuária proveniente de efluente de reator anaeróbio compartimentado que recebe esgoto sanitário, para a base DBO filtrada efluente nos casos da taxa de utilização de oxigênio ser determinada com e sem adição de substrato, foram superiores aos obtidos para o esgoto sanitário bruto, excluindo o valor de b' para o caso da taxa de utilização de oxigênio determinada sem adição de substrato, que apresentou praticamente o mesmo valor. Mas como estes parâmetros dependem da concentração de 
microrganismos, é difícil compará-los com os de RAMALHO e JORDÃO \& PESSOA.

\subsection{6 - Coeficiente $\alpha$}

Como se pode ver na Tabela 5.6, a maioria dos valores médios do coeficiente $\alpha$, obtidos para os quatro reatores em todos os ensaios, ficaram próximos do valor 1 , isto é, para os valores do coeficiente global de transferência de oxigênio determinados com e sem utilização de sulfito de sódio para desoxigenar as amostras. $\mathrm{O}$ valor médio do reator $\mathrm{R} 2$ para o ensaio com utilização de sulfito apresentou a maior discrepância, que pode ter sido devida à influência do sulfito de sódio na utilização de oxigênio pelos microrganismos.

Esses valores próximos de 1 podem ser conseqüência das características da água residuária utilizada, que apresentou valores do coeficiente global de transferência de oxigênio próximos aos da água limpa.

\subsection{7 - Relação F/M, U, $\mathbf{P}_{\mathbf{x}}$ e $\mathbf{P}_{\mathbf{x}}$ '}

Analisando-se os valores da relação F/M (Tabela B.28 do Anexo B) obtidos para os reatores operados em sistema contínuo nas bases DBO e DQO filtrada efluente, nota-se que decresceram com aumento da idade do lodo. Os valores de F/M para os reatores na base DBO filtrada, principalmente o baixo valor do reator R4, não proporcionaram o entumescimento filamentoso do lodo ("bulking"), conforme comprovam os valores do índice volumétrico do lodo que indicam lodo com boas características de sedimentabilidade.

Os valores da relação $\mathrm{F} / \mathrm{M}$ determinados para base $\mathrm{DBO}$ filtrada, excluindo o reator R4 que se mostrou inferior $(0,14 \mathrm{~kg} . \mathrm{DBO} / \mathrm{kg}$.SSVTA.dia), 
se enquadram na faixa de 0,2 a $0,6 \mathrm{~kg}$.DBO $/ \mathrm{kg}$.SSVTA.dia citada por JORDÃO \& PESSOA (1995) como a melhor para o esgoto sanitário bruto (lodo floculado - faixa de ótima sedimentabilidade). Todos os reatores também se enquadram na faixa de 0,07 a $1,1 \mathrm{~kg} . \mathrm{DBO} / \mathrm{kg}$.SSVTA.dia recomendada pela Norma Brasileira NB-570 apud JORDÃO \& PESSOA (1995).

Na Tabela B.29 do Anexo B, pode-se ver que a taxa específica de utilização de substrato para as bases DBO e DQO filtrada efluente decresceu com aumento da idade do lodo e do conseqüente aumento da concentração de microrganismos no reator. Estes resultados podem ter sido ocasionados pelo fato da utilização de substrato estar relacionada com a concentração de microrganismos presentes no tanque de aeração, pois quanto menor esta concentração, maior a utilização, uma vez que todos reatores forneceram praticamente a mesma eficiência. Mais ainda, pode ser notado nesta tabela que os valores da base DQO foram aproximadamente o dobro da base DBO.

Os valores da taxa de utilização de substrato obtidos para os reatores na base DBO estão na faixa de 0,06 a $1,10 \mathrm{~kg}$.DBO $/ \mathrm{kg}$.SSVTA.dia recomendada pela Norma Brasileira NB-570 apud JORDÃO \& PESSOA (1995) para o processo de lodos ativados.

Observando-se os valores da produção líquida de lodo ativado por dia (Tabela B.30 do Anexo B), que representam uma estimativa da quantidade de lodo produzida por dia, e que deve ser descartada, nota-se que decresceram com aumento da idade do lodo para as bases DBO e DQO filtrada efluente. Isto ocorreu pelo também decréscimo do coeficiente de síntese celular observada com aumento da idade do lodo, uma vez que a concentração de substrato no efluente não apresentou significativa variação para as idades do lodo estudadas. Pode-se também notar que a base DBO e DQO tiveram valores próximos para todas idades do lodo.

Com relação à quantidade real do lodo ativado descartado diariamente do tanque de aeração, conforme mostrado na Tabela B.31 do Anexo B, nota-se diminuição com aumento da idade do lodo, conseqüência da maior vazão 
descartada pelas menores idades do lodo. $\mathrm{O}$ reator $\mathrm{R} 4$ apresentou comportamento diferente, com valor superior aos reatores R2 e R3, devido à elevada concentração de microrganismos no tanque de aeração.

Como se pode ver na Tabela B.32 do Anexo B, em que se compara a quantidade real do lodo ativado descartado diariamente do tanque de aeração $\left(\mathrm{P}_{\mathrm{x}}{ }^{\prime}\right)$ com a produção líquida de lodo ativado por dia $\left(\mathrm{P}_{\mathrm{x}}\right)$, que se trata de um valor estimado da quantidade a ser descartada; nota-se que ocorreu desvio entre a quantidade real descartada e a estimada em todos os reatores. Estas diferenças podem ter ocorrido, principalmente, por erros na determinação dos sólidos suspensos voláteis no tanque de aeração dos reatores para cálculo de $\mathrm{P}_{\mathrm{x}}$ ' e na determinação de $\mathrm{Y}_{\mathrm{obs}}$ para cálculo de $\mathrm{P}_{\mathrm{x}}$. Os coeficientes cinéticos $\mathrm{Y} \mathrm{e}$ $\mathrm{k}_{\mathrm{d}}$ utilizados para cálculo de $\mathrm{Y}_{\mathrm{obs}}$, foram determinados por dados experimentais, que proporcionaram uma reta ajustada pelo método dos mínimos quadrados com baixo coeficiente de correlação $\left(\mathrm{r}^{2}\right)$.

\subsection{8 - Exames microscópicos}

A seguir, serão discutidas as presenças dos principais microrganismos observados nos exames microscópicos realizados durante a aclimatação da água residuária, que estão mostrados na Tabela B.33 do Anexo B.

A freqüência elevada de bactérias filamentosas e algas é devida às suas presenças no lodo utilizado como inóculo. A presença de algas no lodo usado na inoculação é conseqüência do sistema de tratamento ser de lagoa aerada, que apresenta grande área exposta ao sol, e de bactérias filamentosas das características de operação da lagoa.

Com a diminuição das bactérias isoladas em suspensão ocorre também diminuição dos protozoários flagelados e protozoários ciliados livre-natantes, pois estes se nutrem das bactérias e consomem grandes quantidades de energia para locomoção. A diminuição das bactérias ocasiona o aumento da 
concentração dos protozoários ciliados fixos, que por serem fixos necessitam de menos energia.

Considerou-se a água residuária como aclimatada, isto é, com o seu lodo podendo ser utilizado como inóculo, ocasião em que apresentou uma frequiência média de ciliados fixos, pois a sua presença está relacionada com a boa floculação.

Os resultados dos exames microscópicos apresentados na Tabela B.34 do Anexo B, que foram realizados durante a operação dos quatro reatores em sistema contínuo, serão discutidos a seguir.

A concentração de bactérias filamentosas foi diminuindo no decorrer do ensaio para os reatores R1 e R2, que possuem as menores idades do lodo, de 5 e 10 dias, respectivamente, e conseqüentemente os maiores descartes diários do lodo, que podem ter prejudicado o crescimento dessas bactérias.

Os protozoários rhizópodos (amebas) estiveram presentes nos reatores R3 e R4, respectivamente, no início e no final do ensaio, que conforme citado anteriormente na revisão, são os primeiros protozoários a se desenvolverem.

As baixas concentrações de bactérias isoladas em suspensão propiciaram o desaparecimento dos protozoários flagelados, que apareceram apenas no segundo dia de ensaio, e também dos protozoários ciliados livrenatantes, que não foram detectados no decorrer do mesmo.

$\mathrm{O}$ aparecimento de fungos unicelulares nos reatores R1, R2 e R3 apenas no oitavo dia de ensaio foram conseqüentes da queda do $\mathrm{pH}$ para valores inferiores a 6,5 e estes desapareceram após o $\mathrm{pH}$ equilibrar-se em torno de 7. Os fungos filamentosos também surgiram com a queda do $\mathrm{pH}$, só que prevaleceram até o final do ensaio, sendo menos freqüentes nos reatores $\mathrm{R} 1 \mathrm{e}$ $\mathrm{R} 2$, provavelmente devido às menores idades do lodo.

A presença de algas nos reatores, que foram provenientes do lodo utilizado como inóculo, diminuíram durante o ensaio, pois tomaram-se certas medidas para evitar ao máximo a presença de luz, como envolvimento dos reatores com papel alumínio e das mangueiras de alimentação com fita opaca 
de cor preta, cobertura dos reatores com lona plástica preta; também procurouse trabalhar, quando possível, no escuro. Essas diminuições foram mais marcantes nos reatores R1 e R2, que pelo fato de apresentarem os maiores descartes do lodo e das algas por possuírem crescimento lento (inferiores as bactérias), tiveram suas concentrações reduzidas durante o ensaio.

A alta concentração de ciliados fixos e, principalmente de rotíferos indicou um grau avançado de estabilidade no sistema.

\section{3 - Ensaios hidrodinâmicos}

Nas Figuras C.1 e C.2 do Anexo C, em que estão representados os ensaios hidrodinâmicos realizados para os reatores R1 e R4, respectivamente, pode-se notar que as curvas de resposta do traçador apresentaram um comportamento semelhante à curva exponencial de $\left(-t / t_{0}\right)$, que representa $o$ comportamento ideal para reatores de mistura completa. Com estes resultados pode-se dizer que os reatores possuem mistura completa e que as equações cinéticas, que foram desenvolvidas baseando-se na mistura completa, podem ser utilizadas. Nestas figuras também pode-se observar que a idade do lodo de 5 e 20 dias, mantidas respectivamente, nos reatores R1 e R4, apresentaram pequena influência nas concentrações de lítio no efluente dos reatores.

As concentrações de lítio obtidas para amostras do lodo do reator R4 foram ligeiramente superiores às do reator $\mathrm{R} 1$, conforme mostrado nas Tabelas C.1 e C.2 do Anexo C, que podem ter sido ocasionadas pela maior concentração de sólidos suspensos voláteis no tanque de aeração do reator R4. 


\section{7 - CONCLUSÕES}

Com base nos resultados obtidos para os dois reatores nos ensaios em sistema descontínuo com tempos de ciclo de 24, 18 e 12 horas, pode-se concluir que:

- A relação DBO:NTK:Fosfato total (C:N:P) da água residuária bruta, de acordo com os ensaios de caracterização, demonstrou que os nutrientes (nitrogênio e fósforo) encontravam-se em excesso, dispensando complementação para suprir as necessidades metabólicas dos microrganismos;

- as oscilą̧ões presentes na qualidade da água residuária bruta, que foram consequiência, principalmente, da operação irregular do reator anaeróbio compartimentado, dificultaram a comparação entre as eficiências conseguidas para os tempos de ciclo estudados e no próprio decorrer dos tempos de ciclo. Porém, aproximaram-se da situação real;

- os valores médios da DBO bruta, DBO filtrada, DQO bruta e DQO filtrada obtidos nos ensaios quando os dois reatores encontravam-se estabilizados dinamicamente foram inferiores a 9, 4, 96 e $36 \mathrm{mg} / \mathrm{L}$, respectivamente. As concentrações médias de SST, SSF e SSV para a água residuária tratada nos reatores foram inferiores a 17,3 e $15 \mathrm{mg} / \mathrm{L}$, respectivamente;

- as altas relações DQO/DBO talvez sejam originadas da transformação de 
$\mathrm{H}_{2} \mathrm{~S} \mathrm{em} \mathrm{H}_{2} \mathrm{SO}_{4}$

- $\quad$ as percentagens médias de remoção da DBO bruta, DBO filtrada, DQO bruta, DQO filtrada obtidas nos ensaios quando os dois reatores achavamse estabilizados dinamicamente foram superiores a $91,91,72$ e $83 \%$, respectivamente, valores esses que podem ser considerados satisfatórios para pós-tratamento de efluentes provenientes de reator anaeróbio compartimentado, através de sistema de lodos ativados por batelada;

- os dois reatores, após a estabilização dinâmica, apresentaram remoção média de SST, SSF e SSV superiores a 76, 77 e $75 \%$, respectivamente, resultados que podem ser considerados satisfatórios para a água residuária utilizada;

- se o reator anaeróbio compartimentado tivesse sido operado regularmente durante os ensaios, em virtude da menor concentração de matéria orgânica disponível no seu efluente (água residuária bruta), a eficiência nos reatores de lodos ativados por batelada seria menor. Porém, os valores da concentração da maioria dos parâmetros analisados, em especial, DBO, DQO e sólidos suspensos, na água residuária tratada dos reatores de lodos ativados por batelada apresentariam pequena variação, independente da qualidade da água residuária bruta;

- apesar de não ser utilizado processo adicional para remover nutrientes, a remoção de fosfato total variou de 9 a $31 \%$, com menor remoção para o tempo de ciclo de 12 horas. A conversão de nitrogênio amoniacal situou entre $98 \%$ e a níveis baixos, a ponto de não serem detectados pelos métodos de análises utilizados. A conversão de NTK e nitrogênio amoniacal próximas de $100 \%$ indicaram que quase todo nitrogênio orgânico foi também convertido; 
- os diferentes tempos de ciclo estudados, apesar das oscilações na qualidade da água residuária bruta, não apresentaram grande influência na remoção média da DBO bruta e filtrada, DQO filtrada, SST, SSF e SSV, e na conversão média de nitrogênio total Kjeldhal e nitrogênio amoniacal;

- os valores do índice volumétrico do lodo durante os ensaios situaram-se na faixa de 40 a $100 \mathrm{~mL} / \mathrm{g}$, o que indica lodo com boas características de sedimentabilidade;

- os sólidos sedimentáveis presentes na água residuária bruta foram retidos satisfatoriamente no interior dos reatores, não sendo detectados na água residuária tratada;

- a presença de ciliados fixos e rotíferos no lodo dos reatores, associada à remoção de matéria orgânica, indicaram uma boa estabilidade no processo;

- o processo anaeróbio antecedendo o aeróbio de lodos ativados por batelada para tratamento de esgoto sanitário resultou em significativa redução de geração de lodo;

- o sistema de tratamento de esgoto sanitário empregando processos anaeróbios seguidos de aeróbio de lodos ativados por batelada pode ser credenciado como alternativa técnica e economicamente viável.

Com relação aos resultados obtidos durante a operação dos quatro reatores em sistema contínuo, pode-se concluir que:

- A relação DBO:NTK:Fosfato obtida para a água residuária afluente, 
como as relações obtidas na caracterização realizada nos ensaios em sistema descontínuo, também mostraram o excesso de nutrientes (nitrogênio e fósforo), dispensando assim, correção nas concentrações;

- as variações nos valores de $\mathrm{pH}$, da concentração de oxigênio dissolvido e da temperatura obtidas no interior dos quatro reatores durante o ensaio, não chegaram comprometer os seus desempenhos;

- pelos valores médios da vazão de alimentação dos reatores, o tempo de detenção hidráulico foi mantido constante, mas o mesmo não se pode dizer para a carga orgânica afluente, que em virtude do reator anaeróbio compartimentado não ter sido operado regularmente durante o ensaio, a água residuária afluente apresentou grandes oscilações na qualidade;

- os valores médios da DBO bruta, DBO filtrada, DQO bruta e DQO filtrada obtidos quando os reatores encontravam-se estabilizados dinamicamente foram inferiores a $8,5,43$ e $33 \mathrm{mg} / \mathrm{L}$, respectivamente. As concentrą̧ões médias de SST, SSF e SSV para os efluentes dos reatores foram inferiores a 6,5, 1,3 e 5,3 mg/L, respectivamente;

- como descrito para o sistema descontínuo, as altas relações DQO/DBO talvez sejam originadas da transformação de $\mathrm{H}_{2} \mathrm{Sem} \mathrm{H}_{2} \mathrm{SO}_{4}$;

- os reatores apresentaram remoção média da DBO bruta, DBO filtrada, DQO bruta e DQO filtrada superior a 95, 90, 87 e $80 \%$, respectivamente, quando estes encontravam-se estabilizados dinamicamente, valores que podem ser considerados satisfatórios para água residuária proveniente de efluentes de reator anaeróbio compartimentado tratando esgoto sanitário;

- $\quad$ as percentagens médias de remoção de SST, SSF e SSV obtidas para os 
reatores após a estabilização dinâmica foram superiores a 95, 98 e 93 \%, respectivamente, resultados que podem ser considerados satisfatório;

- como para o sistema descontínuo, se o reator anaeróbio compartimentado tivesse sido operado regularmente durante o ensaio em sistema contínuo, em virtude da menor concentração de matéria orgânica disponível no seu efluente (água residuária afluente), a eficiência nos reatores de lodos ativados seria menor. Porém, os valores da concentração da maioria dos parâmetros analisados, em especial, DBO, DQO e sólidos suspensos, nos efluentes dos reatores de lodos ativados apresentariam pequena variação, independente da qualidade da água residuária afluente;

- os sólidos sedimentáveis presentes na água residuária afluente foram retidos satisfatoriamente nos reatores, não sendo detectados nos efluentes;

- a concentração de sólidos suspensos voláteis no tanque de aeração cresceu com aumento da idade do lodo, proporcionando aos reatores resultados satisfatórios na remoção de matéria carbonácea e conversão de nitrogênio total Kjeldahl;

- os diferentes tempos de retenção celular mantidos nos reatores apresentaram pequena influência nas percentagens médias de remoção da DBO bruta e filtrada, DQO bruta e filtrada, SST, SSF, SSV e nutrientes;

- mesmo não sendo utilizado processo adicional para remoção de nutrientes, os reatores, após a estabilização dinâmica, apresentaram remoção de fosfato total de até $28 \%$ e conversão de nitrogênio na forma amoniacal até níveis a ponto de não serem detectados pelos métodos de análises utilizados. A alta conversão de NTK e nitrogênio amoniacal, próximas de $100 \%$, indicaram que praticamente todo nitrogênio na forma 
orgânica foi também convertido;

- uma parcela do nitrogênio amoniacal foi convertida em nitrito e nitrato pelo processo de nitrificação, sendo que o nitrito apresentou menores concentrações por ser consumido mais rapidamente;

- quase todos valores do índice volumétrico do lodo obtidos para os reatores, como para os ensaios em sistema descontínuo, situaram-se na faixa de 40 a $100 \mathrm{~mL} / \mathrm{g}$, indicando lodo de boa qualidade de sedimentação;

- os valores médios da taxa de utilização de oxigênio dos ensaios de amostras sem adição de substrato para os quatro reatores foram inferiores ao dos ensaios com adição de substrato; isto pode ter ocorrido pela deficiência de carbono e nutrientes necessários para o metabolismo dos microrganismos;

- a falta de determinação dos coeficientes cinéticos $\mathrm{k}$ e $\mathrm{K}_{\mathrm{s}}$, que apresentaram valores negativos para as bases DBO e DQO filtrada efluente, portanto, sem significado físico, mostraram que os valores experimentais obtidos não se ajustaram ao modelo proposto;

- os coeficientes cinéticos $\mathrm{Y}$ e $\mathrm{k}_{\mathrm{d}}$ e os parâmetros a' e b' obtidos para o pós-tratamento pelo processo de lodos ativados de efluentes provenientes de reator anaeróbio compartimentado à temperatura média de $23,9{ }^{\circ} \mathrm{C}$ foram:

. Base DBO filtrada efluente:

$$
\mathrm{Y}=0,528 \mathrm{e} \mathrm{k}_{\mathrm{d}}=0,046 \mathrm{dia}^{-1}
$$


$\mathrm{a}^{\prime}=0,761 \mathrm{e} \mathrm{b}^{\prime}=0,121 \operatorname{dia}^{-1}$ (determinação de R sem adição de substrato)

$a^{\prime}=0,548$ e b' $=0,556$ dia $^{-1}$ (determinação de R com adição de substrato)

. Base DQO filtrada efluente:

$\mathrm{Y}=0,266 \mathrm{e} \mathrm{k}_{\mathrm{d}}=0,047 \mathrm{dia}^{-1}$

$\mathrm{a}^{\prime}=0,382 \mathrm{e} \mathrm{b}^{\prime}=0,120 \mathrm{dia}^{-1}$ (determinação de R sem adição de substrato)

$a^{\prime}=0,276 \mathrm{e} \mathrm{b}^{\prime}=0,553 \mathrm{dia}^{-1}$ (determinação de $\mathrm{R}$ com adição de substrato);

- o coeficiente $\alpha$ para os quatro reatores em todos os ensaios ficaram próximos de 1, isto é, para os valores do coeficiente global de transferência de oxigênio determinados com e sem utilização de sulfito de sódio para desoxigenar as amostras;

- os valores da relação F/M (base DBO filtrada) obtidos para os reatores, principalmente o baixo valor do reator $\mathrm{R} 4$, não proporcionaram $\mathrm{o}$ entumescimento filamentoso do lodo ("bulking"), conforme comprovam os valores do índice volumétrico do lodo que indicam lodo com boas características de sedimentabilidade;

- a taxa específica de utilização de substrato para as bases DBO e DQO filtrada efluente decresceu com aumento da idade do lodo e conseqüente aumento da concentração de microrganismos no tanque de aeração;

- a quantidade real do lodo ativado descartado diariamente do tanque de aeração $\left(\mathrm{P}_{\mathrm{x}}{ }^{\prime}\right)$ para todos reatores apresentou desvio em relação à produção líquida de lodo ativado por dia $\left(\mathrm{P}_{\mathrm{x}}\right)$, que representa um valor estimado da quantidade a ser descartada, podendo ser ocasionado por erros na determinação dos parâmetros envolvidos; 
- a alta concentração de algas nos reatores, provenientes do lodo utilizado como inóculo, foi decrescendo ao longo do ensaio devido aos descartes diários do lodo e redução da incidência de luz;

- a presença, no lodo dos reatores, de altas concentrações de protozoários ciliados fixos e principalmente de rotíferos, somadas às eficiências obtidas, indicaram um grau avançado de estabilidade;

- os ensaios hidrodinâmicos realizados para os reatores R1 e R4, mostraram que as curvas respostas do traçador aproximam-se da curva exponencial de $\left(-t / t_{0}\right)$, que representa a curva ideal para reatores de mistura completa;

- o processo anaeróbio antecedendo o aeróbio de lodos ativados para tratamento de esgoto sanitário resultou em significativa redução de geração de lodo;

- o sistema de tratamento de esgoto sanitário empregando processos anaeróbios seguidos de aeróbio de lodos ativados pode ser credenciado como alternativa técnica e economicamente viável. 


\section{8 - RECOMENDAÇÕES}

Tendo em vista futuras pesquisas de tratamento de esgoto sanitário empregando processo anaeróbio seguido de processo aeróbio de lodos ativados operados em sistema contínuo ou descontínuo, recomenda-se:

- Inocular os reatores nos sistemas contínuo e descontínuo com lodo que possua baixa concentração de organismos filamentosos e boas características de sedimentabilidade, e no caso de não encontrar lodo com estas características na região próxima da pesquisa, aerar o próprio esgoto sanitário até surgimento de microrganismos que caraterizem etapas avançadas de estabilização da matéria orgânica;

- reduzir a incidência de luz, para evitar o aparecimento de algas;

- utilizar uma mesma amostra para realização de todas análises e exames, para conseguir uma melhor representação do que está ocorrendo no instante da coleta;

- utilizar nos ensaios em sistema descontínuo um conjunto composto de compressor, filtro e registros de agulhas, para melhor ajuste da vazão de ar, ao invés de apenas aeradores de aquário;

- repetir os ensaios em sistema descontínuo nas mesmas condições operacionais e para os mesmos tempos de ciclo, porém com temperatura controlada, e comparar os resultados com os obtidos nesta pesquisa; 
- realizar ensaios em sistema descontínuo, adotando tempos de ciclo entre 6 e 12 horas e idades do lodo superiores a 10 dias, para operação com controle da temperatura;

- acompanhar a degradação da matéria orgânica ao longo de cada tempo de ciclo que for estudado;

- realizar periodicamente calibração das vazões de água residuária afluente aos reatores e limpeza das mangueiras e bombas utilizadas para recalcar a água residuária aos reatores, a fim de evitar grandes variações no tempo de detenção hidráulico adotado;

- repetir o ensaio em sistema contínuo nas mesmas condições operacionais e para as mesmas idades do lodo, várias vezes, para se chegar a uma conclusão mais concreta a respeito dos resultados obtidos; também com controle da temperatura, para verificar a influência da mesma nos resultados;

- realizar ensaios em sistema contínuo, adotando as mesmas idades do lodo e tempos de detenção hidráulico inferiores a 8 horas, para operação com controle da temperatura;

- repetir o ensaio em sistema contínuo em unidade experimental, em que o decantador secundário constitua uma unidade independente do tanque de aeração e que permita controle no retorno do lodo, bem como comparar os resultados com os obtidos nesta pesquisa;

- refazer o ensaio em sistema contínuo variando a relação $\mathrm{F} / \mathrm{M}$ até aproximadamente $1,2 \mathrm{dia}^{-1}$ e comparar com os respectivos valores de IVL obtidos; 
- manter no tanque de aeração a concentração de oxigênio dissolvido na faixa de 1,5 a $2,0 \mathrm{mg} / \mathrm{L}$;

- determinar a concentração de $\mathrm{H}_{2} \mathrm{~S}$ dissolvido no efluente do reator anaeróbio;

- calcular o consumo de energia durante a operação dos reatores de lodos ativados;

- fazer um estudo de remoção de microrganismos patogênicos;

- instalar na saída do efluente final dos reatores de lodos ativados um sistema de desinfeç̧ão para remoção de patogênicos. 


\section{9 - REFERÊNCIAS BIBLIOGRÁFICAS}

ALÉM SOBRINHO, P. (1983). Estudo dos fatores que influem no desempenho do processo de lodos ativados - determinação de parâmetros de projeto para esgotos predominantemente domésticos. Revista DAE. n. 132, p. 49-85, mar.

APHA; AWWA; WPCF (1992). Standard Methods for the Examination of Water and Wastewater. 18. ed. American Public Health Association, American Water Works Association, Water Pollution Control Federation, Washington, D. C.

BELÉM, B. D. do (1996). Pós-tratamento de efluentes de esgoto sanitário através de filtro biológico com taxas variáveis. São Carlos - SP, $101 \mathrm{p}$. Dissertação (mestrado) - Escola de Engenharia de São Carlos, Universidade de São Paulo.

BLUNDI, C. E. (1982). Processo de lodos ativados - Modelos matemáticos e determinação de parâmetros em instalação piloto. São Carlos - SP, 169 p. Dissertação (mestrado) - Escola de Engenharia de São Carlos, Universidade de São Paulo.

BRAILE, P. M.; CAVALCANTI, J. E. W. A. (1993). Manual de tratamento de águas residuárias. São Paulo, CETESB, 764 p. 
* BRANCO, S. M. (1986). Hidrobiologia Aplicada à Engenharia Sanitária. São Paulo, CETESB, 3. ed., 616 p.

* CETESB (1989). Microbiologia de Lodos Ativados. São Paulo, CETESB, 23p.

CHERNICHARO, C. A. de L.; von SPERLING., M. (1993). Considerações sobre o dimensionamento de sistemas de lodos ativados de fluxo intermitente (batelada). In: CONGRESSO BRASILEIRO DE ENGENHARIA SANITÁRIA E AMBIENTAL, 17, Natal, 1993. Anais. Rio de Janeiro, ABES. v. 2, T. I, p. 118-129.

CHIESA, S. C.; RIETH, M. G.; CHING, E. K. L. (1990). Evaluation of activated sludge oxygen uptake rate test procedures. Journal of Environmental Engineering, v. 116, n. 3, may/june, p. 472-486.

CYNAMON, S. E.; ROQUE, O. C. da C. (1993). Tratamento anaeróbioaeróbio de esgotos sanitários em valos. In: CONGRESSO BRASILEIRO DE ENGENHARIA SANITÁRIA E AMBIENTAL, 17, Natal, 1993. Anais. Rio de Janeiro, ABES. v. 2, T. I, p. 398-413.

DALTRO, J. F. et al. (1993). Sistema alternativo de pós-tratamento do efluente de uma unidade anaeróbia. In: CONGRESSO BRASILEIRO DE ENGENHARIA SANITÁRIA E AMBIENTAL, 17, Natal, 1993. Anais. Rio de Janeiro, ABES. v. 2, T. I, p. 199-213.

DORNELlAS, J. C.; FIGUEIREDO, R. F. (1993). Lodos ativados por batelada - Uma alternativa para o tratamento de águas residuárias da indústria cítrica. In: CONGRESSO BRASILEIRO DE ENGENHARIA SANITÁRIA E AMBIENTAL, 17, Natal, 1993. Anais. Rio de Janeiro, ABES. v. 2, T. IV, p. 179-193. 
ECHEVERRÍA, E.; SECO, A.; FERRER, J. (1992). Study of the factors affecting activated sludge settling in domestic wasterwater treatment plants. Water Science Technology, v. 25, n. 4-5, p. 273-279.

GEE, C. S.; PFEFFER, J. T.; SUIDAN, M. T. (1990). Nitrosomonas and Nitrobacter interactions in biological nitrification. Journal of Environmental Engineering, v. 116, n. 1, february, p. 4-17.

HU, P.; STROM, P. F. (1991). Effect of $\mathrm{pH}$ on fungal growth and bulking in laboratory - activated sludges. Research Journal Water Pollution Control Federation (Research Notes), v.63, n. 3, p. 276-277.

IMHOFF, K.; IMHOFF, K. R. (1986). Manual de tratamento de águas residuárias. São Paulo, Editora Edgard Blücher Ltda. Cap. 2, p. 89-112: Dimensionamento e planejamento das estações de tratamento de esgotos.

JORDÃO, E. P.; PESSOA, C. A. (1995). Tratamento de esgotos domésticos. Rio de Janeiro, ABES. 3 ed., cap. 15, p. 371-452: Processo dos lodos ativados.

KAMIYAMA, H.; TSUTIYA, M. T. (1992). Lodo ativado por batelada: um processo econômico para o tratamento de esgotos em estações de grande porte. Revista DAE-SABESP. n. 165, p. 1-7, mai/jun.

KATO, M. T. (1982). Estudo e tratamento de águas residuárias de abatedouro de aves. São Carlos - SP, 262 p. Dissertação (mestrado) Escola de Engenharia de São Carlos, Universidade de São Paulo. 
KIM, C.-won.; SPANJERS, H.; KLAPWIJK, A. (1993). Continuous determination of oxygen transfer coefficient with an on-line respiration meter. Water Science Technology, v. 28, n. 7, p. 63-69.

LARANJEIRA FILHO, B. A. (1989). Estudo comparativo de reatores de lodos ativados em escala de laboratório. São Carlos - SP, 126 p. Dissertação (mestrado) - Escola de Engenharia de São Carlos, Universidade de São Paulo.

MACKERTH, F. J. H.; HERONS, J.; TALLING, J. F. (1978). Water analysis: some revised methods for limnologists. Scientific Publication n. 36. p. 71: nitrite.

MADONI, P. (1994). A sludge biotic index (SBI) for the evaluation of the biological performance of activated sludge plants based on the microfauna analysis. Water Research, v. 28, n. 1, p. 67-75.

METCALF \& EDDY (1979). Wastewater Engineering: Treatment, Disposal and Reuse. Nova York, McGraw-Hill. 2 ed., 920 p.

METCALF \& EDDY (1991). Wastewater Engineering: Treatment, Disposal and Reuse. Nova York, McGraw-Hill. 3 ed., 1334 p.

NOUR, E. A. A. (1996). Tratamento de esgoto sanitário empregando-se reator anaeróbio compartimentado. São Carlos - SP, 266 p. Tese (doutorado) - Escola de Engenharia de São Carlos, Universidade de São Paulo. 
NOVOTNY, V.; IMHOFF, K. R.; OLTHOF, M.; KRENKEL, P. A. (1989). Handbook of urban drainage and wastewater disposal. United States, A Wiley-Interscience Publication. Cap. 7, p. 160-182: Suspended growth biological treatment process.

PEREZ, M. F. (1995). Estudo sobre o emprego da alimentação alternada para o controle do intumescimento do lodo em sistemas de lodos ativados tratando esgotos sanitários predominantemente domésticos. São Paulo, 378 p. Dissertação (mestrado) - Escola Politécnica, Universidade de São Paulo.

POVINELLI, J.; AISSE, M. M. (1987). Sedimentação do lodo secundário obtido no processo dos lodos ativados. In: CONGRESSO BRASILEIRO DE ENGENHARIA SANITÁRIA E AMBIENTAL, 14., São Paulo, 1987. Anais. Rio de Janeiro, ABES. v. 2, T. I, p. 398-428.

POVINELLI, J.; MATHEUS, C. E.; FRAGIÁCOMO (1989). Preservação de "sementes" e sua importância em estudos de tratamento biológico de resíduos orgânicos. In: CONGRESSO BRASILEIRO DE ENGENHARIA SANITÁRIA E AMBIENTAL, 15, Belém, 1989. Anais. Rio de Janeiro, ABES. $6 \mathrm{p}$.

POVINELLI, S. C. S. (1994). Estudo da hidrodinâmica e partida de reator anaeróbio com chicanas tratando esgoto sanitário. São Carlos - SP, 181 p. Dissertação (mestrado) - Escola de Engenharia de São Carlos, Universidade de São Paulo. 
SANT" ANNA, F. S. P. (1982). Tratamento de águas residuárias da industrialização de frutas cítricas pelo processo de lodos ativados. São Carlos - SP, 165 p. Dissertação (mestrado) - Escola de Engenharia de São Carlos, Universidade de São Paulo.

SILVA, S. M. C. P. da (1993). Desenvolvimento de uma nova concepção de tratamento de águas residuárias pela associação de processos anaeróbios e aeróbios. São Paulo, 472 p. + anexo. Tese (doutorado) - Escola Politécnica, Universidade de São Paulo.

SOUSA, J. T. de (1996). Pós-tratamento de efluente de reator anaeróbio de fluxo ascendente em reator aeróbio sequencial em batelada e coluna de lodo anaeróbio para desnitrificação. São Carlos - SP, 258 p. Tese (doutorado) - Escola de Engenharia de São Carlos, Universidade de São Paulo.

TEBBUTT, T. H. Y. (1992). Principles of water quality control. GrãBretanha, BPCC Wheatons Ltda. 4 ed., Cap. 14, p. 159-176: Aerobic biological oxidation.

van HAANDEL, A. C. (1993). Tratamento anaeróbio-aeróbio de esgoto. In: CONGRESSO BRASILEIRO DE ENGENHARIA SANITÁRIA E AMBIENTAL, 17, Natal, 1993. Anais. Rio de Janeiro, ABES. v. 2, T. I, p. 768-783.

van HAANDEL, A. C.; LETTINGA, G. (1994). Tratamento anaeróbio de esgotos - Um manual para regiões de clima quente. Paraíba, Editora . Cap. 7, p. 1-41: Pós-tratamento do efluente de um reator DAFA. 
von SPERLING, M. (1993). Determinação da capacidade de oxigenação de sistemas de lodos ativados em operação. In: CONGRESSO BRASILEIRO DE ENGENHARIA SANITÁRIA E AMBIENTAL, 17, Natal, 1993. Anais. Rio de Janeiro, ABES. v. 2, T. I, p. 152-167.

WEF/ASCE (1992). Design of municipal wastewater treatment plants. Alexandria, WEF; New York, ASCE (WEF Manual of Practice, 8; ASCE Manual and Report on Engineering Practice, 76), v. 1, cap. 11, p. 518-673: Suspended-growth biological treatment. 